Florida International University FIU Digital Commons

3-18-2015

\title{
Conjugated Polymer Nanoparticles for Biological Labeling and Delivery
}

Eladio A. Mendez

emend004@fiu.edu

DOI: $10.25148 /$ etd.FI15032157

Follow this and additional works at: https://digitalcommons.fiu.edu/etd

Part of the Materials Chemistry Commons, Nanotechnology Commons, and the Organic Chemistry Commons

\section{Recommended Citation}

Mendez, Eladio A., "Conjugated Polymer Nanoparticles for Biological Labeling and Delivery" (2015). FIU Electronic Theses and Dissertations. 1837.

https://digitalcommons.fiu.edu/etd/1837 


\title{
FLORIDA INTERNATIONAL UNIVERSITY
}

Miami, Florida

\section{CONJUGATED POLYMER NANOPARTICLES FOR}

BIOLOGICAL LABELING AND DELIVERY

A dissertation submitted in partial fulfillment of the

requirements for the degree of

DOCTOR OF PHILOSOPHY

\author{
in \\ CHEMISTRY \\ by \\ Eladio Mendez
}


To: Dean Michael R. Heithaus

College of Arts and Sciences

This dissertation, written by Eladio Mendez, and entitled Conjugated Polymer Nanoparticles for Biological Labeling and Delivery, having been approved in respect to style and intellectual content, is referred to you for judgment.

We have read this dissertation and recommend that it be approved.

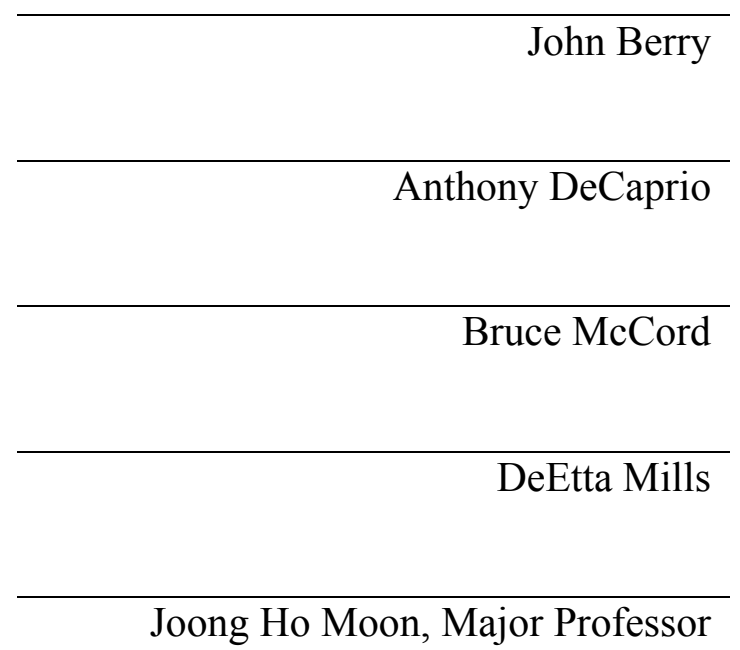

Date of Defense: March 18, 2015

The dissertation of Eladio Mendez is approved.

\begin{tabular}{r}
\hline $\begin{array}{r}\text { Dean Michael R. Heithaus } \\
\text { College of Arts and Sciences }\end{array}$ \\
\hline Dean Lakshmi N. Reddi \\
University Graduate School
\end{tabular}

Florida International University, 2015 
C Copyright 2015 by Eladio Mendez

All rights reserved. 


\section{DEDICATION}

I dedicate this dissertation my family. Without their patience, understanding, support, and most of all, love, the completion of this work would not have been possible.

I love and admire you. 


\section{ACKNOWLEDGMENTS}

I would like to express my special appreciation and thanks to my advisor Professor Dr. Joong Ho Moon, you have been a great mentor for me. I would like to thank you for you pushing me to my limits and challenging me like no one else ever has, encouraging my research and for allowing me to grow as a research scientist. Your advice on both research as well as on my career have been priceless. I would also like to thank my committee members, Dr. John Berry, Dr. DeEtta Mills, Dr. Bruce McCord, and Dr. Anthony DeCaprio for serving as my committee members. I also want to thank you for letting my defense be an enjoyable moment, and for your brilliant comments and suggestions, thanks to you.

I also want to thank those who have taken their time to mentor me through my graduate career. Dr. Howard Holness, thank you for always took time out of your busy schedule to guide me through my academic, professional, and even personal challenges. I also want to thank Dr. Stefan Rose, for all the wisdom, both personal and professional, you have imparted on me. After every discussion we had I felt I was better prepared to tackle the various challenges in my professional life. I am a better student, scientist, and professional because of you.

I would like to thank the present and past members of Dr. Moon's research group, everyone one of them has helped me, taught me, and inspired me in their own way. Tereza Vokata, thank you for all the life, culture, and chemistry advice and monomers. You are my model for what constitutes a great person and scientist. You inspire me to be a more organized, independent, and responsible scientist. Megan Twomey, thank you for 
brightening up every day in the moon lab. You are humor, puns, and all-around greatness, inside and out of the lab, made coming to lab a joy, you inspire me to be more authentic and enjoy life to the fullest. The scientific world is richer for having you. Prakash Manandhar, thank you for always being kind and patient with me. you inspired me to be a better person every day I came in to the lab. Michelle, thank you for always listening to my ramblings, whether it was life or chemistry questions, conversations with you always brought about some new insight. You inspire me to be a strong, smart, independent, sassy black woman, just like you. Salauddin Ahmed, and Yong Myoung, thank you for always encouraging to stay fit and focused, you guys inspire me to be more level headed and patient. I would also like to thank Christopher Machado, Zahilyn Roche, Giselle Maria Gomez, and Charlie Bonano. You guys are wiser and kinder beyond your years; you made my job easy, even when things were extremely difficult, I felt like I learned more from you than the other way around. I would also like to thank present and past members like Youri Lee, Younmi Na, Heather Kumar, Manny Dacosta, and Drs. YoonJoo Ko, Rajib Choudhury, and Rajesh Kumar. You all helped me become a better scientist.

I would also like to thank those people that made life easier for me during my time at the Moon Lab. Christopher Chin, thank you for working with me on the microscope and flow cytometry appointments. Thank you Thelma Robles, Xierra Itayem, Robert Lickliter, Ophelia Weeks, Amy Reid, Charles Bigger and Courney Aiken, and all the people from the MBRS-RISE fellowship who worked with me and helped me stay focus in working on research. None of this could've happened without you. 
Finally, a special thanks to my family. Words cannot express how grateful I am to my mother, Graciela Vidal, and brother, Patricio Mendez, for all of the sacrifices that you've made on my behalf. One of the greatest perks of staying in Miami for my graduate work was to go home to them day in and day out to them, where they showed me what strength, kindness, and unwavering love was. I love you more than you can imagine. I would also like to thank my sister-in-law, Sarah Grattan, both you and my brother have always supported me in all my interests both academic and personal. I also want to thank the people that love and support me from afar; Tia Maria, Tie Eliana, Tia Kena, Monica, and Marcelo. Some of you are no longer with us, but wherever I go I remember you and feel your love. I also want to pay special thanks to my sister Carmen. You show me every day what unconditional love and support is. You inspire me in so many ways. Thank you too, Nicole Brown. You are always there for me, and you've been nothing but a positive influence in my life. Thank you madam.

I would also like to thank all of my friends who supported me in writing, and incented me to strive towards my goal. Thank you Joey Segura, Daniel Buigas, Alex George, Will Bradwell, Antonio Vega, Antonio Vega's amazing bicep, and the rest of my friends. I also would like to thank the people from GiantBomb for keeping me sane with their crazy long podcasts that seem to fit my insane work hours so well.

And to all who are not mentioned here, I want to express my deepest gratitude. Whether it is people I've stayed with, worked with, and to the people who have come and gone from my life. You have all touched my life and helped me in my personal and academic achievements in some way, and I am better for having known you. Thank you. 


\section{ABSTRACT OF THE DISSERTATION \\ CONJUGATED POLYMERS NANOPARTICLES FOR BIOLOGICAL LABELING AND DELIVERY}

by

Eladio Mendez

Florida International University, 2015

Miami, Florida

\section{Professor Joong Ho Moon, Major Professor}

Cancer remains one of the world's most devastating diseases, with more than 10 million new cases every year. However, traditional treatments have proven insufficient for successful medical management of cancer due to the chemotherapeutics' difficulty in achieving therapeutic concentrations at the target site, non-specific cytotoxicity to normal tissues, and limited systemic circulation lifetime. Although, a concerted effort has been placed in developing and successfully employing nanoparticle(NP)-based drug delivery vehicles successfully mitigate the physiochemical and pharmacological limitations of chemotherapeutics, work towards controlling the subcellular fate of the carrier, and ultimately its payload, has been limited. Because efficient therapeutic action requires drug delivery to specific organelles, the subcellular barrier remains critical obstacle to maximize the full potential of NP-based delivery vehicles. The aim of my dissertation work is to better understand how NP-delivery vehicles' structural, chemical, and physical properties affect the internalization method and subcellular localization of the nanocarrier. 
In this work we explored how side-chain and backbone modifications affect the conjugated polymer nanoparticle $(\mathrm{CPN})$ toxicity and subcellular localization. We discovered how subtle chemical modifications had profound consequences on the polymer's accumulation inside the cell and cellular retention. We also examined how complexation of CPN with polysaccharides affects uptake efficiency and subcellular localization.

This work also presents how changes to CPN backbone biodegradability can significantly affect the subcellular localization of the material. A series of triphenyl phosphonium-containing CPNs were synthesized and the effect of backbone modifications have on the cellular toxicity and intracellular fate of the material. A mitochondrial-specific polymer exhibiting time-dependent release is reported. Finally, we present a novel polymerization technique which allows for the controlled incorporation of electron-accepting benzothiadiazole units onto the polymer chain. This facilitates tuning CPN emission towards red emission.

The work presented here, specifically, the effect that side-chain and structure, polysaccharide formulation and CPN degradability have on material's uptake behavior, can help maximize the full potential of NP-based delivery vehicles for improved chemotherapeutic drug delivery. 


\section{TABLE OF CONTENTS}

CHAPTER

PAGE

I. INTRODUCTION TO NANOPARTICLE-BASED DRUG

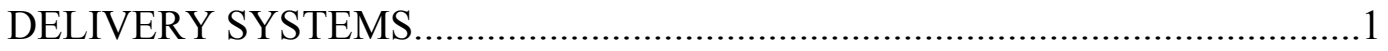

1.1. Challenges in Cancer Therapy .............................................................

1.2. Biological Barriers to Effective Drug Delivery ...........................................2

1.3. Subcellular Barrier ............................................................................... 9

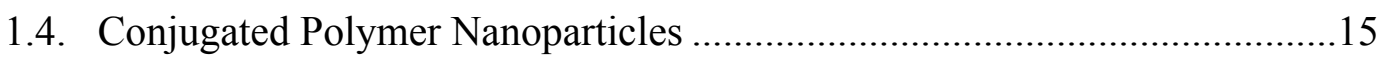

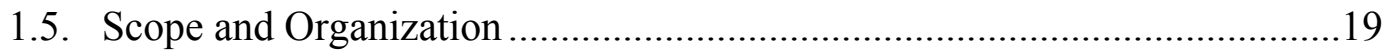

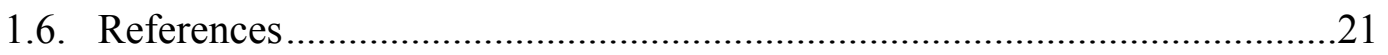

II. SIDE CHAIN AND BACKBONE STRUCTURE-DEPENDENT

SUBCELLULAR LOCALIZATION AND TOXICITY ....................................24

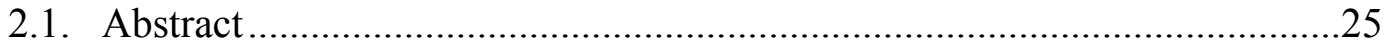

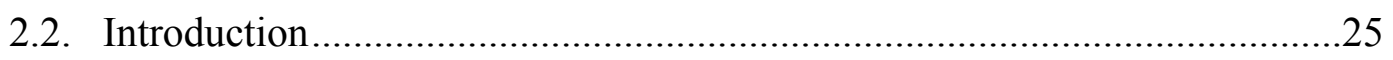

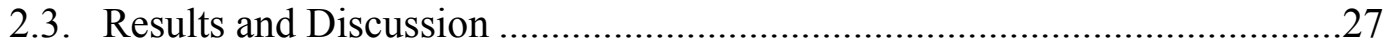

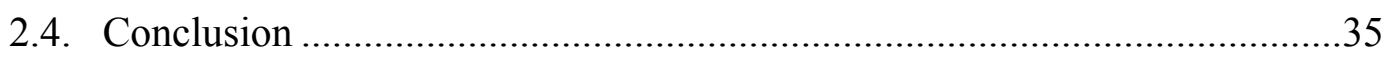

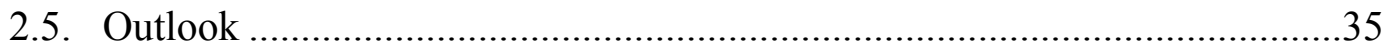

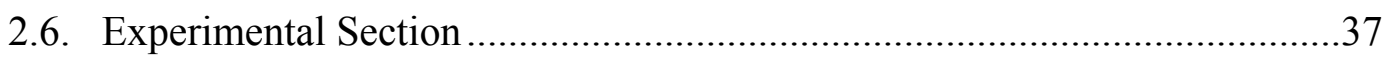

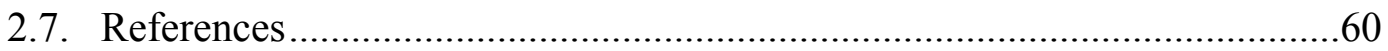

III. COMPLEXATION-DEPENDENT SUBCELLULAR LOCALIZATION

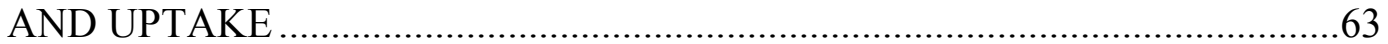

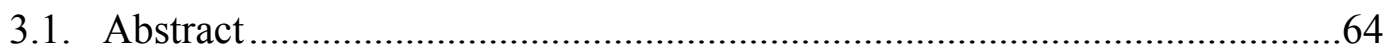

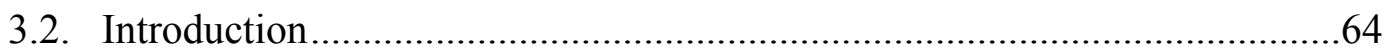

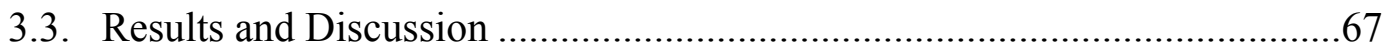

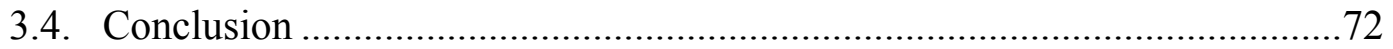

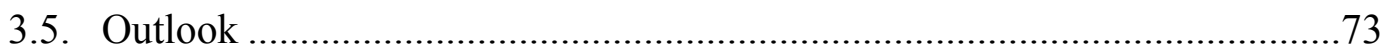

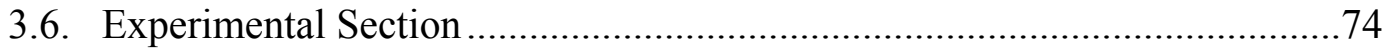

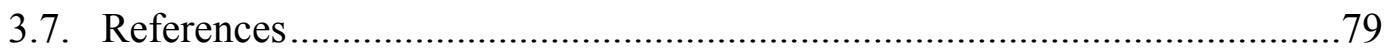


IV. BACKBONE-DEPENDENT SUBCELLULAR LOCALIZATION

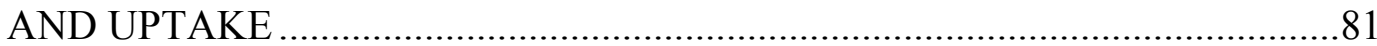

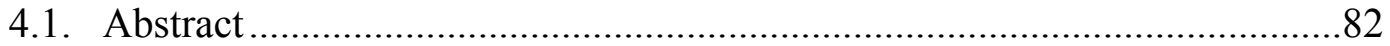

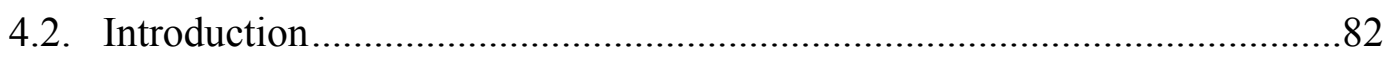

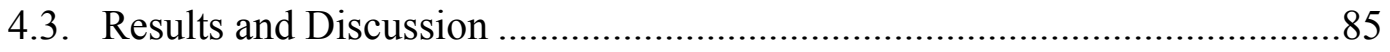

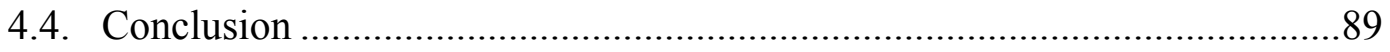

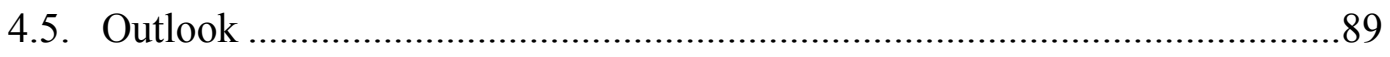

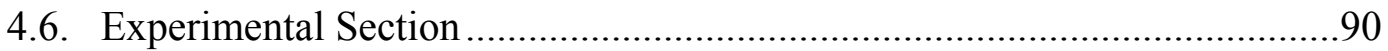

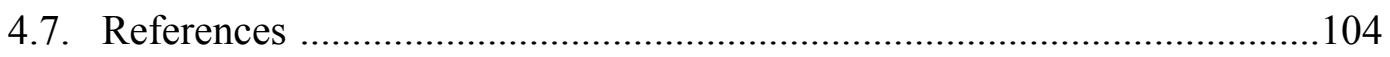

V. COLOR TUNING VIA CONTROLLED INCORPORATION OF HOMO-COUPLED BENZOTHIADIAZOLE TO THE

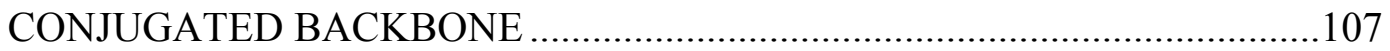

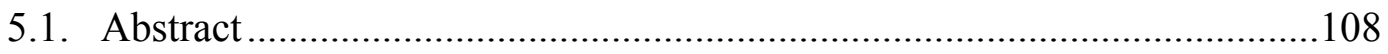

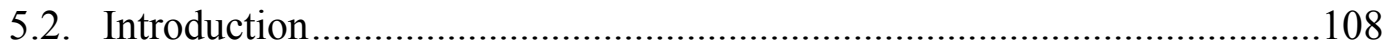

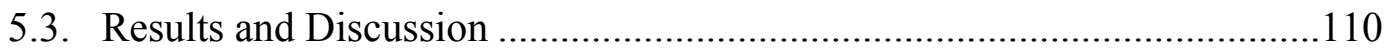

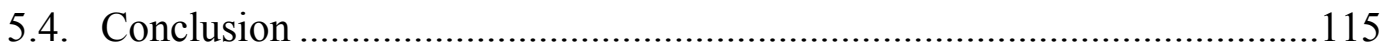

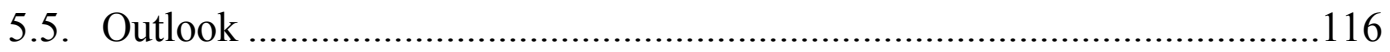

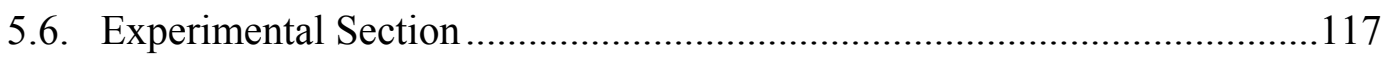

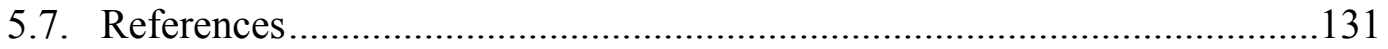

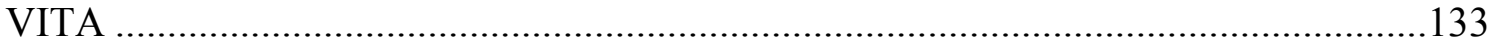




\section{LIST OF FIGURES}

FIGURE

PAGE

Figure 1.1 Schematic illustration of the enhanced permeation and retention

(EPR) effect in solid tumors ....

Figure 1.2 Schematic illustration of NP endocytosis to cross the membrane barrier for cellular entry

Figure 1.3 Common examples of conjugated polymers ........................................16

Figure 2.1 Chemical structures of amine-containing CPs. .....................................26

Figure 2.2 Cellular toxicity of amine-containing CPNs measured by cell viability inhibition at various concentrations....

Figure 2.3a Microscopic images of HeLa cells incubated with CPN-3 and CPN-4 ......31

Figure 2.3b Quantitative analysis of co-localization using the PCC algorithm..............31

Figure 2.4 Quantitative analysis of co-localization using the PCC algorithm..............32

Figure 2.5 Cellular uptake of CPN-1, CPN-2 and CPN-4 measured using flow cytometry.

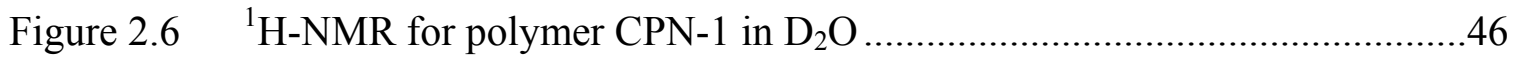

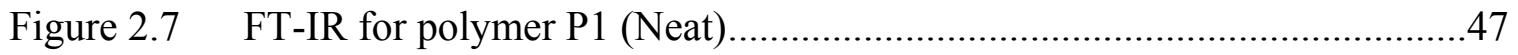

Figure 2.8 DLS for polymer CPN-1 …..................................................... 47

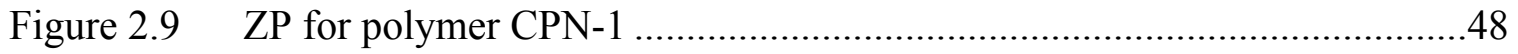

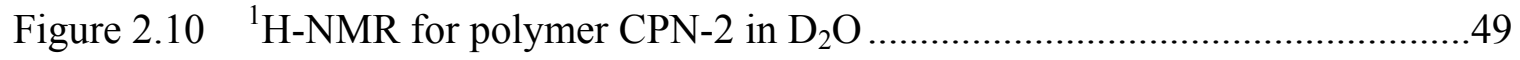

Figure 2.11 FT-IR for polymer P2 (Neat) ..........................................................50

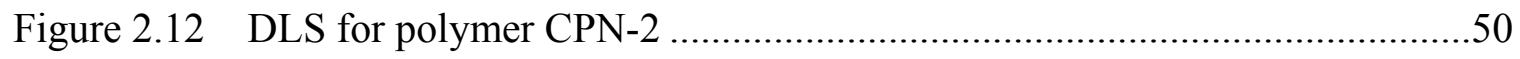

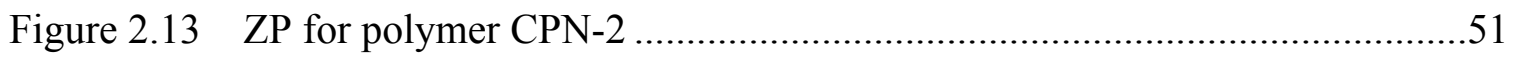

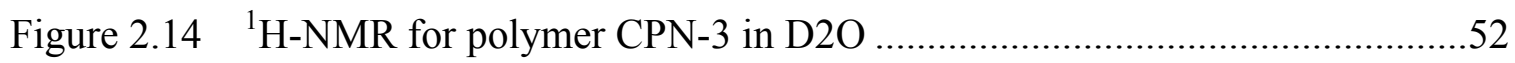

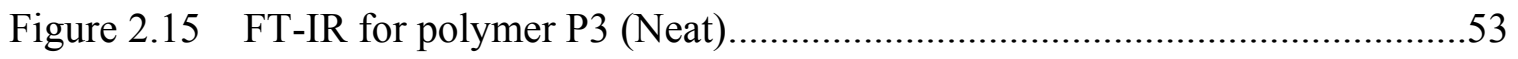




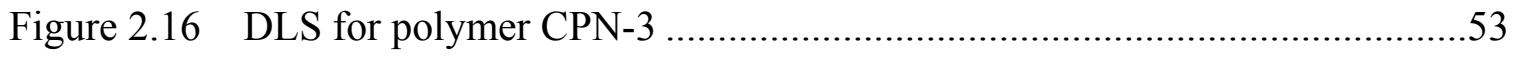

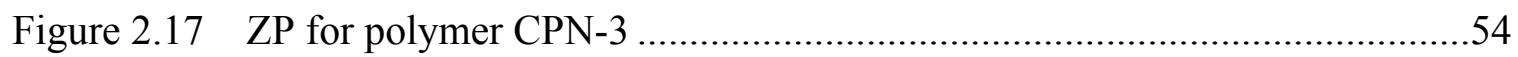

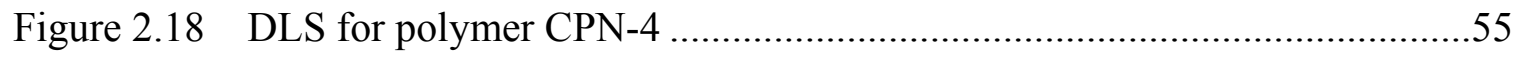

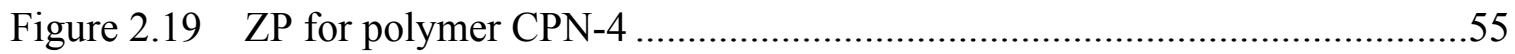

Figure 2.20 Example of microscopic images and PCC analysis ........................................59

Figure 3.1 Chemical structures of amine-containing CPs ....................................66

Figure 3.2 Quantitative analysis of co-localization using the PCC algorithm.............68

Figure 3.3a Cellular uptake of CPN-1 upon HA and CMC complexation ....................70

Figure 3.3b Cellular uptake of CPN-2 upon HA and CMC complexation....................70

Figure 3.4 Cellular uptake of semi-flexible CPN-3 upon HA and CMC complexation ......................................................................... 71

Figure 4.1 Chemical structures of TPP-containing PPEs with and without biodegradable linkers in the backbone. ...............................................8 85

Figure 4.2 Microscopic images of HeLa cells incubated with CPNs .........................84

Figure 4.3 Quantitative co-localization analysis using the PCC algorithm .................87

Figure 4.4 Endocytosis pathways of TPP-containing CPNs...................................8

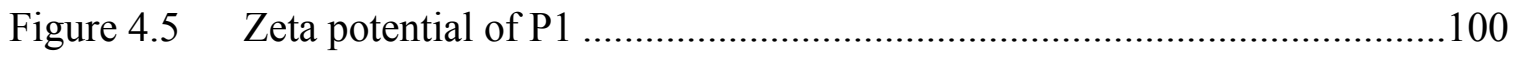

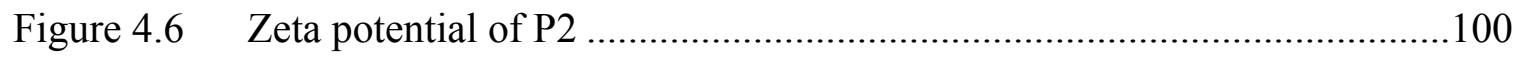

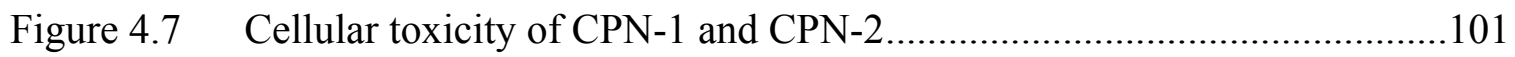

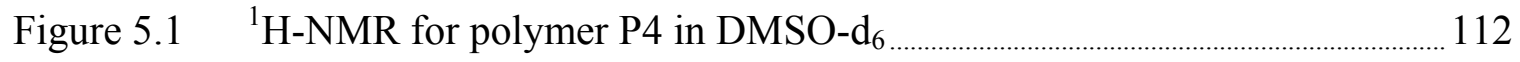

Figure 5.2 $\quad{ }^{1}$ H-NMR aromatic regions for polymer P1-P8 .....................................113

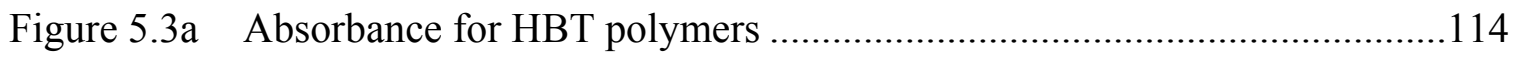

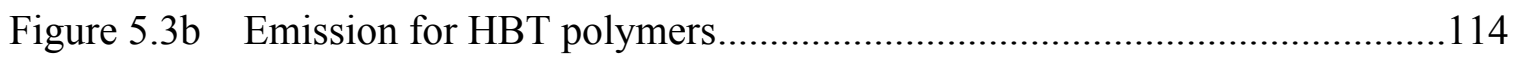

Figure 5.4 $\quad{ }^{1} \mathrm{H}-\mathrm{NMR}$ for polymer BBT-containing polymer in DMSO- $\mathrm{d}_{6} \ldots \ldots \ldots \ldots \ldots \ldots . . . \ldots 16$ 


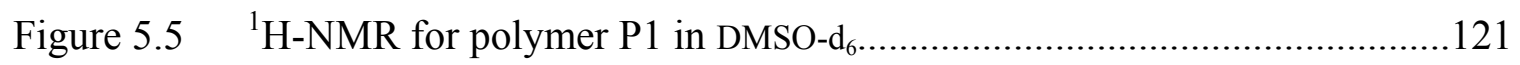

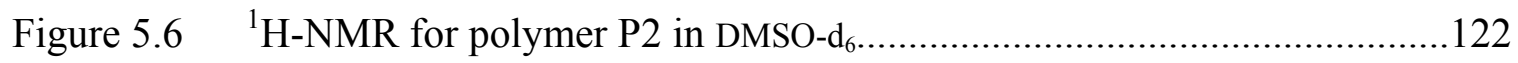

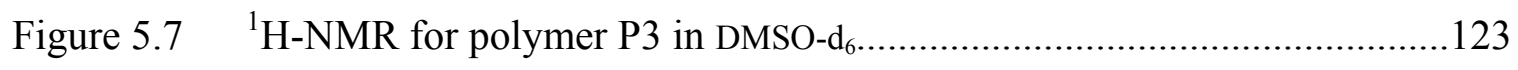

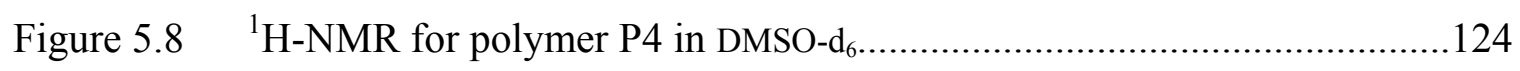

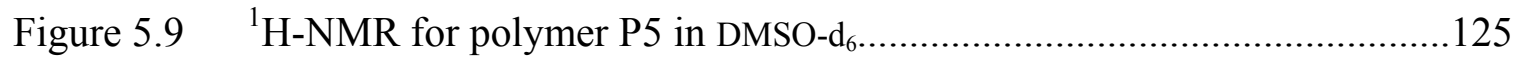

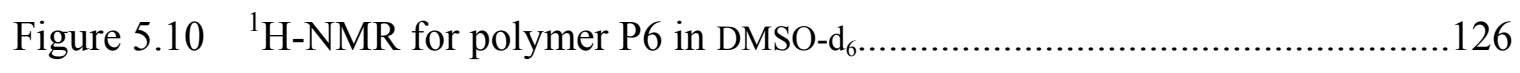

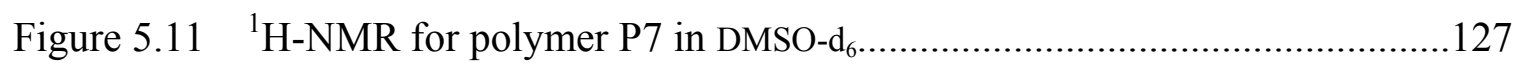

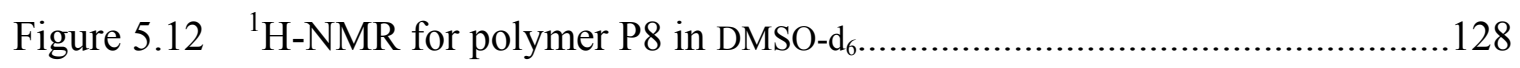

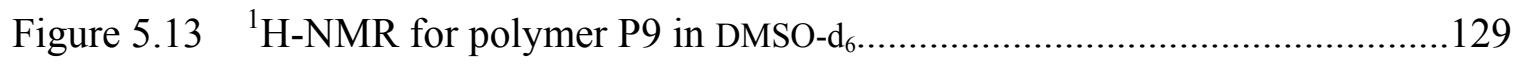

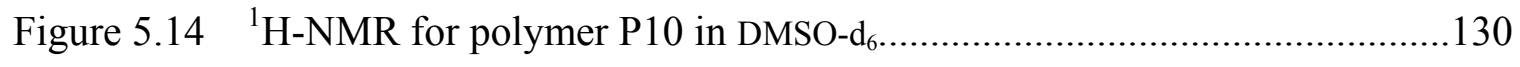

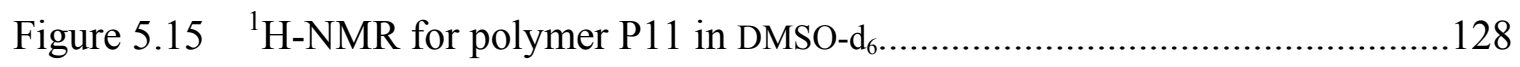




\begin{tabular}{|c|c|}
\hline AA & acetic acid \\
\hline $\mathrm{ACN}$ & acetonitrile \\
\hline Boc & $t$-butyl carbamate \\
\hline BBT & bis-benzothiadiazole \\
\hline BT & benzothiadiazole \\
\hline BTPE & benzothiadiazole-phenylene ethynylene \\
\hline $\mathrm{CP}$ & conjugated polymer \\
\hline $\mathrm{CMC}$ & carboxymethyl cellulose \\
\hline CME & clathrin-mediated endocytosis \\
\hline CvME & caveoli-mediated endocytosis \\
\hline $\mathrm{CPE}$ & conjugated polymer electrolyte \\
\hline CPN & conjugated polymer nanoparticle \\
\hline DBU & 1,8-diazabicycloundec-7-ene \\
\hline DCM & dichloromethane \\
\hline DIPA & $N, N$-diisopropylamine \\
\hline dppf & 1,1'-bis(diphenylphosphino)ferrocene \\
\hline $\mathrm{DMF}$ & dimethylformamide \\
\hline DMSO & dimethylsulfoxide \\
\hline $\mathrm{EtOH}$ & ethanol \\
\hline FRET & fluorescence resonance energy transfer \\
\hline FT-IR & Fourier transform infrared spectroscopy \\
\hline
\end{tabular}




\begin{tabular}{|c|c|}
\hline GPC & gel permeation chromatography \\
\hline GSH & glutathione \\
\hline HA & hyaluronic acid \\
\hline HBT & homo-coupled benzothiadiazole \\
\hline HOMO & highest occupied molecular orbital \\
\hline HR-MS & high-resolution mass spectrometry \\
\hline${ }^{\mathrm{i}} \mathrm{PrOH}$ & isopropyl alcohol \\
\hline LUMO & lowest unoccupied molecular orbital \\
\hline MPC & macropinocytosis \\
\hline $\mathrm{MeCN}$ & acetonitrile \\
\hline $\mathrm{MeOH}$ & methanol \\
\hline $\mathrm{Mn}$ & number average molecular weight \\
\hline Mw & weight average molecular weight \\
\hline $\mathrm{m} / \mathrm{z}$ & mass-to-charge ratio \\
\hline NMR & nuclear magnetic resonance \\
\hline NTA & nanoparticle tracking analysis \\
\hline OD & optical density \\
\hline PA & poly(acetylene) \\
\hline PDI & polydispersity index \\
\hline $\mathrm{Pd}[\mathrm{Cl} 2(\mathrm{PPh} 3) 2]$ & B is(triphenylphosphine)palladium(II) dichloride \\
\hline $\mathrm{Pd}(\mathrm{OAc}) 2$ & palladium(II) acetate \\
\hline $\mathrm{Pd}[(\mathrm{PPh} 3) 4$ & tetrakis(triphenylphosphine)palladium(0) \\
\hline
\end{tabular}




$\begin{array}{ll}\text { PPB } & \text { poly(p-phenylenebutadiynylene }) \\ \text { PPE } & \text { poly(p-phenyleneethynylene }) \\ \text { PPP } & \text { poly(p-phenylene }) \\ \text { PT } & \text { poly(thiophene }) \\ \text { PTFE } & \text { polytetrafluoroethylene } \\ \text { PPV } & \text { poly(p-phenylenevinylene }) \\ \text { QY } & \text { quantum yield } \\ \text { R } & \text { chemical substituent } \\ \text { rt } & \text { room temperature } \\ \text { TEA } & \text { triethylamine } \\ \text { TFA } & \text { trifluoroacetic acid } \\ \text { THF } & \text { tetrahydrofuran } \\ \text { UV-Vis } & \text { ultraviolet-visible } \\ & \end{array}$




\section{CHAPTER I}

INTRODUCTION TO NANOPARTICLE-BASED DRUG

DELIVERY SYSTEMS 


\subsection{Challenges in Cancer Therapy}

Cancer remains one of the world's most devastating diseases, with more than 10 million new cases every year. However, as a result of improved understanding of tumor biology, improved diagnostic devices and treatments, mortality rates have recently begun to

decrease. ${ }^{1}$ Current clinical therapy for cancer includes a combination of chemotherapy, radiotherapy, and surgery, among others. ${ }^{2}$ However, these traditional treatments have proven insufficient for successful medical management of cancer patients because of the undesired physiochemical and pharmacological properties for the chemotherapeutics often employed. ${ }^{2}$ These chemotherapeutics exhibit narrow therapeutic index (TI) because of their difficulty in achieving therapeutic concentrations at the target site, nonspecific cytotoxicity to normal tissues, limited systemic circulation lifetime and problems associated with the physical properties of the drugs, such as low in vivo solubility. At the cellular level, non-specific cellular uptake and undesirable subcellular distributions further reduce the chemotherapeutics' TI.

\subsection{Biological Barriers to Effective Drug Delivery}

There are several biological barriers that must overcome if therapeutic concentrations of the drug are to be effectively delivered to target tumor sites. These barriers can be organized into three distinct levels: a physiological, cellular, and subcellular barrier. Each poses a different challenge for effective drug delivery.

At the physiological level, most drugs will undergo rapid systemic clearance preventing them from staying in circulation long enough to reach the tumor site. This systematic 
clearance results in the drug's degradation in plasma, rapid mononuclear phagocyte system (MPS) uptake, and renal filtration out of the organism. At the cellular level, the cancer cell's phospholipid membrane presents a major barrier to cellular entry. Although drugs enter cells in various ways, many rely on passive transport such as diffusion or channel proteins to facilitate crossing the cell membrane. Passive transport limits the drug internalization once equilibrium between intracellular and extracellular space is reached. Additionally, the presence of membrane bound drug-efflux pumps, which actively vacuum drug molecules out of the cell, further decreases drug internalization into the cell. ${ }^{3}$ Finally, upon internalization into the cell, the distribution of the drug within the subcellular organelles plays a key role in the effectiveness of the drug. For therapeutic action to take place, most drugs require them to reach specific organelles. Depending on the entry pathways and subcellular trafficking, internalized materials will be trafficked into different organelles, which will significantly influence the overall efficiency of the drug. ${ }^{4}$ Successful drug delivery to the target organelle requires all three biological barriers to be overcome which results in a high exclusivity towards a wide variety of molecules. In recent years, two main approaches have been adopted for chemotherapeutics to overcome these biological barriers.

One approach has focused on designing and developing new derivatives of chemotherapeutics exhibiting improved physiochemical and pharmacological properties. ${ }^{5}$ The drug discovery-based approach has had limited success, as even small modifications can often change the function and bioactivity and pharmacokinetics of the parent drug. The other approach has focused on modifying the existing 
chemotherapeutic agents using drug delivery technologies. ${ }^{6}$ As a result, nanoparticle(NP)-based delivery systems have emerged as a promising alternative that can overcome many of the limitations of direct drug modification and offer a platform which can be modified for the intracellular delivery of cargos with varying charge, size, and molecular weight. ${ }^{7}$

\subsubsection{Nanoparticle-based Drug Delivery}

The requirements for a NP-based drug delivery system to be successful include: compatibility with the drug to be delivered, high drug loading efficiency, target-cell specificity, sustained systemic circulation, and a controllable drug release profile. Because they usually exhibit particle sizes 50-200 nm, NP-based delivery systems are often termed "nanocarriers." Ideally, these nanocarriers should be inexpensive, reproducibly synthesized, and exhibit non-toxic biodegradation upon drug release. To tackle these material needs, a number of platforms have been synthesized and explored as possible delivery vehicles; these include naturally-derived polymers $^{8}$, liposomes ${ }^{9}$, and synthetic polymers $^{10}$, among others.

Naturally-derived polymers include bio-polymers like chitosan, hyaluronic acid, cellulose, fibrin, collagen, and gelatin. ${ }^{8}$ These polymers offer good biocompatibility that may positively support cell adhesion and function, and most exhibit biodegradable linkages that further lower toxicity. However, naturally derived polymers also have displayed immunogenicity and offer decreased control over their mechanical properties, inconsistency between batches, and high cost due to limited supply. 
Liposomes are spherical lipid vesicles consisting of a bilayered lipid membrane, which can be prepared synthetically or from natural sources. ${ }^{9}$ These materials allow for the surface charge to be negative, neutral, or positive depending on the lipid head group composition, which has been shown to influence the NP stability, bio-distribution, as well as the uptake by targeted cells. ${ }^{11}$ As a result of their biodegradability and biocompatibility there are several liposomes and lipid-based products currently approved for clinical use in the U.S. ${ }^{12}$. However, liposomes have exhibited particle stability issues, payload incompatibility leading to low drug entrapment, as well as poor particle size control.

Synthetic polymers, which include polyethylene and polystyrene, polyacrylates and polyesters, are synthetically-made polymers offering wide variety of variations to main and side-chains. ${ }^{10}$ They offer good biocompatibility, inexpensive and reproducible synthetic methods compatible with large scale production, controllable biodegradation, and improved drug release profiles. Additionally, incorporation of various functional groups can be synthesized to improve compatibility with the specific drugs to be delivered. Because of these desirable properties, this class of materials has been extensively explored to encapsulate drugs in colloidal systems.

\subsubsection{Pharmacokinetics and Passive Targeting}

To achieve more efficient tumor targeting, drugs must overcome the physiological level barrier caused by the rapid drug clearance via MPS uptake and renal filtration. A simple, widely used technique involves coating therapeutics with a layer of polyethylene glycol (PEG), a synthetic hydrophilic polymer that has been shown to retard MPS recognition and increase circulation time by forming a hydration layer that inhibits 
hydrophobic and electrostatic interactions with plasma proteins. ${ }^{13}$ Incorporation of PEG to drugs results in a pseudo-delivery vehicle layer which results in improved drug solubility, extended circulation life, increased drug stability, and enhanced protection from proteolytic degradation. These pharmacokinetic changes result in more constant and sustained plasma concentrations, which lead to increases in clinical effectiveness when the desired effects are concentration-dependent. Incorporation of other polymers such as N-(2-hydroxypropyl)meth-acrylamide (HPMA) have shown similar enhancements to the circulation time. ${ }^{14}$

Nanocarriers exhibit similar pharmacokinetic enhancements by passively targeting cancer tumors in vivo. Passive targeting is achieved by the enhanced permeability and retention (EPR) effect that arises from the increased permeability of tumor blood vessels, a characteristic of rapid and defective angiogenesis. Enhanced retention in the interstitial fluid surrounding the tumor is achieved due to dysfunctional lymphatic drainage often seen in tumor tissues. The EPR effect enables NPs to accumulate in tumor tissue much more readily than they do in healthy tissues, which results in lower toxicity to normal tissues. NPs with sizes of up to $400 \mathrm{~nm}$ have been reported to exhibit EPR, however, particles with diameters of less than $200 \mathrm{~nm}$ have been reported to be more effective. ${ }^{15}$ Because EPR relies on the increased permeability of tumor blood vessels, passive tumor accumulation is severely diminished in poorly vascularized tumors.

Although the intrinsic EPR effect exhibited by NP-based delivery is an elegant solution to the physiological barrier of drug delivery, its effect on the cellular and subcellular 
barriers remain limited. The EPR effect only facilitates drug escape from plasma into the interstitial fluid surrounding the tumor, resulting in non-uniform drug profusion into the cell, and ultimately, an inability to achieve therapeutic concentrations inside cancer cells.

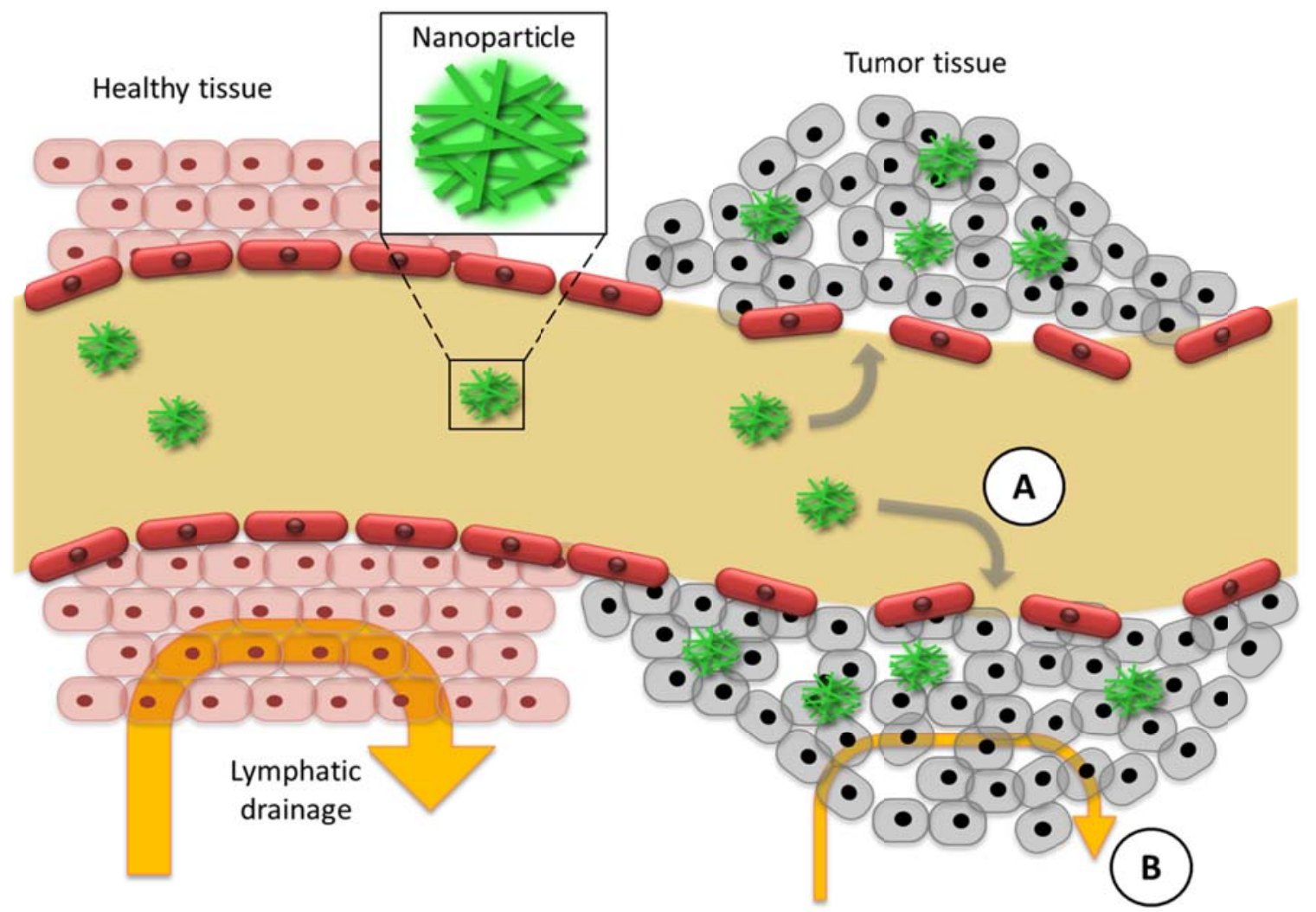

Figure 1.1. Schematic illustration of the enhanced permeation and retention (EPR) effect in solid tumors. A ) Leaky vasculature cause enhanced permeation of nanoparticles into tumor tissues. B) Nanoparticles also experience enhanced retention and accumulation due to poor lymphatic in tumor tissues. This results in passive-targeting nanoparticles exhibiting long-circulating nanoparticles with high affinity towards solid tumors via the EPR effect.

\subsubsection{Active Targeting}

At the cellular level, the cancer cell membrane presents a major barrier to cellular entry, able to exclude large variety of large polar molecules. Unlike small molecules, which passively diffuse into the cell, NPs are mainly internalized via active endocytotic 
pathways. Endocytosis is an energy-dependent process by which cells internalize a variety of macromolecules via membranous vesicles. ${ }^{16}$ Upon interaction with the cell membrane, NPs are mainly internalized via adsorptive or receptor-mediated endocytosis. In adsorptive endocytosis, molecules non-specifically interact with generic complementary binding sites such as negatively charged heparin sulfate proteoglycans and hydrophobic membrane lipids. In receptor-mediated endocytosis, ligands bind to receptors on the cell surface and are internalized by endosomal vesicles. By incorporating ligand moieties onto the nanocarrier, various researchers have made a concerted effort to enhance the cellular uptake of NPs. ${ }^{17}$ The active targeting of cellular membrane receptors which are up regulated or uniquely expressed cancer cells ensures that the nanocarriers are preferentially localized and internalized into cancer tissues.

Early attempts towards active targeting encompassed combining the unique targeting capabilities of monoclonal antibodies with cancer drugs. However, as a consequence of the large size of antibodies, simple incorporation often results in poor size control and increased immune response. ${ }^{18}$ These limitations led to the emergence of alternative targeting ligands such as fragment antigen-binding (Fab) antibodies and growth factors that target overexpressed receptors in cancer cells. ${ }^{19}$ Additionally, numerous studies have reported covalent attachment of targeting ligands for nutrients whose receptors are overexpressed, such as peptides and carbohydrates, to NP surfaces. ${ }^{17}$ The small physical dimension of these ligands enables for NP incorporation in high density without compromising the particle's circulation time or eliciting an immune response. ${ }^{18}$ High ligand density results in improved internalization as the efficiency of receptor-mediated 
endocytosis is dependent on both the strength of the ligand-receptor interaction and the number of interacting receptor-ligand complexes. ${ }^{20}$ Additionally, new dual and multiligand approaches exhibiting synergistic targeting enhancement to the target tumor cells have been reported. ${ }^{21}$

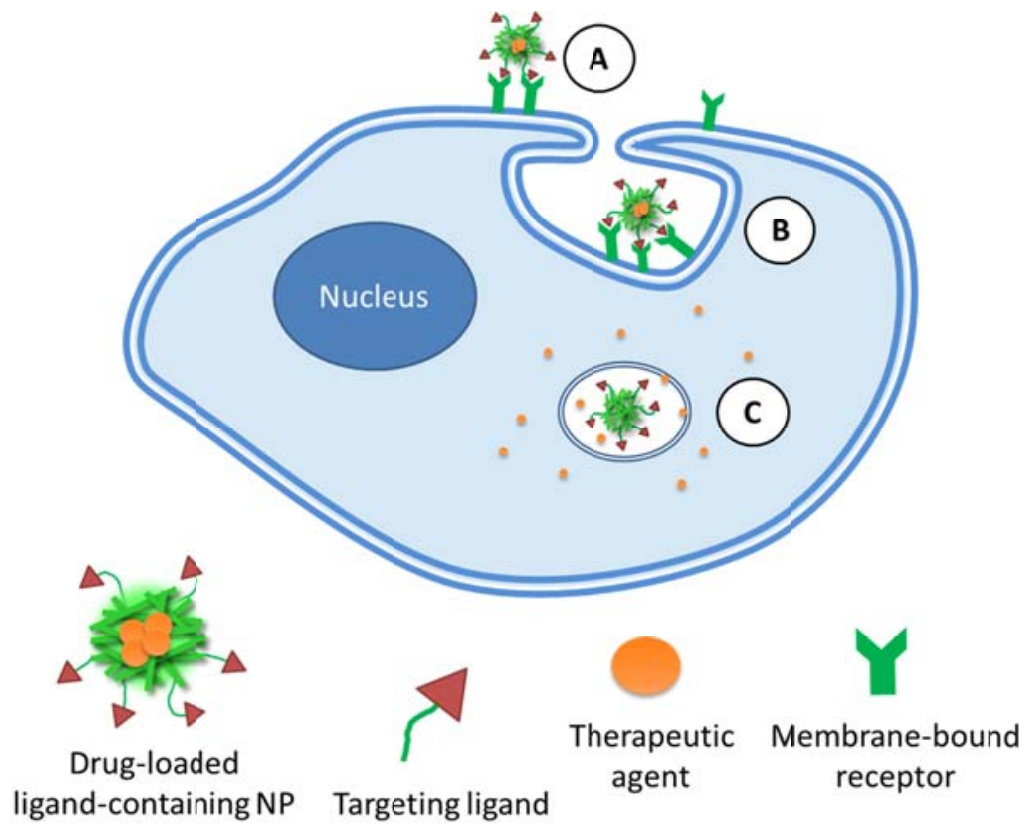

Figure 1.2. Schematic illustration of NP endocytosis to cross the membrane barrier for cellular entry. A) The drug-loaded ligand-containing NP binds to receptor. B) The receptor-NP complex is internalized into the cell via an endocytosis pathway. C) Upon internalization, the therapeutic agent must escape the endosome to reach its target destination.

\subsection{Subcellular Barrier}

In order for therapeutic action to take place, most drugs require them to reach specific organelles such as the nucleus, Golgi apparatus, mitochondria, or endoplasmic reticulum. However, because of their large size and hydrophilic nature, NPs often undergo endocytosis pathways that result in intracellular trafficking via endosomes that 
undergo rapid maturation to lysosomes. ${ }^{22,23}$ Nanoparticle accumulations in lysosomal compartments often lead to enzymatic degradation and/or recycling back to the cell surface, even for systems that take advantage of active targeting by covalent attachment of targeting ligands as they undergo receptor-mediated endocytosis. Therefore, endocytosis poses a major barrier for drug delivery as therapeutic compounds that are transported via these acidic organelles may be inactivated and significantly reduced in concentration before reaching their site of action.

To overcome lysosomal degradation and low delivery efficiency because of recycling out of the cell, a variety of nanocarriers have been developed that respond to the acidic environment of the lysosome. ${ }^{24,} 25$ These $\mathrm{pH}$-responsive carriers aim to increase intracellular drug bioavailability by facilitating release out of the endosome or enhancing drug transit to the cytoplasm. Synthesis of polymer-drug conjugates containing $\mathrm{pH}$-sensitive linkages have been shown to release drugs which then diffuse out of the endosome. Unfortunately, reaching appropriate therapeutic concentrations at the appropriate subcellular target site can be difficult because of low drug-loading capacities. Several cationic polymers have been reported to incorporate "proton sponges" that can facilitate endosomal escape. ${ }^{25}$ These nanocarriers work by incorporating functional groups that can effectively buffer the acidic endosomal environment, prompting the osmotic swelling, rupture out of the vesicle and into the cytoplasm. Similarly, it has been shown that high molecular weight (MW) branched amine-containing polymers can damage and destabilize the endosomal membrane. ${ }^{26}$ Incorporation of charged pendant, such as carboxylic acids, has been demonstrated to 
cause NP swelling upon acidification which can rupture the endosome to initiate the endosomal escape. ${ }^{25}$ Finally, fusogenic peptides have been incorporated for the endosomal escape of several drug delivery systems. ${ }^{27}$ These peptides assume coil-like structures at neutral $\mathrm{pH}$, and that upon acidification in the endosome, result in a conformational change that facilitates penetration out of the endosomal membrane.

An innovative approach has been to forgo endocytosis entirely via incorporation of cellpenetrating peptides (CPPs) that enable transport into the cytosol. ${ }^{28}$ Cell-penetrating peptides avoid endosomal internalization by targeting protein transduction domains for the transport directly into the cytosol. Incorporation of CPPs onto various macromolecules and nanocarriers to assist internalization into mammalian cells. ${ }^{28}$ The promising strategy of using CPPs remains limited by its cost-effectiveness and difficult optimization as the mechanism by which these peptides gain direct access to the cell cytoplasm remains unclear, due to mechanistic differences from peptide to peptide.

Although these strategies have been developed and employed to varying degrees of success, it becomes clear that to improve drug efficacy, the nanocarrier should not only facilitate successful delivery into specific cell types or tissues, but direct the drug to its appropriate intracellular destination.

\subsubsection{Nanocarrier Subcellular Localization}

As a result of the significant amount of research has been devoted to addressing the physiological and cellular barriers, NPs have emerged as a safer and more effective drug delivery option when compared to small molecule chemotherapy. Several nanocarrier 
platforms have been reported exhibiting long systemic circulation lifetime, passive and active targeting ability, cellular internalization through endocytosis, and novel strategies designed to facilitate endosomal escape and avoid lysosomal degradation. ${ }^{24-26}$ However, work towards controlling the subcellular fate of the carrier, and ultimately its payload, has been limited. Because efficient therapeutic action requires drug require delivery to specific organelles, this subcellular barrier remains critical obstacle to maximize the full potential of NP-based delivery vehicles.

\subsubsection{Biological Factors Affecting Subcellular Localization}

The main mechanisms for the endocytotic internalization of nanocarriers are macropinocytosis, Clathrin-mediated endocytosis, and Caveolae-mediated endocytosis. ${ }^{23}$ Depending on the mechanism, the materials are either sorted towards different organelles or recycled out to the extracellular fluid, making the method of internalization the most important factor that affecting the subcellular fate of a nanocarrier. ${ }^{23,30}$

Macropinocytosis (MPC) is an actin-driven endocytosis process that results in the formation of macropinosomes, vesicles of irregular size and shape containing no protein coat. ${ }^{31}$ Macropinosomes result from the activation of tyrosine kinase receptors that trigger actin-driven invagination of the plasma membrane. In human cells, macropinosomes rarely fuses with lysosomes, instead behaving as a distinct vesicle population. ${ }^{30}$ Although contents are often recycled out of the cell, much of the internalized payload can escape from macropinosomes and into the cytosol because of the inherently "leaky" nature of macropinosomes. Active targeting of MPC can be achieved via incorporation of tyrosine 
kinases like epidermal growth factor and platelet-derived growth factor onto the nanocarrier.

Clathrin-mediated endocytosis (CME) is a highly regulated and well-studied energydependent receptor-mediated process. ${ }^{30}$ Transferrin and low-density lipoprotein (LDL) receptors will undergo $\mathrm{CME}$ upon binding with the appropriate ligand. Once bound, the receptor-ligand complex is opsonized in clathrin-coated vesicles, forming vesicles ranging in size from 100 to $150 \mathrm{~nm}$ in diameter. As the vesicle is internalized, the clathrin coat depolymerizes, forming early endosomes. Within these endosomes, the contents are sorted to their appropriate cellular destinations, such as lysosomes, the Golgi apparatus, the nucleus, or the cell surface. ${ }^{30}$ Understanding how to efficiently manipulate the endosomal sorting remains limited, however, GTPases and Rab proteins are known to control this process. Active targeting of CME can be achieved via incorporation of pendant transferrin ligands.

Finally, Caveolae-Mediated Endocytosis (CvME) is an energy-dependent receptormediated process which results in a non-degradative route of internalization. ${ }^{30-32}$ Caveolae are hydrophobic membrane microdomains that are rich in cholesterol and glycosphingolipids-binding receptors. Upon binding with the appropriate ligand, the receptor-ligand complex is internalized via caveosomes, flask-shaped invaginations of the plasma membrane, ranging in size from 50 to $60 \mathrm{~nm}$ in diameter and as large as $500 \mathrm{~nm}$ long, and mediated by membrane-bound caveolin proteins. Once internalized, the contents are sorted within the caveosomes for delivery to the endoplasmic reticulum or Golgi apparatus. Active targeting of $\mathrm{CvME}$ can be achieved via incorporation of 
cholesterol and glycosphingolipids-rich compounds, which have been shown to be preferentially internalized via this endocytotic pathway.

\subsubsection{Control of Subcellular Localization in NP-delivery Systems}

A variety of approaches been reported for NP-based delivery systems which overcome the subcellular barrier presented by the cellular membrane, including cell penetrating peptides, targeting ligands, $\mathrm{pH}$ dependent nanocarriers, as well as targeting specific endocytosis mechanisms, among others. Unfortunately, most of these methods direct the payload towards the cytosol as the target site of delivery. Targeting organelles such as the mitochondria, pose a further challenge as these organelles necessitate penetration of the organelle membranes for effective drug delivery. ${ }^{31}$ Mitochondrial dysfunction is responsible for a variety of human disorders, ranging from neurodegenerative diseases, obesity, diabetes, and cancer. Because mitochondria play a key role in cell death pathways, targeted drug delivery to this organelle could play a crucial role for future cancer treatments.

Although various targeting moieties exist that effectively target these organelles, incorporation of these ligands to macromolecules (e.g. nanocarriers) do not always afford organelle-specific targeting. For example, triphenylphosphonium (TPP) conjugates readily target the mitochondria because of its amphilicity and cationic nature. ${ }^{31}$ Triphenylphosphonium conjugates have been reported to deliver smallmolecular weight antioxidants and nucleic acid oligomers. However, successful mitochondrial localization was only achieved when TPP was incorporated into HPMA with an average molecular weight below $5 \mathrm{kDa}$. Higher molecular HPMA copolymers 
did not show mitochondrial localization even that after polymer microinjection into the cytosol. Other mitochondrial-targeting materials include incorporation of fusogenic peptides, such as Mito-8, to quantum dots to afford mitochondria-specificity. Finally, materials like dequalinium (DQA), which can form liposome-like aggregates, have been reported to exhibit plasmid DNA (pDNA) encapsulation, cellular internalization, and pDNA delivery. ${ }^{34}$ However, DQA does not exhibit improved pharmacokinetics, passive or active targeting towards cancer cells.

\subsection{Conjugated Polymer Nanoparticles}

Conjugated polymer nanoparticles (CPNs) and conjugated polyelectrolytes (CPEs) are emerging fluorescent synthetic polymers that have been employed towards cellular labelling, ${ }^{35}$ sensing, ${ }^{36}$ and delivery ${ }^{37}$ of biological substances. They are prepared from semiconducting conjugated polymers (CP), fluorescent polymers that have been heavily utilized in the fields of electronics for light-emitting diodes (LEDs), photonic devices components, solar cells, and field-effect transistors (FETs). ${ }^{38}$

Various developments have catalyzed the rapid increase in using CPNs for biological applications. Several strategies have been developed to introduce water-solubility and

overcome the inherent hydrophobicity of the material. ${ }^{39}$ Well established synthetic methods allow for facile modifications of $\pi$-electron conjugated backbones and sidechains to tune fluorescent emission, facilitate controllable biodegradation, incorporate targeting units, and improve drug release profiles. Finally, owing to their fluorescent nature, CPNs are a unique delivery platform that can facilitate understanding of how 
chemical structures affect the uptake behavior, bio-distribution and subcellular localization of these polymeric vehicles.

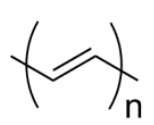

polyacetylene

(PA)

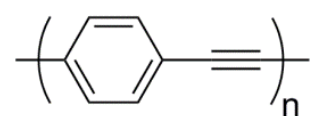

poly(para-phenylene ethynylene) (PPE)

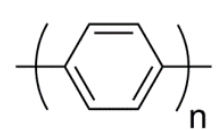

poly(para-phenylene)

(PPP)

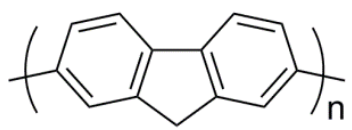

polyfluorene

(PF)

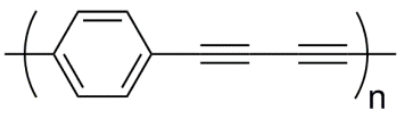

poly(para-phenylene butadiynylene) (PPP)

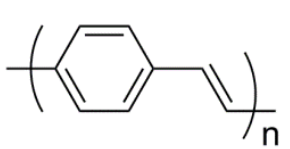

poly(para-phenylenevinylene)

(PPV)

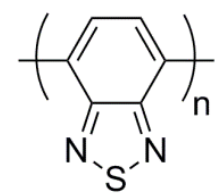

polybenzothiadiazole (PBT)

Figure 1.3. Common examples of conjugated polymers

\subsubsection{Characterization of Endocytosis Mechanisms and Subcellular Localization}

Most methods to study intracellular trafficking of nanomaterials involve either inhibition of specific endocytosis mechanisms using pharmacological inhibitors or colocalization of nanomaterials with specific endocytosis markers and structures. ${ }^{30}$

Various pharmacological inhibitors can be commercially purchased to specifically inhibit certain endocytotic pathways. Clathirin-mediated endocytosis can be distinguished by inhibition under a potassium depletion condition or by treating cells with a pharmacological inhibitor such as chlorpromazine, which specifically inhibits the pit formation by dissociating clathrin lattices. Filipin, nystatin, and methyl- $\beta$ cyclodextrin specifically bind, sequester, or deplete cholesterol, which is involved in the CvME. As a tyrosine kinase inhibitor, genistein also blocks CvME. ${ }^{23}$ Cytochalasin D 
causes actin de-polymerization in the cytoskeleton, resulting in involvement in both the CvME and macropinocytosis. ${ }^{23}$ Bulk amounts of macromolecules can be taken up by cells via macropinocytosis, which involves cell surface ruffling. Since actin cytoskeletons affect membrane ruffling, drugs (e.g., amiloride and its derivatives) that disrupt the function of the actin cytoskeleton can inhibit macropinocytosis. ${ }^{23}$ Phosphatidyl inositol-3-phosphate inhibitor, LY294002 is often used for testing macropinocytosis. Because treatments often show cell type-dependent nonspecific toxicity, baseline toxicity must first be assessed. The change in nanocarrier uptake upon the inhibition of specific endocytotic mechanisms can be measured using flow cytometry. Flow cytometry is an instrumental technology that can measure multiple physical characteristics of cells, such as fluorescence and scattered light, as they flow in a fluid stream through a beam of light. The relative fluorescence intensity per cell can be measured to determine nanocarrier uptake.

Subcellular localization of nanocarriers can be monitored by fluorescent microscopic imaging. ${ }^{31}$ By taking advantage of CPN's fluorescent nature, the materials can be incubated with live cells and can then be co-stained with standard fluorescent dyes which are internalized to specific organelles. For instance, treating cells with pHRhodo Dextran (10kDa) and BODIPY-TR C5-ceramide-BSA complex will label acidic organelles (i.e., endosomes and lysosomes) and Golgi apparatus, respectively. Quantitative co-localization information can then be obtained from the micrographs using the Pearson's Correlation Coefficient (PCC) method. The PCC method gauges the level of overlap by measuring the pixel-by-pixel covariance in the signals of two 
images. Because the PCC method uses normalized signals by subtracting the mean intensity from each pixel's intensity value, PCC is independent of signal levels (i.e. probe brightness) and signal offset (i.e. background). PCC values of 0 and 1 correspond to uncorrelated and perfectly linear correlated images, respectively.

\subsubsection{CPN Characterization}

Internalization mechanism and subcellular localization are influenced by a variety of the CPN's physical properties, such as molecular weight, particle size, and zeta potential. ${ }^{33}$ Therefore, proper characterization of a CPN's physical properties is paramount to accurately correlate the nanocarrier's physiochemical properties with the endocytosis mechanism and subcellular localization.

Physical characteristics often measured for the CPN include molecular weight, polydispersity, and particle size. Polymer molecular weight is typically measured by gel permeation chromatography (GPC), a chromatographic technique which separates a mixture based on size. Molecular weight and polydispersity index (PDI) can be obtained relative to standard samples, typically polystyrene. Particle size can be measured using light scattering techniques such as dynamic light scattering (DLS) or nanoparticle tracking analysis (NTA). Both measure fluctuations in scattered light which is a function of the Brownian motion experienced by the particle. The Brownian motion is related to the hydrodynamic radius through the Stokes-Einstein equation.

Chemical characterization of the polymers can be measured using spectroscopic techniques such nuclear magnetic resonance (NMR) spectroscopy, and various 
absorption and fluorescence spectroscopic techniques. Proper characterization ensures that correlation of chemical moieties, and CPN chemical structure can be properly correlated to endocytosis mechanism and subcellular localization. The chemical structure of a polymer sample can be ascertained by NMR spectroscopy. Changes of magnetic moment of magnetically active nuclei of hydrogen/protons $\left({ }^{1} \mathrm{H}\right)$ and carbon $\left({ }^{13} \mathrm{C}\right)$ are typically obtained. NMR spectra give quantitative information about the relative proportion of each proton in the polymer chain, allowing the average frequency of each monomer in the polymer chain. The presence of numerous functional groups in a polymer sample can be detected using Fourier transform infrared spectroscopy (FTIR). The photophysical properties of conjugated polymers are measured typically using UVVisible absorption spectroscopy absorption and fluorescence spectroscopy.

\subsection{Scope and Organization}

Nanoparticles are emerging as a safer and more effective drug delivery option as compared to small molecule chemotherapy. Delivery of NP vehicles exhibit numerous favorable features such as long systemic circulation lifetime, targeting ability, and cellular internalization through endocytosis. However, work towards controlling the subcellular fate of the carrier, and ultimately its payload, has been limited. Because efficient therapeutic action requires drug require delivery to specific organelles, the subcellular barrier remains critical obstacle to maximize the full potential of NP-based delivery vehicles. The aim of my dissertation work is to better understand how CPN structural, chemical, and physical changes affect the internalization method and subcellular localization of the nanocarrier. 
Understanding how the chemical interactions between $\mathrm{CPN}$ and the cellular membrane affect the subcellular localization and toxicity is paramount to improving overall labelling and delivery efficiency. Chapter 2 details how side-chain and backbone modifications affect the CPN toxicity and subcellular localization. Four model polymers were synthesized containing differing side-chain and backbone structures, but exhibiting similar physical properties (size, charge density). These subtle chemical modifications had profound effects on the polymer accumulation inside the cell and cellular retention. We demonstrate how CPN toxicity and subcellular localization can be tuned by modifying physicochemical properties.

Chapter 3 details how complexation of CPN with polysaccharides affects uptake efficiency and subcellular localization. The effect of siRNA complexation is also explored. Interestingly, upon complexation with polysaccharides subcellular localization does not change, and cellular uptake decreases. Upon siRNA complexation, cellular uptake increases. Therefore, we report how CPN uptake efficiency and subcellular localization is affected upon complexation with polysaccharides and nucleic acids.

Chapter 4 details how changes to CPN backbone structure can significantly affect the subcellular localization of the material. A series of triphenyl phosphonium-containing CPNs were synthesized and the effect of backbone modifications have on the cellular toxicity and intracellular fate of the material were measured. A mitochondrial-specific polymer exhibiting time-dependent release is reported.

Finally, chapter 5 details a novel polymerization technique which allows for the controlled incorporation of electron-accepting benzothiadiazole units onto the polymer 
chain. This facilitates tuning CPN emission towards red emission which is highly desirable, as the sensitivity of any in vivo measurements and optical imaging is significantly enhanced due to minimal autofluorescence from biological tissues at this range. Additionally, this polymer may exhibit different cellular behaviors as the subtle chemical changes influence the entry and localizations.

\subsection{References}

1. $\quad$ Siegel R, Ma J, Zou Z, Jemal A. CA: A Cancer Journal for Clinicians 2014, 64, 9-29.

2. Urruticoechea A, Alemany R, Balart J, Villanueva A, Vinals F, Capella G. Current Pharmaceutical Design 2010, 16, 3-10.

3. Lei T, Srinivasan S, Tang Y, Manchanda R, Nagesetti A, Fernandez-Fernandez A, McGoron A. Nanomedicine: Nanotechnology, Biology and Medicine 2011, 7, 324-332.

4. Sahay G, Alakhova DY, Kabanov AV. Journal Controlled Release 2010, 145, 182.

5. Collins I, Workman P, Nature Chemical Biology 2006, 2, 689.

6. Duncan R. Nature Review Cancer 2006, 6, 688.

7. Heath JR, Davis ME. Annual Review of Medicine 2008, 59, 251.

8. Huang S, Fu X. Journal of Controlled Release 2010, 142, 149-159.

9. $\quad$ Allen TM, Cullis PR. Advanced Drug Delivery Reviews 2013, 65, 36-48.

10. Liechty, W, Kryscio D, Slaughter B. Annual Review of Chemical and Biomolecular Engineering 2010, 1, 149-173.

11. Samad, A.; Sultana, Y.; Aqil, M. Current Drug Delivery 2007, 4, 297-305.

12. Chang H, Cheng M. Journal of Nanomedicine \& Biotherapeutic Discovery 2012, 01 .

13. Wang YY, Lai SK, Suk JS, Pace A, Cone R, Hanes J, Angewandte Chemie International. 2008, 47, 9726. 
14. Whiteman K, Subr V, Ulbrich K, Torchilin V. Journal of Liposome Research 2001, 11, 153-164.

15. Maeda $\mathrm{H}, \mathrm{Wu}$ J, Sawa T, Matsumura Y, Hori K, Journal of Controlled Release 2000, 65, 271.

16. Doherty GJ, McMahon HT. Annual Review of Biochemistry, 2009, 78, 142.

17. Byrne JD, Betancourt T, Brannon-Peppas L. Advanced Drug Delivery Reviews 2008, 60, 1615-1626.

18. Zolnik B, González-Fernández Á, Sadrieh N, Dobrovolskaia M. Endocrinology 2010, 151, 458-465.

19. Arruebo M, Valladares M, González-Fernández Á. Journal of Nanomaterials 2009, 1-24.

20. Bertrand N, Wu J, Xu X, Kamaly N, Farokhzad OC. Cancer nanotechnology 2013, 66, 2-25.

21. Li X, Zhou H, Yang L, Pai-Panandiker AS, Huang X, Yan B. Biomaterials 2011, 32, 2540-5.

22. Li W-S, Jiang D-L, Aida T. Angewandte Chemie International Edition. 2004;43(22):2943-7.

23. Kou L, Sun J, Zhai Y, He Z. Asian Journal of Pharmaceutical Sciences 2013, 8, $1-10$.

24. Gao W, Chan JM, Farokhzad OC. Molecular Pharmaceutics 2010, 7, 1913-1920.

25. Shen Y, Tang H, Radosz M, Van Kirk E, Murdoch WJ. Methods of Molecular Biology 2008, 437, 183-216.

26. Maher MA, Naha PC, Mukherjee SP, Byrne HJ. Toxicology In Vitro 2014, 28, $1449-60$.

27. Lau WL, Ege DS, Lear JD, Hammer DA, DeGrado WF. Biophysical Journal 2004, 86, 272-284.

28. Copolovici DM, Langel K, Eriste E, Langel, Ã. ACS Nano 2014, 8, 1972-1994.

29. Oh N, Park JH. International Journal of Nanomedicine 2014, 9, 51-63.

30. Iversen TG, Skotland T, Sandvig K. Nano Today 2011, 6, 176-185.

31. Kerr MC, Teasdale RD. Traffic 2009, 10, 364-71. 
32. Doherty G, McMahon H. Annual Reviews of Biochemistry 2009, 78, 857-902.

33. Hoye AT, Davoren JE, Wipf P, Fink MP, Kagan VE. Accounts of Chemical Research 2008, 41, 87-97.

34. Weissig V, Lasch J, Erdos G, Meyer HW, Rowe TC, Hughes, J. Pharmaceutical Research 1998, 15, 334-7.

35. Hide F, DÍaz-GarcÍa MA, Schwartz BJ, Heeger AJ. Accounts of Chemical Research. 1997;30(10):430-6.

36. Günes S, Neugebauer H, Sariciftci NS. Chemical Reviews. 2007;107(4):1324-38.

37. Torsi L, Dodabalapur A, Rothberg LJ, Fung AWP, Katz HE. Science. 1996;272(5267):1462-4.

38. McQuade DT, Pullen AE, Swager TM. Chemical Reviews. 2000;100(7):2537-74.

39. Feng L, Zhu C, Yuan H, Liu L, Lv F, Wang S. Chemical Society Reviews 2013, 42, 6620-6633. 


\title{
CHAPTER II
}

\section{SIDE CHAIN AND BACKBONE STRUCTURE-DEPENDENT SUBCELLULAR}

\section{LOCALIZATION AND TOXICITY}

Reproduced in part with permission from Chemical Communications 2013, 49(54), 6048-6050.

\author{
Copyright (C) 2013
}

Royal Society of Chemistry

\section{Eladio Mendez and Joong Ho Moon*}

Department of Chemistry \& Biochemistry, Florida International University, Miami, Florida 33199, United States 


\subsection{Abstract}

The subcellular localizations and toxicity of conjugated polymer nanoparticles (CPNs) are dependent on the chemical structure of the side chain and backbone structures. Amine- containing CPNs exhibit high Golgi localization with no toxicity. Incorporation of short ethylene oxide and tertiary amine side chains contributes to decreased Golgi localization and increased toxicity, respectively.

\subsection{Introduction}

Semiconducting conjugated polymer nanoparticles (CPNs) and conjugated polyelectrolytes (CPEs) are emerging fluorescent biomaterials for cellular labelling, ${ }^{1}$ sensing, ${ }^{2}$ therapeutic, ${ }^{3}$ and delivery ${ }^{4}$ of biological substances. Conjugated Polymers' (CPs) excellent photophysical properties including high molar absorptivity, quantum yield, and energy transfer efficiency make them suitable for the various biological applications. ${ }^{5}$ Well established synthetic methods also allow facile modifications of both $\pi$-electron conjugated backbones and side chains with various sensing or targeting units. By treating non-aqueous soluble CPs under various particle formation conditions, nontoxic soft nanoparticles have been fabricated and used for cellular labelling and nucleic acid delivery. ${ }^{6}$

Understanding cellular interactions and entry pathways of CPNs is paramount to improving overall labelling and delivery efficiency. Depending on the entry pathways, the materials and its payloads (i.e., drugs or genes) will be trafficked into different organelles, which will significantly influence the overall efficiency. ${ }^{7}$ For example, carriers entrapped in endosomes or lysosomes trafficked via a certain type of endocytosis 
will experience recycling of the contents back to the cell surface and degradation processes in acidic lysosomes, lowering overall labelling and delivery efficiency. ${ }^{8}$ Meanwhile, exogenous materials trafficked by non-destructive organelles such as caveosomes to Golgi apparatus (i.e., caveolae-mediated endocytosis) have high intracellular retention. ${ }^{9}$ Delivery via macropinocytosis also can avoid lysosomal degradation routes because macropinosomes do not fuse with the lysosomes, and the membranes of macropinosomes are highly leaky. ${ }^{10}$ Therefore, systematic investigation to understand and modulate the cellular interaction and pathways will have significant impact on designing efficient labelling and delivery vehicles.

Previously, we demonstrated that CPNs fabricated by treating a CP containing both short ethylene oxide (EO) and primary amine (e.g., P1, Figure 1) with organic acids followed by dialysis exhibit efficient cellular labelling and delivery of small interfering RNA

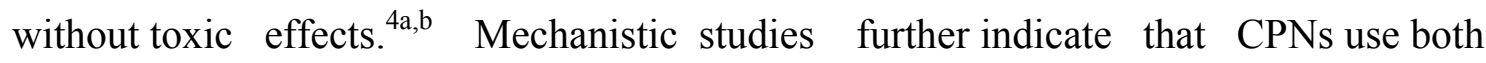

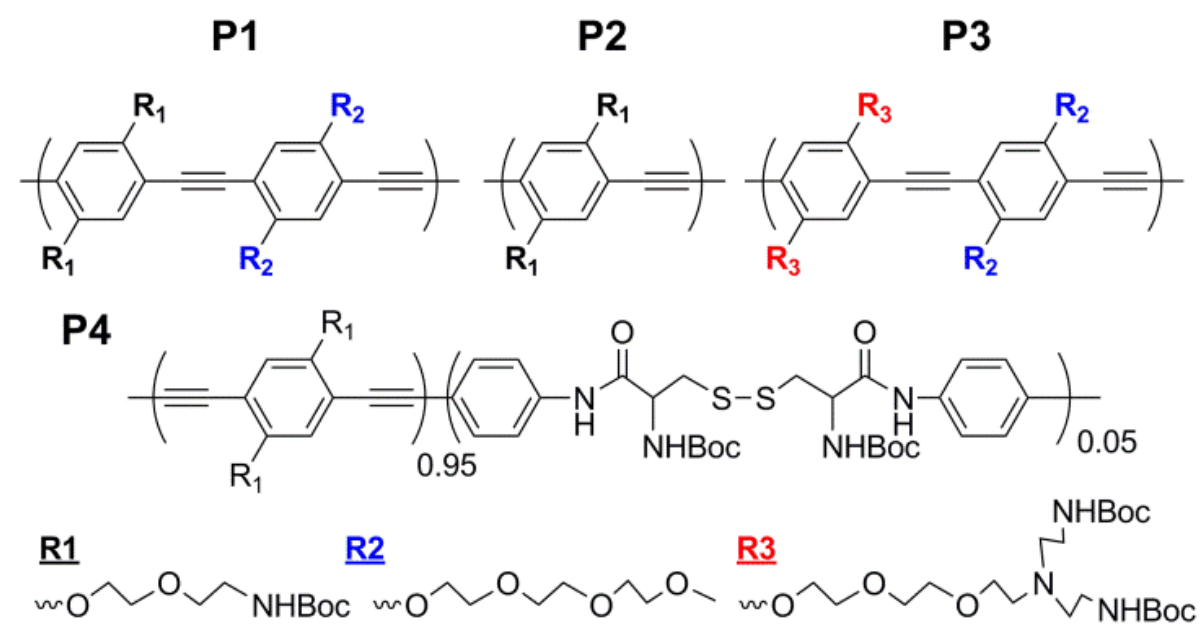

Figure 2.1. Chemical structures of amine-containing CPs. Poly(p-phenyleneethynylenes) (PPEs) with different side chains (P1-P3) and poly(p-phenylenebutadiynylene) (PPB) containing a small amount of flexible unit in the backbone (P4) were synthesized and compared for cellular behaviours. 
energy-dependent and independent entry pathways. Among the energy dependent pathways, CPNs enter cancer cells via caveolae-mediated endocytosis as one of entry pathways. ${ }^{11}$ It is not clear why the CPNs use the specific entry pathway; however, the positive charges and hydrophobicity of CPNs play important roles for interaction with various serum proteins and the cell membranes, which will significantly influence the subsequent cellular uptake. ${ }^{12}$ It is also known that materials having high surface-tovolume ratios exhibit size, shape, and functional group-dependent cellular interactions and subsequent entry. ${ }^{13}$

Based on these results and observations, we hypothesized that chemical modifications in the side chains of CPs will change the subcellular localizations of CPNs, because the modulated surface properties will influence the cellular interactions of CPNs and their subsequent entry into cells.

\subsection{Results and Discussion}

To test the hypothesis, we synthesized four CPNs with different side chain (P1-3) and backbone structures (P4) (Figure 1). Since the cellular interactions and entry processes of nanomaterials are collectively influenced by the physicochemical properties, it is important to keep other physicochemical properties constant when a specific parameter is tested. Because of the particle formation mechanism (i.e., molecular weight independent phase inverse precipitation driven by aqueous insolubility of $\mathrm{CPs}),{ }^{14}$ the shapes and hydrodynamic radii of CPNs are relatively constant. ${ }^{15}$ CPN-2 was designed and synthesized to check the EO side chain effects on the toxicity and localization by removing the EO unit from the repeating unit of CPN-1. CPN-3 was synthesized to 
increase amine density using branched amine side chains containing tertiary amines.

CPN-4 was synthesized to compare the backbone flexibility effects while amine density was maintained close to that of $\mathbf{C P N}-2$. Synthesis of $\mathbf{P 4}$ was reported in our recent publication. ${ }^{16}$ All polymers were treated with a series of organic acids followed by dialysis, affording CPNs that are physically stable in water. Physicochemical properties of CPNs are listed in Table 1. Since aggregation behaviours are concentration dependent, the concentrations of all CPN solutions were adjusted to be $0.5 \mathrm{mM}$. Non-EO containing CPN-2 and CPN-4 exhibited slightly larger hydrodynamic radii than those of CPN-1 and CPN-3 fabricated with EO containing polymers. The difference in hydrodynamic radius among the CPNs is expected to have minimal effects on the cellular interaction and subcellular localization due to the polydisperse nature of CPNs. Zeta potentials of CPNs were determined to be $\sim+42-46 \mathrm{mV}$, except for $\mathbf{C P N}-\mathbf{1}$ exhibiting $\sim+20 \mathrm{mV}$ (Table 2.1).

Table 2.1 Physicochemical properties of CPNs.

\begin{tabular}{|c|c|c|c|c|c|c|c|c|}
\hline CPN & Type & $\begin{array}{c}\mathbf{M}_{\mathrm{n}}{ }^{\mathbf{a}} \\
(\mathrm{kDa})\end{array}$ & $\mathrm{PDI}^{\mathrm{b}}$ & $\begin{array}{c}\lambda_{\max , \text { abs }}{ }^{c} \\
(\mathrm{~nm})\end{array}$ & $\begin{array}{c}\lambda_{\max , ~} \mathrm{em}^{\mathrm{d}} \\
(\mathrm{nm})\end{array}$ & $\begin{array}{l}\text { Hydrodynamic } \\
\text { radius }(\mathrm{nm})^{\mathrm{e}}\end{array}$ & $\mathrm{PDI}^{\mathrm{e}}$ & $\begin{array}{c}\text { Zeta Potential } \\
(\mathrm{mV})^{f}\end{array}$ \\
\hline 1 & P1 (PPE) & 16.4 & 1.49 & 433 & 496 & $61 \pm 6.7$ & $0.27 \pm 0.02$ & $+20 \pm 0.4$ \\
\hline 2 & P2 (PPE) & 11.8 & 1.43 & 427 & 492 & $71 \pm 7.9$ & $0.29 \pm 0.02$ & $+42 \pm 5.1$ \\
\hline 3 & P3 (PPE) & 10.7 & 1.64 & 420 & 496 & $58 \pm 3.4$ & $0.33 \pm 0.06$ & $+44 \pm 1.1$ \\
\hline 4 & P4(PPB) & 22.3 & 2.28 & 444 & 500 & $87 \pm 6.1$ & $0.51 \pm 0.03$ & $+46 \pm 2.3$ \\
\hline
\end{tabular}

${ }^{a}$ Determined by gel permeation chromatography in THF relative to polystyrene standard. ${ }^{b}$ Polydispersity index (PDI) $=\mathrm{M}_{\mathrm{w}} / \mathrm{M}_{\mathrm{n}} \cdot{ }^{c}$ Measured in water. ${ }^{d}$ Measured in water, excitation wavelength $400 \mathrm{~nm} .{ }^{e}$ Measured by DLS at $500 \mu \mathrm{M}$ in water. Mean \pm standard deviation. ${ }^{f}$ Electrophoretic measurement at $\mathrm{pH}$ 7.0. Mean \pm standard deviation. 


\section{Toxicity and Subcellular Localization}

To test how the side chain structure influences cellular toxicity, CPNs were incubated with human cervical carcinoma cells (HeLa) overnight at various concentrations. Zeta potentials of CPNs had no direct correlation to the toxicity, but the chemical structure (i.e., type and density of amine) of the side chains was related to the cellular toxicity. As shown in Figure 2, CPN-3 containing the highest amine density, including tertiary amines, exhibited substantial toxicity starting from $10 \mu \mathrm{M}$, while no cell viability inhibition was observed up to $40 \mu \mathrm{M}$ from the primary amine containing CPNs, whether they contain EO side chains or flexible backbones (i.e., CPN-1, -2, and -4). Compared to CPN-2, which contains the same amount of primary amines per repeating unit as $\mathbf{C P N}-3$, toxicity of CPN-3 can be attributed to both increased amine density and the high buffering capacity of tertiary amines. Membrane disruption properties of synthetic carriers

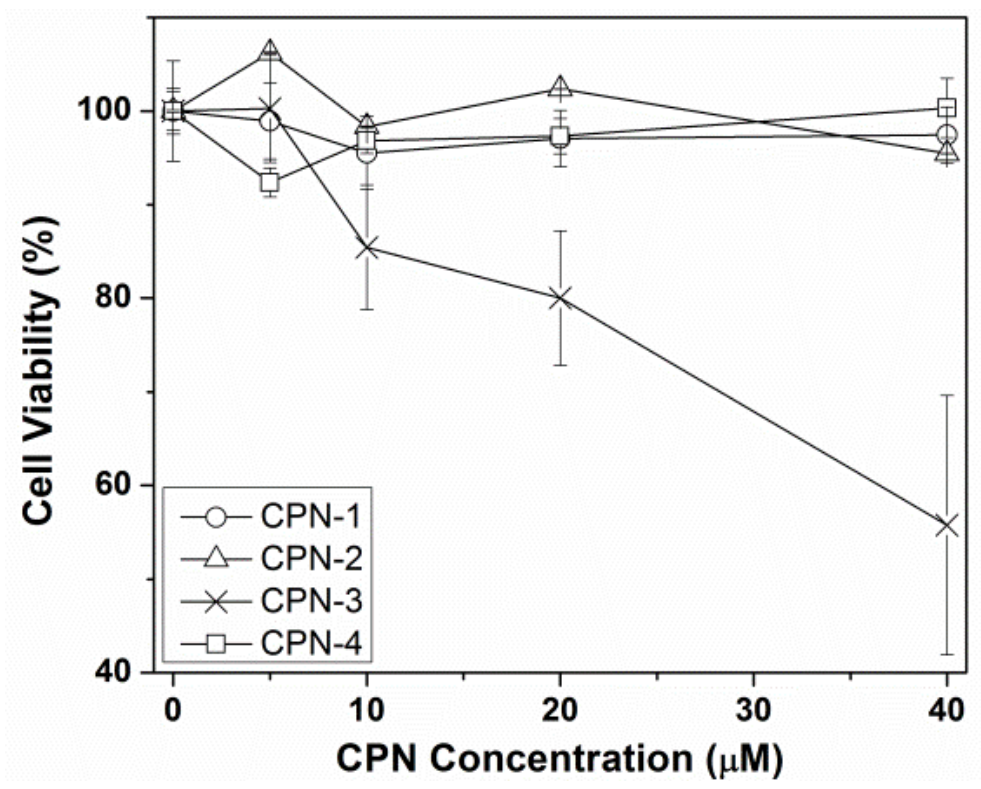

Figure 2.2. Cellular toxicity of amine-containing CPNs measured by cell viability inhibition at various concentrations 
containing tertiary amines have been used to increase payload escape from the endosomes or lysosomes; however, these classes of materials often cause toxicity issues. $^{17}$

Subcellular localization of CPNs was monitored by fluorescent microscopic imaging. Overnight treatment of HeLa cells with CPNs (green) were co-stained with pHRhodo Dextran (10kDa) (red) and BODIPY-TR C5-ceramide-BSA complex (red) for labelling acidic organelles (i.e., endosomes and lysosomes) and Golgi apparatus, respectively (Figure 3a and ESI). CPNs were mainly found at the perinuclear regions (punctuated green dots) and exhibited overlaps with both pHRhodo and BODIPY. Co-localization patterns with the Golgi were clearly distinguishable among CPNs having different side chain or backbone structures (Figure 3a), while overlapping patterns with pHRhodo were relatively uniform. $\mathbf{C P N}-2$ and $\mathbf{C P N}-4$, which only contain primary amine side chains, exhibit high Golgi localizations (Figure 3a), while CPN-1 and CPN-3, which contain both EO and amine side chains, exhibit a relatively low Golgi overlaps.

To obtain quantitative co-localization information, all images were further analysed using the Pearson's Correlation Coefficient (PCC) method. The PCC method gauges the level of overlap by measuring the pixel-by-pixel covariance in the signals of two images. Because the PCC method uses normalized signals by subtracting the mean intensity from each pixel's intensity value, PCC is independent of signal levels (probe brightness) and signal offset (background). ${ }^{18}$ PCC values of 0 and 1 correspond to uncorrelated and perfectly linear correlated images, respectively. Instead of picking small, subjective regions of interest within an image, three independent images of an entire cell were 

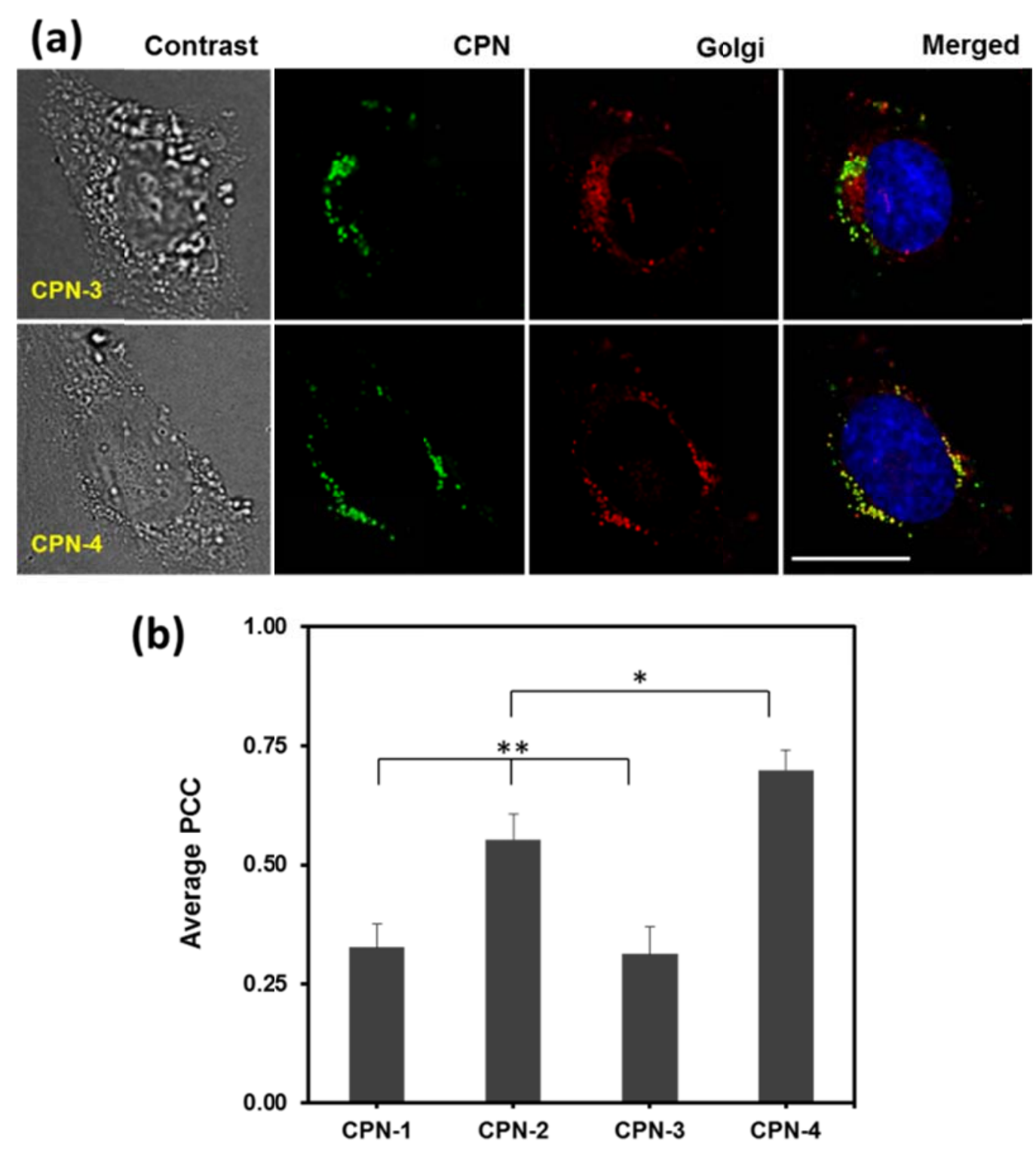

Figure 2.3. (a) Microscopic images of HeLa cells incubated with CPN-3 and CPN-4. Cells then treated by Golgi (red) and nucleus (blue) staining. The scale bar is $20 \mu \mathrm{m}$. CPN-4 exhibits higher overlap with Golgi than CPN-3 does. (b) Quantitative analysis of co-localization using the PCC algorithm. Co-localization with Golgi is dependent on the side chain and backbone structures. The error bar represents \pm standard deviation $(\mathrm{n}=3)$. ${ }^{*}<0.05$ when $\mathbf{C P N}-4$ compared with $\mathbf{C P N}-2$. ${ }^{*} *<0.0005$ when $\mathbf{C P N}-1$ and $\mathbf{C P N}-3$ compared with CPN-2 and CPN-4 ( $\mathrm{n}=3)$.

selected and analysed to increase the analysis objectivity. As shown in Figure 3b, average PCC values were dependent on the side chain and backbone structures of the CPNs. The CPNs with only amine side chains exhibited higher Golgi localization than 
the CPNs containing both EO and amine side chains. In addition, CPNs fabricated with a semi-flexible CP exhibited the highest Golgi localization. One-way ANOVA followed by the Tukey means separation method confirmed that Golgi co-localization of CPN-2 and CPN-4 was statistically significant $(\mathrm{p}<0.003)$ from $\mathbf{C P N}-\mathbf{1}$ and $\mathbf{- 3}$. The Golgi colocalization between $\mathbf{C P N}-2$ and $\mathbf{C P N}-4$ was also statistically significant $(\mathrm{p}<0.05)$.

Additionally, all CPNs exhibited significant late endosome/lysosome colocalization. As shown in Figure 4, average late endosome/lysosome PCC values were not significantly different between CPNs, regardless of side chain and backbone structures. This may be the result of adsorptive endocytosis, in which the polymers non-specifically interact with generic complementary binding sites such as negatively charged heparin sulfate proteoglycans and hydrophobic membrane lipids.

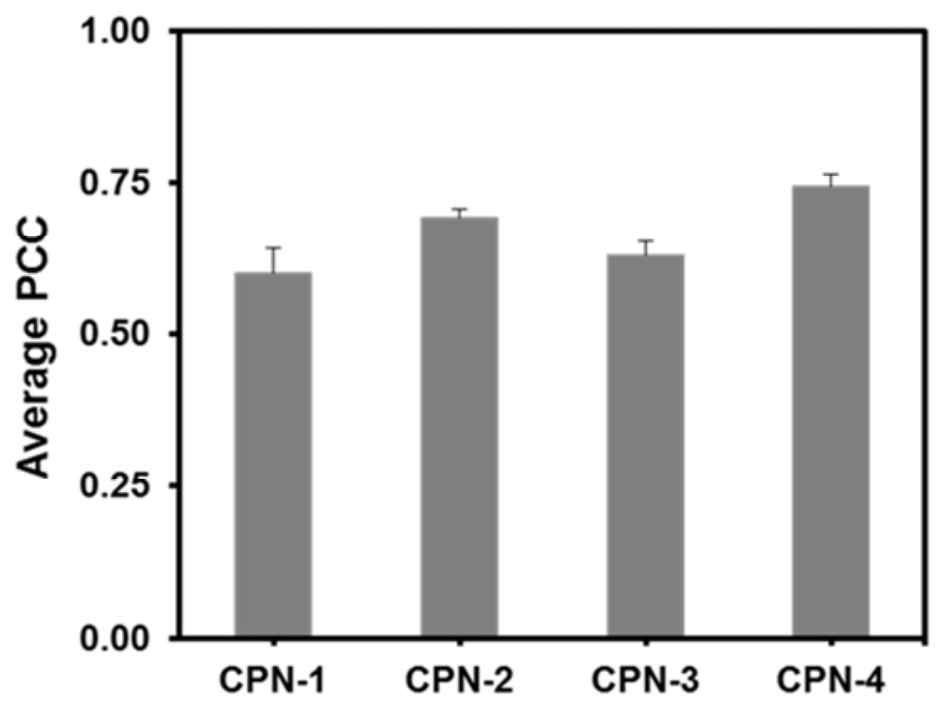

Figure 2.4. Quantitative analysis of co-localization using the PCC algorithm. Co-localization with late endosome/lysosome did not show significant difference regardless of the side chain and backbone structures. The error bar represents \pm standard deviation $(n=3)$. 


\section{CPN Accumulation and Retention}

The different CPN organelle trafficking is expected to significantly influence the polymer's accumulation intracellular retention within the cell. Because all CPNs exhibited entrapment in late endosomes/lysosomes, they will experience recycling back to the cell surface and degradation processes in acidic lysosomes. However, those polymers exhibiting significant traffic to the Golgi apparatus (i.e. CPN-2 and CPN-4) should exhibit increased cellular retention. To measure CPN accumulation, cellular uptake was measured using flow cytometry after 2 hours and overnight (18 hours) treatment with CPN. To measure CPN retention within the cell, cellular uptake was measured by treating cells with the CPN for 2 hours, exchanging media, and allowing HeLa cells to incubate overnight (16 hours). Any remaining fluorescent signal from the CPN within the cell was measured. Cellular uptake comparison between CPNs was made possible by normalizing the mean fluorescence measurements measured by flow cytometer with the CPN quantum yield. It is not expected that CPNs exhibit significant QY changes upon cellular internalization.

For all treatment times tested, $\mathbf{C P N}-\mathbf{4}$ and $\mathbf{C P N}-\mathbf{1}$ exhibited the highest and lowest uptake, respectively (Figure 2.5). After 2 hours of treatment, CPN-2 and CPN-4 exhibited a 4-fold and 8-fold enhancement to cellular uptake over CPN-1, respectively. After overnight treatment, CPN-2 and CPN-4 exhibited a 6-fold and 12-fold enhancement to cellular uptake over $\mathbf{C P N}-1$, respectively. Additionally, CPN-1 did not show any significant difference in uptake between the 2 hour and overnight treatments. In contrast, when comparing 2 hour and overnight treatments, $\mathbf{C P N}-2$ and $\mathbf{C P N}-4$ exhibited 


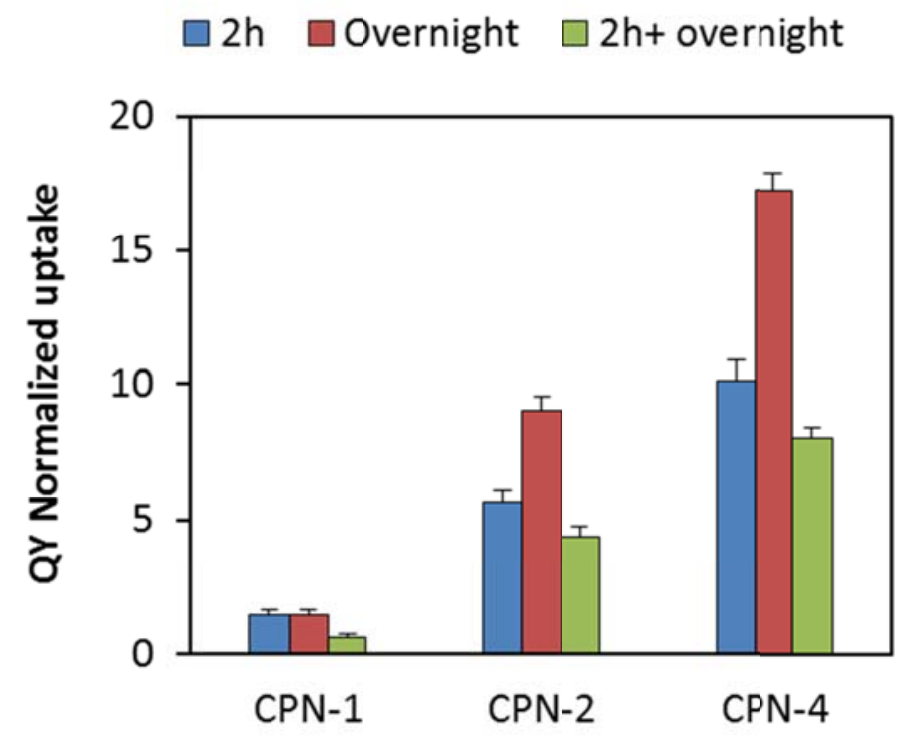

Figure 2.5. Cellular uptake of CPN-1, CPN-2 and CPN-4 measured using flow cytometry. Fluorescence signal was normalized using the CPN's quantum yield resulting relative uptake. The error bar represents \pm standard deviation $(n=3)$.

a $158 \%$ and $170 \%$ uptake increase, respectively. The improved uptake and accumulation of CPN-2 and CPN-4 provide strong evidence for the enhanced internalization that can be achieved by controlling the CPN's subcellular localization.

The effect of subcellular localization on the CPN's cellular retention was measured by comparing the mean fluorescence measured by treating cells with the CPN for 2 hours, and those cells that were treated for 2 hours and allowed to incubate overnight (16 hours). After normalizing the fluorescence signals using the CPN's QY, all materials tested demonstrated decreased fluorescence signal after incubating overnight (Figure 2.5). CPN-1 exhibited the highest clearance, with only $40 \%$ of the original fluorescence intensity remaining after overnight incubation. CPN-2 and CPN-4 exhibited decreased clearance, exhibiting $77 \%$ and $79 \%$ of the original fluorescence intensity, respectively. Although all polymers exhibited different cellular uptake after 2 hours, it should be noted 
that even after overnight incubation $\mathbf{C P N}-2$ and $\mathbf{C P N}-4$ exhibited higher fluorescence signal than even CPN-1 after overnight treatment.

\subsection{Conclusion}

In conclusion, we demonstrated that CPNs are promising biomaterials with tunable physicochemical properties. The side chain and backbone structures of CPNs are closely related to toxicity and subcellular localization. Therefore, cellular interaction and cellular entry pathways of CPNs can be fine-tuned to improve labelling and delivery efficiency. The non-destructive delivery pathway and subcellular location of CPN-2 and CPN-4 afforded biocompatible materials exhibiting remarkable internalization, accumulation and cellular retention. Combining their excellent intrinsic fluorescent natures, tunable physicochemical properties and the related biophysical properties, CPNs make excellent biomaterials to better understand the structure-function between nanocarrier and delivery efficiency. The concept we demonstrated here will lead to the development of novel multifunctional materials for labelling, sensing, and delivery.

\subsection{Outlook}

Since the publication of this work in Macromolecules, a preliminary study of the endocytosis pathway of each CPN was performed. Using pharmacological inhibitors, it was observed that the main endocytotic pathway for EO and primary amine-containing CPN-1 is via CvME, and secondarily via CME. For the primary amine-containing CPN2, the reverse result was observed, with a primary entry mechanism using CME and secondarily via CvME. Branched amine-containing CPN-3 exhibited MPC as its primary 
endocytosis pathway, with CvME its secondary mechanism. Finally, the semi-flexible backbone-containing CPN-4 exhibited almost exclusive MPC uptake, with very weak secondary internalization via CvME uptake.

Interestingly, CPN-2 and CPN-4, both of the high Golgi co-localizing materials presented in this chapter exhibited very different internalization mechanisms. This preliminary endocytosis pathway confirmed CPN-2's CvME, which we hypothesized would be the internalization pathway due to the high Golgi uptake. However, CPN-4 exhibtied very little CvME uptake, instead showing almost exclusive MPC mechanism. In chapter 4, a triphenyl phosphonium-containing $\mathrm{CPN}$ is presented exhibiting polymeric cellular internalization and degradation into conjugated polymer oligomer endosomal escape. We cautiously hypothesize a similar mechanism for $\mathrm{CPN}-4$, whereby the resulting aminecontaining conjugated oligomers are trafficked to the Golgi apparatus.

Further studies on polymers using CPNs presented here have revealed the unique ability for semi-flexible linker containing-CPNs (i.e. CPN-4) to undergo self-assembly reorganization into core-shell nanoparticles upon polyanion complexation. This ordered aggregation allowed for the fabrication of unique CPNs for glycosaminoglycan detection. ${ }^{19}$ In conclusion, the concept presented here has and will continue to facilitate development of novel multifunctional materials for labelling, sensing, and delivery. 


\section{Experimental Section}

\subsubsection{General}

Chemicals, including solvents, were purchased from Fisher Scientific and used as received. Deuterated solvents were purchased from Cambridge Isotope Laboratories (Cambridge,MA). UV-vis spectra were recorded using a Varian Cary 50 Bio spectrophotometer. Fluorescence spectra were obtained using a FluoroLog-3 Spectrofluorometer (Jobin Yvon/ Horiba). 9,10-diphenylanthracene (QY = 1.0) in cyclohexane was used as a fluorescence standard for QY determination. Hydrodynamic radii and Zera potentials were determined by the dynamic light scattering technique using a Zetasizer nano-ZS (Zen 3600, Malvern Instruments Ltd. , Worcestershire, United Kingdom). Disposable capillary cell (DTS1061, Malvern Instruments Ltd., Worcestershire, United Kingdom) used for zeta potential measurements. Low volume disposable cuvettes (ZEN0040, Malvern Instruments Ltd., Worcestershire, United Kingdom) used for DLS analysis. The average molecular weight (Mn) and polydispersity index $\left(\mathrm{PDI}=\mathrm{M}_{\mathrm{w}} / \mathrm{M}_{\mathrm{n}}\right)$ of the polymers were determined by gel permeation chromatography (GPC) against polystyrene standards using a Shimadzu high performance liquid chromatography (HPLC) system fitted with PLgel $5 \mu \mathrm{m}$ MIXED-D columns and SPD-20A ultraviolet- visible (UV-vis) detector. Nuclear magnetic resonance (NMR) spectra were recorded on a $400 \mathrm{MHz}$ and $600 \mathrm{MHz}$ Avance Bruker NMR spectrometer. The $600 \mathrm{MHz}$ NMR spectrometer is equipped with a gradient system capable of producing magnetic field pulse gradients in the z-direction of about $50 \mathrm{G} \mathrm{cm}^{-1}$ and allowing for water preak suppression $\left(\delta=4.8 \mathrm{ppm}\right.$ in $\left.\mathrm{D}_{2} \mathrm{O}\right)$. Experiments were carried out using a $5 \mathrm{~mm} \mathrm{BBI}$ probe and the temperature was $298 \mathrm{~K}$. The mixing time was 
$300 \mathrm{~ms}$ water suppression experiments. Chemical shifts were reported in parts per million (ppm) for ${ }^{1} \mathrm{H}-\mathrm{NMR}$ on the $\delta$ scale based on the middle peak $(\delta=2.50 \mathrm{ppm})$ of the dimethyl sulfoxide (DMSO)- $\mathrm{d}_{6}$ solvent as an internal standard, or 4.8ppm for deuterium hydroxide $\left(\mathrm{D}_{2} \mathrm{O}\right)$ experiments. Dialysis and solvent exchange of CPNs were conducted using an Ultrafiltration Stirred Cell (Millipore, Billerica, MA, USA) with membrane filters [Ultracel ultrafiltration disc, molecular weight cutoff (MWCO): $30 \mathrm{kDa}$ ]. Tables and graphs were plotted using Origin 8 software (OriginLab, Northampton, MA, USA).

\subsubsection{Monomer Synthesis}

Monomer 1 (M1) was synthesized according to Scheme 1. tert-butyl 2,2'azanediylbis(ethane-2,1-diyl)dicarbamate 1 and 2-(2-(2-chloroethoxy)ethoxy)ethyl 4-

methylbenzenesulfonate $\mathbf{2}$ were synthesized according to literature procedures. ${ }^{20,21}$ Condensation of 2 and 2,5-diiodohydroquinone in the presence of $\mathrm{K}_{2} \mathrm{CO}_{3}$ in 2-butanone resulted in 3. Reaction of 1 with 3 using $\mathrm{K}_{2} \mathrm{CO}_{3}$ base in acetonitrile resulted in the formation of M1. 3 and M1 were fully characterized by NMR and mass spectroscopy. 

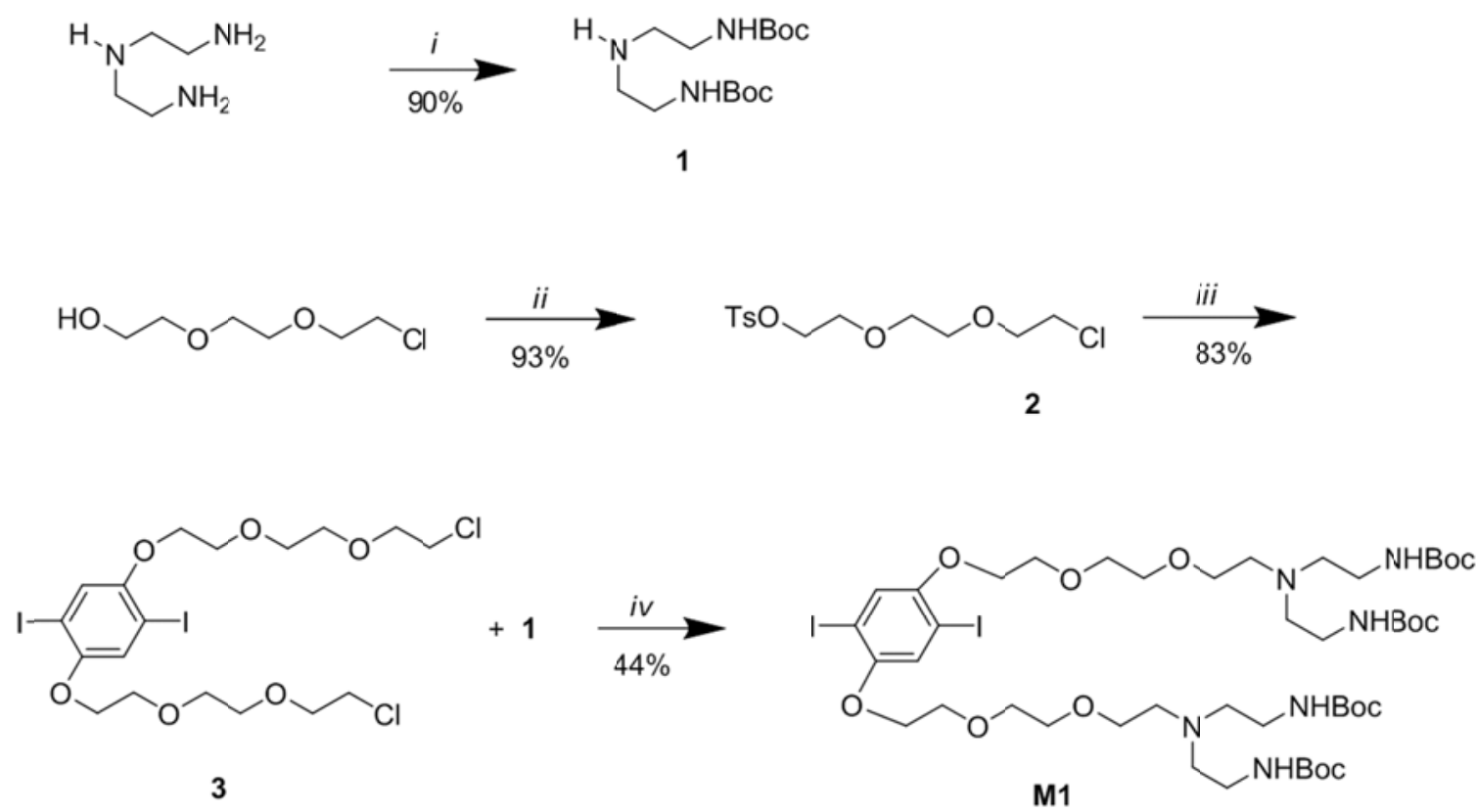

Scheme 1: Synthetic route towards monomer M1. Reagents and conditions: i) BocON,TEA, THF, $0^{\circ} \mathrm{C}, 3 \mathrm{~h}$; ii) $\mathrm{TsCl}$, TEA, MC, room temp., overnight; iii) 2,5-diiodohydroquinone, $\mathrm{K}_{2} \mathrm{CO}_{3}$, 2-butanone, reflux, 1 day; iv) $\mathrm{K}_{2} \mathrm{CO}_{3}, \mathrm{MeCN}$, Reflux, 3 days.

1,4-bis(2-(2-(2-chloroethoxy)ethoxy)ethoxy)-2,5-diiodobenzene (3): A suspension of compound 2 (5.89 mmol; $1.9 \mathrm{~g})$, 2,5-diiodohydroquinone $(2.76 \mathrm{mmol} ; 1 \mathrm{~g})$ and potassium carbonate $(8.28 \mathrm{mmol} ; 1.14 \mathrm{~g})$ in $40 \mathrm{~mL}$ of 2-butanone and was refluxed for 1 day. The mixture was concentrated in vacuo and diluted with $30 \mathrm{~mL}$ of ethyl acetate. The solution was washed with brine $(10 \mathrm{~mL} \times 3)$, dried $\left(\mathrm{Na}_{2} \mathrm{SO} 4\right)$, and evaporated in vauo. The crude product was purified by column chromatography (silica gel, ethyl acetate/ hexane(1:5, $\mathrm{v} / \mathrm{v})$ and Yield: $1.5 \mathrm{~g}(83 \%) .{ }^{1} \mathrm{H}-\mathrm{NMR}(400 \mathrm{MHz}): \delta=7.22(\mathrm{~s}, 1 \mathrm{H}, \mathrm{Ar}-\mathrm{H}), 4.09(\mathrm{t}, 2 \mathrm{H}, \mathrm{Ar}-$ $\left.\mathrm{O}-\mathrm{CH}_{2}, \mathrm{~J}=6\right), 3.87\left(\mathrm{t}, 2 \mathrm{H}, \mathrm{CH}_{2} \mathrm{O}, \mathrm{J}=6\right), 3.82-3.74\left(\mathrm{~m}, 4 \mathrm{H}, \mathrm{OCH}_{2} \mathrm{CH}_{2}\right), 3.69(\mathrm{t}, 2 \mathrm{H}$, $\left.\mathrm{CH}_{2} \mathrm{Cl}\right), 3.61\left(\mathrm{t}, 2 \mathrm{H}, \mathrm{OCH}_{2}, \mathrm{~J}=6\right) .{ }^{13} \mathrm{C}-\mathrm{NMR}(400 \mathrm{MHz}): \delta=153.13,123.52,86.46$, 72.01, 71.43, 71.15, 70.80, 70.33, 69.70, 42.83. HRMS (FTICR): Calcd. for $\mathrm{C}_{18} \mathrm{H}_{26} \mathrm{Cl}_{2} \mathrm{I}_{2} \mathrm{O}_{6}[\mathrm{M}+\mathrm{Na}]^{+}:=679.9534$; found $[\mathrm{M}+\mathrm{Na}]^{+}: 679.9529$. 
tert-butyl 2,2',2",2'"'-[2,2'-(2,2'-[2,2'-(2,5-diiodo-1,4-phenylene)bis(oxy)bis(ethane-2,1diyl)]-bis-(oxy)bis(ethane-2,1-diyl)]bis(oxy)bis(ethane-2,1-diyl)]bis(azanetriyl)tetrakis(ethane-2,1-diyl)-tetracarbamate (M1): A suspension of compound 1 (1.51 mmol; $1 \mathrm{~g})$, compound $3(3.17 \mathrm{mmol} ; 0.96 \mathrm{~g})$ and potassium carbonate $(3.171 \mathrm{mmol}$; $0.28 \mathrm{~g}$ ) in $40 \mathrm{~mL}$ of $\mathrm{MeCN}$ was refluxed for 3 days. The mixture was concentrated in vacuo and diluted with dichloromethane $30 \mathrm{~mL}$. The solution was washed with brine (10 $\mathrm{mL} \times 3)$, dried $\left(\mathrm{Na}_{2} \mathrm{SO} 4\right)$, and evaporated in vacuo. The crude product was purified by column chromatography (silica gel, ethyl acetate/hexane (1:1, v/v). Yield: $0.4 \mathrm{~g}(44 \%)$ $\mathrm{Rf}=0.47$ (3:1 ethyl acetate/hexane). ${ }^{1} \mathrm{H}-\mathrm{NMR}(400 \mathrm{MHz}): \delta=7.25$ (s, 1H, NH-COO), $7.23(\mathrm{~s}, 1 \mathrm{H}, \mathrm{Ar}-\mathrm{H}), 4.10\left(\mathrm{t}, 2 \mathrm{H}, \mathrm{Ar}-\mathrm{O}-\mathrm{CH}_{2}, \mathrm{~J}=6\right), 3.90\left(\mathrm{t}, 2 \mathrm{H}, \mathrm{CH}_{2} \mathrm{O}, \mathrm{J}=6\right), 3.82(\mathrm{t}, 2 \mathrm{H}$, $\left.\mathrm{OCH}_{2}, \mathrm{~J}=6\right), 3.68\left(\mathrm{t}, 2 \mathrm{H}, \mathrm{OCH}_{2}, \mathrm{~J}=6\right), 3.52\left(\mathrm{br}, 2 \mathrm{H}, \mathrm{OCH}_{2}\right), 3.14\left(\mathrm{br}, 4 \mathrm{H}, \mathrm{CH}_{2}{ }_{\mathrm{n}} \mathrm{HBoc}, \mathrm{J}\right.$ = 6), $2.68\left(\mathrm{br}, 2 \mathrm{H}, \mathrm{CH}_{2}{ }_{\mathrm{n}} \mathrm{H}\right), 2.62\left(\mathrm{br}, 4 \mathrm{H}, \mathrm{NHCH}_{2}\right) 1.45\left(\mathrm{~s}, 18 \mathrm{H}, \mathrm{OC}\left(\mathrm{CH}_{3}\right)_{3}\right) ;{ }^{13} \mathrm{CNMR}(400$ MHz): $\delta=156.9,144.3,121.1,83.7,77.2,70.6,70.4,70.3,70.1,59.1,54.2,53.7,51.2$, 50.7, 38.9, 27.3. HRMS (FTICR): Calcd. for $\mathrm{C}_{46} \mathrm{H}_{82} \mathrm{I}_{2}{ }_{n 6} \mathrm{O}_{14}[\mathrm{M}+\mathrm{H}]^{+}:$1197.4051; found $[\mathrm{M}+\mathrm{H}]^{+}: 1197.4032$.

Monomer 2 (M2) was synthesized according to Scheme 2. tert-butyl 2-(2-hydroxyethoxy)ethylcarbamate $\quad 4, \quad$ 2-(2-(tert-butoxycarbonylamino)ethoxy)ethyl 4methylbenzene-sulfonate $\quad \mathbf{5}, \quad$ and $\quad$ tert-butyl 2,2'-[2,2'-(2,5-diiodo-1,4phenylene)bis(oxy)bis(ethane-2,1-diyl)]bis-(oxy)bis(ethane-2,1-diyl)dicarbamate 6 were synthesized according to literature procedures. ${ }^{22-24}$ Coupling of $\mathbf{6}$ with trimethylsilylacetylene using Sonogashira coupling yielded compound 7, which was 
trimethylsilyl-deprotected to yield M2. Compounds 7 and $\mathbf{M} 2$ were fully characterized by NMR and mass spectroscopy.

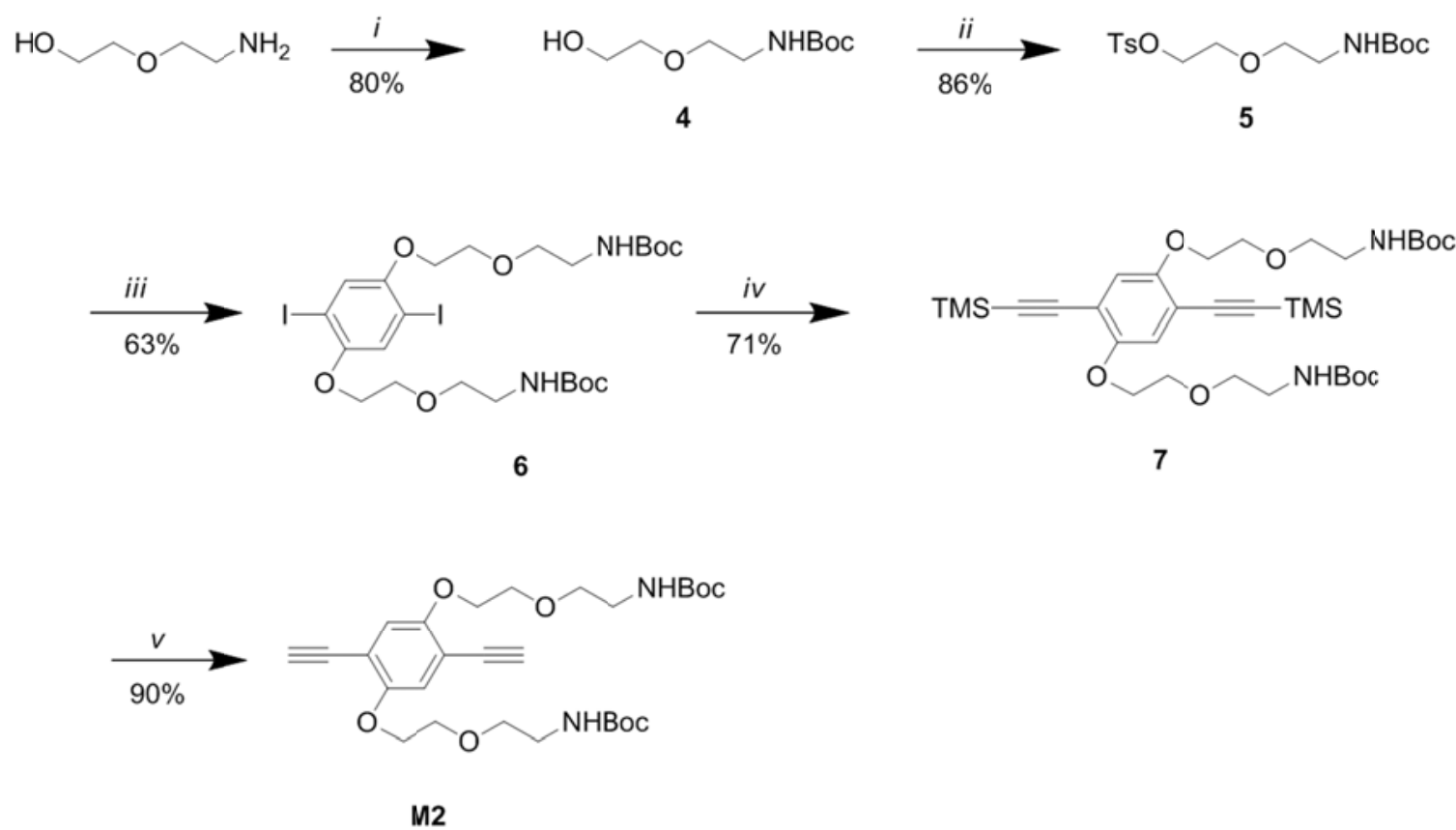

Scheme 2: Synthetic route towards monomer M2. Reagents and conditions: i) $\mathrm{Boc}_{2} \mathrm{O}, \mathrm{MC}$, room temp., overnight; ii) TsCl, TEA, MC, room temp., overnight; iii) 2,5-diiodohydroquinone, $\mathrm{K}_{2} \mathrm{CO}_{3}$, $\mathrm{DMF}, 80^{\circ} \mathrm{C}, 1$ day; iv) Trimethylsilylacetylene, $\mathrm{Pd}\left(\mathrm{PPh}_{3}\right)_{2} \mathrm{Cl}_{2}$, CuI, diisopropylamine, THF, $60^{\circ} \mathrm{C}, 12 \mathrm{~h}$; v) $\mathrm{K}_{2} \mathrm{CO}_{3}, \mathrm{MeOH}$, room temp., overnight.

tert-butyl 2,2'-(2,2'-(2,5-bis[(trimethylsilyl)ethynyl)-1,4-phenylene)bis(oxy)bis-(ethane2,1-diyl)]bis-(oxy)bis(ethane-2,1-diyl)dicarbamate (7): Compound 6 (2.03 mmol, $1.5 \mathrm{~g}$ ) was added to a Schlenk flask fitted with a stir bar, $\mathrm{Pd}\left(\mathrm{PPh}_{3}\right){ }_{2} \mathrm{Cl}_{2}(0.203 \mathrm{mmol}, 146 \mathrm{mg})$ and $\mathrm{CuI}(0.100 \mathrm{mmol}, 20 \mathrm{mg})$. A solution of THF $(20 \mathrm{~mL})$ and diisopropylamine $(10 \mathrm{~mL})$ was then added to the reaction mixture. Subsequently, trimethylsilylacetylene (5.10 mmol, $0.7 \mathrm{~mL}$ ) was added to the reaction mixture. The reaction was allowed to proceed for $12 \mathrm{~h}$ at $60{ }^{\circ} \mathrm{C}$, cooled to room temperature and the solvent was evaporated. The suspension was re-dissolved with methylenechloride, washed with saturated ammonium chloride $(2 \times 30 \mathrm{~mL})$, and then dried over magnesium sulfate. The solvent was evaporated to produce dark brown oil, which was purified by column chromatography (silica gel, 
ethyl acetate/ hexane $(4: 1, \mathrm{v} / \mathrm{v})$. Yield : 0.94g ( $71 \%) .{ }^{1} \mathrm{H}-\mathrm{NMR}(400 \mathrm{MHz}): \delta=7.23(\mathrm{~s}$, $1 \mathrm{H}, \mathrm{Ar}-\mathrm{H}), 5.0\left(\mathrm{~s}, 1 \mathrm{H}, \mathrm{CH}_{2}-\mathrm{NH}\right), 4.10\left(\mathrm{t}, 2 \mathrm{H}, \mathrm{Ar}-\mathrm{OCH}_{2}, \mathrm{~J}=6\right), 3.81\left(\mathrm{t}, 2 \mathrm{H}, \mathrm{OCH}_{2}, \mathrm{~J}=6\right)$, $3.83\left(\mathrm{t}, 2 \mathrm{H}, \mathrm{OCH}_{2}, \mathrm{~J}=6\right), 3.65(\mathrm{~s}, 1 \mathrm{H}, \mathrm{ArCCH}), 3.36\left(\mathrm{q}, 2 \mathrm{H}, \mathrm{CH}_{2}{ }_{\mathrm{n}} \mathrm{H}, \mathrm{J}=6\right), 1.43(\mathrm{~s}, 10 \mathrm{H}$, $\left.\mathrm{OC}\left(\mathrm{CH}_{3}\right)_{3}\right), 0.05(\mathrm{~s}, 9 \mathrm{H}, \mathrm{TMS}) .{ }^{13} \mathrm{C}-\mathrm{NMR}(400 \mathrm{MHz}): \delta=171.1,156.0,154.0,118.1$, $114.5,100.8,79.1,77.5,71.9,70.6,69.6,68.0,60.4,53.5,41.3,28.4,21.0,19.2,14.2$. HRMS (FTICR): Calcd. for $\mathrm{C}_{34} \mathrm{H}_{56}{ }_{\mathrm{n} 2} \mathrm{O}_{8} \mathrm{Si}_{2}[\mathrm{M}+\mathrm{H}]^{+}:$: 677.3648; found $[\mathrm{M}+\mathrm{H}]^{+}:$: 677.3644 .

tert-butyl 2,2'-[2,2'-(2,5-diethynyl-1,4-phenylene)bis(oxy)bis(ethane-2,1-diyl)]bis(oxy)bis(-ethane-2,1-diyl)dicarbamate (M2): A $20 \mathrm{~mL}$ vial was charged with compound 8 (1.42 mmol, $0.400 \mathrm{~g})$, Potassium carbonate $(0.70 \mathrm{mmol}, 0.100 \mathrm{~g}) 15 \mathrm{~mL}$ of $\mathrm{MeOH}$ and left to stir overnight at room temperature. The resulting mixture was gravity filtered, the solvent was evaporated and the reaction mixture was purified by column chromatography (silica gel, ethyl acetate). Yield : 0.34g (90\%). ${ }^{1} \mathrm{H}-\mathrm{NMR}(400 \mathrm{MHz}): \delta=7.00(\mathrm{~s}, 1 \mathrm{H}, \mathrm{Ar}-$ H), $5.0\left(\mathrm{~s}, 1 \mathrm{H}, \mathrm{CH}_{2}-\mathrm{NH}\right), 4.15\left(\mathrm{t}, 2 \mathrm{H}, \mathrm{Ar}-\mathrm{OCH}_{2}, \mathrm{~J}=6\right), 3.81\left(\mathrm{t}, 2 \mathrm{H}, \mathrm{OCH}_{2}, \mathrm{~J}=6\right), 3.65(\mathrm{t}$, $\left.2 \mathrm{H}, \mathrm{OCH}_{2}, \mathrm{~J}=6\right), 3.39(\mathrm{~s}, 1 \mathrm{H}, \mathrm{ArCCH}), 3.36\left(\mathrm{q}, 2 \mathrm{H}, \mathrm{CH}_{2}{ }_{n} \mathrm{H}, \mathrm{J}=6\right), 1.56(\mathrm{~s}, 10 \mathrm{H}$, $\left.\mathrm{OC}\left(\mathrm{CH}_{3}\right)_{3}\right) ;{ }^{13} \mathrm{C}-\mathrm{NMR}(400 \mathrm{MHz}): \delta=156.7,154.1,118.3,113.7,83.0,79.5,71.9,70.6$, 69.3, 69.25, 40.7, 28.4. HRMS (FTICR): Calcd. for $\mathrm{C}_{28} \mathrm{H}_{40}{ }_{n 2} \mathrm{O}_{8}[\mathrm{M}+\mathrm{H}]^{+}:$533.2857; found $[\mathrm{M}+\mathrm{H}]^{+}: 533.2849$.

Monomer 3 (M3) was synthesized according to Scheme 3. 2-(2-methoxyethoxy)ethyl 4methyl-benzenesulfonate 8, 1,4-diiodo-2,5-bis(2-(2-methoxyethoxy)ethoxy)benzene 9, 
(2,5-bis(2-(2-methoxyethoxy)ethoxy)-1,4-phenylene)bis(ethyne-2,1-

diyl)bis(trimethylsilane) $\quad \mathbf{1 0}, \quad$ and 1,4-diethynyl-2,5-bis(2-(2methoxyethoxy)ethoxy)benzene M3 were synthesized according to literature procedures. ${ }^{25}$
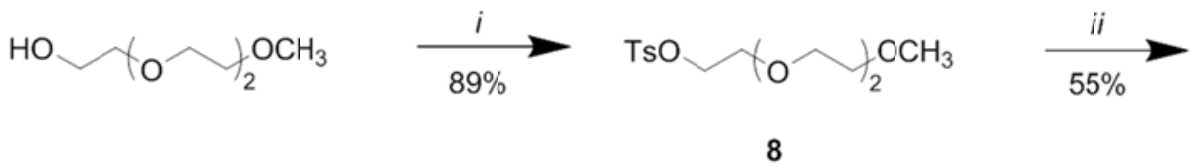

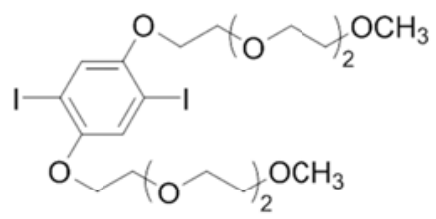

9

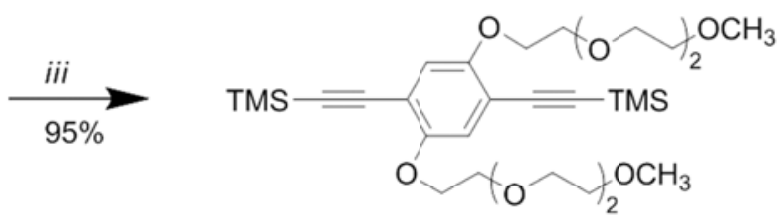

10

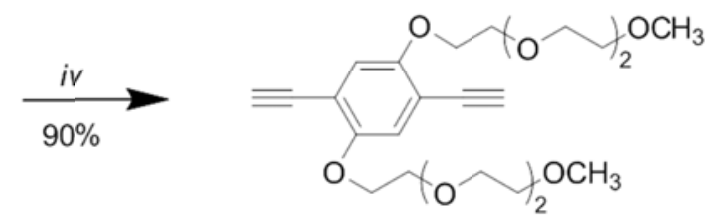

M3

Scheme 3: Synthetic route towards monomer M2. Reagents and conditions: i) TsCl, TEA, MC, room temp., overnight; ii) 2,5-diiodohydroquinone, $\mathrm{K}_{2} \mathrm{CO}_{3}, \mathrm{DMF}, 80^{\circ} \mathrm{C}$, overnight; iii) Trimethylsilylacetylene, $\mathrm{Pd}\left(\mathrm{PPh}_{3}\right)_{2} \mathrm{Cl}_{2}$, CuI, diisopropylamine, THF, $60^{\circ} \mathrm{C}, 12 \mathrm{~h}$; iv) $1 \mathrm{~m} \mathrm{KOH}(\mathrm{aq}), \mathrm{THF}, \mathrm{MeOH}$, room temp., overnight.

\subsubsection{Polymer Synthesis and Characterization}

\subsubsection{General Procedure}

A Schlenk flask was charged with aryl halide monomer (1.0 eqiv) and diactylene monomer (1.0 equiv), along with $\mathrm{Pd}\left[\left(\mathrm{PPh}_{3}\right)_{2} \mathrm{Cl}_{2}\right]$ (0.2 equiv) and $\mathrm{CuI}(0.95$ equiv). The Schlenk flask was evacuated and filled with $\mathrm{N}_{2}$ three times. A solution of anhydrous 
dimethylformamide (DMF) $(4 \mathrm{~mL})$ and freshly distilled trimethylamine $(1 \mathrm{~mL})$ was degassed, and $1 \mathrm{~mL}$ of the mixed solution was transferred to the Schlenk flask using a cannular needle. The reaction was heated at $70{ }^{\circ} \mathrm{C}$ for $14 \mathrm{~h}$. The solution was then cooled to room temperature and transferred dropwise to cold ethyl ether, resulting in precipitation. After centrifugation ( $2 \mathrm{~min}, 4000 \mathrm{rpm}$ ), the supernatant was decanted, and the precipitate was redissolved in DMF (1 mL) for further purification. See Scheme 4.

2.6.3.2. CPN Formation. Boc-deprotection of the polymer was carried out by mixing a solution of polymer in DMSO- $\mathrm{d}_{6}$ with acetic acid $(2 \mathrm{~mL})$ and trifluoroacetic acid $(1 \mathrm{~mL})$ and allowed to stir at room temperature for 5 days. The mixture was then added to acetic acid $(20 \mathrm{~mL})$, allowed to stir overnight, and centrifuged, and supernatant was added dropwise ( 2 drops/s) to $500 \mathrm{~mL}$ water $(18 \Omega)$ while stirring. Using a solvent-resistant stir cell fitted with a $30 \mathrm{kDa}-\mathrm{MWCO}$ membrane, the solution was concentrated to approximately $10 \mathrm{~mL}$, and dialyzed against $1 \mathrm{~L}$ of water. The resulting solution was further dialyzed in a $10 \mathrm{KDa}$ membrane for 3 days. The solution was subsequently filtered through a Teflon (PTFE) syringe filter $(0.45 \mu \mathrm{m})$ and used for further analysis. Deprotection was confirmed with ${ }^{1} \mathrm{H}-\mathrm{NMR}$. See Scheme 4. 

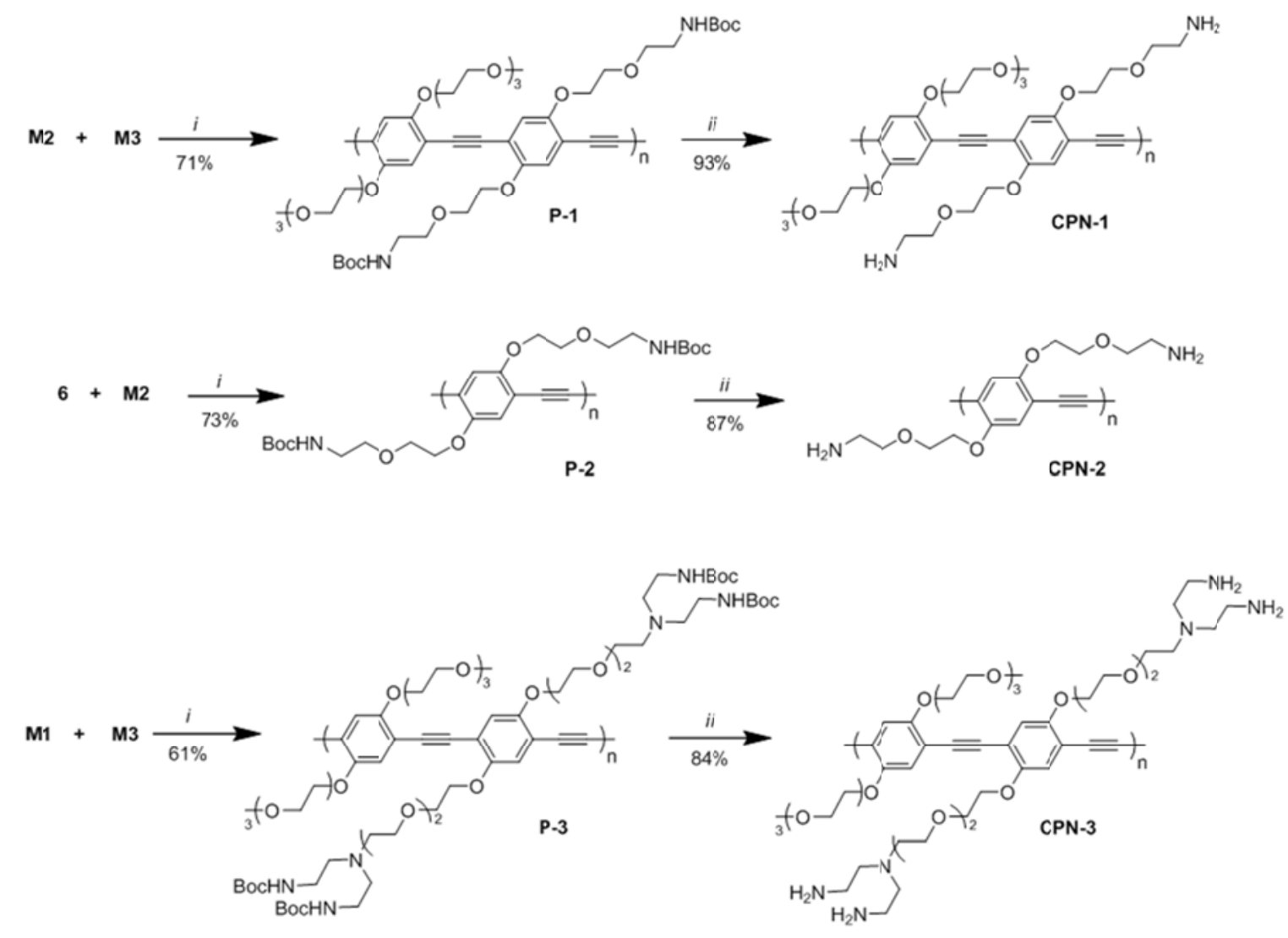

Scheme 3: Synthetic route towards CPN-1, CPN-2 and CPN-3. Reagents and conditions: i) $\mathrm{Pd}\left(\mathrm{PPh}_{3}\right)_{2} \mathrm{Cl}_{2}$, CuI, TEA, DMF , $70^{\circ} \mathrm{C}, 14 \mathrm{~h}$; ii) TFA, AcOH, DMF, room temp., 5 days.

P1. Using the general procedure described above, the polymerization of monomer 9 (32 $\mathrm{mg}, 0.044 \mathrm{mmol})$ and monomer $13(20 \mathrm{mg}, 0.044 \mathrm{mmol})$ in the presence of $\mathrm{Pd}\left[\left(\mathrm{PPh}_{3}\right)_{2} \mathrm{Cl}_{2}\right](3 \mathrm{mg}, 0.0044 \mathrm{mmol})$ and $\mathrm{CuI}(0.2 \mathrm{mg}, 0.0022 \mathrm{mmol})$ yielded PPE polymer P-1 ( $32 \mathrm{mg}, 71 \%$ ). Molecular weight of boc-protected polymer was obtained and characterized. Resulting mixture was purified by precipitation in cold ethyl ether (x3). An aliquot was redissolved in THF and molecular weight obtained and photophycal properties characterized. The rest of the material was dissolved in DMSO- $\mathrm{d}_{6}$ and characterized using ${ }^{1} \mathrm{H}-\mathrm{NMR}$. CPN formation was then carried out as described in general procedure to yield $\mathbf{C P N}-1$. 
P1: GPC: $\mathrm{M}_{\mathrm{w}}=24.43 \mathrm{kDa} ; \mathrm{M}_{\mathrm{n}}=16.4 \mathrm{kDa} ; \mathrm{PDI}=1.49 . \mathrm{UV} \lambda_{\max }=427 \mathrm{~nm}$; fluo $\lambda_{\max }(400$ $\mathrm{nm}$ ex $)=471 \mathrm{~nm}$; QY $=41 \%$ in DMF. ${ }^{1} \mathrm{H}-\mathrm{NMR}(400 \mathrm{MHz}): \delta=7.35$ (br, $\left.1 \mathrm{H}, \mathrm{Ar}-\mathrm{H}\right), 6.87$ (br, 0.5H, NHCOO), 4.08 (br, 2H, Ar-OCH $), 3.91$ (br, $2 \mathrm{H} \mathrm{CH}_{2} \mathrm{O}$ ), 3.82 (br, $2 \mathrm{H}, \mathrm{OCH}_{2}$ ), 3.58 (br, $2 \mathrm{H}, \mathrm{CH}_{2} \mathrm{O}$ ), 3.48 (br, $\left.2 \mathrm{H}, \mathrm{OCH}_{2}\right), 3.34$ (br, $2 \mathrm{H}, \mathrm{CH}_{2} \mathrm{O}$ ), 3.27 (br, $2 \mathrm{H}, \mathrm{OCH}_{2}$ ), $2.72\left(\mathrm{br}, 3 \mathrm{H}, \mathrm{OCH}_{3}\right), 1.47\left(\mathrm{~s}, 8 \mathrm{H}, \mathrm{OC}\left(\mathrm{CH}_{3}\right)_{3}\right)$. FT-IR (Neat): v = $3372(\mathrm{br}), 2982(\mathrm{w})$, 2935 (m), 2875 (s), 1710 (vs; C=O), 1513 (vs), 1461 (w), 1425 (m), 1425 (m), 1393 (m), $1363(\mathrm{~s}), 1276(\mathrm{~s}), 1219(\mathrm{~s}), 1172(\mathrm{~m}), 1120(\mathrm{~m}), 1060$ (m), $1033(\mathrm{~m})$.

CPN-1: UV $\lambda_{\max }=433 \mathrm{~nm}$; fluo $\lambda_{\max }(400 \mathrm{~nm}$ ex $)=496 \mathrm{~nm}$; QY $=3 \%$ in water. ${ }^{1} \mathrm{H}-$ $\operatorname{NMR}(600 \mathrm{MHz}): \delta=7.36(\mathrm{br}, 1 \mathrm{H}, \mathrm{Ar}-\mathrm{H}), 4.3-3.0$ (br, $23 \mathrm{H},-\mathrm{OCH}_{2}-\mathrm{CH}_{2}-$ chains), 1.30 (s, 0.21H). FT-IR (Neat): v = 3374 (br), 2982 (w), 2935 (m), 2875 (s), 1674 (br), 1610 (w), $1500(\mathrm{~m}), 1461(\mathrm{w}), 1423(\mathrm{w}), 1390(\mathrm{w}), 1360(\mathrm{~m}), 1279(\mathrm{w}), 1250(\mathrm{w}), 1213(\mathrm{br})$, 1104 (br), 1059 (br), 1035 (m).

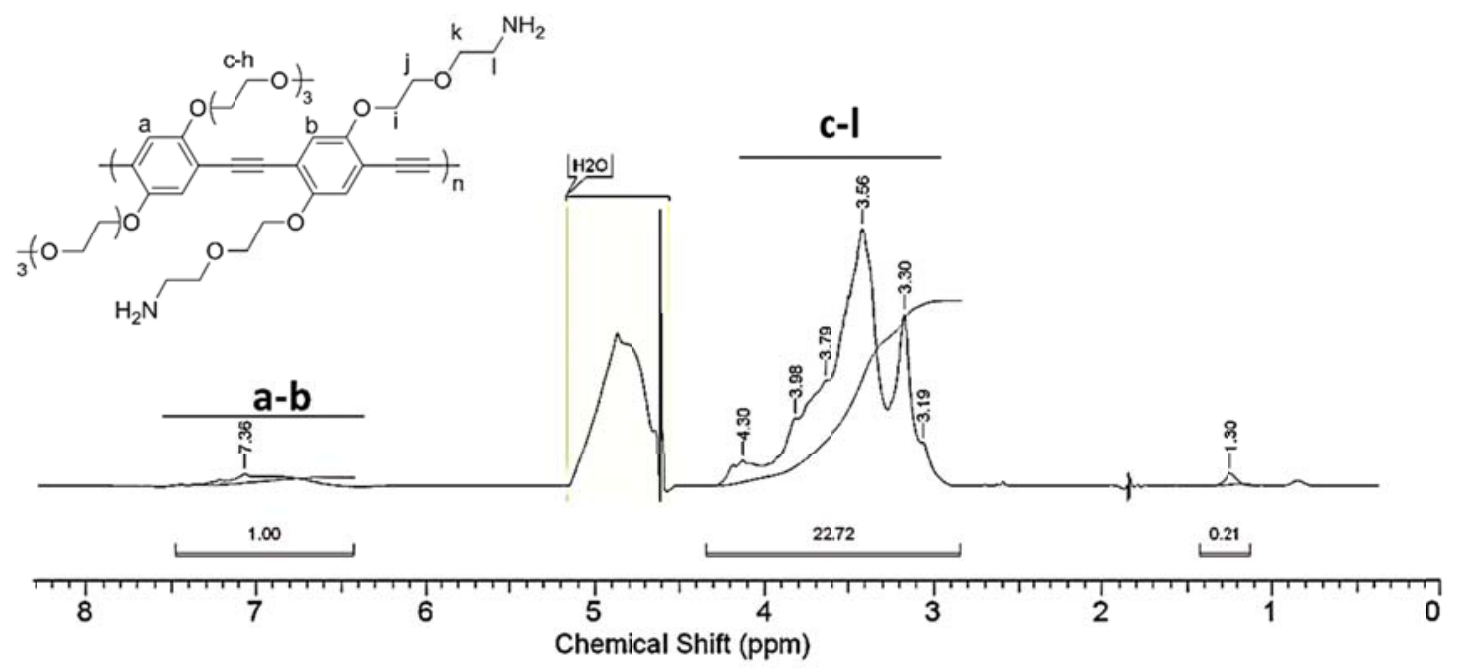

Figure 2.6. ${ }^{1} \mathrm{H}-\mathrm{NMR}$ for polymer $\mathbf{C P N}-1$ in $\mathrm{D}_{2} \mathrm{O}$ 


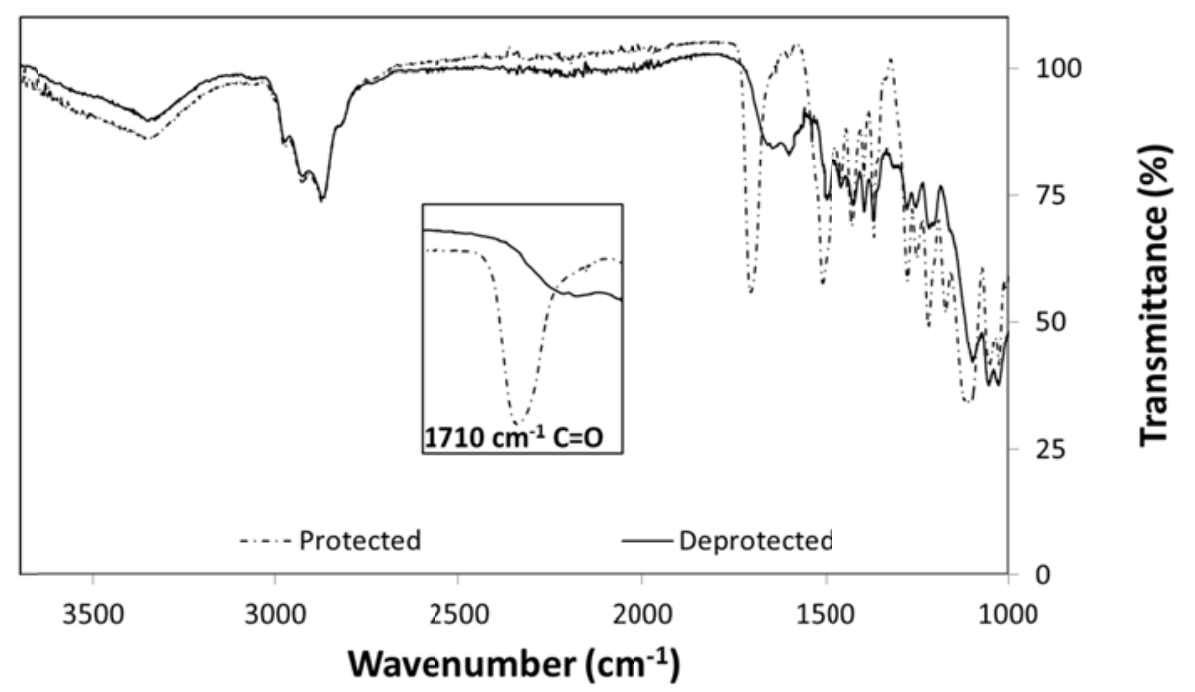

Figure 2.7. FT-IR for polymer P1 (Neat)

Results

$\begin{array}{rlllll} & & \text { Diam. (nm) } & \text { \% Intensity } & \text { Width (nm) } \\ \text { Z-Average (d.nm): } & 60.55 & \text { Peak 1: } & 92.46 & 94.9 & 55.58 \\ \text { Pdl: } & 0.293 & \text { Peak 2: } & 13.82 & 5.1 & 3.029 \\ \text { Intercept: } & 0.920 & \text { Peak 3: } & 0.000 & 0.0 & 0.000\end{array}$

Result quality : Good

Size Distribution by Intensity

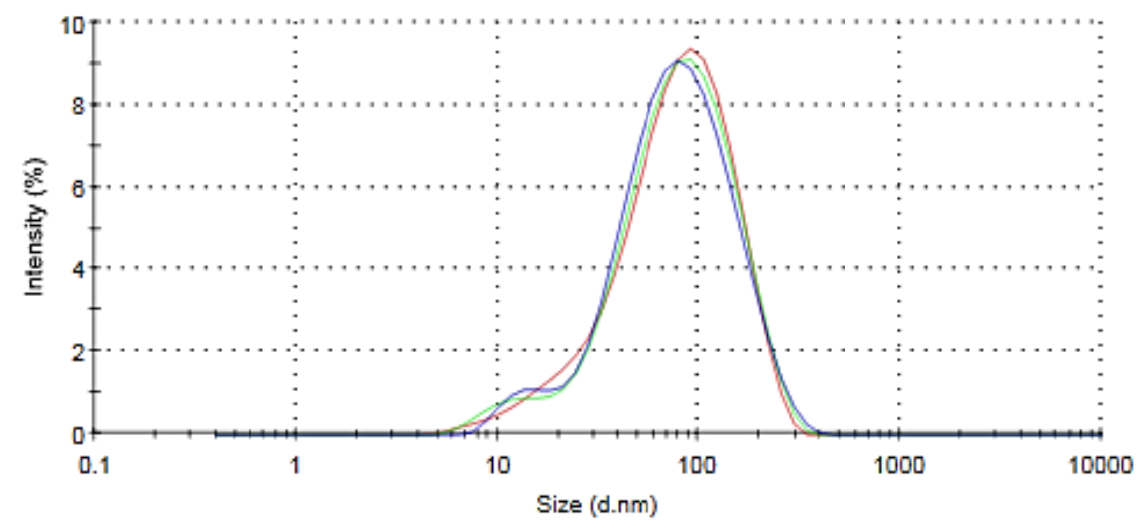

Record 42: EM3-1451

Record 44: EM3-145 3

Record 46: EM3-145 5

Figure 2.8. DLS for polymer CPN-1 
Results

\begin{tabular}{|c|c|c|c|c|}
\hline & & Mean $(\mathrm{mV})$ & Area (\%) & Width $(\mathrm{mV})$ \\
\hline Zeta Potential (mV): 20.2 & Peak 1: & 20.2 & 99.7 & 7.73 \\
\hline Zeta Deviation $(\mathrm{mV}): 7.84$ & Peak 2: & -9.98 & 0.3 & 1.78 \\
\hline Conductivity $(\mathrm{mS} / \mathrm{cm}): 0.732$ & Peak 3: & 0.00 & 0.0 & 0.00 \\
\hline
\end{tabular}

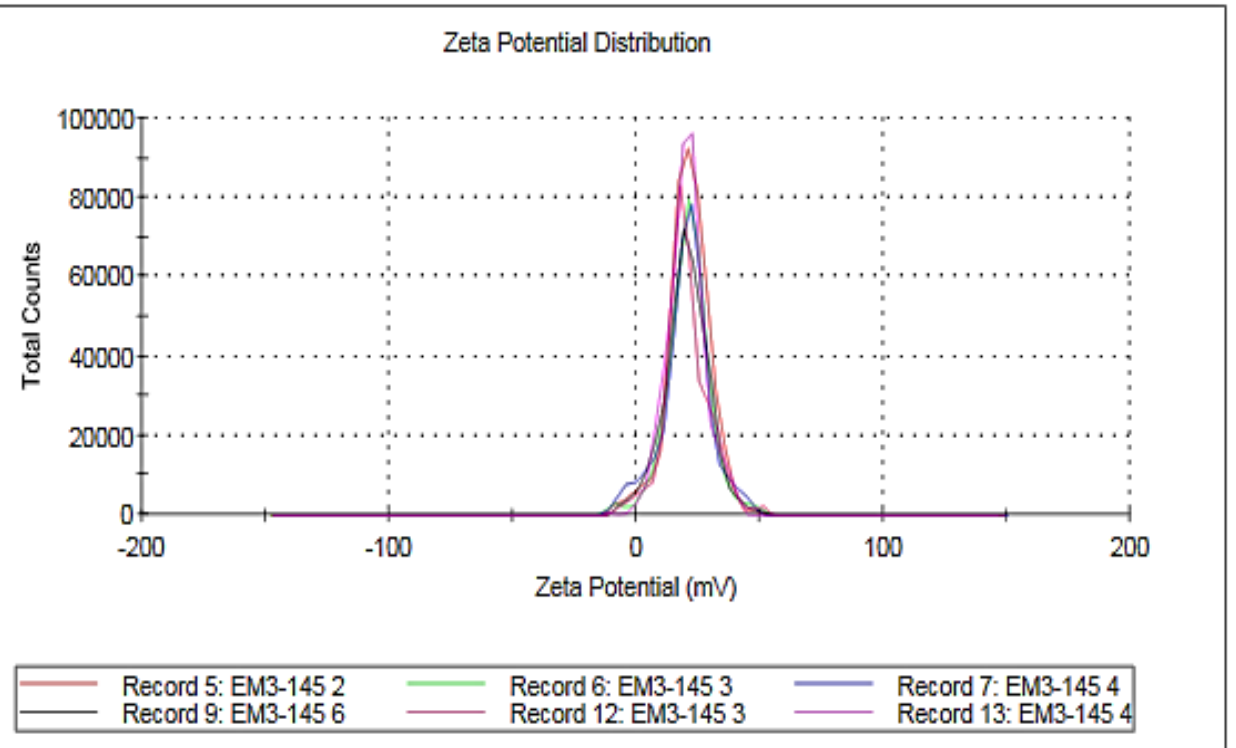

Figure 2.9. ZP for polymer CPN-1

P2. Using the general procedure described above, the polymerization of 6 (30 $\mathrm{mg}, 0.056$ $\mathrm{mmol})$ and monomer $\mathbf{M} 2(41 \mathrm{mg}, 0.056 \mathrm{mmol})$ in the presence of $\mathrm{Pd}\left[\left(\mathrm{PPh}_{3}\right)_{2} \mathrm{Cl}_{2}\right](4 \mathrm{mg}$, $0.0056 \mathrm{mmol})$ and $\mathrm{CuI}(0.3 \mathrm{mg}, 0.0028 \mathrm{mmol})$ yielded PPE polymer P2 ( $44 \mathrm{mg}, 73 \%$ ). Resulting mixture was purified by precipitation in cold ethyl ether (x3). An aliquot was redissolved in THF and molecular weight obtained and photophycal properties characterized. The rest of the material was dissolved in DMSO- $\mathrm{d}_{6}$ and characterized using ${ }^{1} \mathrm{H}-\mathrm{NMR}$. CPN formation was then carried out as described in general procedure to yield CPN-2 
P2: GPC: $\mathrm{M}_{\mathrm{w}}=16.9 \mathrm{kDa} ; \mathrm{M}_{\mathrm{n}}=11.8 \mathrm{kDa} ; \mathrm{PDI}=1.43 . \mathrm{UV} \lambda_{\max }=432 \mathrm{~nm}$; fluo $\lambda_{\max }(400$ $\mathrm{nm}$ ex $)=475 \mathrm{~nm}$; QY $=37 \%$ in DMF. ${ }^{1} \mathrm{H}-\mathrm{NMR}\left(400 \mathrm{MHz}, \mathrm{DMSO}_{6}, \delta\right): 7.16(\mathrm{~s}, 1 \mathrm{H}$, Ar-H), 6.72 (s, 0.2H, NH-Boc), 4.21 (br, 2H, Ar- $\left.-\mathrm{OCH}_{2}\right), 3.80$ (br, 2H, $\left.\mathrm{CH}_{2} \mathrm{O}\right), 3.66$ (br, $\left.2 \mathrm{H}, \mathrm{OCH}_{2}\right), 3.52\left(\mathrm{br}, 2 \mathrm{H}, \mathrm{CH}_{2}{ }_{\mathrm{n}} \mathrm{H}\right), 1.37\left(\mathrm{~s}, 8 \mathrm{H}, \mathrm{C}\left(\mathrm{CH}_{3}\right)_{3}\right)$. FT-IR (Neat): $v=3366$ (br), 2933 (w), 2865 (s), 1704 (vs; C=O), 1507 (vs), 1457 (w), 1423 (w), 1365 (s), 1277 (w), 1247 (w), $1219(\mathrm{~s}), 1172(\mathrm{w}), 1108$ (s), 1057 (s), 1026 (w), 945 (s), $860 \mathrm{~cm}-1$ (m).

CPN-2: UV $\lambda_{\max }=427 \mathrm{~nm}$; fluo $\lambda_{\max }(400 \mathrm{~nm}$ ex $)=492 \mathrm{~nm}$; QY $=2 \%$ in water. ${ }^{1} \mathrm{H}-\mathrm{NMR}$ (600 MHz, $\mathrm{D}_{2} \mathrm{O}, \delta$ ): 7.03 (br, 1H, Ar-H), 4.24-2.76 (br, 10.74H, $\mathrm{OCH}_{2} \mathrm{CH}_{2} \mathrm{OCH}_{2} \mathrm{CH}_{2}$ ), 1.36 (s, 0.46H). FT-IR (Neat): v = 3417 (br), 2925 (w), 2865 (s), 1647 (br), 1495 (w), $1462($ w), 1418 (w), 1357 (w), $1283($ w), 1205 (s), 1094 (s), 1040 (w), $936($ w), $841($ w) $\mathrm{cm}^{-1}$.

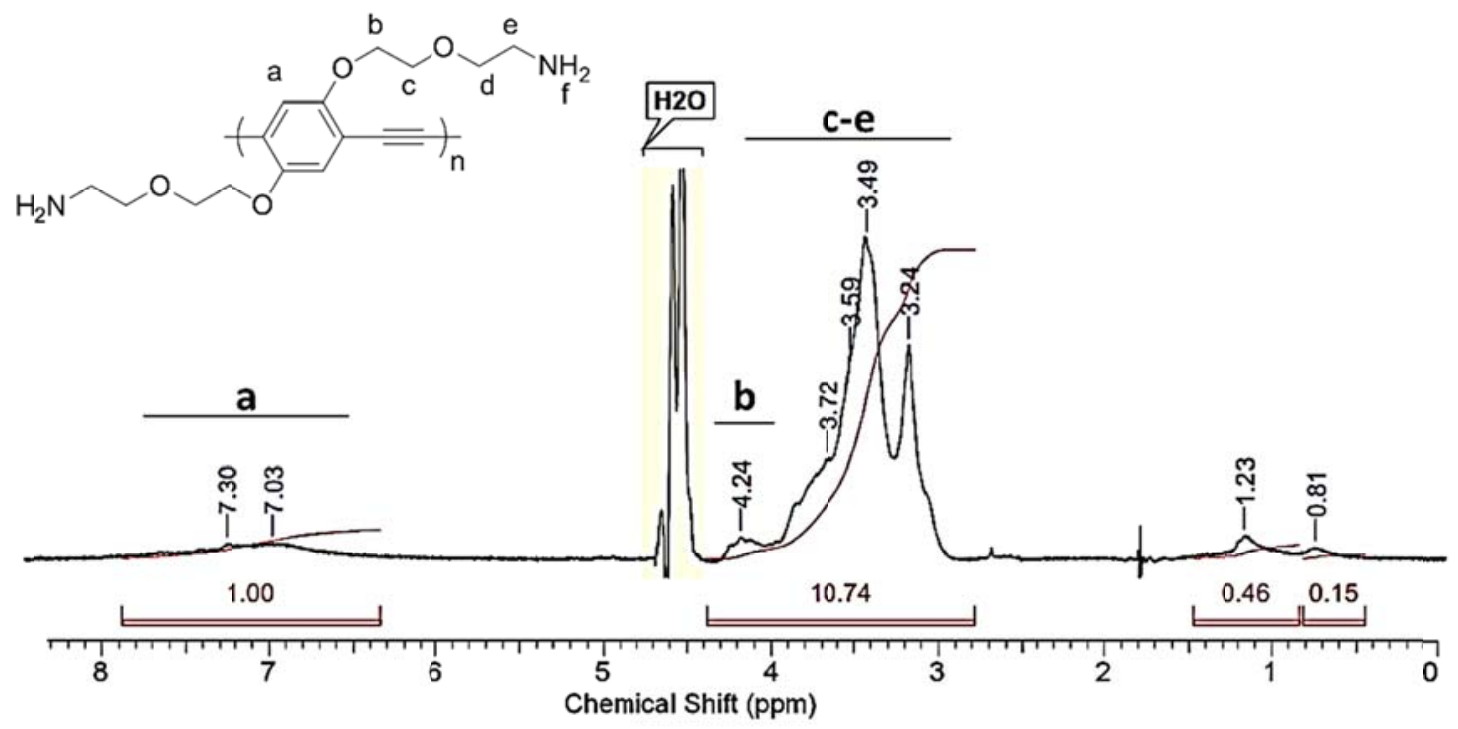

Figure 2.10. ${ }^{1} \mathrm{H}-\mathrm{NMR}$ for polymer $\mathbf{C P N}-2$ in $\mathrm{D}_{2} \mathrm{O}$ 


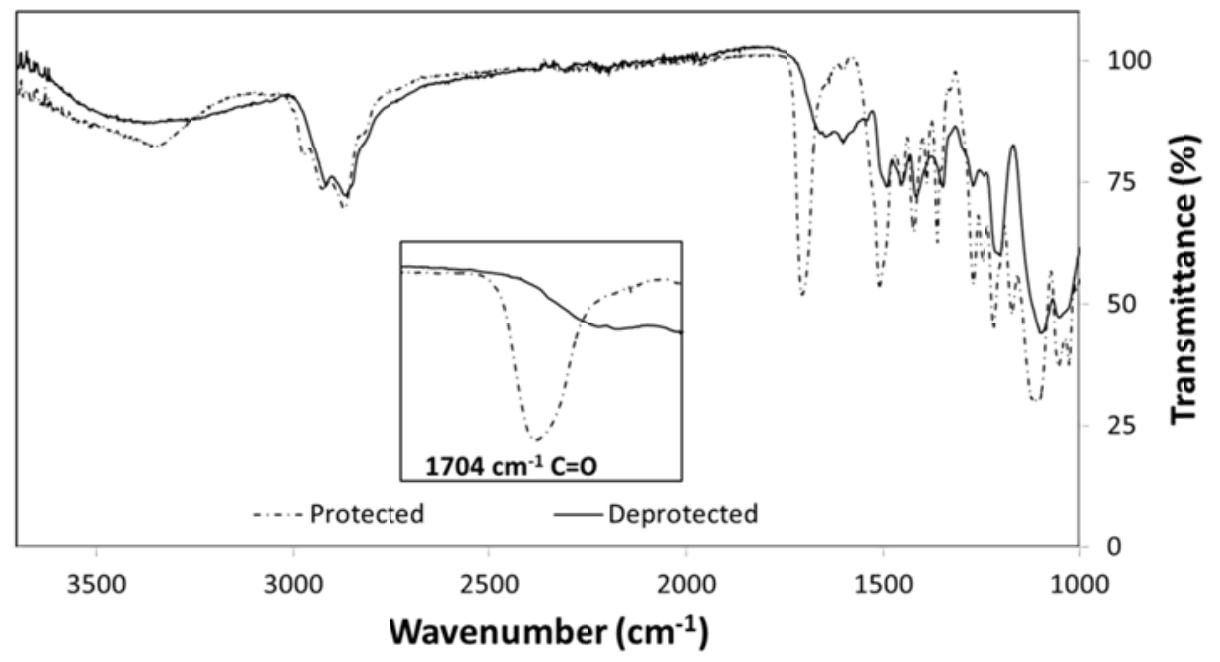

Figure 2.11. FT-IR for polymer P2 (Neat)

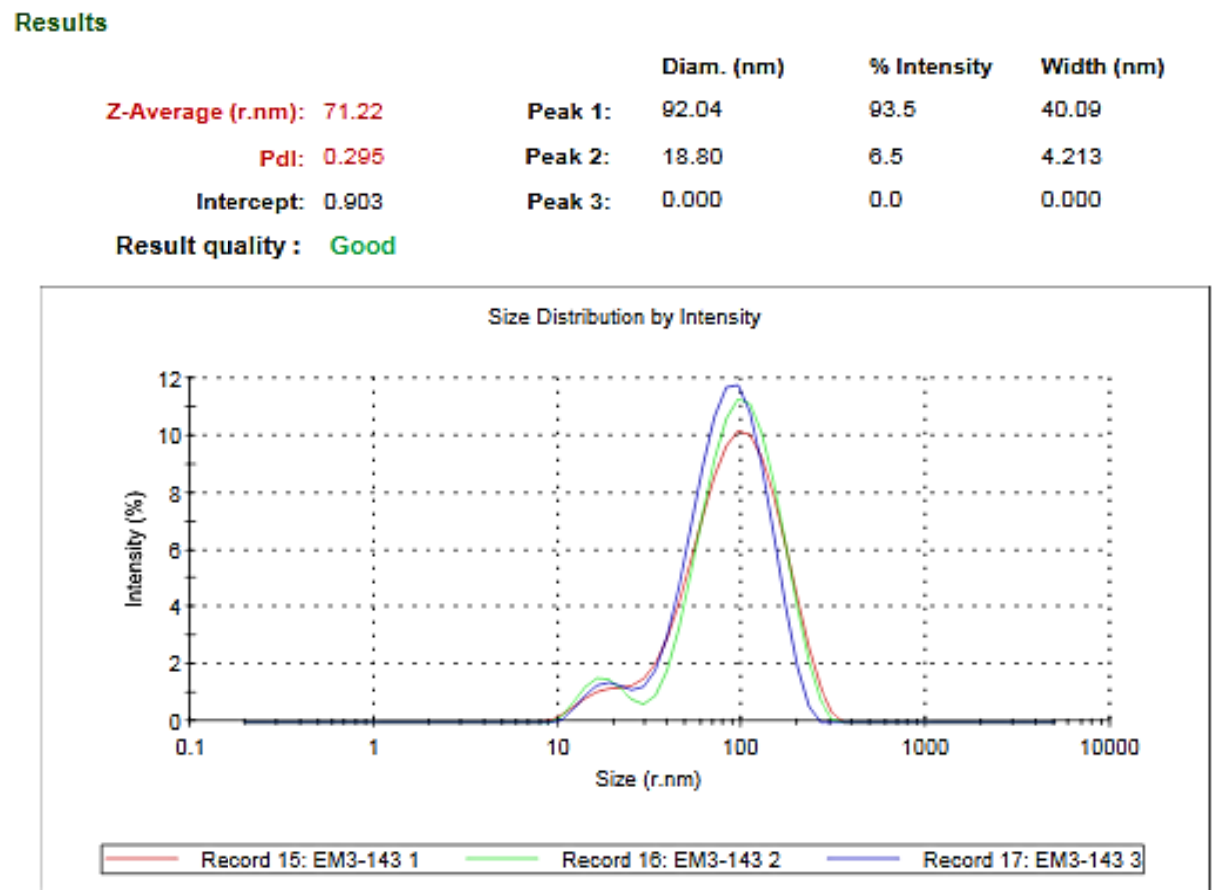

Figure 2.12. DLS for polymer CPN-2 


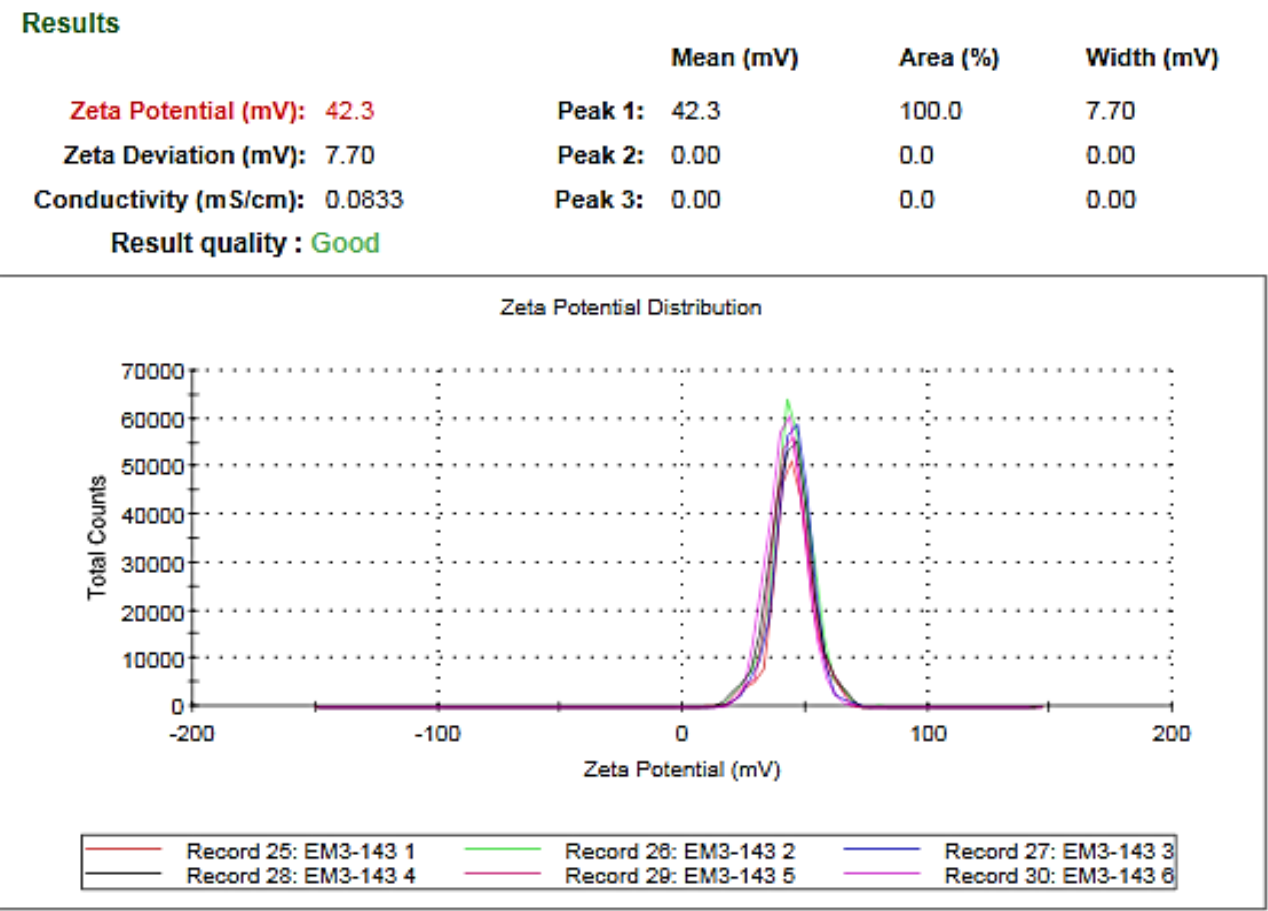

Figure 2.13. ZP for polymer CPN-2

P3. Using the general procedure described above, the polymerization of monomer 4 (65 $\mathrm{mg}, 0.054 \mathrm{mmol})$ and monomer $13(32 \mathrm{mg}, 0.054 \mathrm{mmol})$ in the presence of $\operatorname{Pd}\left[\left(\mathrm{PPh}_{3}\right)_{2} \mathrm{Cl}_{2}\right](8 \mathrm{mg}, 0.0054 \mathrm{mmol})$ and $\mathrm{CuI}(0.4 \mathrm{mg}, 0.0022 \mathrm{mmol})$ yielded PPE polymer P3 ( $45 \mathrm{mg}, 61 \%$ ). Resulting mixture was purified by precipitation in cold ether (x3). An aliquot was redissolved in THF and molecular weight obtained and photophycal properties characterized. The rest of the material was dissolved in DMSO- $\mathrm{d}_{6}$ and characterized using ${ }^{1} \mathrm{H}-\mathrm{NMR}$. CPN formation was then carried out as described in general procedure to yield $\mathbf{C P N}-\mathbf{3}$.

P3: $\mathrm{GPC}: \mathrm{M}_{\mathrm{w}}=17.5 \mathrm{kDa} ; \mathrm{M}_{\mathrm{n}}=10.7 \mathrm{kDa} ; \mathrm{PDI}=1.64$. UV $\lambda_{\max }=420 \mathrm{~nm}$; fluo $\lambda_{\max }(400$ $\mathrm{nm}$ ex $)=469 \mathrm{~nm} ; \mathrm{QY}=35 \%$ in DMF. ${ }^{1} \mathrm{H}-\mathrm{NMR}(400 \mathrm{MHz}): \delta=7.70-6.95(\mathrm{br}, 1 \mathrm{H}, \mathrm{Ar}-$ H), 4.0-3.24 (br, 42H, $\mathrm{OCH}_{2} \mathrm{CH}_{2}$ ), 2.30-1.94 (br, 6H, $\left.\mathrm{NCH}_{2} \mathrm{CH}_{2}{ }_{n} \mathrm{H}\right), 1.30(\mathrm{~s}, 10 \mathrm{H}$, 
OC( $\left.\left(\mathrm{CH}_{3}\right)_{3}\right)$. FT-IR (Neat): v = 3357 (br), 2909 (br), 1656 (vs; C=O), 1500 (w), 1441 (w), $1421(\mathrm{w}), 1391(\mathrm{w}), 1367(\mathrm{~m}), 1340(\mathrm{w}), 1316(\mathrm{w}), 1280(\mathrm{w}), 1250(\mathrm{~m}), 1228(\mathrm{w}), 1208$ (w), 1162 (m), 1103 (m), 1060 (br), 1034 (br).

CPN-3: UV $\lambda_{\max }=420 \mathrm{~nm}$; fluo $\lambda_{\max }(400 \mathrm{~nm}$ ex $)=496 \mathrm{~nm}$; $\mathrm{QY}=2 \%$ in water. ${ }^{1} \mathrm{H}-$ $\operatorname{NMR}(600 \mathrm{MHz}): \delta=7.70-6.45$ (br, $1 \mathrm{H}, \mathrm{Ar}-\mathrm{H}), 4.3-2.5$ (br, $28 \mathrm{H}, \mathrm{OCH}_{2}-\mathrm{CH}_{2}-$ chains), 2.17 (br, 4H, $\mathrm{NCH}_{2} \mathrm{CH}_{2}{ }_{\mathrm{n}} \mathrm{H}$ ) FT-IR (Neat): v = 3369 (br), 2982 (w), 2936 (m), 2875 (br), 1685 (br), 1631 (br), 1500 (br), 1460 (w), 1426 (s), 1361 (br), 1358 (br), 1279 (m), 1249 (w), 1203 (vs), 1181 (w), 1103 (br), 1047 (br).

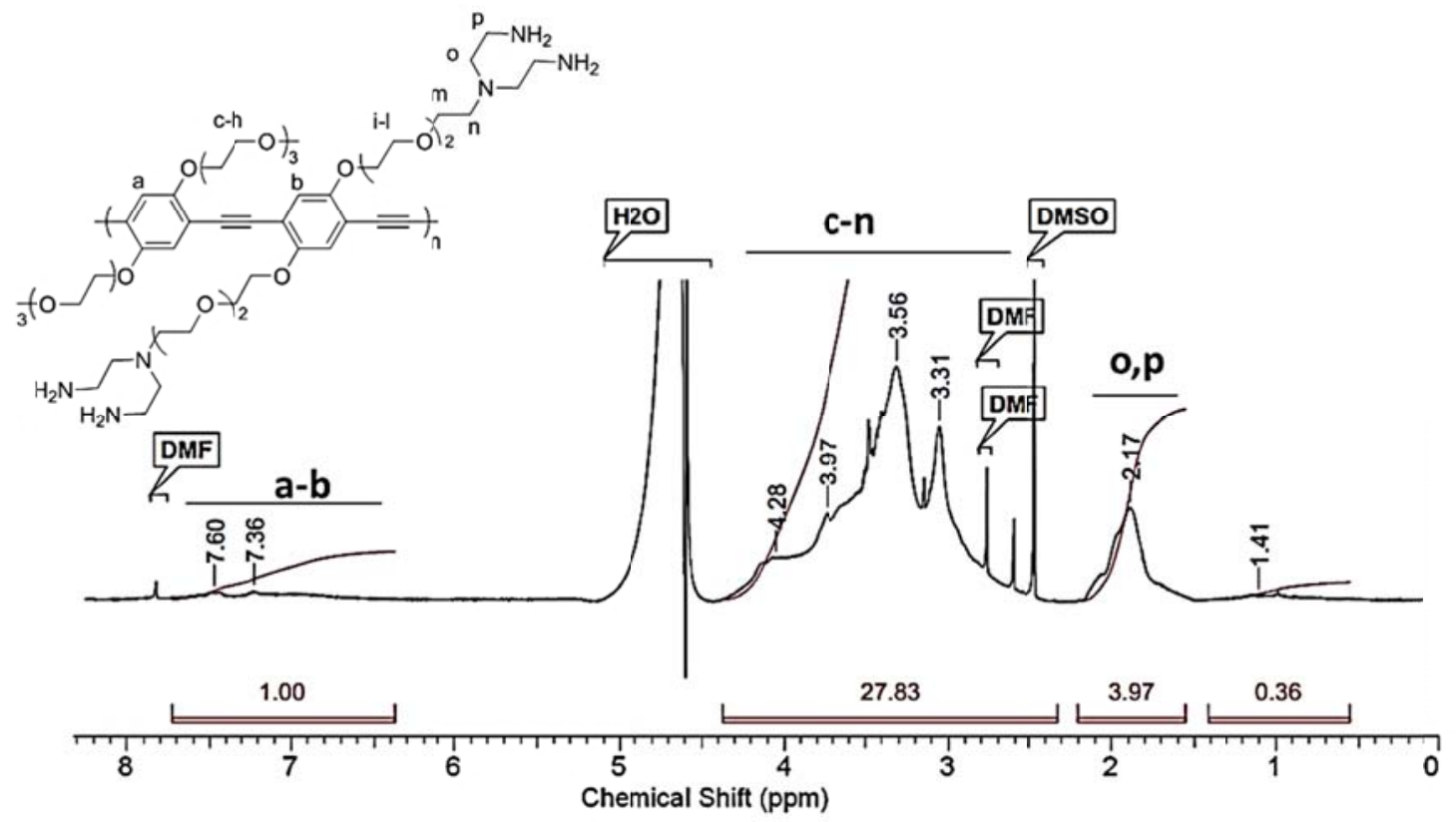

Figure 2.14. ${ }^{1} \mathrm{H}-\mathrm{NMR}$ for polymer $\mathbf{C P N}-3$ in $\mathrm{D}_{2} \mathrm{O}$ 


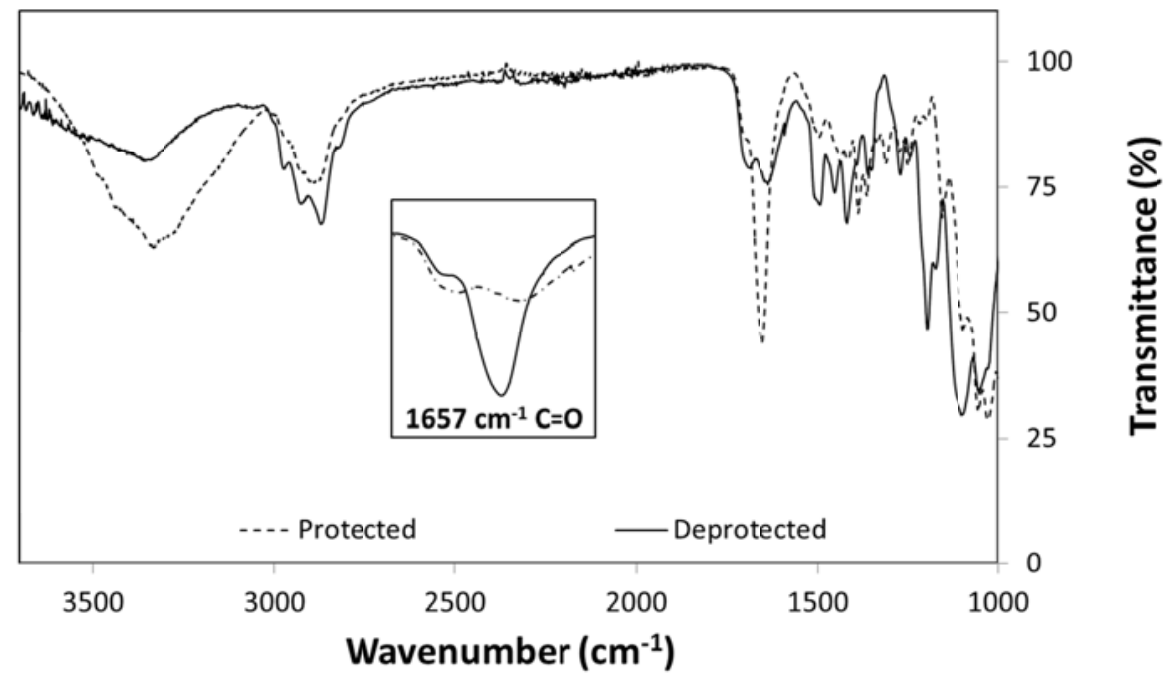

Figure 2.15. FT-IR for polymer P3 (Neat)

Results

$\begin{array}{llll} & \text { Mean }(\mathrm{mV}) & \text { Area }(\%) & \text { Width }(\mathrm{mV}) \\ \text { Peak 1: } & 45.0 & 100.0 & 14.3 \\ \text { Peak 2: } & 0.00 & 0.0 & 0.00 \\ \text { Peak 3: } & 0.00 & 0.0 & 0.00\end{array}$

Conductivity $(\mathrm{mS} / \mathrm{cm}): 0.263$

Result quality : Good

Zeta Potential Distribution
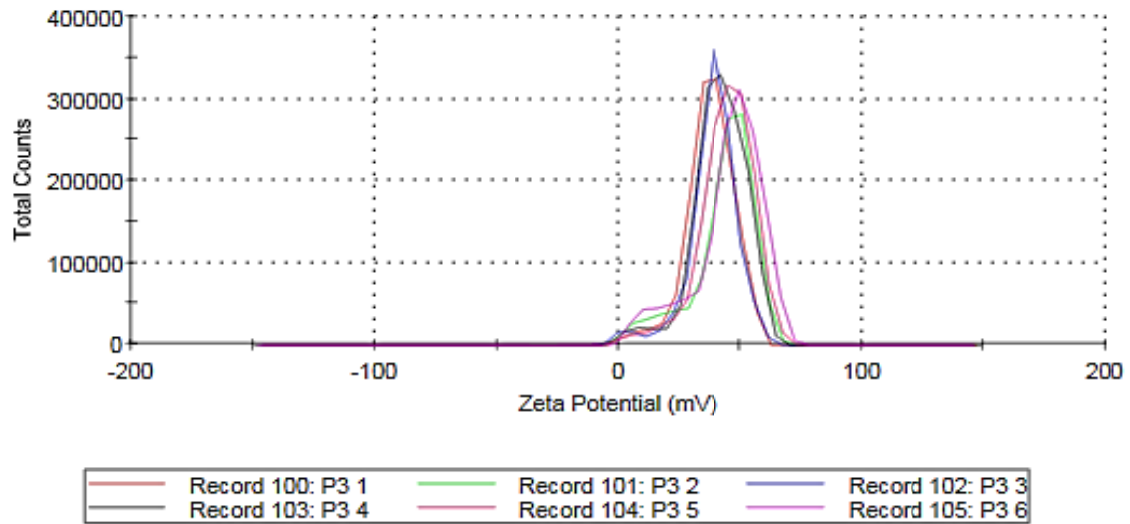

Figure 2.16. DLS for polymer CPN-3 


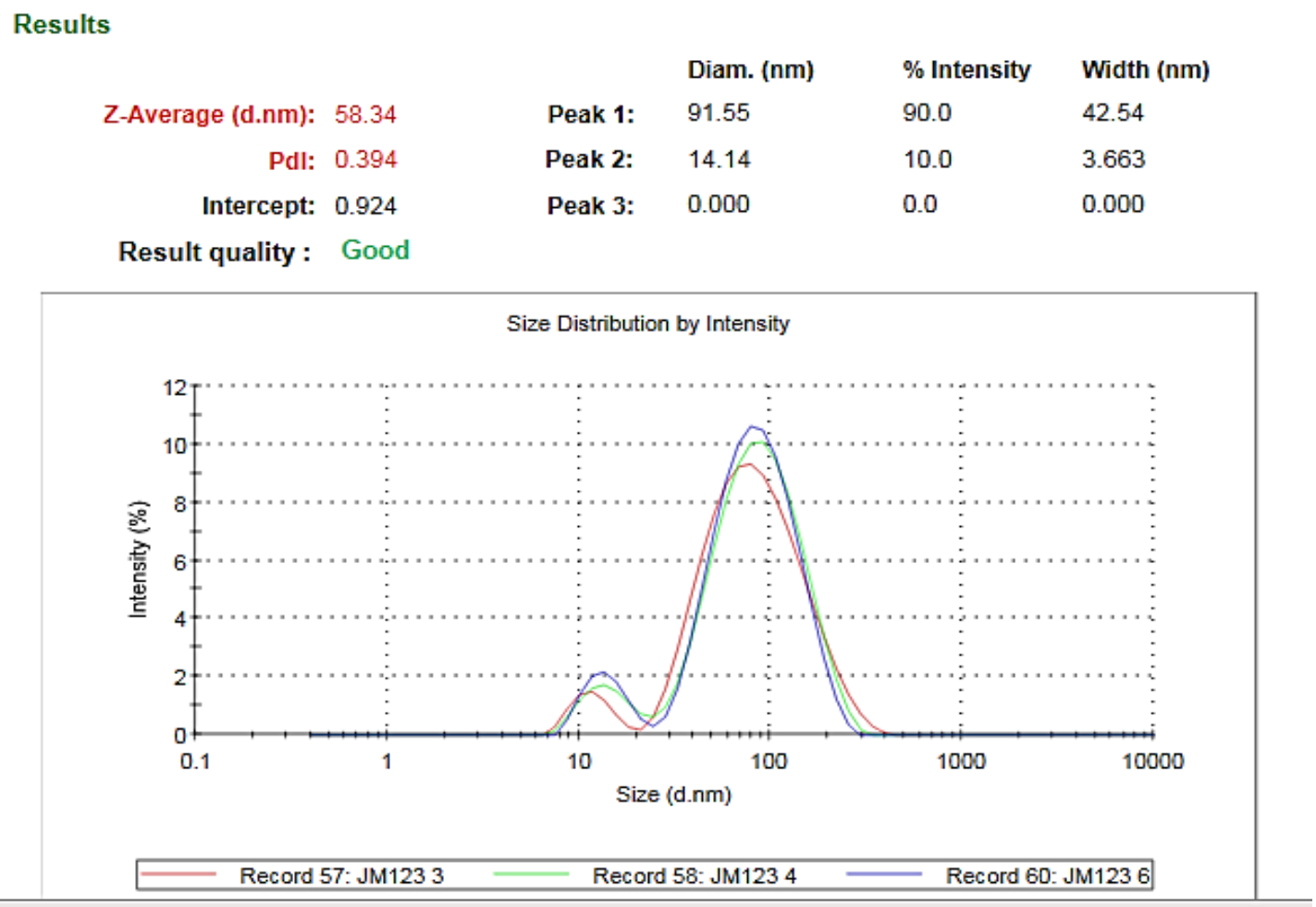

Figure 2.17. ZP for polymer CPN-3

Polymer P4. Polymer synthesis, deprotection, CPN fabrication, and characterization is described elsewhere. ${ }^{26}$ 
Results

$\begin{array}{rlllll} & & \text { Diam. }(\mathrm{nm}) & \% \text { Intensity } & \text { Width }(\mathrm{nm}) \\ \text { Z-Average (d.nm): } & 84.61 & \text { Peak 1: } & 167.7 & 85.7 & 96.47 \\ \text { Pdl: } & 0.538 & \text { Peak 2: } & 22.74 & 14.3 & 7.349 \\ \text { Intercept: } & 0.721 & \text { Peak 3: } & 0.000 & 0.0 & 0.000\end{array}$

Result quality : Good

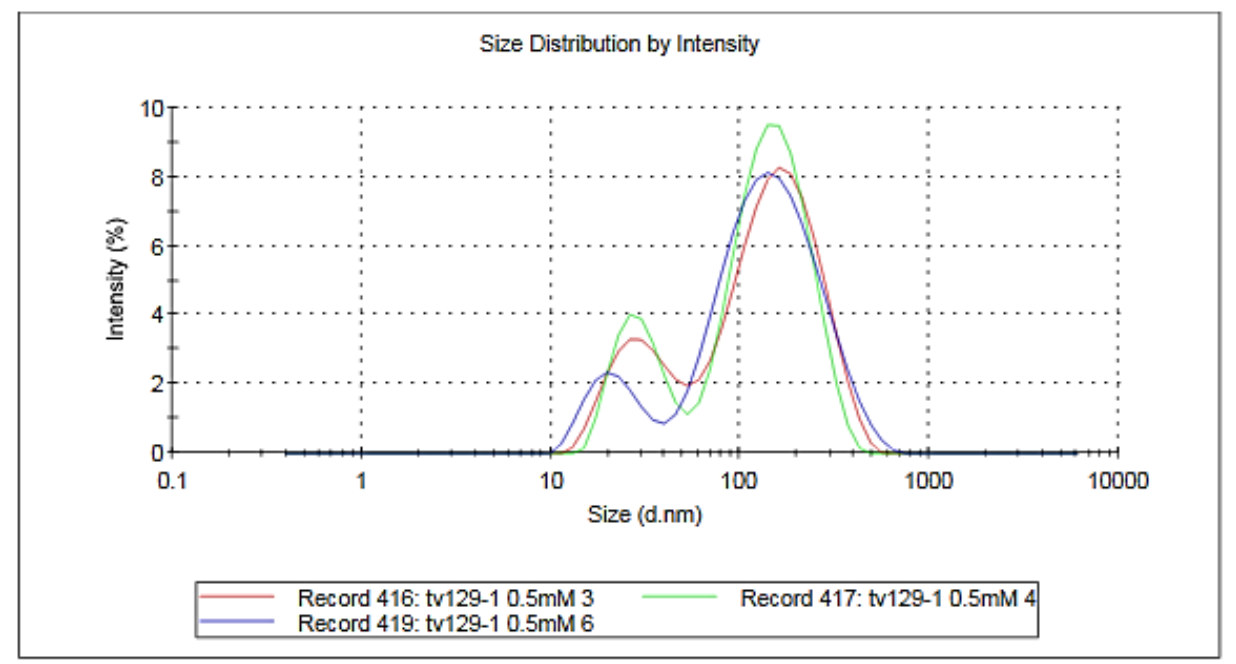

Figure 2.18. DLS for polymer CPN-4

Results

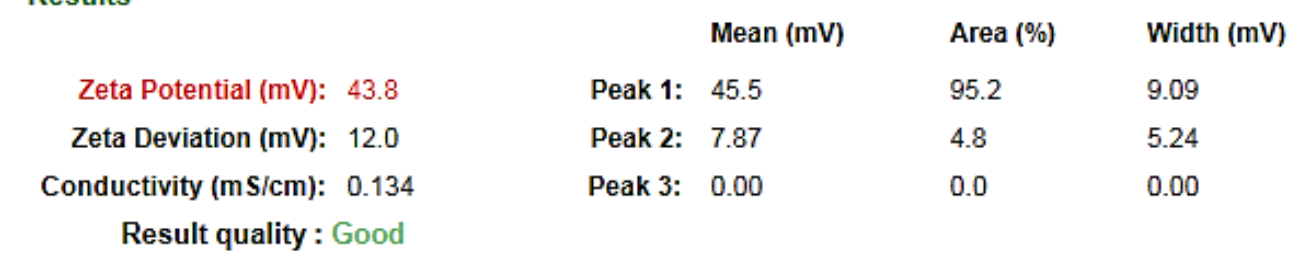

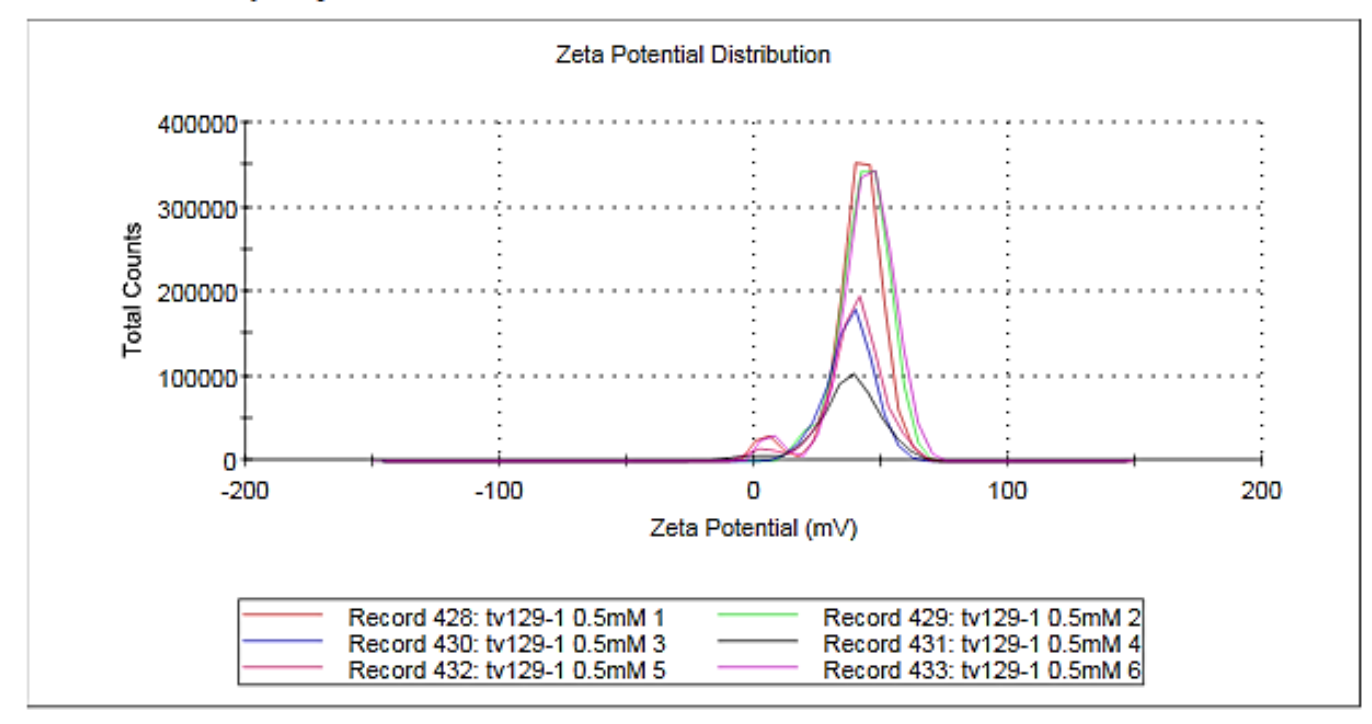

Figure 2.19. ZP for polymer $\mathrm{CPN}-4$ 


\subsubsection{Polymer Deprotection}

Confirmed using ${ }^{1} \mathrm{H}-\mathrm{NMR}$ data by looking at characteristic Boc proton peak (1.36ppm) and $\sim 1700 \mathrm{~cm}^{-1}$ infrared band for the carbonate $(\mathrm{C}=\mathrm{O})$ group. IR samples were prepared by lyophilization to prepare neat sample. IR scans from 4000 to $700 \mathrm{~cm}^{-1}$ are presented below, depicting absence of boc-carbonate group and confirming deprotection.

\subsubsection{Gel Permeation Chromatography}

Samples dissolved in THF were filtered through a Teflon (PTFE) syringe filter $(0.25 \mu \mathrm{m})$ three times. The average molecular weight $(\mathrm{Mn})$ and polydispersity index $\left(\mathrm{PDI}=\mathrm{M}_{\mathrm{w}} / \mathrm{M}_{\mathrm{n}}\right)$ of the polymers were determined by gel permeation chromatography (GPC) against polystyrene standards using a Shimadzu high performance liquid chromatography (HPLC) system fitted with PLgel $5 \mu \mathrm{m}$ MIXED-D columns and SPD-20A ultravioletvisible (UV-Vis) detector.

\subsubsection{Dyniamic Light Scattering (DLS)}

Hydrodynamic radii and Zera potentials (ZP) were determined by dynamic light scattering technique using a Zetasizer nano-ZS (Zen 3600, Malvern Instruments Ltd.). Three polymer aliquots of $500 \mu \mathrm{M}$ CPN were independently prepared by filtering through a Teflon (PTFE) syringe filter $(0.45 \mu \mathrm{m})$. DLS samples loaded in a low volume $(1.5 \mathrm{~mL})$ disposable cuvette, and Zeta potential samples into disposable capillary cell. Averages and standard deviations reported in the main text. Figures S7-14, show representative reports for polymer $\mathbf{C P N}-\mathbf{1}, \mathbf{- 2}, \mathbf{- 3}$ and $\mathbf{- 4}$. 


\subsubsection{Cell Culture}

\subsubsection{General}

HeLa cells (human cervical cancer, purchased from ATCC), seeded into a 100 x $20 \mathrm{~mm}$ style sterile tissue culture dish (\#353003 BD Falcon, Durham, NC, USA), cultured in minimum essential medium (MEM)/Earle's balanced salt solution (EBSS) (400 $\mu \mathrm{L}$, HyClone, SH30024) medium containing 10\% fetal bovine serum (FBS) and $100 \mathrm{U} / \mathrm{m}$ penicillin for $24 \mathrm{~h}$ under $5 \% \mathrm{CO}_{2}$ at $37{ }^{\circ} \mathrm{C}$, and subcultured every 48 hours. pHRhodo Dextran 10kDa (\#P10361 Molecular probes, Life technologies, New York, USA) and BODIPY-TR C5 -ceramide-BSA complex (\#B34400 Molecular probes, Life technologies, New York, USA) were used for endosome and Golgi apparatus staining, respectively.

\subsubsection{Microscopic Imaging}

10,000 HeLa cells were seeded into a glass-bottomed eight-well chamber slide (Lab-Tek Thermo Scientific) and cultured in a minimum essential medium (MEM)/Earle's balanced salt solution (EBSS) $(400 \mu \mathrm{L})$ medium containing $10 \%$ fetal bovine serum (FBS) and $100 \mathrm{U} / \mathrm{m}$ penicillin for $24 \mathrm{~h}$ under $5 \% \mathrm{CO}_{2}$ at $37^{\circ} \mathrm{C} .80 \mu \mathrm{L}$ of $20 \mu \mathrm{M}$ CPNs in water was added to the culture medium directly, and the cells were further cultured overnight (final CPN concentration: $4 \mu \mathrm{M}$ ). For endosome staining, pHRhodo Dextran $10 \mathrm{kDa}(5 \mu \mathrm{M})$ was incubated for $30 \mathrm{~min}$ at $37^{\circ} \mathrm{C}$. For Golgi apparatus staining, BODIPYTR C5 -ceramide-BSA complex (final $10 \mu \mathrm{M}$ ) was incubated for $30 \mathrm{~min}$ at $4{ }^{\circ} \mathrm{C}$. After washing with fresh medium, the cells were further incubated for $30 \mathrm{~min}$ at $37^{\circ} \mathrm{C}$. A $1 \mu \mathrm{L}$ 
aliquot of Hoechst $(5 \mu \mathrm{g} / \mathrm{mL})$ was added to the culture medium and incubated with the cells for $10 \mathrm{~min}$ at $37^{\circ} \mathrm{C}$, and washed two times with phosphate buffered saline (PBS). The cells were fixed with $4 \%$ paraformaldehyde for $10 \mathrm{~min}$. Fluorescent images of the cells were obtained using a DeltaVision Elite Microscope System (Applied Precision, Issaquah, Washington, USA) equipped with bandpass filters such as blue $(410-460 \mathrm{~nm}$, Hoechst), green (500-550 nm, CPNs), and red (595-635 nm, Golgi and endosome). Top and bottom of the chosen cells was identified, and a Z-stack plot was imaged for each channel.

\subsubsection{Colocalization study}

Z-stack microscope images of each sample was obtained as described above. Colocalization analysis was conducted for three independent cells per polymer and per organelle (Golgi apparatus and endosome). Colocalization analysis was conducted using the microscope software (Softworx 5.0 application, Applied Precision, Issaquah, Washington, USA). Region of interest (ROI) was selected to contain all of the cell. Pearsons Correlation Coefficient (PCC) was used to determine colocalization. Negative control of colocalization was performed by analysis of blue and green channels staining the nucleus and CPN, respectively. Three independent images of an entire cell were selected and analysed to increase the analysis objectivity. A representative example is shown in figure 2.20. 


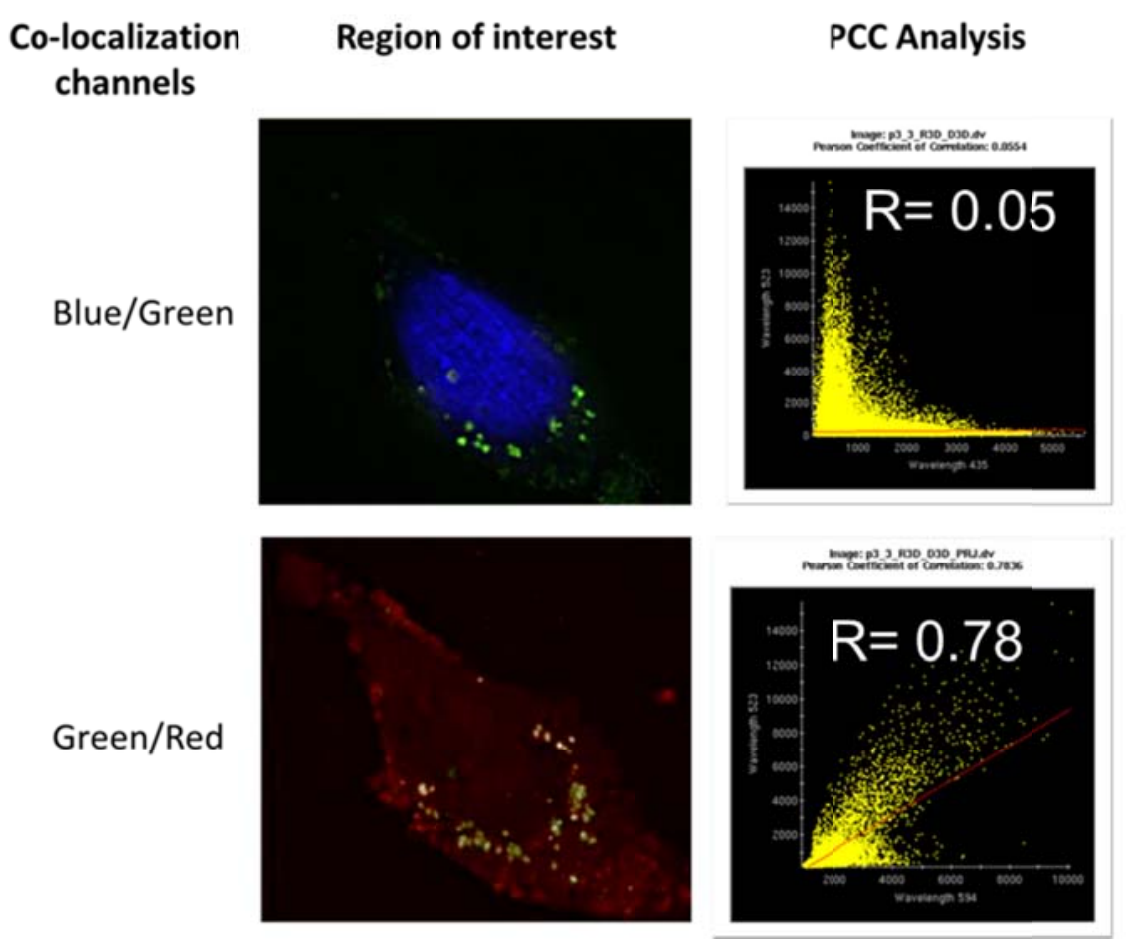

Figure 2.20. Example of microscopic images and PCC analysis. HeLa cells incubated with $\mathbf{C P N - 3}$ and PCC co-localization analysis of the region of interest. Control and experimental co-localization using blue/green and green/red channels, respectively.

Experimental colocalization PCC values were obtained using the green and red channels staining the CPN and the target organelle (Golgi or endosome). Representative images shown in figures S-16 and S-17. Quantification and statitical analysis was performed by averaging PCC values between the independent cells per polymer and per organelle. Oneway ANOVA followed by Tukey means separation method was conducted for PCC colocalization values between samples of same organelle using Origin 8 software.

2.6.4.4. Toxicity Assay HeLa cells ( 10000 cells/well) in $200 \mu \mathrm{L}$ of complete medium were seeded into a 96-well plate and cultured for one day in a 5\% CO2 incubator at 37 
${ }^{\circ} \mathrm{C}$. CPNs with various concentrations (5 to $\left.40 \mu \mathrm{M}\right)$ were added and incubated overnight.

To measure toxicity, $10 \mu \mathrm{L}$ of WST-1 [2-(4-iodophenyl)-3-(4-nitrophenyl)-5-(2,4disulfophenyl)-2H-tetrazolium] (Cayman Chemical, Ann Arbor, MI, USA) solution was added into each well, and the plate was further incubated for $4 \mathrm{~h}$ at $37^{\circ} \mathrm{C}$. Cell viability was compared by measuring absorbance values at $450 \mathrm{~nm}$ using a microplate well reader (Synergy 2, BioTek, Winooski, VT, USA). Relative cell viability as a function of CPN concentration was obtained by subtracting absorbance values of each sample well with control CPN absorbance at $450 \mathrm{~nm}$.

\subsection{References}

1 I. B. Kim, H. Shin, A. J. Garcia, U. H. F. Bunz, Bioconjugate Chem. 2007, 18, 815; X. L. Feng, Y. L. Tang, X. R. Duan, L. B. Liu, S. J. Wang, Mater. Chem. 2010, 20, 1312; K. Lee, J. Lee, E. J. Jeong, A. Kronk, K. S. J. Elenitoba-Johnson, M. S. Lim, J. Kim, Adv. Mater. 2012, 24, 2479; C. F. Wu, D. T. Chiu, Angew. Chem. Int. Ed. 2013, 52, 3086.

2 M. D. Disney, J. Zheng, T. M. Swager, P. H. Seeberger, J. Am. Chem. Soc. 2004, 126, 13343; C. H. Fan, S. Wang, J. W. Hong, G. C. Bazan, K. W. Plaxco, A. J. Heeger, Proc. Natl. Acad. Sci. USA 2003; 100, 6297, H. A. Ho, K. Dore, M. Boissinot, M. G. Bergeron, R. M. Tanguay, D. Boudreau, M. J. Leclerc, Am. Chem. Soc. 2005, 127, 12673; K. E. Achyuthan, T. S. Bergstedt, L. Chen, R. M. Jones, S. Kumaraswamy, S. A. Kushon, K. D. Ley, L. Lu, D. McBranch, H. Mukundan, F. Rininsland, X. Shi, W. Xia, D. G. J. Whitten, Mater. Chem. 2005, 15, 2648; C. J. Sun, B. S. Gaylord, J. W. Hong, B. Liu, G. C. Bazan, Nat. Protoc. 2007, 2, 2148; B. Liu, G. C. Bazan, Chem. Mater. 2004, 16, 4467.

3 Y. Wang, S. D. Jett, J. Crum, K. S. Schanze, E. Y. Chi, D. G. Whitten, Langmuir 2013, 29, 781; C. L. Zhu, Q. Yang, F. T. Lv, L. B. Liu, S. Wang, Adv. Mater. 2013, 25, 1203; C. F. Xing, L. B. Liu, H. W. Tang, X. L. Feng, Q. Yang, S. Wang, G. C. Bazan, Adv. Funct. Mater. 2011, 21, 4058.

4 J. H. Moon, E. Mendez, Y. Kim, A. Kaur, Chem. Commun. 2011, 47, 8370; A. T. Silva, N. Alien, C. M. Ye, J. Verchot, J. H. Moon, BMC Plant Biol. 2010, 10, 291; X. L. Feng, F. T. Lv, L. B. Liu, Q. Yang, S. Wang, G. C. Bazan, Adv. Mater. 2012, 24, 5428. 
5 S. W. Thomas, G. D. Joly, T. M. Swager, Chem. Rev. 2007, 107, 1339; C. L. Zhu, L. B. Liu, Q. Yang, F. T. Lv, S. Wang, Chem. Rev. 2012, 112, 4687.

6 J. H. Moon, W. McDaniel, P. MacLean, L. E. Hancock Angew. Chem. Int. Ed. 2007, 46, 8223; C. F. Wu, C. Szymanski, J. McNeill, Langmuir 2006, 22, 2956; M. C. Baier, J. Huber, S. J. Mecking, Am. Chem. Soc. 2009, 131, 14267.

7 R. Duncan, S. C. W. Richardson, Mol. Pharm. 2012, 9, 2380, G. Sahay, D. Y. Alakhova, A.V. J. Kabanov, Controlled Release 2010, 145, 182.

8 J. Rejman, A. Bragonzi, M. Conese, Mol. Ther. 2005, 12, 468.

9 L. Pelkmans, A. Helenius, Traffic 2002, 3, 311.

10 I. A. Khalil, K. Kogure, S. Futaki, H. Harashima, J. Biol. Chem. 2006, 281, 3544.

11 J. Lee, M. Twomey, C. Machado, G. Gomez, M. Doshi, A. J. Gesquiere, J. H. Moon, Macromol. Biosci., In print (DOI 10.1002/mabi.201300030)

12 A. E. Nel, L. Madler, D. Velegol, T. Xia, E. M. V. Hoek, P. Somasundaran, F.

Klaessig, V. Castranova, M. Thompson, Nature Mater. 2009, 8, 543; L. P. Fernando, P. K. Kandel, J. Yu, J. McNeill, P. C. Ackroyd, K. A. Christensen, Biomacromolecules 2010, 11, 2675.

13 S. J. Tan, N. R. Jana, S. J. Gao, P. K. Patra, J. Y. Ying, Chem. Mater. 2010, 22, 2239.

14 Y. J. Ko, E. Mendez, J. H. Moon, Macromolecules 2011, 44, 5527.

15 Pancake-like shapes of CPNs on a mica surface were observed from atomic force microscopy imaging. See Macromol. Biosci. 2013

16 T. Vokatá, J. H. Moon, Macromolecules 2013, 46, 1253.

17 C. -C. Lee, Y. Liu, T. M. Reineke, Bioconjugate Chem. 2008, 19, 428.

18 K. W. Dunn, M. M. Kamocka, J. H. McDonald, Am. J. Physiol.-Cell Ph. 2011, 300, C723.

19 M. Twomey, T. Vokatá, M.R. Kumar, J.H. Moon, Chem. Commun., 2015,51, 4065-4068

20 B.-L. Deng, R. L. Beingessner, R. S. Johnson, N. K. Girdhar, C. Danumah, T. Yamazaki and H. Fenniri, Macromolecules, 45, 7157-7162. 
21 J. Motoyanagi, T. Fukushima, A. Kosaka, N. Ishii and T. Aida, J. Polym. Sci., Part A: Polym. Chem., 2006, 44, 5120-5127.

22 X.-X. Zhang, C. A. H. Prata, T. J. McIntosh, P. Barthel̀ leÌ my and M. W. Grinstaff, Bioconjugate Chem., 21, 988-993.

23 J. A. Cruz-Morales and P. Guadarrama, J. Mol. Struct., 2005, 779, 1-10.

24 J. H. Moon, W. McDaniel, P. MacLean and L. F. Hancock, Angew. Chem. Int. Ed., 2007, 46, 8223-8225.

25 J. K. Lee, Y. H. Jung, J. B. H. Tok and Z. Bao, ACS Nano, 5, 2067-2074.

26 T. Vokatá and J. H. Moon, Macromolecules, 2013, 46, 1253-1259. 
CHAPTER III

COMPLEXATION-DEPENDENT SUBCELLULAR LOCALIZATION

AND UPTAKE 


\subsection{Abstract}

The cellular uptake and subcellular localizations of conjugated polymer nanoparticles (CPNs) is significantly affected upon complexation with polysaccharides. Incorporation of short ethylene oxide onto amine-containing CPNs afford polyplexes with reduced late endosome/lysosome localization and enhanced cellular uptake. CPNs with only amine side-chains, regardless of backbone structure, did not exhibit enhanced cellular uptake.

\subsection{Introduction}

Semiconducting conjugated polymer nanoparticles (CPNs) have attracted much attention for cellular labelling, ${ }^{1}$ sensing,,${ }^{2}$ and delivery of therapeutics. ${ }^{4}$ Upon treating non-aqueous soluble conjugated polymers (CPs) under various particle formation conditions, they can form non-toxic soft nanoparticles for cellular labelling and nucleic acid delivery. ${ }^{5}$ Previously, we fabricated various cationic CPNs by treating a non-aqueous soluble, primary amine-containing poly(p-phenyleneethynylene) (PPE) and flexible-linker containing poly(p-phenylenebutadiynylene) (PE-d-PPB) with organic acids followed by dialysis. ${ }^{6}$ The CPN's subcellular localizations and toxicity were dependent on the chemical structure of the side chain and backbone structures. Amine-containing PPEs and PE-d-PPBs exhibited high Golgi localization with no toxicity. Upon incorporation of short ethylene oxide chains Golgi localization significantly decreased. Recently, we demonstrated that upon complexation with hyaluronic acid (HA), CPNs form fluorescent core-shell nanoparticles exhibiting photophysical, size, and morphological changes. ${ }^{7}$ These changes were enhanced when the CPN contained a semi-flexible linker. The resulting polymer-polysaccharide complex (polyplex) exhibited improved cancer cell 
specificity towards human cervical carcinoma (HeLa) cells. Several nanocarrier platforms have reported similar formulations with naturally-derived polymers. ${ }^{8}$ Upon preparation, these formulations these formulations have afforded nanocarriers with increased stability, improved pharmacokinetics, improved cancer-specificity and lower toxicity.

While active targeting by CPNs remains highly desirable, it becomes clear that to improve the drug efficacy the nanocarrier should not only facilitate successful delivery into specific cell types or tissues, but direct the drug to its appropriate intracellular destination. Because most drugs require delivery specific organelles, the increased cancer-cell specificity and decreased carrier toxicity will not improve delivery efficiency if the drugs are not delivered to the proper organelle. Therefore, understanding how subcellular localization and uptake are affected upon polysaccharide complexation is paramount to improving overall labelling and delivery efficiency.

Work towards understanding how CMC or HA complexation affects nanoparticle uptake efficiency and subcellular fate has been limited. Hyaluronic acid has been reported to display molecular-weight dependent endocytosis pathways. ${ }^{9} \quad$ Receptor-mediated endocytosis and macropinocytosis of bulk phase HA have been reported for low $\left(10^{4}\right.$ $\mathrm{kDa})$ and high molecular $\left(10^{6} \mathrm{kDa}\right)$ weight $\mathrm{HA}$, respectively. Although mechanistic studies of CMC uptake mechanisms remain limited, various compounds incorporating $\mathrm{CMC}$ or using $\mathrm{CMC}$ hydrogels report late endosome, and lysosomal co-localization and improved HeLa cell uptake. ${ }^{10}$ Previously, we reported that core-CP shell-HA nanoparticles can be obtained when semi-flexible CPs were treated with polyanionic HA, while non-flexible CPs produce random complexes upon HA treatment. ${ }^{11}$ Therefore, we 
hypothesize that upon complexation of $\mathrm{CMC}$ or HA with semi-flexible linker-containing CPNs, the resulting polyplex will exhibit significant polysaccharide-like cellular uptake, such as enhanced cellular uptake and significant late endosome/lysosome localization, in addition to the already reported cancer cell-specificity. We did not expect the cellular uptake enhancement or increased late endosome/lysosome localization to be as significant in non-flexible CPs due to the random nature of the complex.

To test the hypothesis, we fabricated three CPNs from polymers exhibiting different side chain (CPN-1 and CPN-2) and backbone structures (CPN-3) (Figure 1). Synthesis and characterization of $\mathbf{C P N}-1$ and $\mathbf{C P N}-2$ were reported in Chapter 2. Because of the particle formation mechanism (i.e., molecular weight independent phase inverse precipitation driven by aqueous insolubility of $\mathrm{CPs}),{ }^{12}$ the shapes and hydrodynamic radii of CPNs are relatively constant. ${ }^{13} \mathbf{C P N}-\mathbf{2}$ was utilized to test the ethylene oxide (EO)-

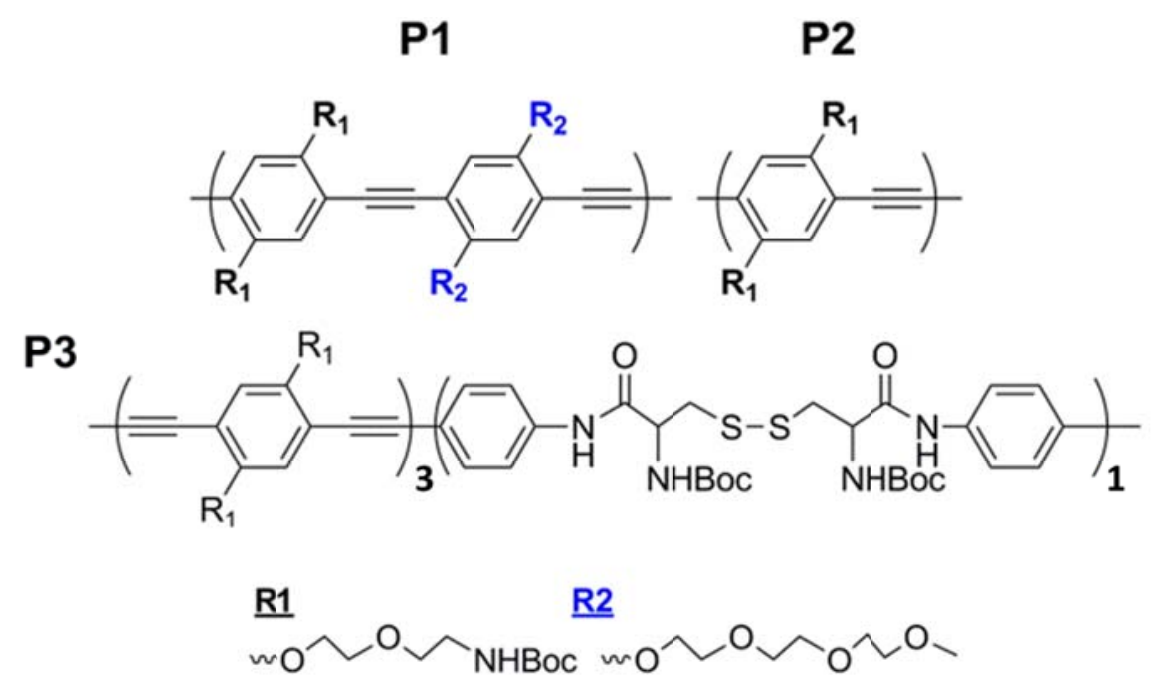

Figure 3.1. Chemical structures of amine-containing CPs. Poly(p-phenyleneethynylenes) (PPEs) with different side chains (CPN-1, CPN-2) and poly(p-phenylenebutadiynylene) (PPB) containing a small amount of flexible unit in the backbone (CPN-3) were synthesized and cellular behavior was compared. 
side chain effects from non-EO containing $\mathbf{C P N}-1$ and the resulting complexation and cell uptake behavior. CPN-3 was designed to test the effect the biodegradable-linker has on the complexation and uptake behavior compared to CPN-2.

Subcellular localization of CPNs was monitored by fluorescent microscopic imaging. Overnight treatment of HeLa cells with CPNs (green) were co-stained with pHRhodo Dextran (10kDa) (red) for labelling acidic organelles (i.e., endosomes and lysosomes) after overnight CPN/polyplex treatment. The Pearson's Correlation Coefficient (PCC) was used to examine co-localization evaluation, with scores of 0 and 1 correspond to uncorrelated and perfectly linearly correlated colors, respectively. Mean PCC scores from three independent images of an entire cell were selected and analyzed to examine analysis variance. Changes in cellular uptake were measured using flow cytometry for polymers by themselves and after complexation with CMC or HA.

\subsection{Results and Discussion}

\section{Subcellular Localization}

To test how the CPN's subcellular localization is influenced upon CMC or HA complexation, the CPN polyplexes were incubated with human cervical carcinoma cells (HeLa) overnight. As shown in Figure 3.2, CPN-2 exhibited no significant change to late endosome/lysosome localization upon complexation with HA or CMC. CPN-1 polyplexes exhibited significant decreases in late endosome/lysosome localization, suggesting a decrease in adsorptive endocytosis. If CPN-1's high endosomal/lysosomal co-localization is the result of the polymer's non-specific interaction with generic 
complementary binding sites, like negatively charged heparin sulfate proteoglycans and hydrophobic membrane lipids in the cell membrane, then polyplex formation should reduce this non-specific interaction; this decrease, should in turn, affect the late endosome/lysosome colocalization. However, this should also result in an increase to late/endosome/lysosome colocalization, as $\mathrm{CMC} / \mathrm{HA}$ complexation should improve macropinocytotic uptake. Materials that are internalized via macropinosomes have been reported to often diffusion out of the vesicle and into the cytosol. ${ }^{14,15}$ Macropinosomal escape could be occurring for both CPN-1 and CPN-2 polyplexes, however, the increased amine-density afforded by CPN-2 might make diffusion out of the macropinocytotic vesicle difficult.

Finally, CPN-3 polyplexes exhibited significant increases to late endosome/lysosome localization. It was expected that $\mathbf{C P N - 3}$ would exhibit the most significant change to

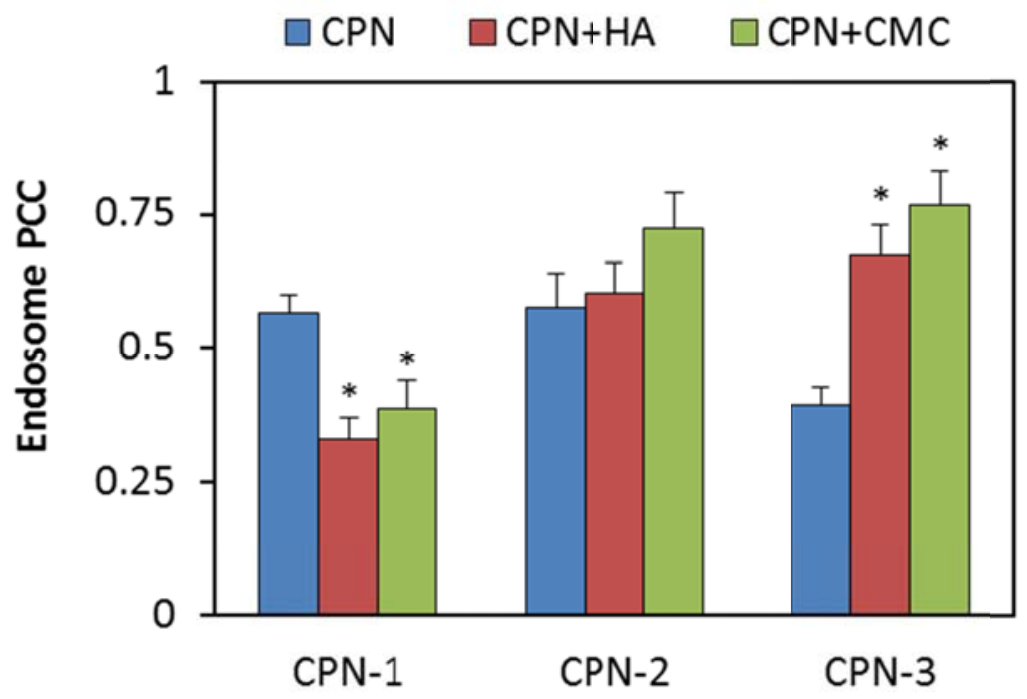

Figure 3.2. Quantitative analysis of co-localization using the PCC algorithm. Co-localization with late endosome/lysosome significantly decreased and increased for CPN-1 and CPN-3, respectively. The error bar represents \pm standard deviation $(\mathrm{n}=3) .{ }^{*} \mathrm{p}<0.005$ when $\mathrm{CPN}$ is compared to polyplex (CPN+HA or $\mathrm{CPN}+\mathrm{CMC})$. 
late endosome/lysosome colocalization because of core-CP shell-CMC/HA morphology that is facilitated by the semi-flexible nature of the material. Indeed, this was indeed observed for both CMC and HA polyplexes.

\section{CPN Polyplex cellular uptake}

To measure the CPN-polysaccharide polyplex accumulation was measured using flow cytometry. Briefly, cellular uptake was measured after 2 hours and overnight (18 hours) treatment. To measure the polyplex retention/clearance, cellular uptake was measured by treating cells with the CPN for 2 hours, exchanging media, and allowing HeLa cells to incubate overnight (16 hours). Any remaining CPN signal within the cell can be measured to compare relative retention between CPNs. Cellular uptake comparison between these polyplexes was made possible by normalizing the mean fluorescence measurements obtained from the flow cytometer.

The cellular uptake by the non-flexible CPNs, and the resulting polyplex upon HA and CMC complexation are summarized in figure 3.3. The resulting polyplex of $\mathrm{CMC} / \mathrm{HA}$ with $\mathbf{C P N}-1$ resulted in a 2-fold enhancement into HeLa cells for all treatment times tested. There was no significant difference between the uptake facilitated upon CMC or HA complexation. The significant increase in uptake is interesting, when coupled with the fact that late endosome/lysosome localization significantly decreased for the CPN-1 polyplexes. The combined results provide further evidence supporting the subcellular localization changes exhibited by CPN-1 resulting from decreased non-specific interaction with generic complementary binding sites, like negatively charged heparin 

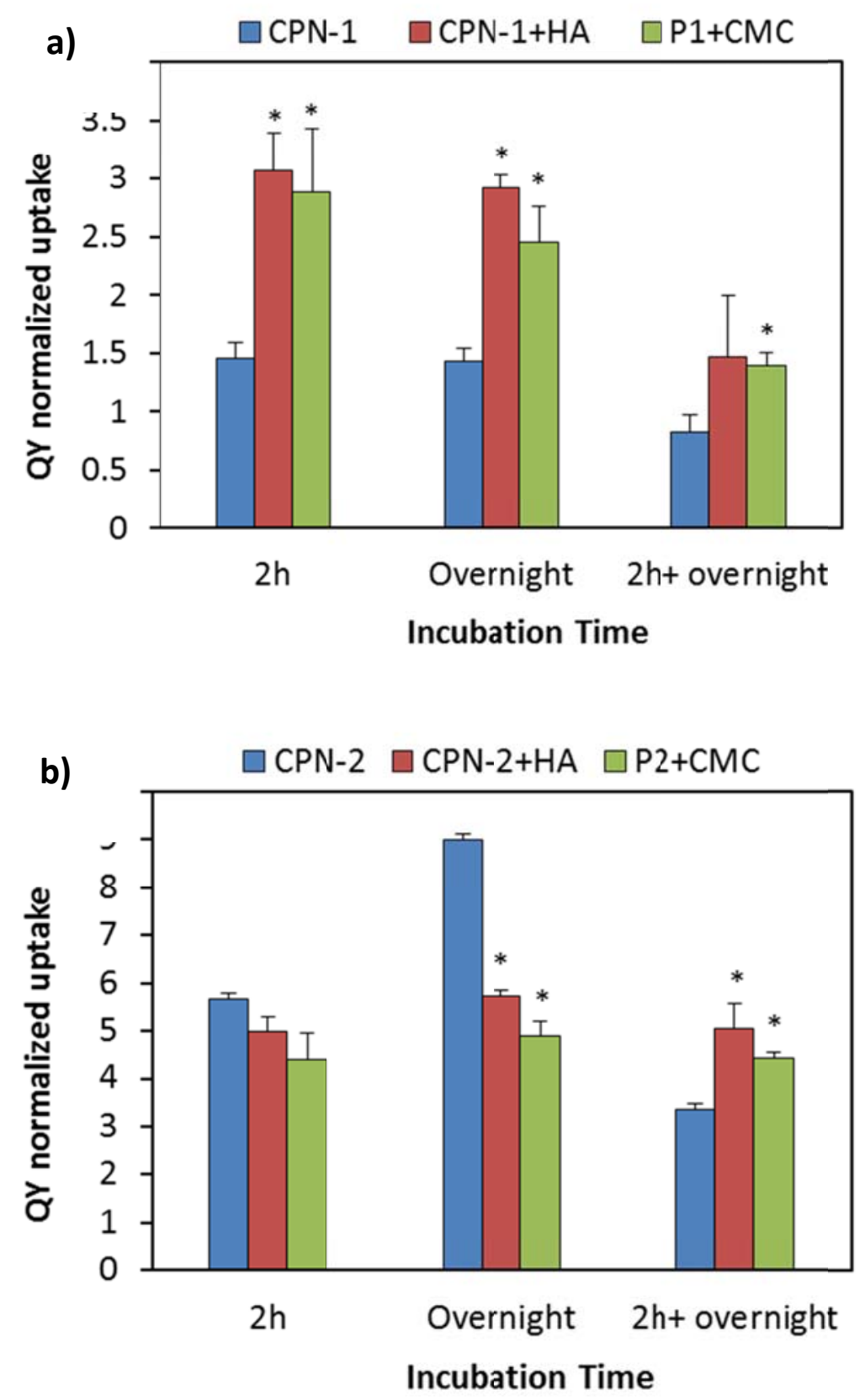

Figure 3.3. Cellular uptake of (a) $\mathrm{CPN}-1$ and (b) $\mathrm{CPN}-2$ upon $\mathrm{HA}$ and $\mathrm{CMC}$ complexation. Measured using flow cytometry where fluorescence signal was normalized using the CPN's quantum yield resulting relative uptake. The error bar represents \pm standard deviation $(n=3){ }^{*} \mathrm{p}<0.005$ when CPN is compared to polyplex $(\mathrm{CPN}+\mathrm{HA}$ or $\mathrm{CPN}+\mathrm{CMC})$. 
sulfate proteoglycans and hydrophobic membrane lipids in the cell membrane, resulting from $\mathrm{CMC}$ and HA complexation.

The resulting polyplex between CMC and HA complexation with $\mathbf{C P N}-2$ did not exhibit any of the uptake enhancement seen with CPN-1. In fact, the resulting $\mathbf{C P N}-2$ polyplexes exhibited significant decreases in HeLa cell uptake using all three treatment conditions. There was no significant difference in uptake between $\mathbf{C P N}-2-\mathbf{H A}$ and $\mathbf{C P N}-$ 2-CMC polyplex.

Finally, the cellular uptake by the semi-flexible linker containing CPN-3, and the resulting polyplex upon $\mathrm{HA}$ and $\mathrm{CMC}$ complexation are summarized in figure 3.4. Similar to the effect exhibited by CPN-2, upon CMC and HA complexation, CPN-3 did not exhibit any of the uptake enhancement seen with CPN-1. The polyplexes exhibited small but significant decreases in HeLa cell uptake using all three treatment conditions.

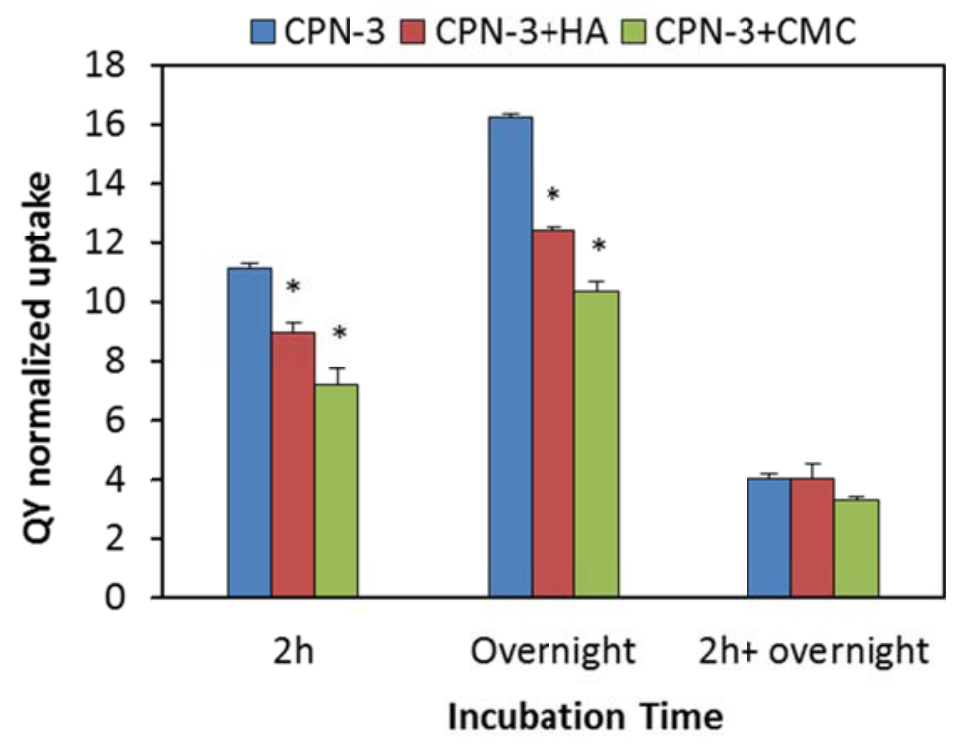

Figure 3.4. Cellular uptake of semi-flexible CPN-3 upon HA and CMC complexation. Measured using flow cytometry where fluorescence signal was normalized using the CPN's quantum yield resulting relative uptake. The error bar represents \pm standard deviation $(n=3) .{ }^{*} \mathrm{p}<0.005$ when $\mathrm{CPN}$ is compared to polyplex $(\mathrm{CPN}+\mathrm{HA}$ or $\mathrm{CPN}+\mathrm{CMC})$. 


\subsection{Conclusion}

The significant decrease in uptake upon complexation with HA and CMC, coupled with the subcellular changes that resulted in increased late endosome/lysosome localization after overnight treatment, do not support our initial hypothesizes that $\mathbf{C P N}-\mathbf{3}$ would exhibit the most significant cellular uptake enhancement. We expected improved uptake due to the formation of core- $\mathrm{CP}$ shell-CMC/HA morphology that is facilitated by the semi-flexible nature of the material. If the uptake is significantly influenced by the complexing polysaccharide, then we expect the polyplex to exhibit improved internalization via macropinocytosis. This phenomenon could be occurring for both CPN-2 and CPN-3 polyplexes, however, the increased amine-density in both CPNs might make diffusion out of the macropinocytotic vesicle difficult. There is further evidence supporting this hypothesis, as $\mathbf{C P N}-1$, containing half the amine density of CPN-2 and CPN-3, indeed exhibits the uptake enhancement and decreased endosome localization we expected from CPN-3. In conclusion the cellular uptake and subcellular localizations of CPNs were significantly affected upon complexation with polysaccharides. Incorporation of short ethylene oxide onto amine-containing CPNs afford polyplexes with reduced late endosome/lysosome localization and enhanced cellular uptake. CPNs with only amine side-chains, regardless of backbone structure, did not exhibit enhanced cellular uptake. A detailed study in the endocytosis mechanisms for the uptake of these polyplexes could shed light into this interesting phenomenon. 


\subsection{Outlook}

Since the writing of this chapter, a preliminary study of the endocytosis pathway of each CPN-polysaccharide polyplex was performed. The endocytosis pathways for CPN-1, CPN-2 were previously determined to be $\mathrm{CvME} / \mathrm{CME}$ and $\mathrm{CME} / \mathrm{CvME}$, respectively (see Chapter 2). CPN-3 was determined to be MPC. Upon complexation with HA, all resulting HA-polyplexes exhibited $\mathrm{MPC}$ and $\mathrm{CvME}$ as their main and secondary endocytosis pathways, respectively. This observed change in endocytosis pathway occurred regardless of the nature of the polymer used. These results further support our hypothesis. We had observed improved uptake due to the formation of core-CP shell$\mathrm{CMC} / \mathrm{HA}$ morphology that is facilitated by the semi-flexible nature of the material. If the uptake is significantly influenced by the complexing polysaccharide, then we expected the polyplex to exhibit improved internalization via macropinocytosis. We did in fact observe this phenomenon upon HA complexation. The effects on endocytosis pathway were upon $\mathrm{CMC}$ complexation were not as significant, however. The resulting increase in hydrodynamic radius of the CMC-polyplex could cause the observed changes, and remains an interesting avenue for future work.

Further studies on polymers using semi-flexible CPNs here have revealed that the nature of the conjugated backbone, and the amount of flexible linker play a crucial role in the controlled aggregation of the resulting polyplex. In conclusion, the understanding the role that backbone and the semi-flexible linker play in the controlled aggregation, and the resulting biophysical properties, will continue to facilitate development of novel multifunctional materials for labelling, sensing, and delivery. 


\subsection{Experimental Section}

\subsubsection{General}

Chemicals, including solvents, were purchased from Fisher Scientific and used as received. Deuterated solvents were purchased from Cambridge Isotope Laboratories (Cambridge, MA). UV-vis spectra were recorded using a Varian Cary 50 Bio spectrophotometer. Fluorescence spectra were obtained using a FluoroLog-3 Spectrofluorometer (Jobin Yvon/ Horiba). 9,10-diphenylanthracene (QY = 1.0) in cyclohexane was used as a fluorescence standard for QY determination. The average molecular weight $(\mathrm{Mn})$ and polydispersity index $\left(\mathrm{PDI}=\mathrm{M}_{\mathrm{w}} / \mathrm{M}_{\mathrm{n}}\right)$ of the polymers were determined by gel permeation chromatography (GPC) against polystyrene standards using a Shimadzu high performance liquid chromatography (HPLC) system fitted with PLgel $5 \mu \mathrm{m}$ MIXED-D columns and SPD-20A ultraviolet- visible (UV-vis) detector. Nuclear magnetic resonance (NMR) spectra were recorded on a $400 \mathrm{MHz}$ and $600 \mathrm{MHz}$ Avance Bruker NMR spectrometer. The $600 \mathrm{MHz}$ NMR spectrometer is equipped with a gradient system capable of producing magnetic field pulse gradients in the z-direction of about $50 \mathrm{G} \mathrm{cm}^{-1}$ and allowing for water peak suppression $\left(\delta=4.8 \mathrm{ppm}\right.$ in $\left.\mathrm{D}_{2} \mathrm{O}\right)$. Experiments were carried out using a $5 \mathrm{~mm} \mathrm{BBI}$ probe and the temperature was $298 \mathrm{~K}$. The mixing time was $300 \mathrm{~ms}$ water suppression experiments. Chemical shifts were reported in parts per million (ppm) for ${ }^{1} \mathrm{H}-\mathrm{NMR}$ on the $\delta$ scale based on the middle peak $(\delta=2.50 \mathrm{ppm})$ of the dimethyl sulfoxide (DMSO)- $\mathrm{d}_{6}$ solvent as an internal standard, or 4.8ppm for deuterium hydroxide $\left(\mathrm{D}_{2} \mathrm{O}\right)$ experiments. Dialysis and solvent exchange of CPNs were conducted using an Ultrafiltration Stirred Cell (Millipore, Billerica, MA, 
USA) with membrane filters [Ultracel ultrafiltration disc, molecular weight cutoff (MWCO): $30 \mathrm{kDa}$ ]. Tables and graphs were plotted using Origin 8 software (OriginLab, Northampton, MA, USA).

\subsubsection{Polymer Synthesis and Characterization}

P3. A Schlenk flask was charged with of monomer $9(32 \mathrm{mg}, 0.044 \mathrm{mmol})$ and monomer $13(20 \mathrm{mg}, 0.044 \mathrm{mmol})$ in the presence of $\mathrm{Pd}\left[\left(\mathrm{PPh}_{3}\right)_{2} \mathrm{Cl}_{2}\right](3 \mathrm{mg}, 0.0044 \mathrm{mmol})$ and $\mathrm{CuI}$ (0.2 mg, $0.0022 \mathrm{mmol})$. The Schlenk flask was evacuated and filled with $\mathrm{N}_{2}$ three times. A solution of anhydrous dimethylformamide (DMF) $(4 \mathrm{~mL})$ and freshly distilled trimethylamine $(1 \mathrm{~mL})$ was degassed, and $1 \mathrm{~mL}$ of the mixed solution was transferred to the Schlenk flask using a cannula needle. The reaction was heated at $70{ }^{\circ} \mathrm{C}$ for $14 \mathrm{~h}$. The solution was then cooled to room temperature and transferred drop wise to cold ethyl ether, resulting in precipitation. After centrifugation ( $2 \mathrm{~min}, 4000 \mathrm{rpm}$ ), the supernatant was decanted, and the precipitate was dissolved in DMF (1 mL) to yield P3.

Molecular weight of boc-protected polymer was obtained and characterized. Resulting mixture was purified by precipitation in cold ethyl ether (x3). An aliquot was dissolved in THF and molecular weight obtained and photophysical properties characterized. The rest

of the material was dissolved in DMSO- $\mathrm{d}_{6}$ and characterized using ${ }^{1} \mathrm{H}-\mathrm{NMR}$. CPN formation was then carried out as described in general procedure to yield CPN-3. 
P3: GPC: $\mathrm{M}_{\mathrm{w}}=24.43 \mathrm{kDa} ; \mathrm{M}_{\mathrm{n}}=16.4 \mathrm{kDa}$; PDI $=1.49 . \mathrm{UV} \lambda_{\max }=427 \mathrm{~nm}$; fluo $\lambda_{\max }(400$ $\mathrm{nm}$ ex $)=471 \mathrm{~nm}$; QY $=41 \%$ in DMF. ${ }^{1} \mathrm{H}-\mathrm{NMR}(400 \mathrm{MHz}): \delta=7.35$ (br, $\left.1 \mathrm{H}, \mathrm{Ar}-\mathrm{H}\right), 6.87$ (br, 0.5H, NHCOO), 4.08 (br, $2 \mathrm{H}, \mathrm{Ar}-\mathrm{OCH}_{2}$ ), 3.91 (br, $2 \mathrm{H} \mathrm{CH}_{2} \mathrm{O}$ ), 3.82 (br, $2 \mathrm{H}, \mathrm{OCH}_{2}$ ), 3.58 (br, $2 \mathrm{H}, \mathrm{CH}_{2} \mathrm{O}$ ), 3.48 (br, $2 \mathrm{H}, \mathrm{OCH}_{2}$ ), 3.34 (br, $2 \mathrm{H}, \mathrm{CH}_{2} \mathrm{O}$ ), 3.27 (br, $2 \mathrm{H}, \mathrm{OCH}_{2}$ ), $2.72\left(\mathrm{br}, 3 \mathrm{H}, \mathrm{OCH}_{3}\right), 1.47\left(\mathrm{~s}, 8 \mathrm{H}, \mathrm{OC}\left(\mathrm{CH}_{3}\right)_{3}\right)$. FT-IR (Neat): v = $3372(\mathrm{br}), 2982(\mathrm{w})$, 2935 (m), 2875 (s), 1710 (vs; C=O), 1513 (vs), 1461 (w), 1425 (m), 1425 (m), 1393 (m), 1363 (s), 1276 (s), 1219 (s), $1172(\mathrm{~m}), 1120(\mathrm{~m}), 1060$ (m), 1033 (m).

CPN-3: UV $\lambda_{\max }=433 \mathrm{~nm}$; fluo $\lambda_{\max }(400 \mathrm{~nm}$ ex $)=496 \mathrm{~nm}$; QY $=3 \%$ in water. ${ }^{1} \mathrm{H}-$ $\operatorname{NMR}(600 \mathrm{MHz}): \delta=7.36$ (br, $1 \mathrm{H}, \mathrm{Ar}-\mathrm{H}), 4.3-3.0$ (br, $23 \mathrm{H},-\mathrm{OCH}_{2}-\mathrm{CH}_{2}-$ chains), 1.30 (s, 0.21H). FT-IR (Neat): v = 3374 (br), 2982 (w), 2935 (m), 2875 (s), 1674 (br), 1610 (w), $1500(\mathrm{~m}), 1461(\mathrm{w}), 1423(\mathrm{w}), 1390(\mathrm{w}), 1360(\mathrm{~m}), 1279(\mathrm{w}), 1250(\mathrm{w}), 1213(\mathrm{br})$, 1104 (br), 1059 (br), 1035 (m).

\subsubsection{CPN Formation}

Boc-deprotection of the polymer was carried out by mixing a solution of polymer in DMSO- $\mathrm{d}_{6}$ with acetic acid $(2 \mathrm{~mL})$ and trifluoroacetic acid $(1 \mathrm{~mL})$ and allowed to stir at room temperature for 5 days. The mixture was then added to acetic acid $(20 \mathrm{~mL})$, allowed to stir overnight, and centrifuged, and supernatant was added drop wise ( 2 drops/s) to 500 $\mathrm{mL}$ water $(18 \Omega)$ while stirring. Using a solvent-resistant stir cell fitted with a $30 \mathrm{kDa}-$ MWCO membrane, the solution was concentrated to approximately $10 \mathrm{~mL}$, and dialyzed against $1 \mathrm{~L}$ of water. The resulting solution was further dialyzed in a $10 \mathrm{KDa}$ membrane 
for 3 days. The solution was subsequently filtered through a Teflon (PTFE) syringe filter $(0.45 \mu \mathrm{m})$ and used for further analysis. Deprotection was confirmed with ${ }^{1} \mathrm{H}-\mathrm{NMR}$.

\subsubsection{Polymer Deprotection}

Confirmed using ${ }^{1} \mathrm{H}-\mathrm{NMR}$ data by looking at characteristic Boc proton peak (1.36ppm) and $\sim 1700 \mathrm{~cm}^{-1}$ infrared band for the carbonate $(\mathrm{C}=\mathrm{O})$ group. IR samples were prepared by lyophilization to prepare neat sample. IR scans from 4000 to $700 \mathrm{~cm}^{-1}$ are presented below, depicting absence of boc-carbonate group and confirming deprotection.

\subsubsection{Gel Permeation Chromatography}

Samples dissolved in THF were filtered through a Teflon (PTFE) syringe filter $(0.25 \mu \mathrm{m})$ three times. The average molecular weight $(\mathrm{Mn})$ and polydispersity index $\left(\mathrm{PDI}=\mathrm{M}_{\mathrm{w}} / \mathrm{M}_{\mathrm{n}}\right)$ of the polymers were determined by gel permeation chromatography (GPC) against polystyrene standards using a Shimadzu high performance liquid chromatography (HPLC) system fitted with PLgel $5 \mu \mathrm{m}$ MIXED-D columns and SPD-20A ultravioletvisible (UV-Vis) detector.

\subsubsection{Cell Culture}

\subsubsection{General}

Human cervical cancer (HeLa) cells (purchased from ATCC), seeded into a 100 x $20 \mathrm{~mm}$ style sterile tissue culture dish (\#353003 BD Falcon, Durham, NC, USA), cultured in 
minimum essential medium (MEM)/Earle's balanced salt solution (EBSS) (400 $\mu \mathrm{L}$, HyClone, SH30024) medium containing 10\% fetal bovine serum (FBS) and $100 \mathrm{U} / \mathrm{m}$ penicillin for $24 \mathrm{~h}$ under $5 \% \mathrm{CO}_{2}$ at $37{ }^{\circ} \mathrm{C}$, and subcultured every 48 hours. pHRhodo Dextran 10kDa (\#P10361 Molecular probes, Life technologies, New York, USA) and BODIPY-TR C5 -ceramide-BSA complex (\#B34400 Molecular probes, Life technologies, New York, USA) were used for endosome and Golgi apparatus staining, respectively.

\subsubsection{Microscopic Imaging.}

Approximately 10,000 HeLa cells were seeded into a glass-bottomed eight-well chamber slide (Lab-Tek Thermo Scientific) and cultured in a minimum essential medium (MEM)/Earle's balanced salt solution (EBSS) $(400 \mu \mathrm{L})$ medium containing $10 \%$ fetal bovine serum (FBS) and $100 \mathrm{U} / \mathrm{m}$ penicillin for $24 \mathrm{~h}$ under $5 \% \mathrm{CO}_{2}$ at $37^{\circ} \mathrm{C} .80 \mu \mathrm{L}$ of 20 $\mu \mathrm{M}$ CPNs in water was added to the culture medium directly, and the cells were further cultured overnight (final CPN concentration: $4 \mu \mathrm{M}$ ). For endosome staining, pHRhodo Dextran $10 \mathrm{kDa}(5 \mu \mathrm{M})$ was incubated for $30 \mathrm{~min}$ at $37^{\circ} \mathrm{C}$. After washing with fresh medium, the cells were further incubated for $30 \mathrm{~min}$ at $37{ }^{\circ} \mathrm{C}$. A $1 \mu \mathrm{L}$ aliquot of Hoechst $(5 \mu \mathrm{g} / \mathrm{mL})$ was added to the culture medium and incubated with the cells for 10 min at 37 ${ }^{\circ} \mathrm{C}$, and washed two times with phosphate buffered saline (PBS). The cells were fixed with $4 \%$ paraformaldehyde for $10 \mathrm{~min}$. Fluorescent images of the cells were obtained using a DeltaVision Elite Microscope System (Applied Precision, Issaquah, Washington, USA) equipped with bandpass filters such as blue (410-460 nm, Hoechst), green 
(500-550 nm, CPNs), and red (595-635 nm, Golgi and endosome). Top and bottom of the chosen cells was identified, and a Z-stack plot was imaged for each channel.

\subsubsection{Colocalization study}

Z-stack microscope images of each sample was obtained as described above. Colocalization analysis was conducted for three independent cells per polymer and per organelle (Golgi apparatus and endosome). Colocalization analysis was conducted using the microscope software (Softworx 5.0 application, Applied Precision, Issaquah, Washington, USA). Region of interest (ROI) was selected to contain the entire cell. Pearson's Correlation Coefficient (PCC) was used to determine colocalization. Negative control of colocalization was performed by analysis of blue and green channels staining the nucleus and CPN, respectively. Three independent images of an entire cell were selected and analyzed to increase the analysis objectivity. Experimental colocalization PCC values were obtained using the green and red channels staining the CPN and the target organelle (endosome). One-way ANOVA followed by Tukey means separation method was conducted for PCC colocalization values between samples of same organelle using Origin 8 software.

\subsection{References}

$1 \quad$ K. Lee, J. Lee, E. J. Jeong, A. Kronk, K. S. J. Elenitoba-Johnson, M. S. Lim, J. Kim, Adv. Mater. 2012, 24, 2479; C. F. Wu, D. T. Chiu, Angew. Chem. Int. Ed. 2013, 52, 3086.

2 K. E. Achyuthan, T. S. Bergstedt, L. Chen, R. M. Jones, S. Kumaraswamy, S. A. Kushon, K. D. Ley, L. Lu, D. McBranch, H. Mukundan, F. Rininsland, X. Shi, W. Xia, D. G. J. Whitten, Mater. Chem. 2005, 15, 2648;

3 Y. Wang, S. D. Jett, J. Crum, K. S. Schanze, E. Y. Chi, D. G. Whitten, Langmuir 
2013, 29, 781; C. F. Xing, L. B. Liu, H. W. Tang, X. L. Feng, Q. Yang, S. Wang, G. C. Bazan, Adv. Funct. Mater. 2011, 21, 4058.

4 J. H. Moon, E. Mendez, Y. Kim, A. Kaur, Chem. Commun. 2011, 47, 8370; 2010, 10, 291; X. L. Feng, F. T. Lv, L. B. Liu, Q. Yang, S. Wang, G. C. Bazan, Adv. Mater. 2012, 24, 5428.

5 C. J. Sun, B. S. Gaylord, J. W. Hong, B. Liu,, G. C. Bazan, Nat. Protoc. 2007, 2, 2148

6 E. Mendez and J. H. Moon, Chem. Commun., 2013, 49, 6048

7 Megan Twomey, Yoonmi Na, Zahilyn Roche, et al Macromolecules, 2013, 46 (15), 6374-6378

$8 \quad$ K. Li and B. Liu, Chem. Soc. Rev., 2014, 43, 6570

9 HSS Qhattal and X Liu, Mol Pharm. 2011 Aug 1; 8(4): 1233-1246.

10 Rejman, A. Bragonzi, M. Conese, Mol. Ther. 2005, 12, 468.

11 T. Vokatá, J. H. Moon, Macromolecules 2013, 46, 1253

12 Y. J. Ko, E. Mendez, J. H. Moon, Macromolecules 2011, 44, 5527.

13 R G Aswathy et al, J Biomat and Nano, 2012, 3, 254-261

14 X. L. Feng, Y. L. Tang, X. R. Duan, L. B. Liu, S. J. Wang, Mater. Chem. 2010, 20,1312

15 M.C. Kerr, R.D. Teasdale. Traffic 2009, 10, 364-71. 


\section{CHAPTER IV}

POLYMER BACKBONE DEGRADATION-DEPENDENT

SUBCELLULAR LOCALIZATION 


\subsection{Abstract}

Quantitative mitochondria labeling was achieved by endocytosis of biodegradable conjugated polymer nanoparticle $(\mathrm{CPN})$ followed by the polymer backbone degradation. The degraded conjugated oligomers (COs) were efficiently trafficked to the target organelle, while non-degradable CPNs remain mainly in endosomes. The presented strategy of highly specific intracellular labeling of target organelle will contribute to increase accuracy of biological imaging and sensing.

\subsection{Introduction}

Mitochondrial dysfunction is a key component in various human diseases such as cancer $^{1}$, obesity ${ }^{2}$, diabetes ${ }^{3}$ and neurodegenerative diseases ranging from Leber's hereditary optic neuropathy ${ }^{4}$ to Alzheimer's disease ${ }^{5}$. Because the mitochondrion plays a key role in cell death pathways, targeted drug delivery to this organelle could play a crucial role for future cancer treatments. ${ }^{6}$ However, the efficient delivery of therapeutics into this key organelle has been limited by the highly regulated process required to achieve mitochondrial internalization.

Successful drug delivery requires permeation through the lipophilic cell membrane, mitochondrial trafficking, and penetration of the mitochondrial membrane, which results in a high exclusivity towards a wide variety of molecules. Incorporation of lipophilic moieties such as triphenylphosphonium (TPP), which contain a delocalized positive charge, has been reported to facilitate cellular and mitochondrial membrane permeation. ${ }^{7}$ While direct modification of drugs with TPP, or targeting moieties like $i t^{8}$, has facilitated internalization into the mitochondria, they are limited to small molecular weight payloads 
and suffer from non-specific cellular adsorption. ${ }^{9}$ Additionally, the intrinsic diffusion mechanism requires relatively high probe concentrations, which often lead to nonspecific uptake and toxicity issues.

Polymeric delivery vehicles overcome many of the limitations of direct drug modification and offer a platform that that can be modified for the intracellular delivery of cargos of varying charge, size, and molecular weight. Upon appropriate fabrications and surface modifications, polymer nanoparticles can circulate longer in the blood stream and target the disease tissues using both passive (i.e., the enhanced permeation and retention effect) and active (i.e., interaction of ligands specific to the cell surface receptors) targeting strategies.

Mitochondrial localization of nanocarriers via incorporation of targeting ligands has seen limited success. For example, mitochondrial localization was observed by incorporation of TPP onto N-(2-Hydroxypropyl)methacrylamide (HPMA) only in copolymers with an average molecular weight below $5 \mathrm{kDa}$. Higher molecular HPMA copolymers did not show any mitochondrial localization, even after polymer microinjection into the cytosol. Emerging technologies such as dequalinium, which can form liposome-like aggregates, have been reported to exhibit plasmid DNA (pDNA) encapsulation, cellular internalization, and pDNA delivery to the mitochondria. Similar success has been reported with fusogenic peptides. However, these materials do not exhibit improved pharmacokinetics, passive or active targeting towards cancer cells.

Here we present a strategy to combine advantages of both small molecules (i.e., high targeting efficiency) and large polymeric materials (i.e., better cellular entry and in vivo 
properties) to achieve quantitative intracellular organelle labeling. Using the biodegradability of conjugated polymer nanoparticles (CPNs), almost quantitative mitochondria labeling was achieved. Upon endocytosis, CPNs were de-assembled and degraded to low molecular weight, fluorescent mitochondria probes that were efficiently trafficked to mitochondria. The results support that biodegradable CPNs are promising labeling and therapeutic delivery materials to mitochondria.

CPNs are fluorescent biomaterials fabricated by self-assembly of non-aqueous solution conjugated polymers (CPs) in an aqueous solution. Owing to their excellent photophysical and biophysical properties, have been employed for CPNs have gained many recent attentions for microscopic cell/tissue imaging, ${ }^{10-13}$ biological sensing ${ }^{14-19}$, and nucleic acid delivery. ${ }^{20-22}$ Recently, we demonstrated that subtle CPN side-chain and backbone modifications significantly influence the cellular behaviors including toxicity, entry mechanism, and subcellular localization.

Herein we report CPN-1 (Figure 4.1), a disulfide linker-containing poly(phenylene ethynylene) with TPP side-chains exhibiting mitochondria-specific co-localization. To obtain the fluorescent properties comparable to a fully conjugated PPE, the amount of disulfide monomer in the PPE backbone was maintained less than 50\%. Using a fully conjugated PPE, CPN-2 was also fabricated to support the concept that the degradability of CPNs is a crucial part for high intracellular organelle targeting. 


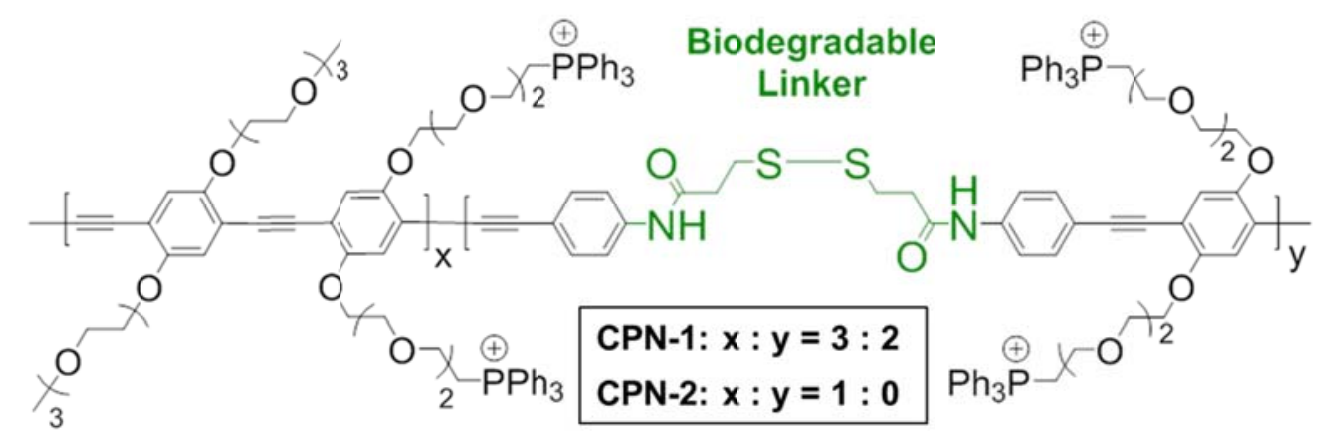

Figure 4.1. Chemical structures of TPP-containing PPEs with and without biodegradable linkers in the backbone. CPN-1 (x:y=3:2) and CPN-2 (x:y=1:0) were fabricated with the corresponding PPEs via selfassembly.

\subsection{Results and Discussion}

Human cervical carcinoma (HeLa) cells were incubated with biodegradable CPN-1 and non-degradable CPN-2 for overnight, respectively. The metabolic activity of HeLa cells incubated with CPNs was measured by MTT assay. CPN-1 exhibits no viability inhibition up to $40 \mu \mathrm{M}$, while $\mathbf{C P N}-2$ exhibits a slight inhibition $(\sim 10 \%$ viability decrease) (see Supporting Information). CPNs were taken up by cells and found in the cytosolic compartment (Figure 4.2). Unlike to CPN-2, which exhibits a characteristic punctuated pattern, the fluorescent pattern of CPN-1 was somewhat diffused and granular (Figure 4.2).

For analyzing subcellular localizations of CPNs, various organelles (i.e., nucleus, Golgi, endosome, and mitochondria) were post-stained using commercially available dyes. The Pearson's Correlation Coefficient (PCC) was used to quantitative co-localization evaluation. PCC scores of 0 and 1 correspond to uncorrelated and perfectly linearly correlated colors, respectively. Mean PCC scores from three independent images of an entire cell were selected and analyzed to increase the analysis objectivity. CPN-1 
exhibited almost exclusive mitochondrial co-localization (PCC 0.89), while minimal endosome (0.25) and Golgi apparatus (0.23) co-localizations were observed (Figure 4.3). Meanwhile, CPN-2 showed high endosomal co-localization (PCC 0.76) with minimal mitochondrial and Golgi apparatus co-localization (Figure 4.3). Fluorescence analysis of the mitochondrial fraction of Hela cells incubated with CPNs also clearly support the quantitative localization of CPN-1 in mitochondria. Fluorescent intensities at $495 \mathrm{~nm}$ of mitochondria and cytosolic fractions, respectively, were compared.
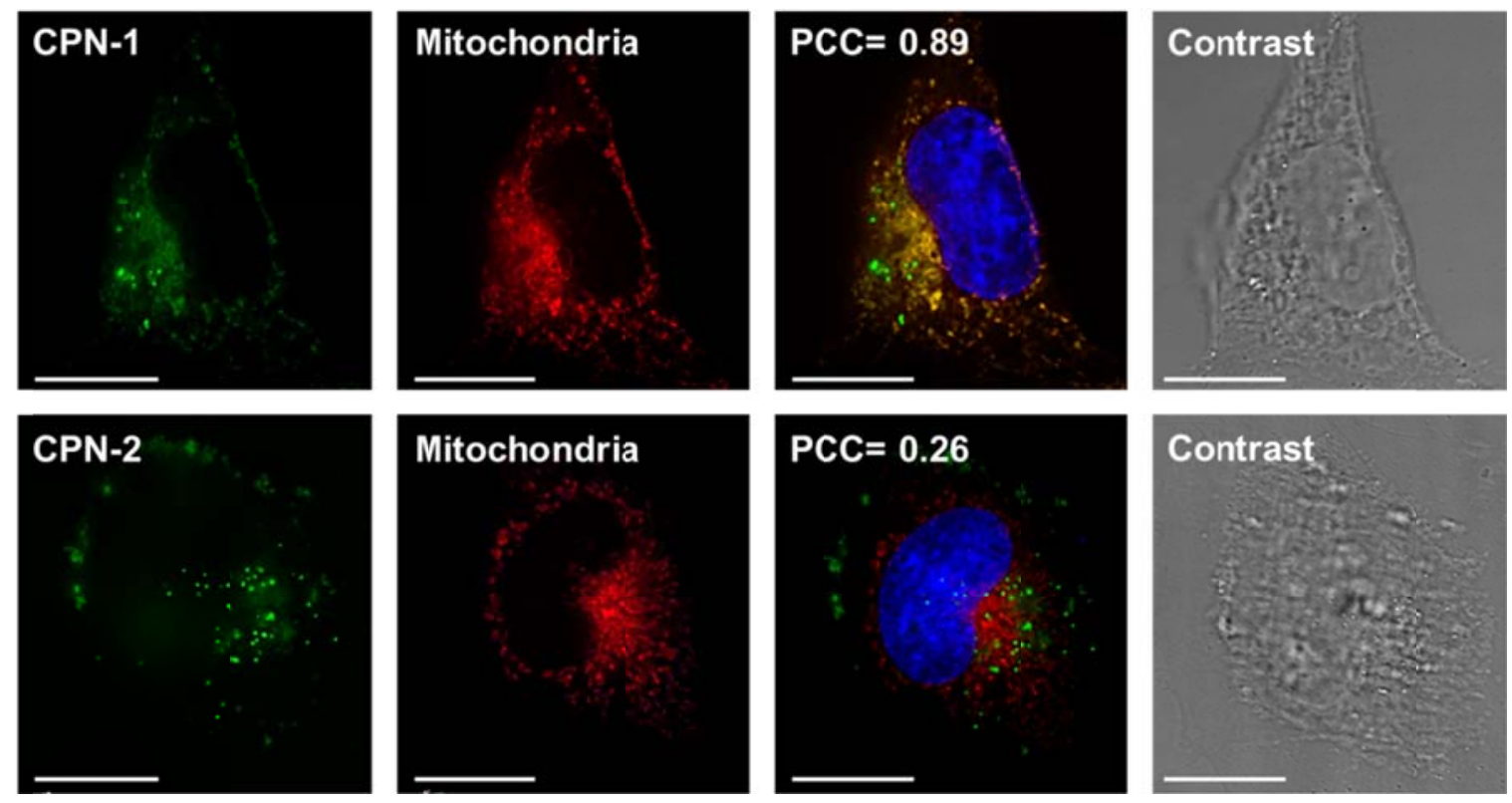

Figure 4.2. Microscopic images of HeLa cells incubated with CPNs. Cells treated with CPNs for 18 hours followed by mitochondrial (red) and nuclear (blue) staining. The scale bar is $20 \mu \mathrm{m}$.

This dramatic subcellular localization difference between CPNs with the same side chains (i.e., TPP) implies that self-assembly structures of CPNs possibly influence cellular entry routes and the intracellular fates. We previously found that CPs with flexible linkers tend to form aggregates with high interpolymer interactions compared with CPs without the flexibility. Because of the flexible disulfide bonds, therefore, the 


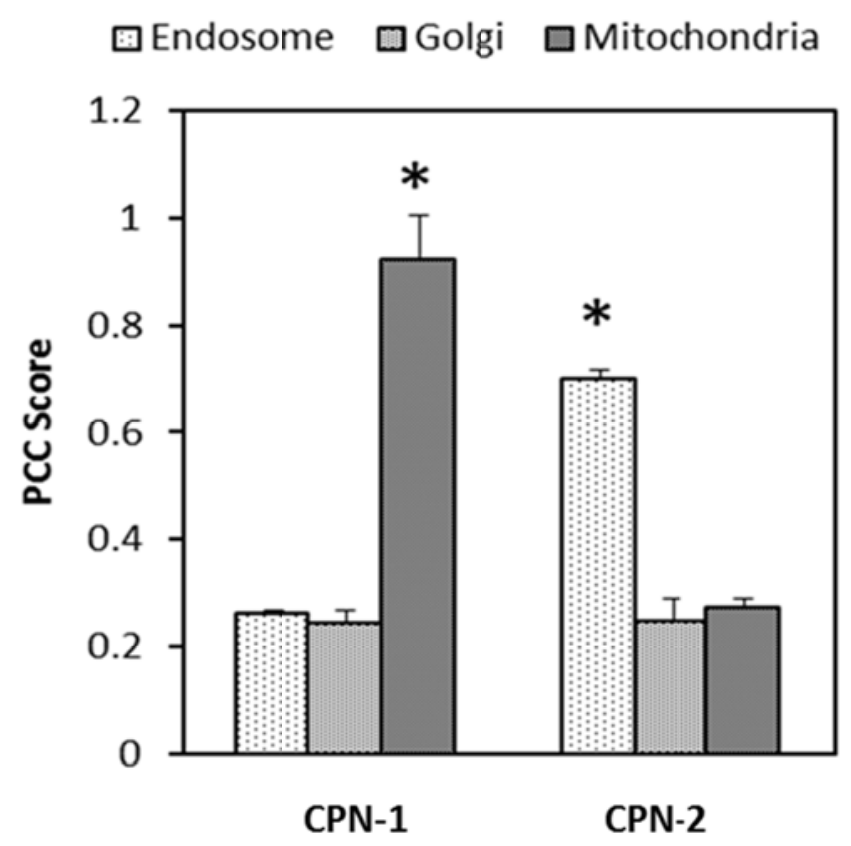

Figure 4.3. Quantitative co-localization analysis using the PCC algorithm. CPN-1 and CPN-2 exhibit high mitochondria and endosome localization, respectively. The error bar represents \pm standard deviation $(\mathrm{n}=3)$. ANOVA-Tukey test demonstrate statistically different CPN-1 and CPN-2 co-localization with endosome and mitochondria. $* \mathrm{p}<0.0005$.

surface properties of CPN-1 will be different and influential for cellular interactions and subsequent cellular entry. To test endocytosis pathways, HeLa cells pretreated with pharmacological inhibitors of various endocytosis pathways were incubated with CPNs for 2 hours and mean fluorescent intensity of cells were monitored by flow cytometry.

As shown in Figure 4.4, CPNs use various endocytosis pathways to enter HeLa cell, determined by the reduced uptake of CPNs under the inhibitors tested. In addition to caveolae-mediated endocytosis (CvME), uptake of CPN-1 via macropinocytosis (MPC) also noticeably reduced. Although further mechanistic and trafficking studies are currently underway, we speculate that the high mitochondria localization of CPN-1 is closely related to a series of cellular processes of MPC internalization of CPN-1, 


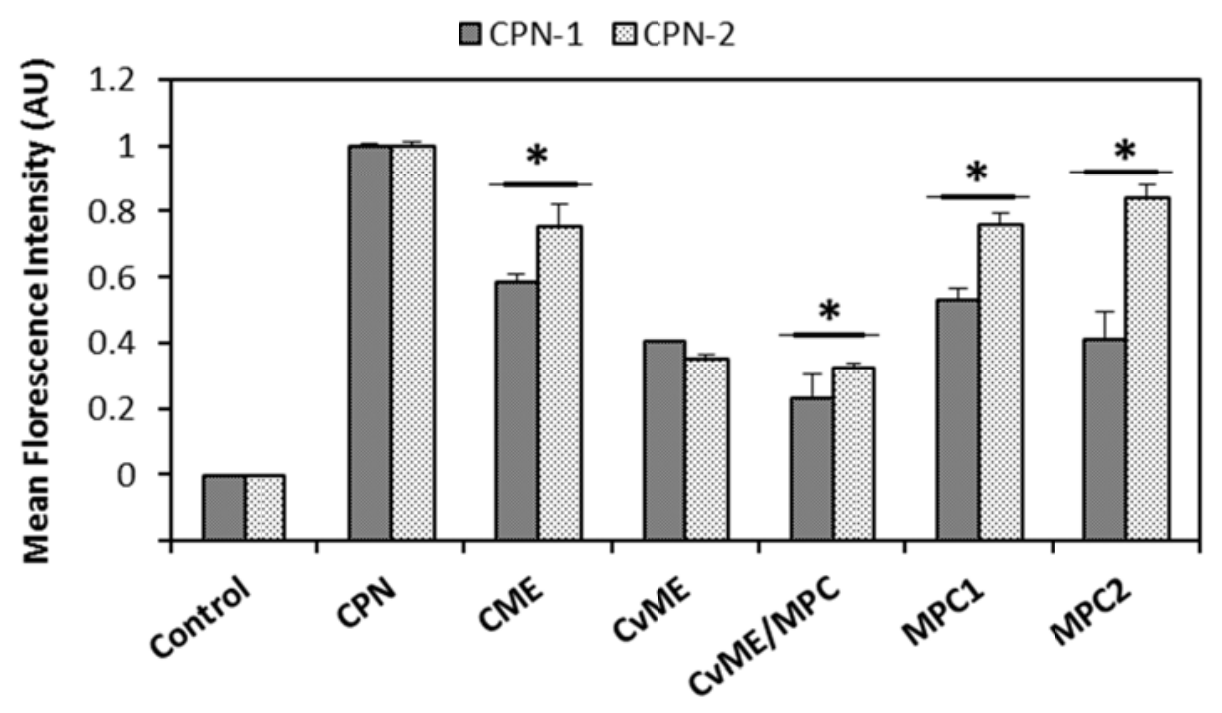

Figure 4.4. Endocytosis pathways of TPP-containing CPNs. Average of three independent $(n=3)$ endocytosis inhibition measurements of CPNs under pharmacological inhibitors treatments. Mean fluorescent intensity of HeLa cell (Control), CPNs only (CPN), chlorpromazine (24 mM, CME), genistein (210 $\mu \mathrm{M}$, CvME), methyl- $\beta$-cyclodextrin (1000 mM, CvME/MPC), LY294002 (120 $\mu \mathrm{M}$, MPC), and cytochalasin D $(0.04 \mathrm{mM}, \mathrm{MPC})$ were measured using flow cytometry. Error bars represent standard deviation. ${ }^{*} \mathrm{p}<0.05$ when compared between polymers $\mathrm{CPN}-1$ and $\mathrm{CPN}-2$.

degradation of disulfide bonds to generate low molecular weight COs, better escaping of endosomes and macropinosomes due to increased hydrophobicity of COs, and increased diffusion to trafficking to mitochondria. MPC is known as a relatively non-destructive pathway as the macropinosomes are non-acidic and leaky.

To determine whether the observed CPN-1 mitochondrial specificity is related to the degradation kinetics, we measured endosome and mitochondrial co-localization as a function of time. Subcellular localization was monitored by fluorescent microscopic imaging, with CPNs incubated for 3, 6, 12, and 18 hours in HeLa cells. PCC scoring between CPN and mitochondrial or endosomal markers was measured and averaged from three independent trials (Figure 4.5). CPN-1 exhibited a time-dependent mitochondrial 
and endosomal co-localization. As incubation time increased, CPN-1 localized more strongly towards the mitochondria, with almost exclusive mitochondrial localization at 18 hours incubation. CPN-2, meanwhile, did not show time-dependent co-localization, exhibiting no significant change in mitochondrial or endosomal localization as incubation time increased. Although $\mathbf{C P N}-2$ has high mitochondria targeting TPPs, the nondegradability, large molecular weight, and poor endosome escaping and diffusion efficiency of CPN-2 limit mitochondria targeting. The time-dependency of CPN-1 on colocalization supports that degradation of biodegradable linkers play a significant role in mitochondrial trafficking of TPP functionalized COs.

\subsection{Conclusion}

We present here a new strategy to achieve a unique time-dependent mitochondrialspecific localization of CPNs. We demonstrated that disulfide-containing CPN exhibits active cellular internalization as polymer nanoparticles via a variety of endocytosis, and undergoes degradation to actively trafficking to the mitochondria as low molecular weight oligomers. The concept we demonstrated here will lead to the development of novel polymeric materials for improved intracellular targeting and drug delivery efficiency. Currently, we are performing in vivo studies including pharmacokinetics and biodistribution, fine-tuning of degradation kinetics, and targeted delivery of drugs to mitochondria.

\subsection{Outlook}

Since the writing of this chapter, a several non-flexible-containing TPP copolymers were synthesized and screened for mitochondrial-specificity. Preliminary results indicate the 
semi-flexible linker plays a key role in the mitochondrial-specificity exhibited by $\mathrm{CPN}-1$. Because the key towards the mitochondrial-specificity appears to be the biodegradable linker, a variety of applications for sensing and delivery emerge by covalent incorporation of oxygen species (ROS)-sensitive attachment to the CPN. However, the role that molecular weight play in the mitochondrial-specificity has yet to be explored. Additionally, whether the CPN localizes on the outer or inner mitochondrial membrane

or mitochondrial lumen, remains to be determined. Successful development of mitochondria-specific fluorescent label, delivery vehicle, or (ROS) sensors, will depend on the fate of the CPN. Finally, determination of the precise mechanism by which the CPN undergoes endosomal escape will facilitate optimization and development of future CPN polymers. In conclusion, the understanding the role that the semi-flexible linker plays in the CPN degradation within the cell, and the resulting subcellular distribution, will continue to facilitate development of novel multifunctional materials for labelling, sensing, and delivery.

\subsection{Experimental Section}

Polymer synthesis and characterization was carried out by Dr. Rajesh Kumar Manian. Toxicity assay was carried out by Yong Myoung.

\subsubsection{General Information.}

Chemicals, including solvents, were purchased from Fisher Scientific and used as received. Deuterated solvents were purchased from Cambridge Isotope Laboratories (Cambridge, MA). UV-vis spectra were recorded using a Varian Cary 50 Bio 
spectrophotometer. Fluorescence spectra were obtained using a FluoroLog-3 Spectrofluorometer (Jobin Yvon/Horiba). 9, 10-diphenylanthracene $(\mathrm{QY}=1.0)$ in cyclohexane was used as a fluorescence standard for QY determination. The average molecular weight $(\mathrm{Mn})$ and polydispersity $(\mathrm{PDI}=\mathrm{Mw} / \mathrm{Mn})$ of the polymers were determined by gel permeation chromatography (GPC) against polystyrene standards using a Shimadzu high performance liquid chromatography (HPLC) system fitted with PLgel $5 \mu \mathrm{m}$ MIXED-D columns and SPD-20A ultraviolet-visible (UV-vis) detector. Nuclear magnetic resonance (NMR) spectra were recorded on a $400 \mathrm{MHz}$ Avance Bruker NMR spectrometer. ${ }^{1} \mathrm{H}$ and ${ }^{13} \mathrm{C}$ NMR chemical shifts are given in ppm relative to $\mathrm{Si}\left(\mathrm{CH}_{3}\right)_{4}$, with the solvent resonance used as internal reference. ${ }^{1} \mathrm{H}$ NMR on the $\delta$ scale based on the middle peak $(\delta=2.50 \mathrm{ppm})$ of the dimethyl sulfoxide DMSO-d6 solvent as an internal standard or 7.26 ppm for chloroform $\left(\mathrm{CDCl}_{3}\right)$ experiments. ${ }^{31} \mathrm{P}$ NMR chemical shifts are reported in ppm relative to $\mathrm{H}_{3} \mathrm{PO}_{4}$. The mass spectrometric data were obtained at the mass spectrometry facility of the Florida International University. Analytical thin layer chromatography (TLC) was performed on TLC Silica gel $60 \mathrm{~F}_{254}$. The TLC plates were visualized by shortwave $(254 \mathrm{~nm})$ or longwave $(360 \mathrm{~nm})$ UV light. Flash chromatography on silica gel (230-400 mesh) was performed. Fourier transform infrared (FT-IR) spectrum was obtained on a PerkinElmer Spectrum 100 FT-IR Spectrometer; fine powder sample was mounted on an attenuated total reflection cell. 


\subsubsection{Monomer Synthesis.}

\section{Scheme 4.1:}

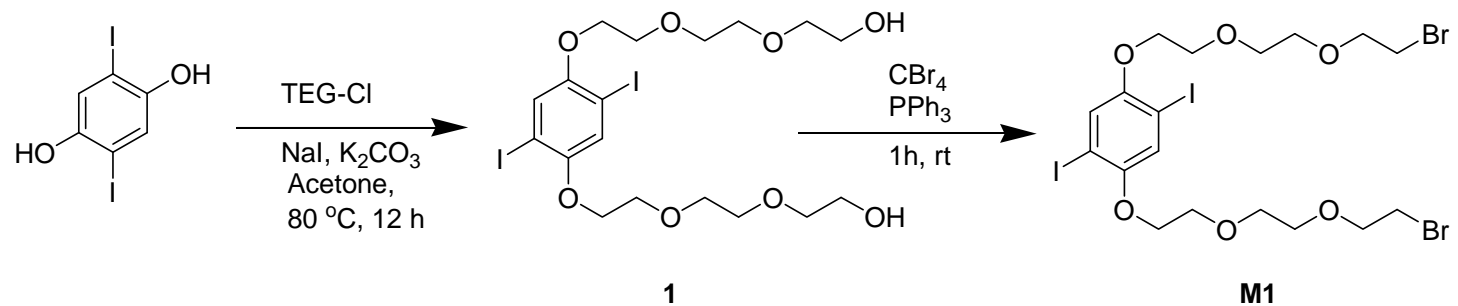

\subsubsection{Synthesis of monomer $1^{33}$}

1, 4-Dihydroxy-2, 5-diiodobenzene $(5.00 \mathrm{~g}, 13.80 \mathrm{mmol})$ was dissolved in acetone (20

$\mathrm{mL})$ and the resulting solution was added slowly to a stirred suspension of $\mathrm{K}_{2} \mathrm{CO}_{3}(7.60$ $\mathrm{g}, 55.25 \mathrm{mmol})$ and $\mathrm{NaI}(8.30 \mathrm{~g}, 55.25 \mathrm{mmol})$. The reaction mixture was allowed to stir for $10 \mathrm{~min}$ followed by the slow addition of TEG-Cl $(5.80 \mathrm{~g}, 34.53 \mathrm{mmol})$. The reaction was heated to $80{ }^{\circ} \mathrm{C}$ for $12 \mathrm{~h}$. The solution was cooled to room temperature, the solvent was removed, and the resulting slurry was re-dissolved in $\mathrm{CH}_{2} \mathrm{Cl}_{2}(100 \mathrm{~mL})$. The solution was extracted with water $(100 \mathrm{~mL} \times 3)$ and the organic fractions were collected and concentrated in vacuo until an oily residue remained. The crude product was purified by silica gel chromatography (95:5 EA / Hexane). The product was off-white solid. Yield: $5.80 \mathrm{~g}(67.0 \%) .{ }^{1} \mathrm{H}$ NMR $\left(400 \mathrm{MHz}, \mathrm{CDCl}_{3}\right): \delta 7.24(\mathrm{~s}, 2 \mathrm{H}), 4.09-4.15(\mathrm{t}, 4 \mathrm{H}), 3.86-3.92$ $(\mathrm{t}, 4 \mathrm{H}), 3.77-3.82(\mathrm{~m}, 4 \mathrm{H}), 3.69-3.76(\mathrm{~m}, 8 \mathrm{H}), 3.60-3.66(\mathrm{~m}, 4 \mathrm{H}), 2.29(\mathrm{br}, 2 \mathrm{H}) ;{ }^{13} \mathrm{C}$ $\operatorname{NMR}\left(400 \mathrm{MHz}, \mathrm{CDCl}_{3}\right): \delta 153.51,123.21,86.52,72.51,71.22,70.54,70.28,69.66$, 61.82 


\subsubsection{Synthesis of monomer $\mathrm{M1}^{34}$}

A suspension of compound $1(5.00 \mathrm{~g}, 7.98 \mathrm{mmol})$ was dissolved in $25 \mathrm{~mL}$ of DCM carbon tetrabromide $(8.00 \mathrm{~g}, 23.95 \mathrm{mmol})$ and triphenyl phosphine $(12.60 \mathrm{~g}, 23.95 \mathrm{mmol})$ added slowly to the reaction mass. The mixture was stirred at room temperature for $2 \mathrm{~h}$. The solvent was removed and the crude product was purified by column chromatography (1: 4 EA / Hexane). The product was white solid. Yield: $5.30 \mathrm{~g}(81.2 \%) .{ }^{1} \mathrm{H}$ NMR (400 $\left.\mathrm{MHz}, \mathrm{CDCl}_{3}\right): \delta 7.30(\mathrm{~s}, 2 \mathrm{H}), 4.10-4.15(\mathrm{t}, 4 \mathrm{H}), 3.89-3.92(\mathrm{t}, 4 \mathrm{H}), 3.85-3.87(\mathrm{t}, 4 \mathrm{H}), 3.68-$ $3.76(\mathrm{~m}, 4 \mathrm{H}), 3.60-3.65(\mathrm{~m}, 4 \mathrm{H}), 3.45-3.51(\mathrm{~m}, 4 \mathrm{H}) .{ }^{13} \mathrm{C} \mathrm{NMR}\left(400 \mathrm{MHz}, \mathrm{CDCl}_{3}\right): \delta$ $153.37,123.49,86.47,71.30,71.19,70.71,70.33,69.70,30.42$.

Monomer 2 (M2) was synthesized according to literature procedure (Scheme 2) ${ }^{35}$.

\section{Scheme 4.2}
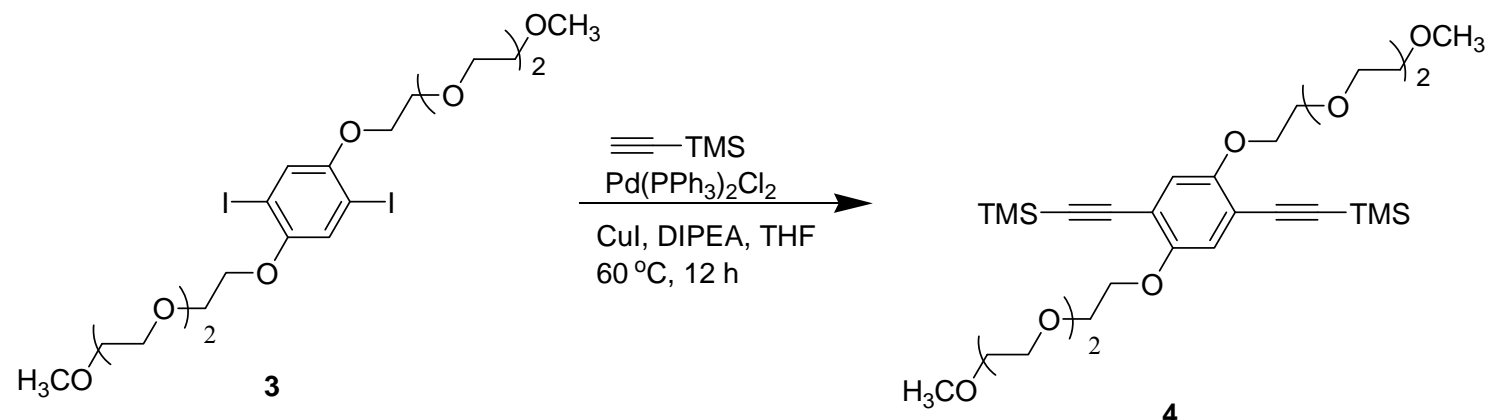


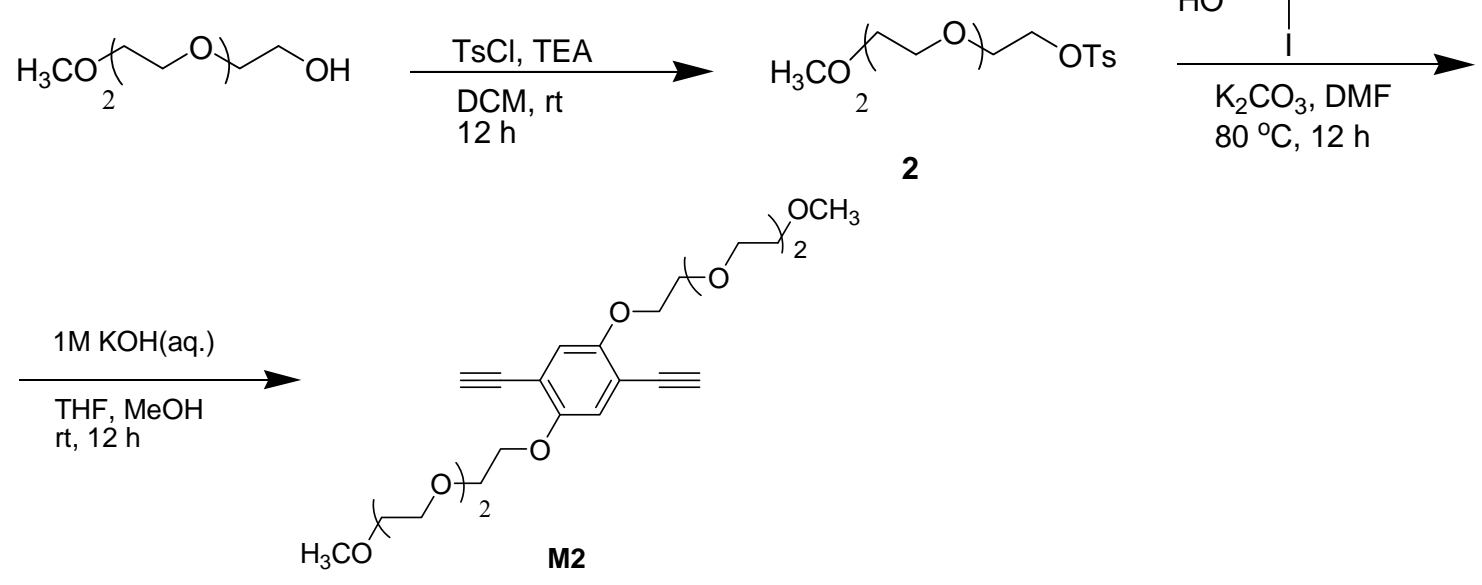

\subsubsection{Synthesis of monomer M3.}

\section{Scheme 4.3:}

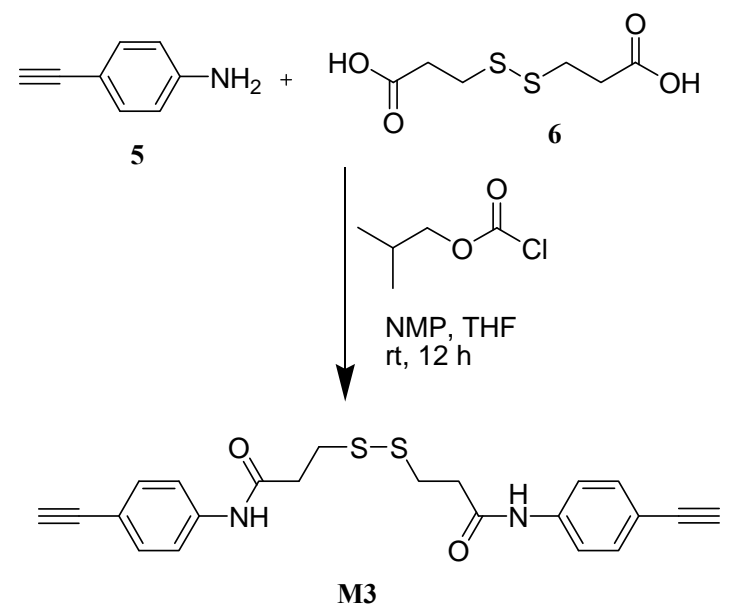

3,3'-Dithiodipropionic acid (1.00 $\mathrm{g}, 4.76 \mathrm{mmol})$ was dissolved in anhydrous tetrahydrofuran $(20 \mathrm{~mL})$ in a round bottom flask, which was evacuated and filled with nitrogen. $N$-methylmorpholine $(0.90 \mathrm{~g}, 9.52 \mathrm{mmol})$ was added, and the suspension was allowed to stir until the entire solid was dissolved. Isobutyl chloroformate $(1.30 \mathrm{~g}, 9.52$ mmol) was added, and the mixture was allowed to stir at room temperature for $15 \mathrm{~min}$. A 
solution of 4-ethynylaniline $(1.10 \mathrm{~g}, 9.52 \mathrm{mmol})$ in anhydrous THF (10 mL) was prepared under a $\mathrm{N}_{2}$ atmosphere and transferred into the reaction flask using a cannula. The reaction was allowed to proceed overnight, after which the reaction mixture was filtered. The filtrate was concentrated in vacuo, and the resulting solid was precipitated overnight from the DCM / diethyl ether solvent system. Yield: $0.70 \mathrm{~g}(36.0 \%) .{ }^{1} \mathrm{H}$ NMR (400 MHz, DMSO): $\delta 10.20(\mathrm{~s}, 2 \mathrm{H}), 7.50-7.70(\mathrm{~d}, 4 \mathrm{H}), 7.35-7.40(\mathrm{~d}, 4 \mathrm{H}), 4.09(\mathrm{~s}, 2 \mathrm{H})$, 2.95-3.10 (t, 4H), 2.62-2.78 (t, 4H). ${ }^{13} \mathrm{C}$ NMR (400 MHz, DMSO): $\delta 169.53,139.68$, 132.36, 118.94, 116.12, 83.49, 79.65, 36.08, 33.38. HRMS (ESI): Calcd for $\mathrm{C}_{22} \mathrm{H}_{20}$ ${ }_{\mathrm{n} 2} \mathrm{O}_{2} \mathrm{~S}_{2}[\mathrm{M}+\mathrm{Na}]^{+}:$431.0858; found $[\mathrm{M}+\mathrm{Na}]^{+}: 431.0801$.

\subsubsection{Polymer Synthesis.}

General Procedure. A Schlenk flask was charged with monomer M1 (1.00 eqiv.), M2 (0.5 eqiv.), $\mathbf{M 3}$ (0.5 eqiv.) $\mathrm{Pd}\left[\left(\mathrm{PPh}_{3}\right)_{2} \mathrm{Cl}_{2}\right]$ ( 0.10 equiv.) and $\mathrm{CuI}$ (0.05 equiv.). The Schlenk flask was evacuated and filled with $\mathrm{N}_{2}$. A solution of anhydrous dimethylformamide $(4 \mathrm{~mL})$ and diisopropylamine $(1 \mathrm{~mL})$ was degassed, and $2.5 \mathrm{~mL}$ of the mixed solution was transferred to the Schlenk flask using a cannular needle. The reaction was allowed to stir at room temperature for $12 \mathrm{~h}$. The solution was then transferred drop wise to methanol, resulting in precipitation. After centrifugation (3 min, $4000 \mathrm{rpm})$, the supernatant was decanted, and the precipitate was redissolved in DCM (1 $\mathrm{mL})$ for further purification. 


\subsubsection{Synthesis of $P 1$.}

\section{Scheme 4.4:}
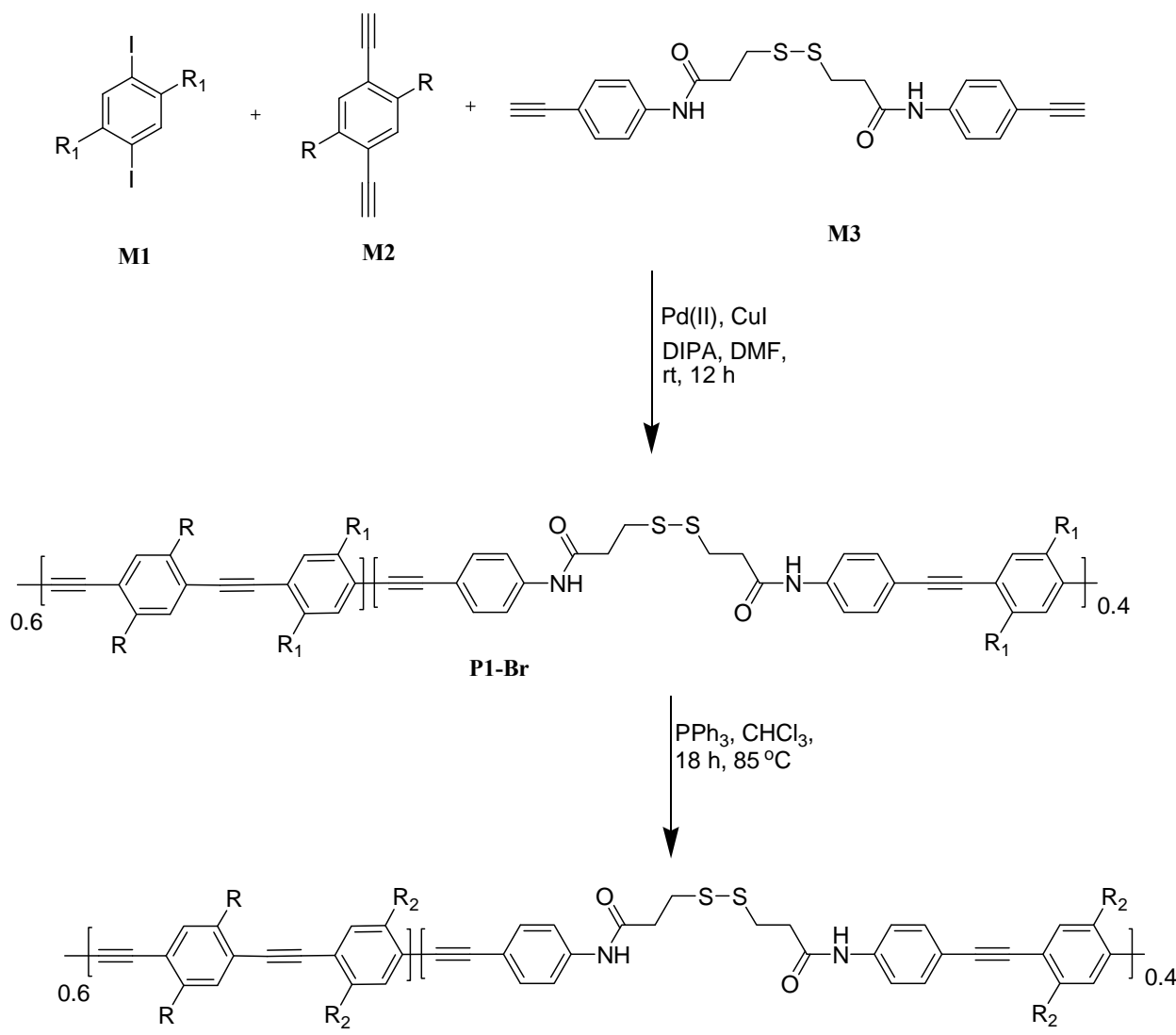

P1

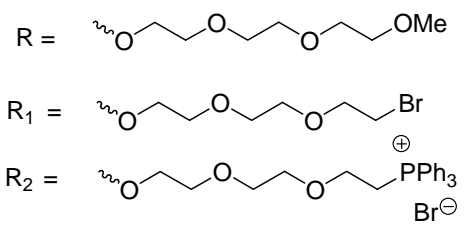

P1-Br. Using general procedure described above, the polymerization of monomer M1 (100 $\mathrm{mg}, 0.133 \mathrm{mmol}), \mathbf{M} 2(30 \mathrm{mg}, 0.066 \mathrm{mmol})$ and $\mathbf{M 3}(28 \mathrm{mg}, 0.066 \mathrm{mmol})$ in the presence of $\mathrm{Pd}\left[\left(\mathrm{PPh}_{3}\right)_{2} \mathrm{Cl}_{2}\right](9.3 \mathrm{mg}, 0.013 \mathrm{mmol})$, and $\mathrm{CuI}(1.3 \mathrm{mg}, 0.007 \mathrm{mmol})$. Resulting mixture was purified by precipitation in methanol (x3) Yield: $105 \mathrm{mg}(42.5 \%)$. 
An aliquot was redissolved in THF and molecular weight obtained and photo physical properties characterized in DCM.

P1-Br: GPC: $M_{\mathrm{w}}=13.66 \mathrm{kDa} ; \mathrm{M}_{\mathrm{n}}=09.30 \mathrm{kDa}$; PDI $=1.42 . \mathrm{UV}$-vis: $\lambda_{\max }=400 \mathrm{~nm}$; fluo $\lambda_{\max }=467 \mathrm{~nm} ; \mathrm{QY}=0.69 \%$ and $\varepsilon=42716.79 \mathrm{M}^{-1} \mathrm{~cm}^{-1}$ (Per repeating Unit) in DCM. ${ }^{1} \mathrm{H}$ NMR (400 MHz, $\left.\mathrm{CDCl}_{3}\right): \delta 8.25-8.50(\mathrm{br}, 2 \mathrm{H}), 7.50-7.65$ (br, 4H), 7.39-7.52 (br, 4H), 6.90-7.10 (br, 4H), 4.10-4.30 (br, 10H), 3.85-4.00 (br, 11H), 3.70-3.80 (br, $22 \mathrm{H}), 3.60-$ 3.70 (br, $14 \mathrm{H}), 3.50-3.60$ (br, $4 \mathrm{H}), 3.40-3.50$ (br, 5H), 3.30-3.45 (br, $6 \mathrm{H}), 3.00-3.10$ (br, 3H) and 2.75-2.90 (br, 3H). FT-IR (neat): $v=2924,2868,1671,1589,1512,1408,1352$, $1265,1214,1097,1041,937,838 \mathrm{~cm}^{-1}$.

\subsubsection{Synthesis of $P 1$.}

Triphenyl phosphine $(141 \mathrm{mg}, 0.540 \mathrm{mmol})$ was dissolved in chloroform and resulting solution was added to a stirred suspension of P1-Br (100 mg, $0.054 \mathrm{mmol})$. The reaction was heated to $85^{\circ} \mathrm{C}$ for $12 \mathrm{~h}$. The resulting mixture was purified by precipitation in ethyl acetate (x5). Yield: $70 \mathrm{mg}(44.7 \%)$.

P1: UV-vis: $\lambda_{\max }=405 \mathrm{~nm}$; fluo $\lambda_{\max }=472 \mathrm{~nm} ; \mathrm{QY}=0.40 \%$ and $\varepsilon=67606.65 \mathrm{M}^{-1} \mathrm{~cm}^{-1}$ (Per repeating Unit) in DMSO. ${ }^{1} \mathrm{H}$ NMR (400 MHz, $\mathrm{CDCl}_{3}$ ): $\delta$ 7.98-8.10 (br, 2H), 7.407.90 (br, 40H), 7.26-7.45 (br, 4H), 6.80-7.10 (br, 4H), 4.00-4.40 (br, 10H), 3.10-3.90 (br, $65 \mathrm{H}$ ), and 2.75-3.00 (br, 2H). FT-IR (neat): $v=2921,2870,1683,1597,1520,1430$, $1408,1210,1099,1047 \mathrm{~cm}^{-1}$. 


\section{Scheme 4.5:}

\subsubsection{Synthesis of $P 2$.}<smiles>[R]c1cc(I)c([R])cc1I</smiles>

M1<smiles>[R]c1cc(C#C)c([R])cc1C#C</smiles>

M2

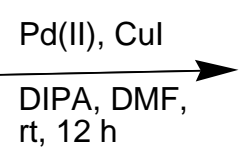

$\mathrm{rt}, 12 \mathrm{~h}$
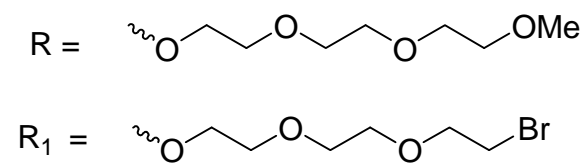

$\mathrm{R}_{2}=$

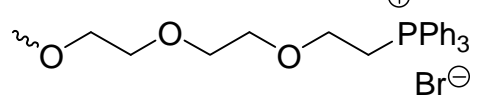

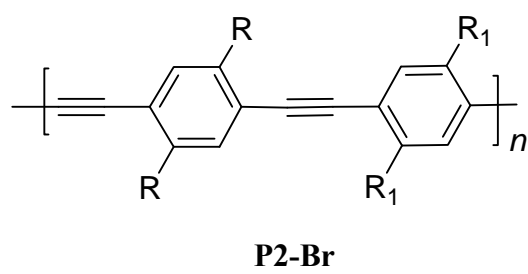

$\mathrm{PPh}_{3}, \mathrm{CHCl}_{3}$, $18 \mathrm{~h}, 85^{\circ} \mathrm{C}$

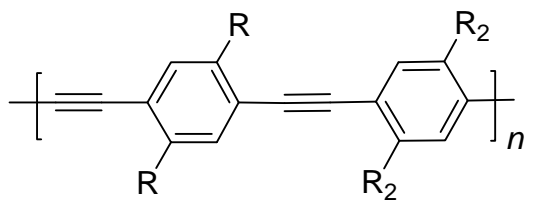

P2

P2-Br. Using general procedure described above, the polymerization of monomer M1 $(100 \mathrm{mg}, 0.133 \mathrm{mmol})$ and $\mathbf{M} 2(60.0 \mathrm{mg}, 0.133 \mathrm{mmol})$ in the presence of $\mathrm{Pd}\left[\left(\mathrm{PPh}_{3}\right)_{2} \mathrm{Cl}_{2}\right]$ (9.3 $\mathrm{mg}, 0.013 \mathrm{mmol})$, and $\mathrm{CuI}(1.3 \mathrm{mg}, 0.007 \mathrm{mmol})$. Resulting mixture was purified by precipitation in methanol (x3) Yield: $0.15 \mathrm{~g}(88.5 \%)$. An aliquot was redissolved in THF and molecular weight obtained and photo physical properties characterized in DCM.

P2-Br: GPC: $\mathrm{M}_{\mathrm{w}}=26.36 \mathrm{kDa} ; \mathrm{M}_{\mathrm{n}}=15.98 \mathrm{kDa} ;$ PDI $=1.65$. UV-vis: $\lambda_{\max }=432 \mathrm{~nm}$; fluo $\lambda_{\max }=473 \mathrm{~nm} ; \mathrm{QY}=0.53 \%$ and $\varepsilon=23526.82 \mathrm{M}^{-1} \mathrm{~cm}^{-1}$ (Per repeating Unit) in DCM. ${ }^{1} \mathrm{H}$ NMR (400 MHz, $\mathrm{CDCl}_{3}$ ): $\delta$ 7.05-7.10 (br, 4H), 4.25-4.30 (br, 8H), 3.87-3.95 (br, 9H), 3.75-3.80 (br, 12H), 3.59-3.65 (br, 13H), 3.45-3.52 (br, 4H), 3.42-3.48 (4H), 3.35-3.38 (br, 7H). FT-IR (neat): $v=2923,2870,2197,1510,1423,1270,1241,1092,1060 \mathrm{~cm}^{-1}$. 


\subsubsection{Synthesis of $P 2$.}

Triphenyl phosphine $(270 \mathrm{mg}, 1.02 \mathrm{mmol})$ was dissolved in chloroform and resulting solution was added to a stirred suspension of P2-Br (100 mg, $0.102 \mathrm{mmol})$. The reaction was heated to $85^{\circ} \mathrm{C}$ for $12 \mathrm{~h}$. The resulting mixture was purified by precipitation in ethyl acetate (x5). Yield: $95 \mathrm{mg}(61.7 \%)$.

P2: UV-vis: $\lambda_{\max }=436 \mathrm{~nm}$; fluo $\lambda_{\max }=478 \mathrm{~nm} ; \mathrm{QY}=0.25 \%$ and $\varepsilon=46128.66 \mathrm{M}^{-1} \mathrm{~cm}^{-}$ ${ }^{1}$ (Per repeating Unit) in DMSO. ${ }^{1} \mathrm{H}$ NMR (400 MHz, DMSO): $\delta$ 7.56-7.90 (br, 32H), 7.02-7.12 (br, 4H), 6.98-7.00 (br, 1H), 4.15-4.30 (br, 8H), 3.80-3.95 (br, 4H), 3.72-3.79 (br, 6H), 3.50-3.60 (br, 15H), 3.34-3.50 (br, 14H), 3.35-3.40 (br, 4H), 3.10-3.20 (br, 9H). FT-IR (neat): $v=3393,2874,2190,1625,1493,1437,1420,1353,1207,1102,1046 \mathrm{~cm}^{-}$ 1.

\subsubsection{Determination of zeta potentials of $P 1$ and $P 2$.}

Dynamic light scattering measurements were performed by Zetasizer nano-ZS (Zen 3600, Malvern Instruments Ltd.) using a folded capillary cell (Catalog \# DTS1060), at room temperature. The samples were prepared at approximately $0.1 \mathrm{mM}$ in a $5 \% \mathrm{DMSO}$ (v/v) solution using deionized water $(18 \Omega)$, which was filtered through $0.45 \mu \mathrm{m}$ PTFE syringe filter. Each sample was measured six times. 


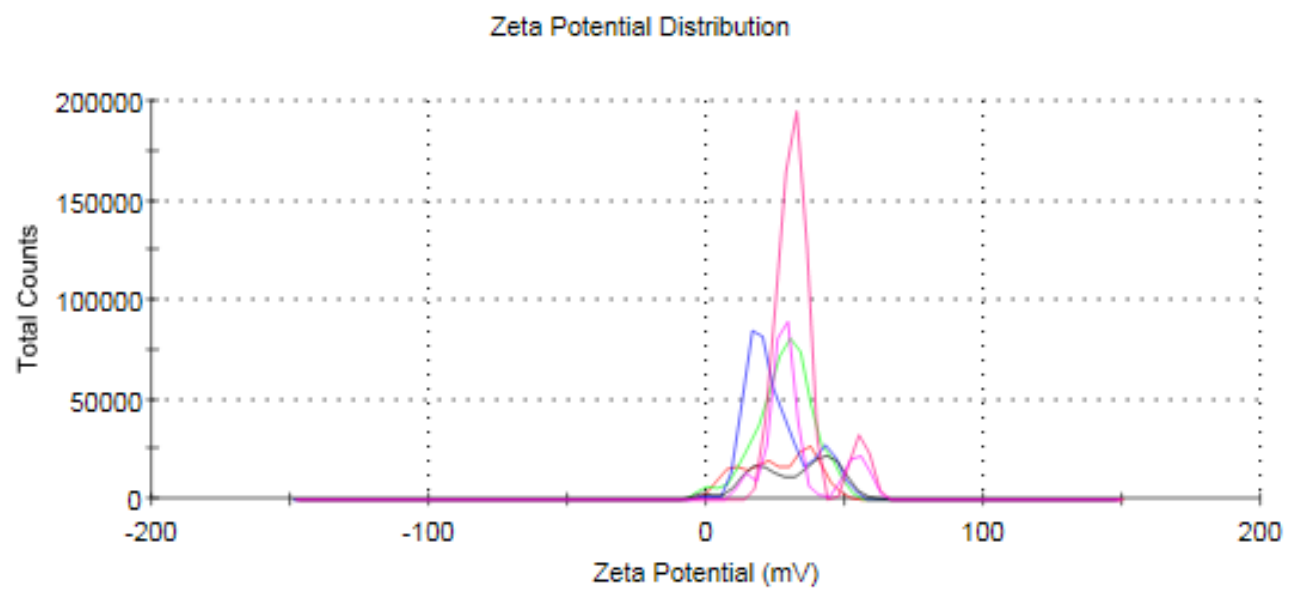

Figure 4.5. Zeta potential of P1

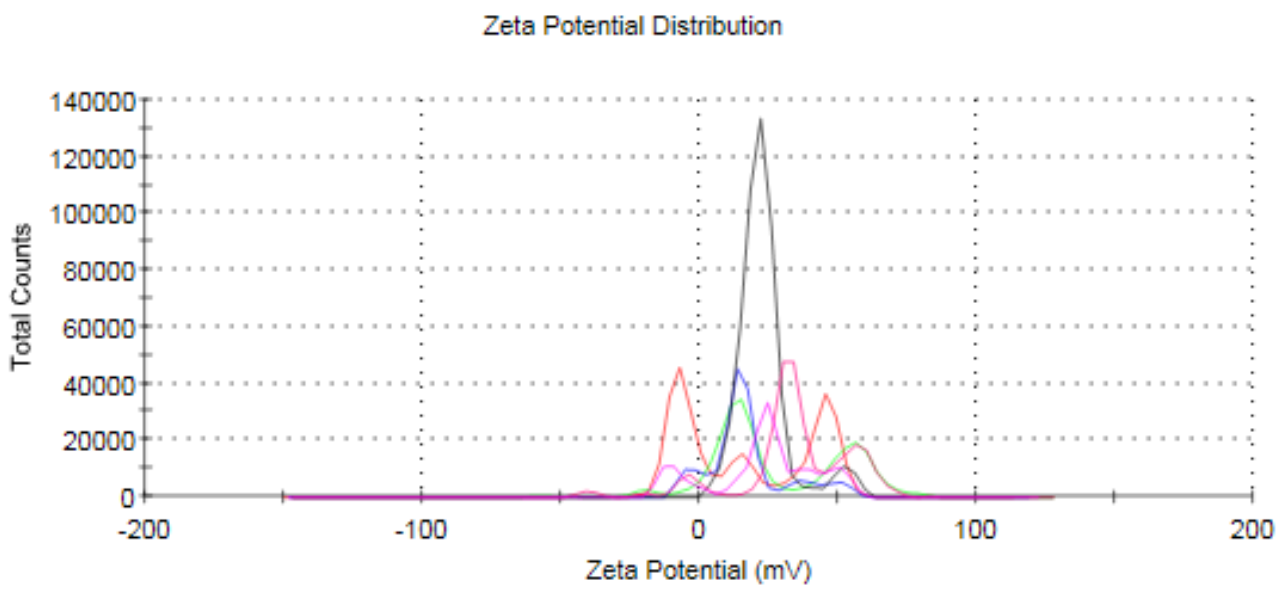

Figure 4.6. Zeta potential of $\mathbf{P 2}$

\subsubsection{Toxicity Assay.}

HeLa cells (ca. 10000 cells per well) in $200 \mu \mathrm{L}$ of complete medium were seeded into a 96-well plate and cultured for one day in a $5 \% \mathrm{CO}_{2}$ incubator at $37{ }^{\circ} \mathrm{C}$. CPNs with various concentrations ( 1 to $40 \mu \mathrm{M}$ ) were added and incubated for $24 \mathrm{~h}$. To measure toxicity, $10 \mu \mathrm{L}$ of MTT solution $\left(5 \mathrm{mg} \mathrm{mL}^{-1}\right.$ in PBS) and $90 \mu \mathrm{L}$ of complete medium were then added into each well, and the plate was further incubated for $4 \mathrm{~h}$ at $37^{\circ} \mathrm{C}$. After formed MTT formazan crystals were dissolved in dimethyl sulfoxide (100 $\mu \mathrm{L})$, the 
absorbance intensity measured by a microplate well reader (infinite M1000 PRO, TECAN, Switzerland) at $540 \mathrm{~nm}$. Relative cell viability (\%) as a function of CPN concentration was expressed as a percentage relative to the untreated control cells All measurements were triplicated and standard deviation was included in the error bar.

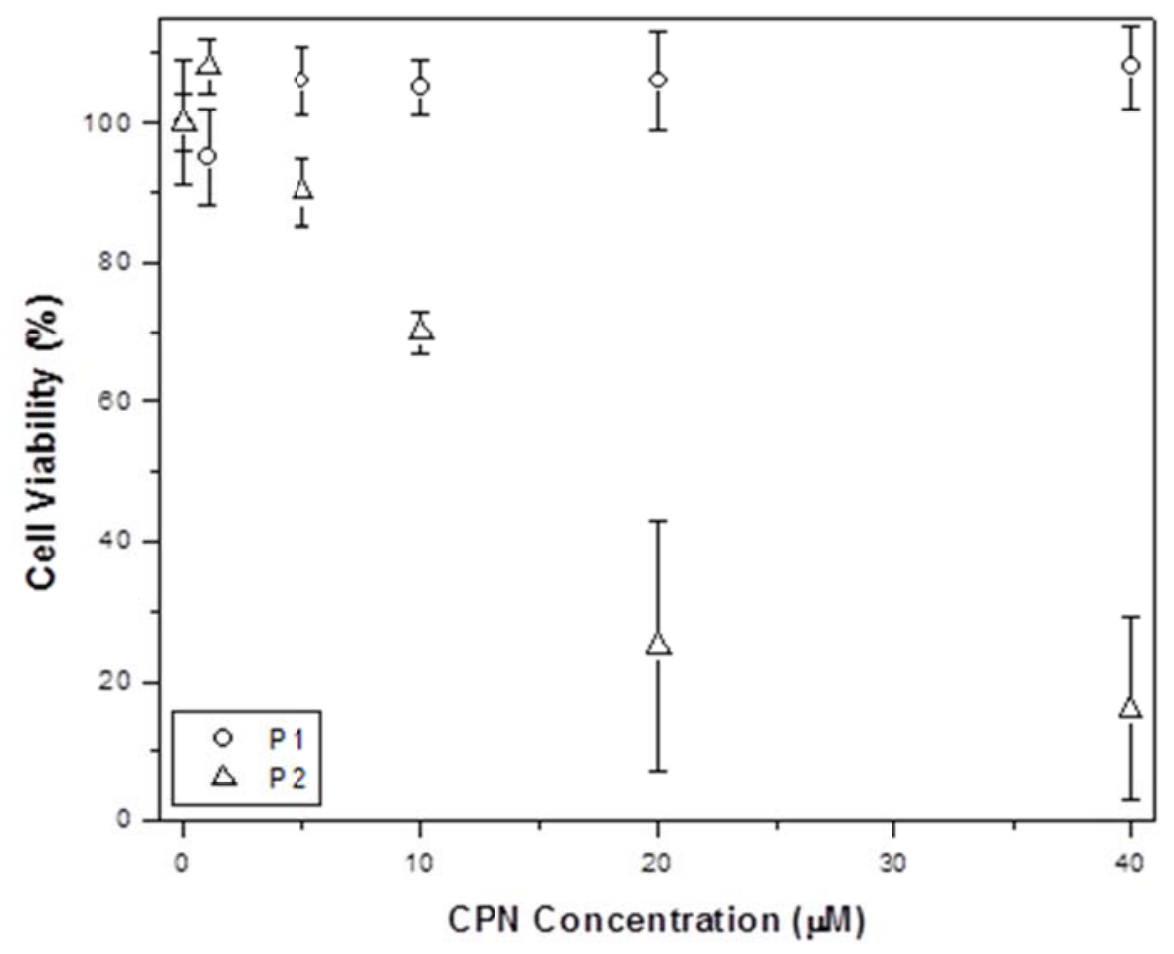

Figure 4.7. Cellular toxicity of $\mathbf{C P N}-1$ and $\mathbf{C P N}-2$

\subsubsection{Light scattering measurements of CPN-1 and CPN-2.}

Nanoparticle tracking analysis (NTA) were performed with a LM10 HS (NanoSight, Amesbury, United Kingdom), equipped with a sCMOS camera, sample chamber with a $488 \mathrm{~nm}$ blue laser, and Viton fluoroelastomer o-ring. The samples were prepared in 
similar manner for absorption and emission measurements using $10 \%$ methanol (v/v) in water $(18 \Omega$ ) filtered through $0.45 \mu \mathrm{m}$ polytetrafluoroethylene (PTFE) syringe filters. The samples were injected into the sample chamber with $1 \mathrm{~mL}$ sterile syringes (Restek Corporation, Pennsylvania, USA) until the liquid reached the tip of the nozzle. All measurements were performed at $25^{\circ} \mathrm{C}$ using a $\mathrm{LM} 14 \mathrm{C}$ temperature controller (NanoSight, Amesbury, United Kingdom). Each sample was measured three times.

\subsubsection{Cell Culture.}

\section{General.}

HeLa cells (human cervical cancer, purchased from ATCC), seeded into a $100 \times 20 \mathrm{~mm}$ style sterile tissue culture dish (\#353003 BD Falcon, Durham, NC, USA), cultured in minimum essential medium (MEM)/Earle's balanced salt solution (EBSS) (400 $\mu \mathrm{L}$, HyClone, SH30024) medium containing 10\% fetal bovine serum (FBS) and $100 \mathrm{U} / \mathrm{m}$ penicillin for $24 \mathrm{~h}$ under $5 \% \mathrm{CO}_{2}$ at $37^{\circ} \mathrm{C}$, and subcultured every 48 hours. pHRhodo Dextran 10kDa (\#P10361 Molecular probes, Life technologies, New York, USA) and BODIPY-TR C5 -ceramide-BSA complex (\#B34400 Molecular probes, Life technologies, New York, USA) were used for endosome and Golgi apparatus staining, respectively.

\subsubsection{Microscopic Imaging.}

10,000 HeLa cells were seeded into a glass-bottomed eight-well chamber slide (Lab-Tek Thermo Scientific) and cultured in a minimum essential medium (MEM)/Earle's balanced salt solution (EBSS) $(400 \mu \mathrm{L})$ medium containing $10 \%$ fetal bovine serum 
(FBS) and $100 \mathrm{U} / \mathrm{m}$ penicillin for $24 \mathrm{~h}$ under $5 \% \mathrm{CO}_{2}$ at $37{ }^{\circ} \mathrm{C} .80 \mu \mathrm{L}$ of $20 \mu \mathrm{M}$ CPNs in water was added to the culture medium directly, and the cells were further cultured overnight (final CPN concentration: $4 \mu \mathrm{M}$ ). For endosome staining, pHRhodo Dextran $10 \mathrm{kDa}(5 \mu \mathrm{M})$ was incubated for $30 \mathrm{~min}$ at $37^{\circ} \mathrm{C}$. For Golgi apparatus staining, BODIPYTR C5 -ceramide-BSA complex (final $10 \mu \mathrm{M}$ ) was incubated for $30 \mathrm{~min}$ at $4{ }^{\circ} \mathrm{C}$. After washing with fresh medium, the cells were further incubated for 30 min at $37^{\circ} \mathrm{C}$. A $1 \mu \mathrm{L}$ aliquot of Hoechst $(5 \mu \mathrm{g} / \mathrm{mL})$ was added to the culture medium and incubated with the cells for 10 min at $37^{\circ} \mathrm{C}$, and washed two times with phosphate buffered saline (PBS). The cells were fixed with $4 \%$ paraformaldehyde for 10 min. Fluorescent images of the cells were obtained using a DeltaVision Elite Microscope System (Applied Precision, Issaquah, Washington, USA) equipped with bandpass filters such as blue $(410-460 \mathrm{~nm}$, Hoechst), green (500-550 nm, CPNs), and red (595-635 nm, Golgi and endosome). Top and bottom of the chosen cells was identified, and a Z-stack plot was imaged for each channel.

\subsubsection{Colocalization study.}

Z-stack microscope images of each sample was obtained as described above. Colocalization analysis was conducted for three independent cells per polymer and per organelle (Golgi apparatus and endosome). Colocalization analysis was conducted using the microscope software (Softworx 5.0 application, Applied Precision, Issaquah, Washington, USA). Region of interest (ROI) was selected to contain all of the cell. Pearsons Correlation Coefficient (PCC) was used to determine colocalization. Negative control of colocalization was performed by analysis of blue and green channels staining 
the nucleus and CPN, respectively. Three independent images of an entire cell were selected and analysed to increase the analysis objectivity.

4.7. References

1. D. C. Wallace, in Annual Review of Genetics, Annual Reviews, 2005, vol. 39, pp. 359-407.

2. C. Fleury, M. Neverova, S. Collins, S. Raimbault, O. Champigny, C. LeviMeyrueis, F. Bouillaud, M. F. Seldin, R. S. Surwit, D. Ricquier and C. H. Warden, Nature Genet., 1997, 15, 269-272.

3. D. E. Kelley, J. He, E. V. Menshikova and V. B. Ritov, Diabetes, 2002, 51, 29442950.

4. V. Carelli, F. N. Ross-Cisneros and A. A. Sadun, Prog. Retin. Eye Res., 2004, 23, 53-89.

5. K. Hirai, G. Aliev, A. Nunomura, H. Fujioka, R. L. Russell, C. S. Atwood, A. B. Johnson, Y. Kress, H. V. Vinters, M. Tabaton, S. Shimohama, A. D. Cash, S. L. Siedlak, P. L. R. Harris, P. K. Jones, R. B. Petersen, G. Perry and M. A. Smith, J. Neurosci., 2001, 21, 3017-3023.

6. S. Fulda, L. Galluzzi and G. Kroemer, Nat Rev Drug Discov, 2003, 9, 447-464.

7. M. P. Murphy, Biochimica et Biophysica Acta (BBA) - Bioenergetics, 2008, 1777, 1028-1031.

8. G. R. Chamberlain, D. V. Tulumello and S. O. Kelley, ACS Chemical Biology, 8, 1389-1395.

9. S. Rin Jean, D. V. Tulumello, S. P. Wisnovsky, E. K. Lei, M. P. Pereira and S. O. Kelley, ACS Chemical Biology, 9, 323-333.

10. I. B. Kim, H. Shin, A. J. Garcia and U. H. F. Bunz, Bioconjugate Chem., 2007, $18,815-820$.

11. X. L. Feng, Y. L. Tang, X. R. Duan, L. B. Liu and S. Wang, J. Mater. Chem., 2010, 20, 1312-1316.

12. K. Lee, J. Lee, E. J. Jeong, A. Kronk, K. S. J. Elenitoba-Johnson, M. S. Lim and J. Kim, Adv. Mater., 2012, 24, 2479-2484.

13. C. F. Wu and D. T. Chiu, Angew. Chem. Int. Ed., 2013, 52, 3086-3109. 
14. M. D. Disney, J. Zheng, T. M. Swager and P. H. Seeberger, J. Am. Chem. Soc., 2004, 126, 13343-13346.

15. C. H. Fan, S. Wang, J. W. Hong, G. C. Bazan, K. W. Plaxco and A. J. Heeger, Proc. Natl. Acad. Sci. USA, 2003, 100, 6297-6301.

16. H. A. Ho, K. Dore, M. Boissinot, M. G. Bergeron, R. M. Tanguay, D. Boudreau and M. Leclerc, J. Am. Chem. Soc., 2005, 127, 12673-12676.

17. K. E. Achyuthan, T. S. Bergstedt, L. Chen, R. M. Jones, S. Kumaraswamy, S. A. Kushon, K. D. Ley, L. Lu, D. McBranch, H. Mukundan, F. Rininsland, X. Shi, W. Xia and D. G. Whitten, J. Mater. Chem., 2005, 15, 2648-2656.

18. C. J. Sun, B. S. Gaylord, J. W. Hong, B. Liu and G. C. Bazan, Nat. Protoc., 2007, 2, 2148-2151.

19. B. Liu and G. C. Bazan, Chem. Mater., 2004, 16, 4467-4476.

20. J. H. Moon, E. Mendez, Y. Kim and A. Kaur, Chem. Commun., 2011, 47, 83708372 .

21. A. T. Silva, N. Alien, C. M. Ye, J. Verchot and J. H. Moon, BMCPlant Biol., 2010, 10, 291.

22. X. L. Feng, F. T. Lv, L. B. Liu, Q. Yang, S. Wang and G. C. Bazan, Adv. Mater., 2012, 24, 5428-5432.

23. R. Duncan and S. C. W. Richardson, Mol. Pharm., 2012, 9, 2380-2402.

24. G. Sahay, D. Y. Alakhova and A. V. Kabanov, J. Controlled Release, 2010, 145, 182-195.

25. J. Rejman, A. Bragonzi and M. Conese, Mol. Ther., 2005, 12, 468-474.

26. J. Callahan and J. i. Kopë̈ ek, Biomacromolecules, 2006, 7, 2347-2356.

27. M. Breunig, S. Bauer and A. Goepferich, European Journal of Pharmaceutics and Biopharmaceutics, 2008, 68, 112-128.

28. S. Biswas and V. P. Torchilin, in Cancer nanotechnology, vol. 66, pp. 26-41.

29. J. Lee, M. Twomey, C. Machado, G. Gomez, M. Doshi, A. J. Gesquiere and J. H. Moon, Macromolecular bioscience, 13, 913-920.

30. L. Kou, J. Sun, Y. Zhai and Z. He, vol. 8, pp. 1-10. 
31. I. A. Khalil, K. Kogure, S. Futaki and H. Harashima, J. Biol. Chem., 2006, 281, 3544-3551.

32. L. Pelkmans and A. Helenius, Traffic, 2002, 3, 311-320.

33. Phillips, R. L.; Kim, I. K.; Tolbert, L. M.; Bunz, U. H. F. J. Am. Chem. Soc. 2008, 130 , 6952-6954.

34. Xue, C.; Donuru, V. R. R.; Liu, H. Macromolecules 2006, 39, 5747-5752.

35. Moon, J. H.; McDaniel, W.; MacLean, P.; Hancock, L. F. Angew. Chem. Int. Ed.; 2007, 46, 8223-8225. 
CHAPTER V

CONTROLLED INCORPORATION OF

HOMO-COUPLED BENZOTHIADIAZOLE TO THE

CONJUGATED BACKBONE 


\subsection{Abstract}

We successfully controlled the incorporation of homo-coupled benzothiadiazole(HBT) blocks onto the conjugated polymer nanoparticle (CPN). This was achieved by employing competing polymerization conditions between the cross (i.e., Sonogashira) and homo-coupling reactions. Using these conditions we were able to synthesize a suite of polymers such as BT-containing poly-parapheneylene ethynelene (BTPEs), HBTcontaining PPE (HBT-PE), and BTPE-containing poly-parapheneylene butadiyene (BTPE-PPB), exhibiting a range of emissions. This advancement can result in the synthesis of new and exciting red-emissive polymers for tissue labeling and cellular sensing.

\subsection{Introduction}

Conjugated polymer nanoparticles (CPNs) are promising fluorescent biomaterials exhibiting high brightness and efficient energy transfer making them suitable for cellular labelling and sensing applications. ${ }^{1}$ Various chemosensors have been reported that take advantage of the unique signal amplification or superquenching as the fluorescent CPN interacts with analytes of interest. ${ }^{2}$ Because of their conjugated nature, any interaction occurring along the polymeric backbone will result in the perturbation of the electron transport properties of the conjugated system affects the entire assembly. Additionally, CPNs exhibit aggregation based absorbance and emission changes, making CPN-based molecular probes sensitive even minor perturbations upon analyte-polymer interactions and binding. ${ }^{3}$ Therefore, a multitude of analyte-CPN interactions will result in large signal amplification due to the collective features of the CP. ${ }^{4}$ 
For biological applications, synthesis of CPs exhibiting red emission is highly desirable as the sensitivity of any in vivo measurements and optical imaging is enhanced due to minimal autofluorescence from biological tissues at this range CPs that have incorporated electron donating and accepting moieties onto the conjugated backbone have been shown to effectively modulate the CP's electronic properties resulting in red shifted emissions. ${ }^{5}$ As an electron-accepting moiety, 2,1,3-Benzothiadiazole (BT) has been used in various oligomers and polymers, exhibiting orange to red emission, with higher incorporation of the BT units into the CP backbone improving absorption, thermal stability, electrochemical and charge transport properties of the resulting copolymers. ${ }^{6}$ Among BT-containing CPs, materials containing homo-coupled benzothiadiazole (HBT) segments in the conjugated backbone have been shown to further improve the materials optical and electronic properties. ${ }^{7}$ Despite these favorable properties, there have been few reports on the use of HBT-containing materials due to a lack of an efficient method for their synthesis. Most reports of HBT synthesize include time- and step-intensive methods involving the synthesis of $7,7^{\prime}$-dibromo-4,4'-bibenzo[c] $[1,2,5]$ thiadiazole which is then polymerized. ${ }^{8-9}$ However, copper-catalyzed oxidative addition under strong basic conditions has also been reported for HBT synthesis. ${ }^{10}$

Recently, we reported the synthesis of flexible poly(p-phenylenebutadiynylene)s (PPBs) using competing Sonogashira and Glaser coupling conditions, and taking advantage of the differences in monomer reactivity to incorporate a small amount $(\sim 10 \%)$ of flexible, non-conjugated linkers into the backbone. ${ }^{11}$ The reaction conditions provide limited control over the proportion of flexible monomer incorporation, effectively affording 
phenylene-ethynylene(PE)-doped PPBs. We hypothesized that by using competing Sonogashira and benzothiadiazole homo-coupling conditions, we could easily synthesize HBT-containing PPEs.

Here we report a one-pot method for the controlled incorporation of HBT blocks onto the $\mathrm{CP}$ backbone. Using commercially available $\mathrm{BT}$ monomers, we were able to synthesize HBT-containing CPs without employing the time- and step-intensive methods usually employed to afford these polymers. Using this one-pot method, we successfully synthesized a suite of polymers such as BT-containing poly-parapheneylene ethynelene (BTPEs), HBT-containing PPE (HBT-PE), and BTPE-containing poly-parapheneylene butadiyene (BTPE-PPB), exhibiting a range of emissions.

\subsection{Results and Discussion}

It was hypothesized that high copper content and increased base strength would facilitate HBT incorporation during the polymerization process. This is because HBT synthesis has been reported via copper-catalyzed oxidative addition under strong basic conditions, the modified coupling conditions. To create a competing environment between the cross (i.e., Sonogashira) and homo-coupling of the monomers, varying amounts of copper (5\% or 95\% molar equivalents) catalyst and organic bases of increasing base strength (TEA $>$ morpholine $>$ Pyridine $>\mathrm{K}_{2} \mathrm{CO}_{3}$ ) were employed. The reactions were carried out in a nitrogen environment at $60^{\circ} \mathrm{C}$ in overnight using dimethylformamide as the 
Scheme 5.1. Synthesis of HBT-BTPE and BTPE polymers
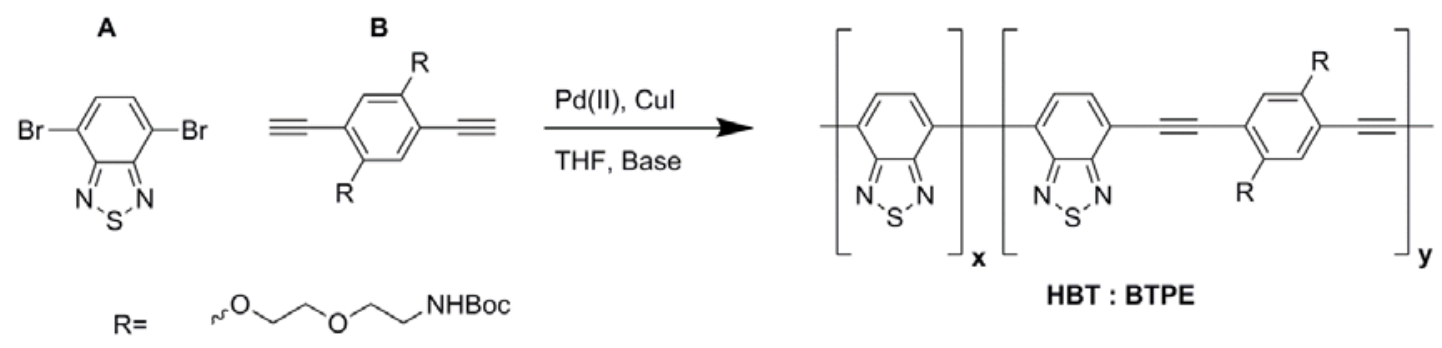

Table 5.1. . List of polymer chemical structures at various reaction conditions

\begin{tabular}{cccccc}
\hline Polymer & CuI & Pd(II) & Base & $\mathbf{x}^{\mathbf{a}}$ & $\mathbf{y}^{\mathbf{a}}$ \\
\hline P1 & $5 \%$ & $5 \%$ & TEA & 0 & 1 \\
P2 & $5 \%$ & $5 \%$ & Morpholine & 0.12 & 1 \\
P3 & $5 \%$ & $5 \%$ & Pyridine & 0.4 & 1 \\
P4 & $5 \%$ & $5 \%$ & $\mathrm{~K}_{2} \mathrm{CO}_{3}$ & 0.7 & 1 \\
P5 & $95 \%$ & $5 \%$ & TEA & 0.4 & 1 \\
P6 & $95 \%$ & $5 \%$ & Morpholine $^{2}$ & 0.8 & 1 \\
P7 & $95 \%$ & $5 \%$ & Pyridine $_{2}$ & 1.4 & 1 \\
P8 & $95 \%$ & $5 \%$ & $\mathrm{~K}_{2} \mathrm{CO}_{3}$ & 2.4 & 1 \\
P9 & $2 \mathrm{eq}$ & $5 \%$ & $\mathrm{~K}_{2} \mathrm{CO}_{3}$ & 2.4 & 1 \\
\hline
\end{tabular}

${ }^{\mathrm{a}}$ Determined by ${ }^{1} \mathrm{H}$ NMR peak integration.

polymerization solvent, as outlined in Scheme 5.1. A series of polymers were prepared under these modified palladium/copper/base conditions as listed in Table 5.1.

The chemical structure of the resulting polymers was assessed by ${ }^{1} \mathrm{H}$ NMR spectroscopy. An example of the quantitative assessment of the presence HBT segments is illustrated 
on the structure of polymer P4 (Figure 5.1). The ${ }^{1} \mathrm{H}$ NMR spectrum clearly exhibits three distinct aromatic peaks at 7.95, 7.30, and $6.74 \mathrm{ppm}$ corresponding to HBT, BT, and PE aromatic peaks, respectively. 2-dimensional NMR confirms that peak the peaks at 7.95 and $7.30 \mathrm{ppm}$ are both from a BT moiety. The integration ratio between the HBT (7.95ppm) and PE (6.74ppm) peaks indicates that the incorporation of the HBT-segments to the conjugated backbone was approximate $66 \%$. Figure 5.2 demonstrated the increasing incorporation of HBT onto the conjugated backbone as demonstrated by the increasing size of the HBT aromatic peak increases as a function of base strength and copper catalyst loading. Full NMR spectra for all polymers are included in the Experimental Section.

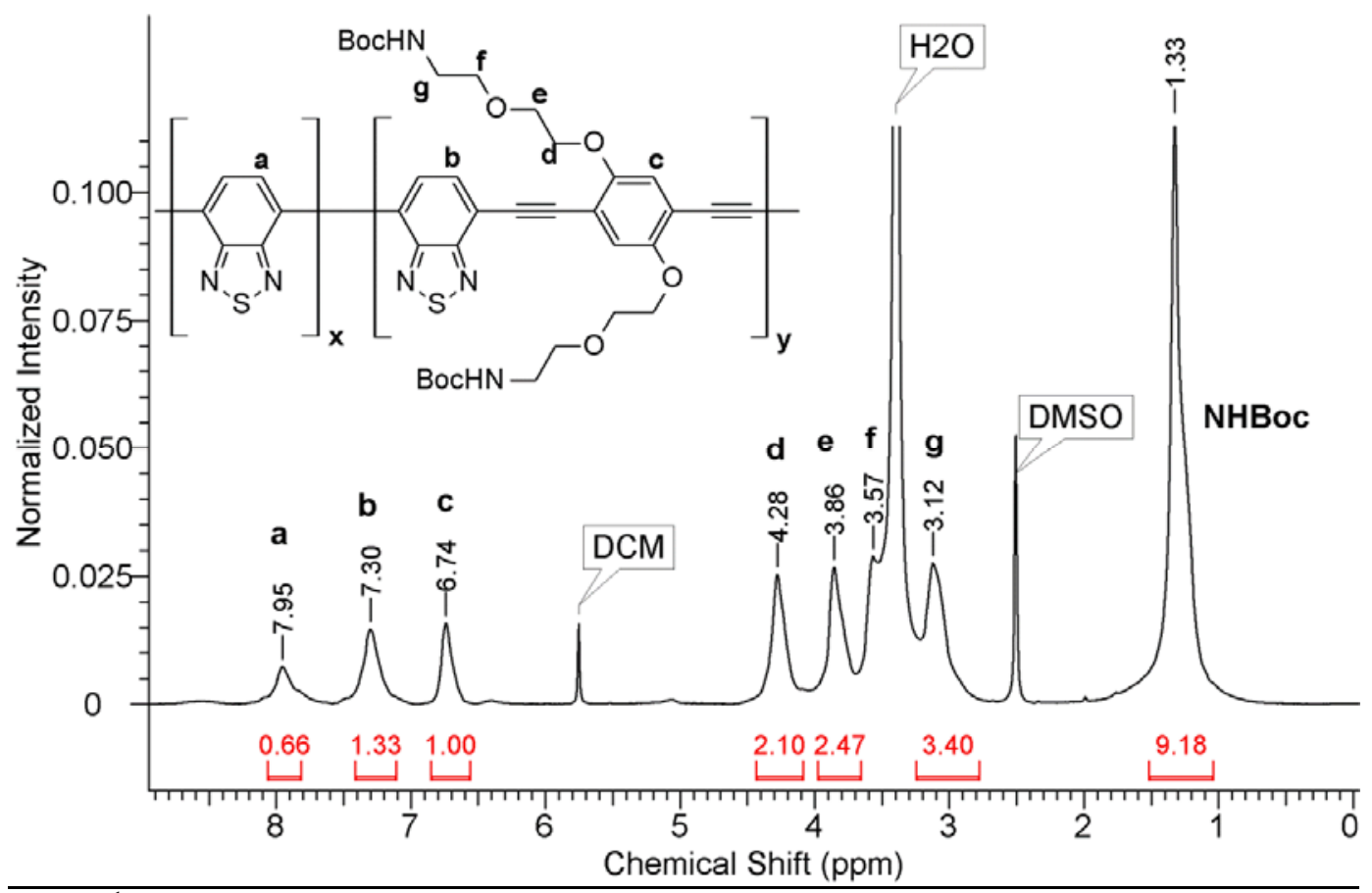

Figure 5.1. ${ }^{1} \mathrm{H}-\mathrm{NMR}$ for polymer $\mathbf{P 4}$ in $\mathrm{DMSO}^{\mathrm{d}} \mathrm{d}_{6}$ 

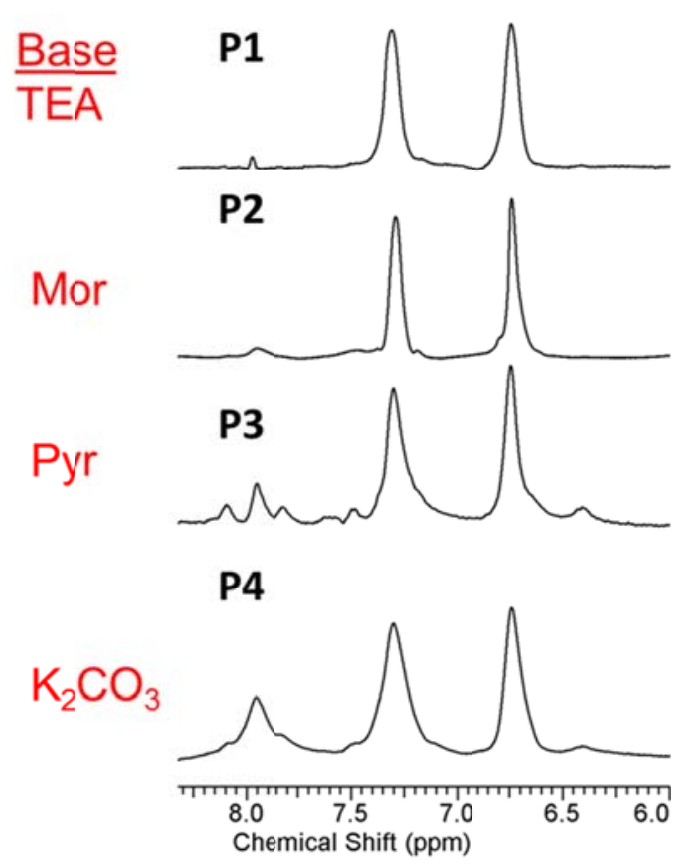

$5 \% \mathrm{Cul}$
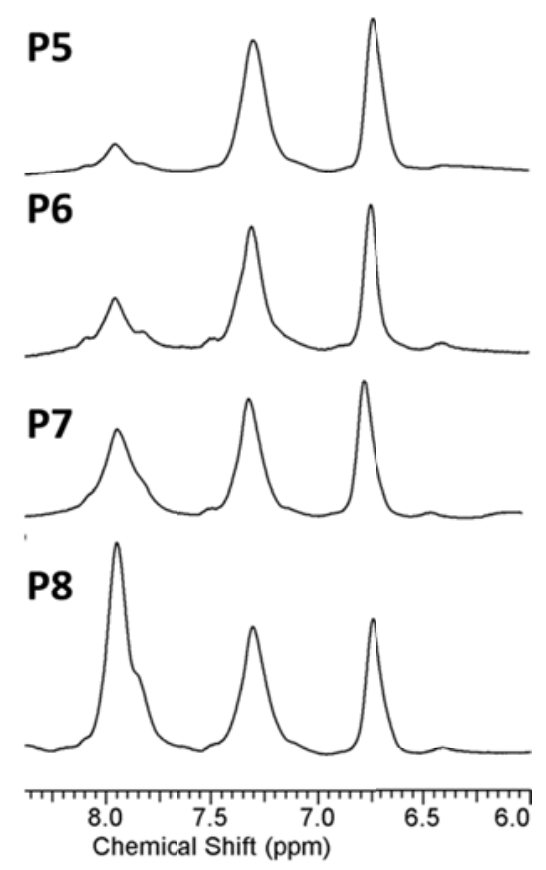

$95 \%$ Cul

Figure 5.2. ${ }^{1} \mathrm{H}-\mathrm{NMR}$ aromatic regions for polymer P1-P8

Although increased copper catalyst conditions will heavily favor formation of PPB segments onto the conjugated backbone, no such incorporation was observed for polymer P1-P8. An integration ratio of greater than 1 between BT (7.30ppm) and PE (6.74ppm) peaks would signal formation of PPB segments. We hypothesize that the activated nature of the BT monomer enhances BT-PE formation, thereby reducing PPB formation. To test this hypothesis, two more polymers, P10 and P11, were synthesized under increased palladium and copper catalyst to facilitate PPB formation. We expected enhanced PPB under these conditions given that Glaser-coupling is the result of palladium-assisted copper catalysis, and BT-homocoupling the result of increased copper and base. ${ }^{13-14}$ 

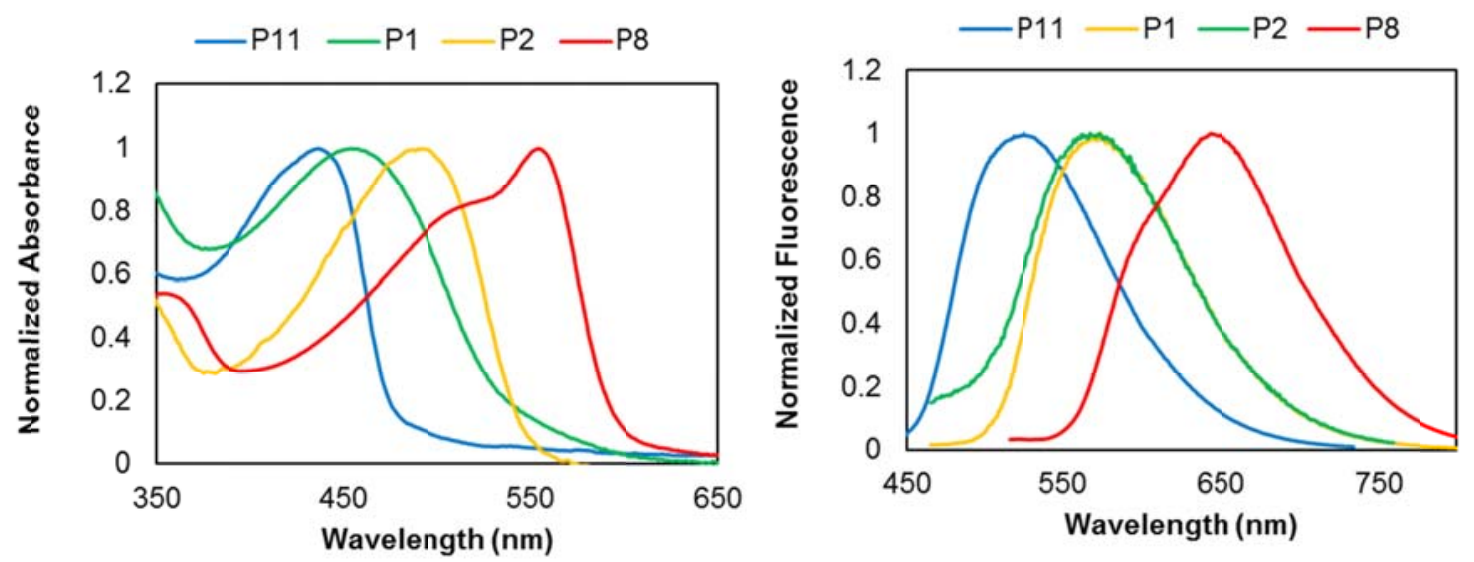

Figure 5.3. A) Absorbance and B) emission spectra for selected polymers. As HBT incorporation increases, materials experience absorbance and emission red-shifts. P11 (BTPE-PPB), containing no HBT segments shows most blue shifted absorbance and emission profiles.

Indeed, under these conditions, PPB formation was observed; spectra and details are in the experimental section.

The absorption and emission spectra of BTPE and HBT were also representative of increased BT incorporation. As BT incorporation increased, polymer absorbance and emission was further red shifted. Similarly, control polymers such as PPB-BTPE copolymer P11, exhibited the expected blue shift due to the lack of HBT segments. Selected absorbance and emission spectra are highlighted in figure 5.3.

Because the stoichiometric balance needed for Sonogashira coupling is broken as HBTincorporation increases, the resulting molecular weights and yields are expected to decrease. Molecular weights, solubility, and reaction yields were consistent with the breaking of stoichiometric balance, physical properties of polymers P1-P8 are listed in table 5.2. 
Table 5.2. Physical and optical properties

\begin{tabular}{cccccc}
\hline Polymer & Yield (\%) & $\begin{array}{c}\mathbf{M}_{\mathbf{n}} \\
(\mathbf{k D a})^{\mathbf{a}}\end{array}$ & PDI $^{\mathbf{b}}$ & $\begin{array}{c}\text { Abs } \\
\lambda \mathbf{m a x} \\
(\mathbf{n m})^{\mathbf{c}}\end{array}$ & $\begin{array}{c}\mathbf{E m} \\
\boldsymbol{\lambda} \mathbf{m a x} \\
(\mathbf{n m})^{\mathbf{e}}\end{array}$ \\
\hline P1 & 65 & 13.5 & 1.69 & 454 & 571 \\
P2 & 71 & 10.3 & 1.95 & 497 & 595 \\
P3 & 40 & 12.4 & 1.76 & 502 & 633 \\
P4 & 48 & 12.7 & 1.75 & 494,553 & 620 \\
P5 & 67 & 14.5 & 1.89 & 500,551 & 621 \\
P6 & 54 & 8.52 & 1.92 & 551 & 640 \\
P7 & 62 & 14.5 & 1.89 & 553 & 646 \\
P8 & 57 & 8.52 & 1.92 & 552 & 651
\end{tabular}

${ }^{a}$ Determined by gel permeation chromatography in THF. ${ }^{b} \mathrm{PDI}$ (polydispersity index) $=\mathrm{Mw} / \mathrm{Mn}$. ${ }^{\mathrm{c}} \mathrm{Measured}$ in ACN. ${ }^{d} \mathrm{P} 1, \mathrm{P} 2, \mathrm{P} 3$ excitation wavelength $450 \mathrm{~nm}, \mathrm{P} 4-\mathrm{P} 8$ excitation wavelength $500 \mathrm{~nm}$ in ACN.

\subsection{Conclusion}

In conclusion, by creating a competing environment between the cross (i.e., Sonogashira) and homo-coupling of the monomers, we were able to synthesize HBT-containing CPs without employing the time- and step-intensive methods usually employed to afford these polymers. Additionally, we successfully synthesized a suite of polymers such as BTcontaining poly-parapheneylene ethynelene (BTPEs), HBT-containing PPE (HBT-PE), and BTPE-containing poly-parapheneylene butadiyene (BTPE-PPB), exhibiting a range of emissions. This advancement can result in the synthesis of new and exciting redemissive polymers for tissue labeling and cellular sensing. 


\subsection{Outlook}

Since the writing of this chapter, bisbenzothiadiazole (BBT) monomer was synthesized to confirm the identity of the BBT moiety being generated in situ and incorporated onto the conjugated backbone. The monomer was then used to generate a bisbenzothidiazolephenylene ethynylene copolymer, exhibiting the 7.95 and $6.73 \mathrm{ppm}$ peaks for the characteristic BBT and PE aromatic protons, respesctively, see Figure 5.4.

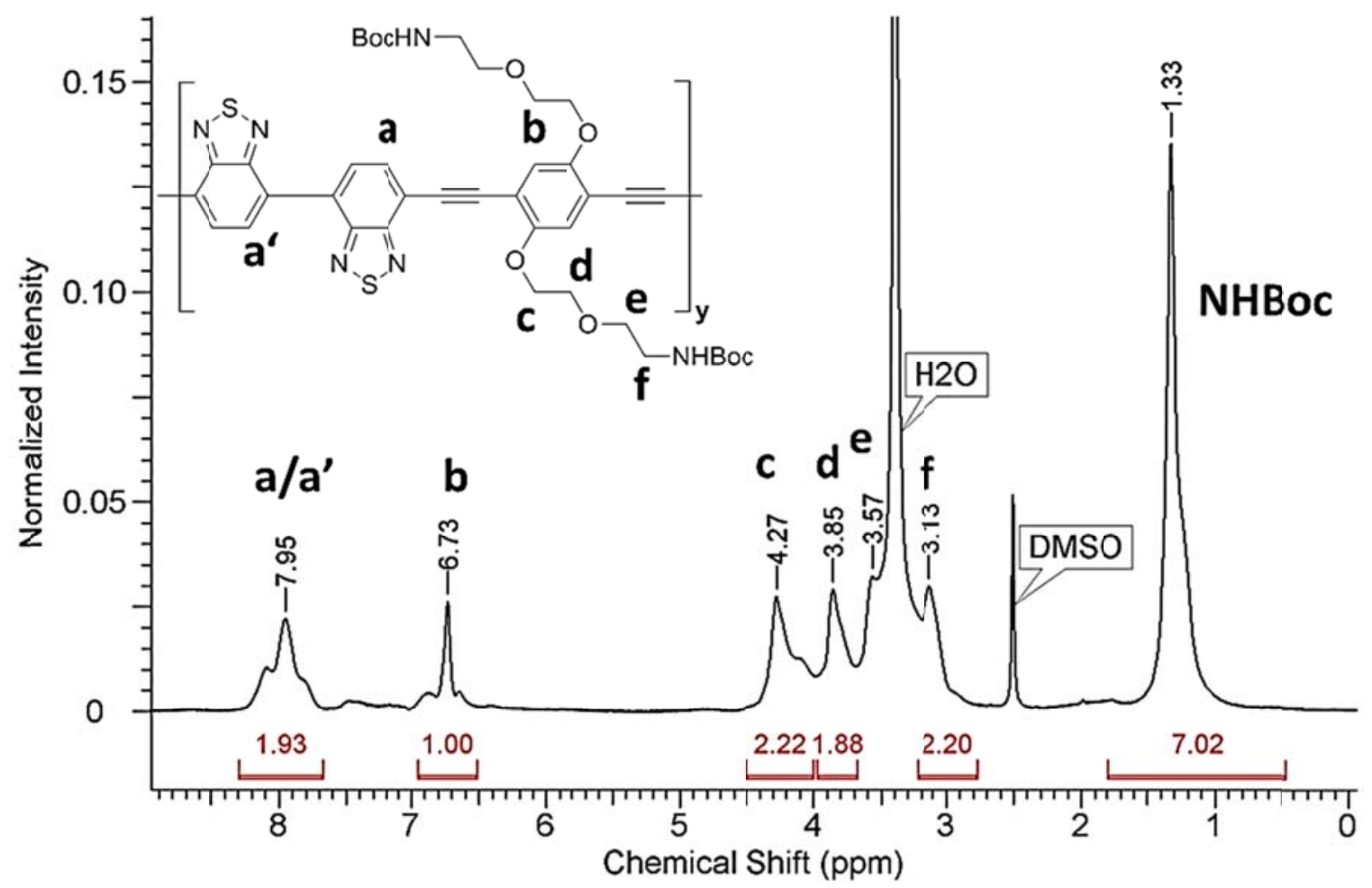

Figure 5.4. ${ }^{1} \mathrm{H}-\mathrm{NMR}$ for polymer BBT-containing polymer in $\mathrm{DMSO}-\mathrm{d}_{6}$

Inspired by the recent works by Maisonneuve ${ }^{15}$ and Bunz ${ }^{16}$, polymer P8 was screened as a molecular sensor for the analytical detection of environmentally and biologically relevant metal ions; the polymer exhibited remarkable quenching sensitivity towards 
molecular tin (Sn). Interestingly, as HBT-incorporation increased, tin sensitivity exponentially increased, with polymers P7 and P8 exhibiting low nanomolar and high picomolar sensitivity, respectively. Among the different metal ions, tin, has been established to be an essential trace element for some animals. Although tin is not easily absorbed by animals and humans, tin deficiency has been linked with poor growth, hearing loss, and increased cancer risk. Acute tin toxicity has been shown to affect iron and copper metabolism by interfering with heme and cytochrome P450. Because the role tin plays in biochemical processes at the cellular level remains largely unknown, there is great importance is attached to developing sensitive tin-specific chemosensors. In recent years, significant emphasis has been placed on the development of new, highly selective fluorescent chemosensors of different architectures for metal cations because of their potential applications in biochemistry and environmental research. Owing to their excellent photophysical and biophysical properties, CPNs are rapidly emerging as an exciting fluorescent platform for sensitive biological sensing.

\subsection{Experimental Section}

5.5.1. General Data. Chemicals, including solvents, were purchased from Fisher Scientific and used as received. Deuterated solvents were purchased from Cambridge Isotope Laboratories (Cambridge,MA). UV-vis spectra were recorded using a Varian Cary 50 Bio spectrophotometer. Fluorescence spectra were obtained using a FluoroLog-3 Spectrofluorometer (Jobin Yvon/ Horiba). 9,10-diphenylanthracene (QY = 1.0) in cyclohexane was used as a fluorescence standard for QY determination. The average molecular weight $(\mathrm{Mn})$ and polydispersity index $\left(\mathrm{PDI}=\mathrm{M}_{\mathrm{w}} / \mathrm{M}_{\mathrm{n}}\right)$ of the polymers were 
determined by gel permeation chromatography (GPC) against polystyrene standards using a Shimadzu high performance liquid chromatography (HPLC) system fitted with PLgel $5 \mu \mathrm{m}$ MIXED-D columns and SPD-20A ultraviolet- visible (UV-vis) detector. Nuclear magnetic resonance (NMR) spectra were recorded on a $400 \mathrm{MHz}$ and $600 \mathrm{MHz}$ Avance Bruker NMR spectrometer. Chemical shifts were reported in parts per million (ppm) for ${ }^{1} \mathrm{H}-\mathrm{NMR}$ on the $\delta$ scale based on the middle peak $(\delta=2.50 \mathrm{ppm})$ of the dimethyl sulfoxide (DMSO)- $\mathrm{d}_{6}$ solvent as an internal standard. Solutions of Tables and graphs were plotted using Origin 8 software (OriginLab, Northampton, MA, USA).

\subsubsection{Polymer Synthesis.}

General Procedure. A Schlenk flask was charged with aryl halide monomer A (1.0 eqiv) and diactylene monomer $\mathbf{B}$ (1.0 equiv), along with $\mathrm{Pd}\left[\left(\mathrm{PPh}_{3}\right)_{2} \mathrm{Cl}_{2}\right](0.1$ equiv) and $\mathrm{CuI}$ ( 0.05 or 0.95 equiv). The Schlenk flask was evacuated and filled with $\mathrm{N}_{2}$ three times. A solution of anhydrous dimethylformamide (DMF) (4 mL) and freshly distilled trimethylamine $(1 \mathrm{~mL})$ was degassed, and $1 \mathrm{~mL}$ of the mixed solution was transferred to the Schlenk flask using a cannular needle. The reaction was heated at $70{ }^{\circ} \mathrm{C}$ for $14 \mathrm{~h}$. The solution was then cooled to room temperature and transferred dropwise to cold methanol, resulting in precipitation. After centrifugation ( $2 \mathrm{~min}, 4000 \mathrm{rpm}$ ), the supernatant was decanted, and the precipitate was redissolved in $\operatorname{DCM}(1 \mathrm{~mL})$ for and precipitated two more times for purification. The resulting precipitate was then dried under high vacuum for 2 days, weighed and characterized. 
Scheme 5.2. Generalized scheme for BTPE-PPB formation

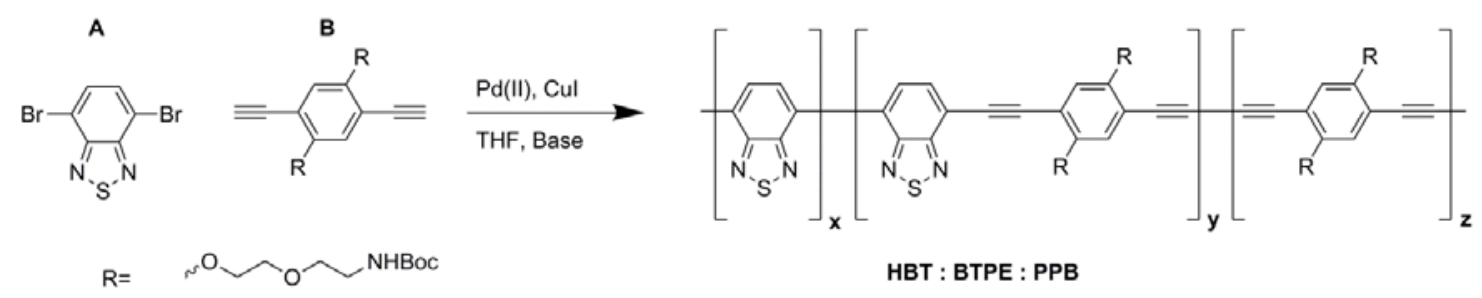

Table 5.3. Chemical properties of $\mathrm{P} 8, \mathrm{P} 10$, and $\mathrm{P} 11$

\begin{tabular}{ccccccc} 
Polymer & CuI & Pd(II) & Base & $\mathbf{x}$ & $\mathbf{y}$ & $\mathbf{z}$ \\
\hline P8 & $95 \%$ & $5 \%$ & $\mathrm{~K}_{2} \mathrm{CO}_{3}$ & 1.2 & 1 & 0 \\
P10 & $95 \%$ & $10 \%$ & $\mathrm{~K}_{2} \mathrm{CO}_{3}$ & 0.15 & 1 & 0.45 \\
P11 & $95 \%$ & $20 \%$ & $\mathrm{~K}_{2} \mathrm{CO}_{3}$ & 0 & 1 & 2.1
\end{tabular}

Table 5.4. Physical and optical properties of $\mathrm{P} 8, \mathrm{P} 10$, and $\mathrm{P} 11$

\begin{tabular}{|c|c|c|c|c|c|c|c|c|}
\hline Polymer & $\mathrm{Cul}$ & Pd(II) & Base & $\begin{array}{c}\text { Yield } \\
(\%)\end{array}$ & $\begin{array}{c}\mathbf{M}_{\mathbf{n}} \\
(\mathrm{kDa})\end{array}$ & PDI & $\begin{array}{c}\text { Abs } \\
\lambda \mathbf{m a x} \\
(\mathbf{n m})\end{array}$ & $\begin{array}{c}\text { Em } \\
\lambda \max \\
(\mathbf{n m})\end{array}$ \\
\hline
\end{tabular}

\begin{tabular}{cccccccccc}
\hline P9 & 2 eq & $5 \%$ & $\mathrm{~K}_{2} \mathrm{CO}_{3}$ & 37 & 13.5 & 1.97 & 540 & 671 & 5.0 \\
P10 & $95 \%$ & $10 \%$ & $\mathrm{~K}_{2} \mathrm{CO}_{3}$ & 71 & 10.3 & 1.95 & 420,500 & 608 & 5.5 \\
P11 & $95 \%$ & $20 \%$ & $\mathrm{~K}_{2} \mathrm{CO}_{3}$ & 40 & 12.4 & 1.76 & 400 & 525 & 3.6 \\
Mod & $5 \%$ & $5 \%$ & $\mathrm{~K}_{2} \mathrm{CO}_{3}$ & 41 & 9.87 & 1.81 & 500 & 622 & 3.1
\end{tabular}


P1. Using the general procedure described above, the polymerization of monomer 9 (32 $\mathrm{mg}, 0.044 \mathrm{mmol})$ and monomer $13(20 \mathrm{mg}, 0.044 \mathrm{mmol})$ in the presence of $\operatorname{Pd}\left[\left(\mathrm{PPh}_{3}\right)_{2} \mathrm{Cl}_{2}\right](3 \mathrm{mg}, 0.0044 \mathrm{mmol})$ and $\mathrm{CuI}(0.2 \mathrm{mg}, 0.0022 \mathrm{mmol})$ yielded $\mathrm{PPE}$ polymer P-1 ( $32 \mathrm{mg}, 71 \%$ ). Molecular weight of boc-protected polymer was obtained and characterized. Resulting mixture was purified by precipitation in cold ethyl ether (x3). An aliquot was redissolved in THF and molecular weight obtained and photophycal properties characterized. The rest of the material was dissolved in DMSO- $_{6}$ and characterized using ${ }^{1} \mathrm{H}-\mathrm{NMR}$.

P1: GPC: $\mathrm{M}_{\mathrm{w}}=22.82 \mathrm{kDa} ; \mathrm{M}_{\mathrm{n}}=13.5 \mathrm{kDa} ; \mathrm{PDI}=1.69 . \mathrm{UV} \lambda_{\max }=427 \mathrm{~nm}$; fluo $\lambda_{\max }(400$ $\mathrm{nm}$ ex $)=471 \mathrm{~nm}$; QY $=41 \%$ in DMF. ${ }^{1} \mathrm{H}-\mathrm{NMR}(400 \mathrm{MHz}): \delta=7.31(\mathrm{br}, 1 \mathrm{H}, \mathrm{Bt}-\mathrm{H}), 6.74$ (br, 1H, Ph-H), 4.27 (br, 2H CH$\left.{ }_{2} \mathrm{OPh}\right), 3.83$ (br, 2H, $\mathrm{OCH}_{2}$ ), 3.56 (br, 2H, $\left.\mathrm{CH}_{2} \mathrm{O}\right), 3.09$ (br, 2H, $\left.\mathrm{OCH}_{2}\right), 1.33\left(\mathrm{~s}, 7 \mathrm{H}, \mathrm{OC}\left(\mathrm{CH}_{3}\right)_{3}\right)$. FT-IR (Neat): $v=3372(\mathrm{br}), 2982(\mathrm{w}), 2935$ (m), 2875 (s), 1710 (vs; C=O), 1513 (vs), 1461 (w), 1425 (m), 1425 (m), 1393 (m), 1363 (s), $1276(\mathrm{~s}), 1219(\mathrm{~s}), 1172(\mathrm{~m}), 1120(\mathrm{~m}), 1060(\mathrm{~m}), 1033(\mathrm{~m})$. 


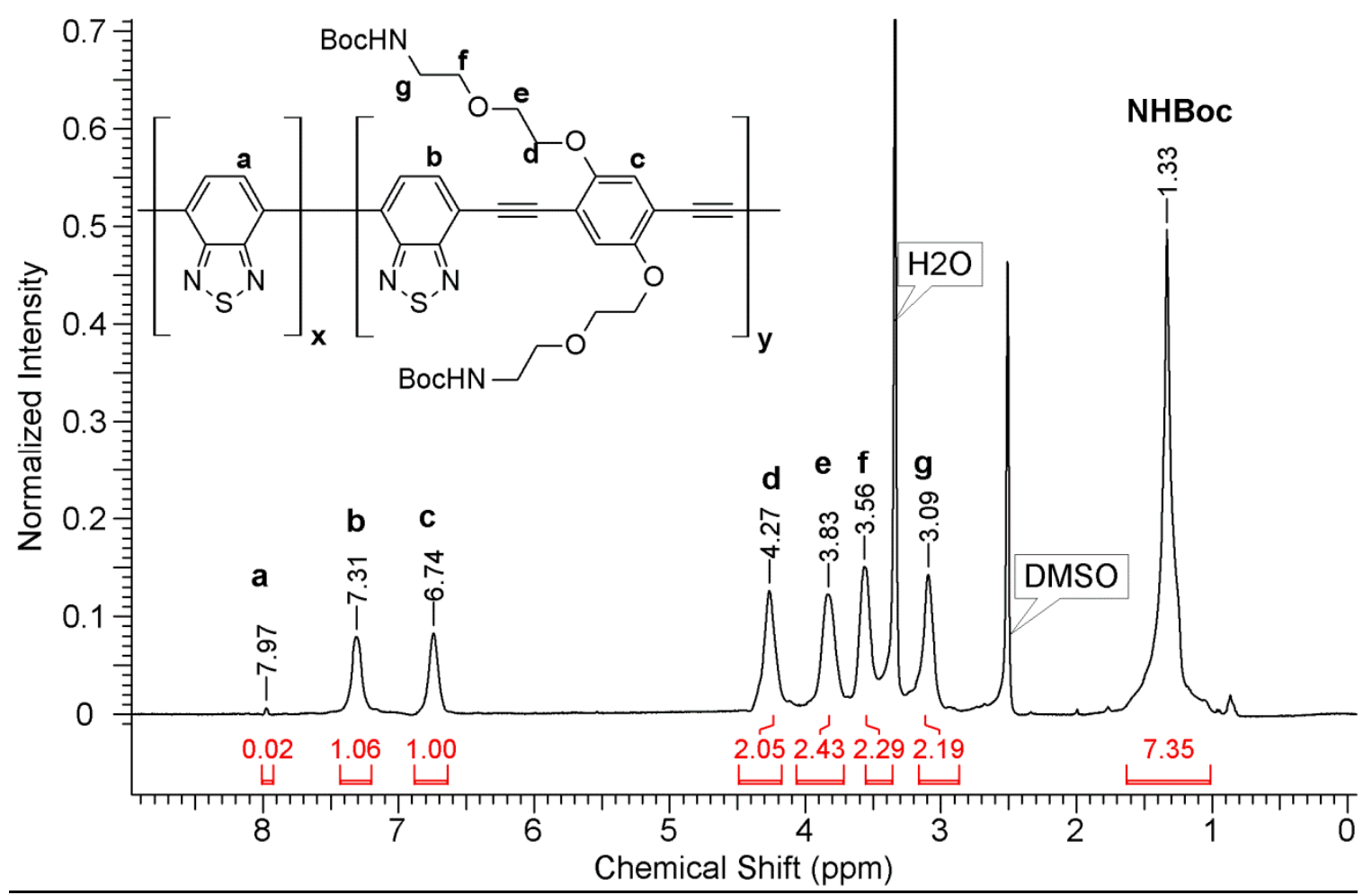

Figure 5.5. ${ }^{1} \mathrm{H}-\mathrm{NMR}$ for polymer $\mathbf{P 1}$ in DMSO- $\mathrm{d}_{6}$

P2. Using the general procedure described above, the polymerization of 6 ( $30 \mathrm{mg}, 0.056$ mmol) and monomer M2 $(41 \mathrm{mg}, 0.056 \mathrm{mmol})$ in the presence of $\mathrm{Pd}\left[\left(\mathrm{PPh}_{3}\right)_{2} \mathrm{Cl}_{2}\right](4 \mathrm{mg}$, $0.0056 \mathrm{mmol}$ ) and $\mathrm{CuI}(0.3 \mathrm{mg}, 0.0028 \mathrm{mmol}$ ) yielded PPE polymer P2 ( $44 \mathrm{mg}, 73 \%$ ). Resulting mixture was purified by precipitation in cold ethyl ether (x3). An aliquot was redissolved in THF and molecular weight obtained and photophycal properties characterized. The rest of the material was dissolved in DMSO- $\mathrm{d}_{6}$ and characterized using ${ }^{1} \mathrm{H}-\mathrm{NMR}$. CPN formation was then carried out as described in general procedure to yield CPN-2

P2: GPC: $\mathrm{M}_{\mathrm{w}}=20.09 \mathrm{kDa} ; \mathrm{M}_{\mathrm{n}}=10.3 \mathrm{kDa} ; \mathrm{PDI}=1.95 . \mathrm{UV} \lambda_{\max }=427 \mathrm{~nm}$; fluo $\lambda_{\max }(400$ $\mathrm{nm}$ ex $)=471 \mathrm{~nm}$; QY $=41 \%$ in DMF. ${ }^{1} \mathrm{H}-\mathrm{NMR}(400 \mathrm{MHz}): \delta=7.95$ (br, 0.12H, HBt-H), 7.29 (br, 1H, Bt-H), 6.74 (br, 1H, Ph-H), 4.27 (br, 2H CH${ }_{2} \mathrm{OPh}$ ), 3.85 (br, $2 \mathrm{H}, \mathrm{OCH}_{2}$ ), 
3.09 (br, 2H, $\left.\mathrm{OCH}_{2}\right), 1.32\left(\mathrm{~s}, 8 \mathrm{H}, \mathrm{OC}\left(\mathrm{CH}_{3}\right)_{3}\right)$. FT-IR (Neat): v = 3372 (br), $2982(\mathrm{w})$, 2935 (m), 2875 (s), 1710 (vs; C=O), 1513 (vs), 1461 (w), 1425 (m), 1425 (m), 1393 (m), 1363 (s), 1276 (s), 1219 (s), 1172 (m), 1120 (m), 1060 (m), 1033 (m).

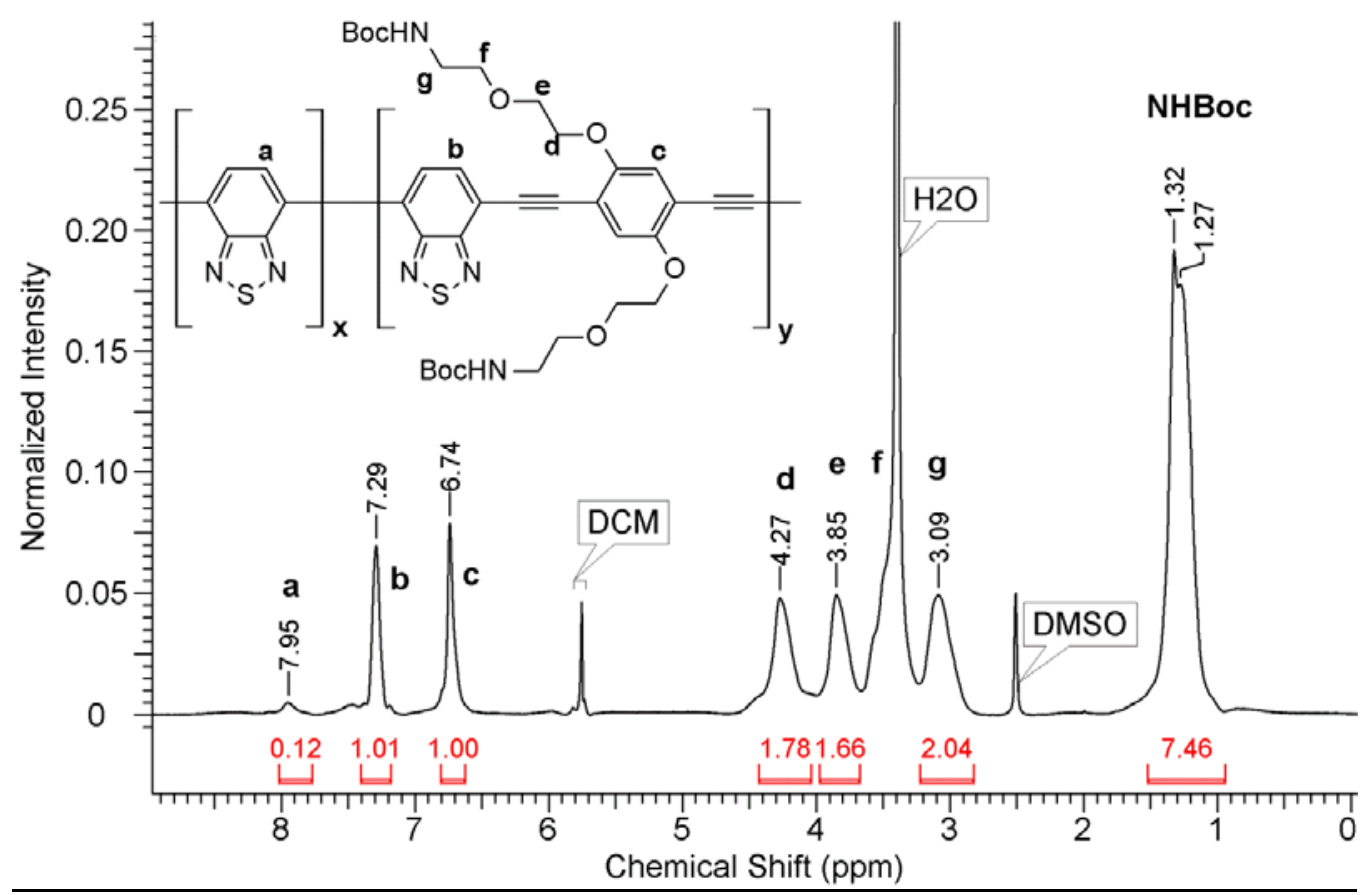

Figure 5.6. ${ }^{1} \mathrm{H}-\mathrm{NMR}$ for polymer $\mathbf{P} 2$ in $\mathrm{DMSO}-\mathrm{d}_{6}$

P3. Using the general procedure described above, the polymerization of monomer 4 (65 $\mathrm{mg}, \quad 0.054 \mathrm{mmol})$ and monomer $13(32 \mathrm{mg}, 0.054 \mathrm{mmol})$ in the presence of $\operatorname{Pd}\left[\left(\mathrm{PPh}_{3}\right)_{2} \mathrm{Cl}_{2}\right](8 \mathrm{mg}, 0.0054 \mathrm{mmol})$ and $\mathrm{CuI}(0.4 \mathrm{mg}, 0.0022 \mathrm{mmol})$ yielded PPE polymer P3 ( $45 \mathrm{mg}, 61 \%$ ). Resulting mixture was purified by precipitation in cold ether (x3). An aliquot was redissolved in THF and molecular weight obtained and photophycal properties characterized. The rest of the material was dissolved in DMSO- $\mathrm{d}_{6}$ and characterized using ${ }^{1} \mathrm{H}-\mathrm{NMR}$. 
P3: GPC: $\mathrm{M}_{\mathrm{w}}=21.82 \mathrm{kDa} ; \mathrm{M}_{\mathrm{n}}=12.4 \mathrm{kDa} ; \mathrm{PDI}=1.76 . \mathrm{UV} \lambda_{\max }=427 \mathrm{~nm}$; fluo $\lambda_{\max }(400$ $\mathrm{nm}$ ex $)=471 \mathrm{~nm} ; \mathrm{QY}=41 \%$ in DMF. ${ }^{1} \mathrm{H}-\mathrm{NMR}(400 \mathrm{MHz}): \delta=7.95(\mathrm{t}, 0.37 \mathrm{H}, \mathrm{HBt}-\mathrm{H})$, 7.30 (br, 1H, Bt-H), 6.74 (br, 1H, Ph-H), 4.28 (br, 2H CH $2 \mathrm{OPh}), 3.86$ (br, $2 \mathrm{H}, \mathrm{OCH}_{2}$ ), $3.11\left(\mathrm{br}, 3 \mathrm{H}, \mathrm{OCH}_{2}\right), 1.33\left(\mathrm{~s}, 10 \mathrm{H}, \mathrm{OC}\left(\mathrm{CH}_{3}\right)_{3}\right)$. FT-IR (Neat): $v=3372(\mathrm{br}), 2982(\mathrm{w})$, 2935 (m), 2875 (s), 1710 (vs; C=O), 1513 (vs), 1461 (w), 1425 (m), 1425 (m), 1393 (m), 1363 (s), 1276 (s), 1219 (s), 1172 (m), 1120 (m), 1060 (m), 1033 (m).

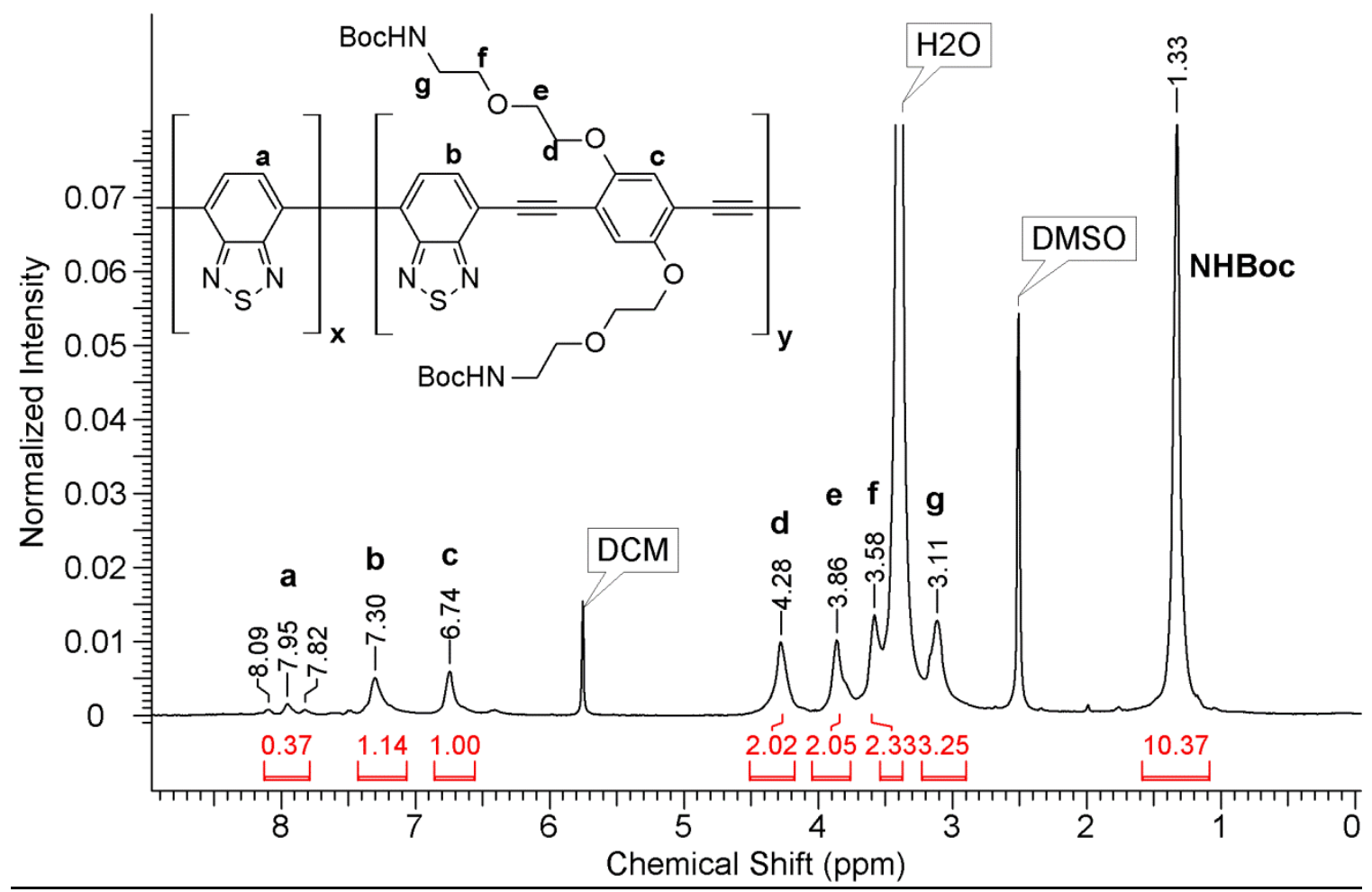

Figure 5.7. ${ }^{1} \mathrm{H}-\mathrm{NMR}$ for polymer $\mathbf{P 3}$ in $\mathrm{DMSO}-\mathrm{d}_{6}$

P4: GPC: $\mathrm{M}_{\mathrm{w}}=22.23 \mathrm{kDa} ; \mathrm{M}_{\mathrm{n}}=12.7 \mathrm{kDa} ; \mathrm{PDI}=1.75 . \mathrm{UV} \lambda_{\max }=427 \mathrm{~nm}$; fluo $\lambda_{\max }(400$ $\mathrm{nm}$ ex $)=471 \mathrm{~nm}$; QY $=41 \%$ in DMF. ${ }^{1} \mathrm{H}-\mathrm{NMR}(400 \mathrm{MHz}): \delta=7.95(\mathrm{t}, 0.6 \mathrm{H}, \mathrm{HBt}-\mathrm{H})$, 7.30 (br, 1H, Bt-H), 6.74 (br, 1H, Ph-H), 4.28 (br, 2H CH $\mathrm{CH}_{2} \mathrm{OPh}$ ), 3.86 (br, 2H, $\mathrm{OCH}_{2}$ ), $3.12\left(\mathrm{br}, 2 \mathrm{H}, \mathrm{OCH}_{2}\right), 1.33\left(\mathrm{~s}, 8 \mathrm{H}, \mathrm{OC}\left(\mathrm{CH}_{3}\right)_{3}\right)$. FT-IR (Neat): $v=3372(\mathrm{br}), 2982(\mathrm{w})$, 
2935 (m), 2875 (s), 1710 (vs; C=O), 1513 (vs), 1461 (w), 1425 (m), 1425 (m), 1393 (m), 1363 (s), 1276 (s), $1219(\mathrm{~s}), 1172(\mathrm{~m}), 1120(\mathrm{~m}), 1060$ (m), 1033 (m).

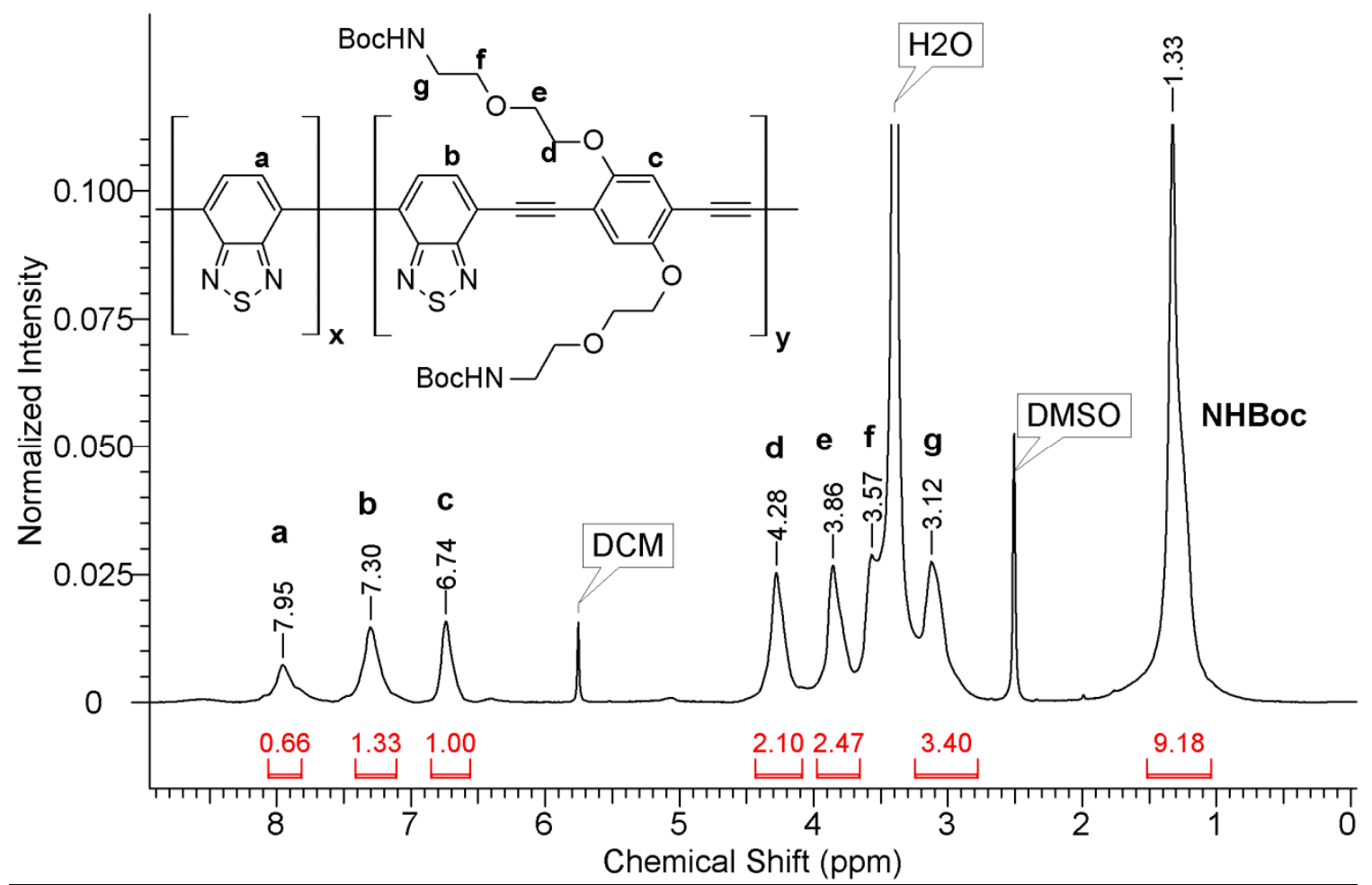

Figure 5.8. ${ }^{1} \mathrm{H}-\mathrm{NMR}$ for polymer $\mathbf{P} 4$ in $\mathrm{DMSO}_{-} \mathrm{d}_{6}$

P5: GPC: $\mathrm{M}_{\mathrm{w}}=27.41 \mathrm{kDa} ; \mathrm{M}_{\mathrm{n}}=14.5 \mathrm{kDa} ; \mathrm{PDI}=1.89 . \mathrm{UV} \lambda_{\max }=427 \mathrm{~nm}$; fluo $\lambda_{\max }(400$ $\mathrm{nm}$ ex $)=471 \mathrm{~nm} ; \mathrm{QY}=41 \%$ in DMF. ${ }^{1} \mathrm{H}-\mathrm{NMR}(400 \mathrm{MHz}): \delta=7.95(\mathrm{t}, 2.3 \mathrm{H}, \mathrm{HBt}-\mathrm{H})$, 7.30 (br, 1H, Bt-H), 6.74 (br, 1H, Ph-H), 4.28 (br, 2H CH $2 \mathrm{OPh}$ ), 3.86 (br, 2H, $\mathrm{OCH}_{2}$ ), $3.12\left(\mathrm{br}, 2 \mathrm{H}, \mathrm{OCH}_{2}\right), 1.33\left(\mathrm{~s}, 8 \mathrm{H}, \mathrm{OC}\left(\mathrm{CH}_{3}\right)_{3}\right)$. FT-IR (Neat): $v=3372(\mathrm{br}), 2982(\mathrm{w})$, 2935 (m), 2875 (s), 1710 (vs; C=O), 1513 (vs), 1461 (w), 1425 (m), 1425 (m), 1393 (m), 1363 (s), 1276 (s), 1219 (s), $1172(\mathrm{~m}), 1120$ (m), 1060 (m), 1033 (m). 


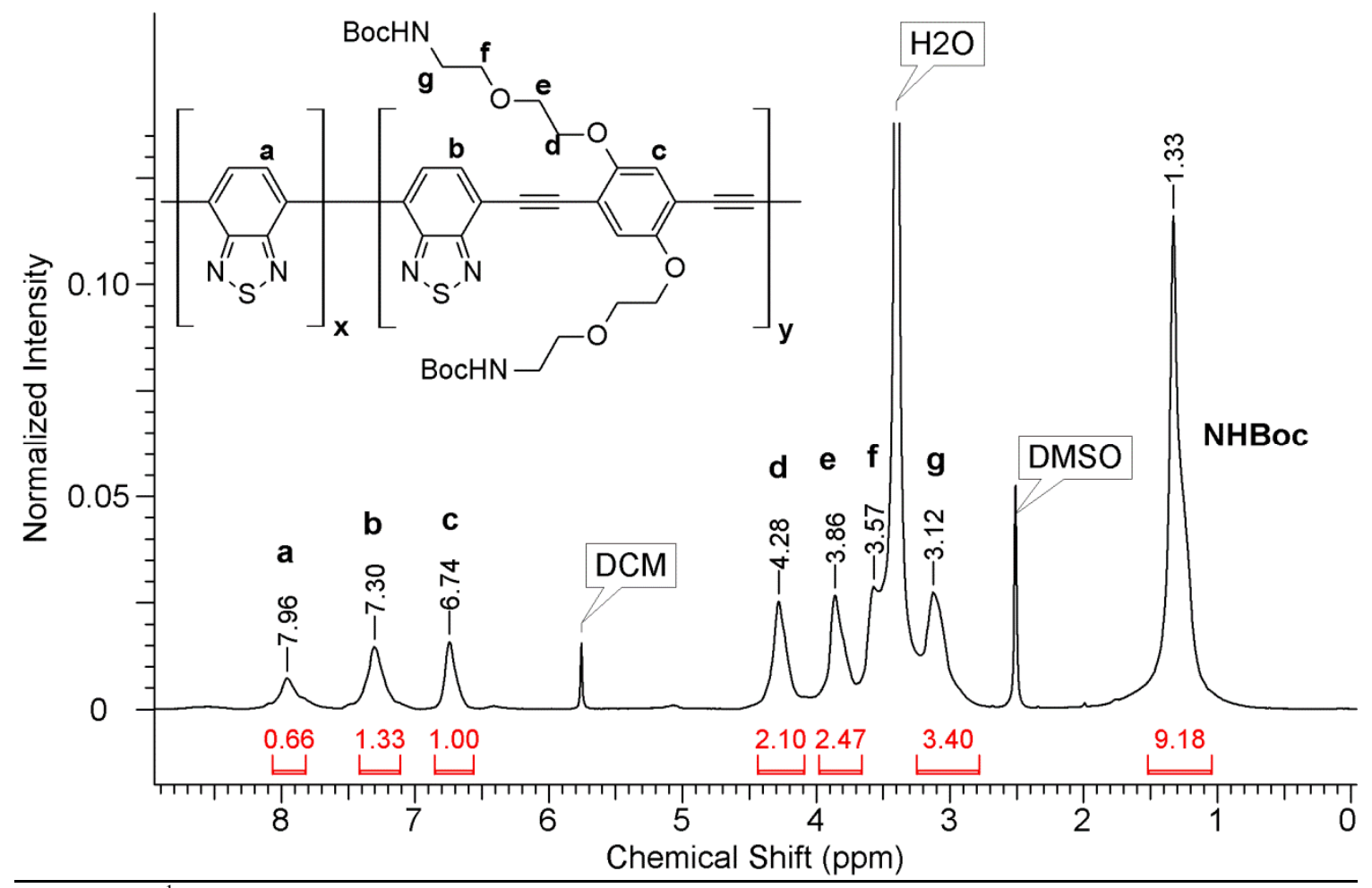

Figure 5.9. ${ }^{1} \mathrm{H}-\mathrm{NMR}$ for polymer P5 in DMSO-d $\mathrm{d}_{6}$

P6: GPC: $\mathrm{M}_{\mathrm{w}}=16.36 \mathrm{kDa} ; \mathrm{M}_{\mathrm{n}}=8.52 \mathrm{kDa} ; \mathrm{PDI}=1.92 . \mathrm{UV} \lambda_{\max }=427 \mathrm{~nm}$; fluo $\lambda_{\max }(400$ $\mathrm{nm}$ ex $)=471 \mathrm{~nm} ; \mathrm{QY}=41 \%$ in DMF. ${ }^{1} \mathrm{H}-\mathrm{NMR}(400 \mathrm{MHz}): \delta=7.95(\mathrm{t}, 0.7 \mathrm{H}, \mathrm{HBt}-\mathrm{H})$, 7.30 (br, 1H, Bt-H), 6.75 (br, 1H, Ph-H), 4.28 (br, 2H CH $\mathrm{CH}_{2} \mathrm{OPh}$ ), 3.86 (br, 2H, $\mathrm{OCH}_{2}$ ), $3.13\left(\mathrm{br}, 2 \mathrm{H}, \mathrm{OCH}_{2}\right), 1.33\left(\mathrm{~s}, 8 \mathrm{H}, \mathrm{OC}\left(\mathrm{CH}_{3}\right)_{3}\right)$. FT-IR (Neat): v = $3372(\mathrm{br}), 2982(\mathrm{w})$, 2935 (m), 2875 (s), 1710 (vs; C=O), 1513 (vs), 1461 (w), 1425 (m), 1425 (m), 1393 (m), 1363 (s), 1276 (s), 1219 (s), 1172 (m), 1120 (m), 1060 (m), 1033 (m). 


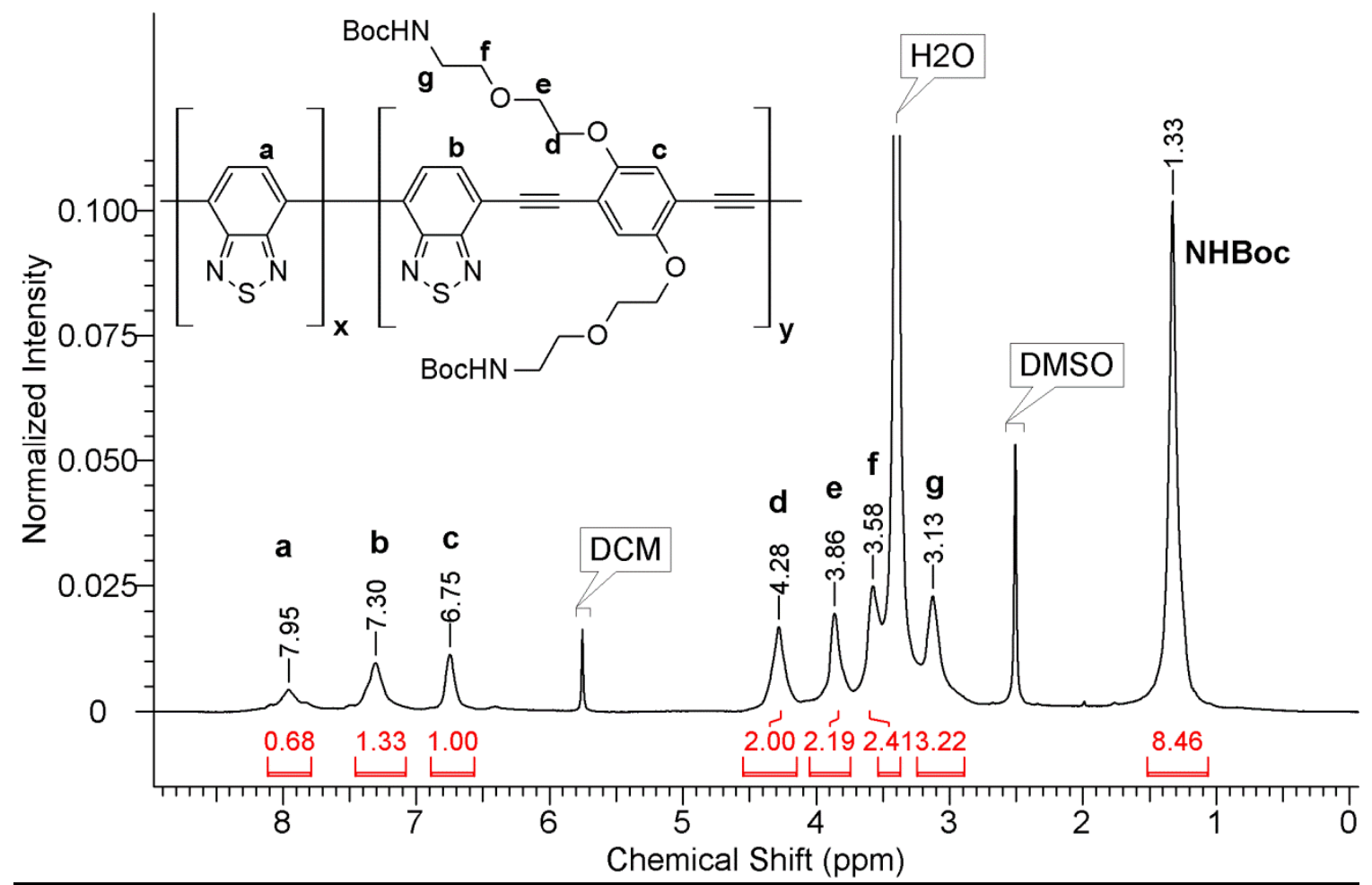

Figure 5.10. ${ }^{1} \mathrm{H}-\mathrm{NMR}$ for polymer P6 in DMSO-d

P7: GPC: $M_{\mathrm{w}}=27.41 \mathrm{kDa} ; \mathrm{M}_{\mathrm{n}}=14.5 \mathrm{kDa} ; \mathrm{PDI}=1.89 . \mathrm{UV} \lambda_{\max }=427 \mathrm{~nm}$; fluo $\lambda_{\max }(400$ $\mathrm{nm}$ ex $)=471 \mathrm{~nm} ; \mathrm{QY}=41 \%$ in DMF. ${ }^{1} \mathrm{H}-\mathrm{NMR}(400 \mathrm{MHz}): \delta=7.95(\mathrm{t}, 0.7 \mathrm{H}, \mathrm{HBt}-\mathrm{H})$ 7.30 (br, 1H, Bt-H), 6.75 (br, 1H, Ph-H), 4.28 (br, 2H CH $\left.\mathrm{CH}_{2} \mathrm{OPh}\right), 3.86$ (br, 2H, $\mathrm{OCH}_{2}$ ), $\left.\mathrm{CH}_{2} \mathrm{O}\right), 3.13\left(\mathrm{br}, 2 \mathrm{H}, \mathrm{OCH}_{2}\right), 1.33\left(\mathrm{~s}, 7 \mathrm{H}, \mathrm{OC}\left(\mathrm{CH}_{3}\right)_{3}\right)$. FT-IR (Neat): v = 3372 (br), 2982 (w), 2935 (m), 2875 (s), 1710 (vs; C=O), 1513 (vs), 1461 (w), 1425 (m), 1425 (m), 1393 (m), 1363 (s), $1276(\mathrm{~s}), 1219$ (s), $1172(\mathrm{~m}), 1120(\mathrm{~m}), 1060$ (m), 1033 (m). 


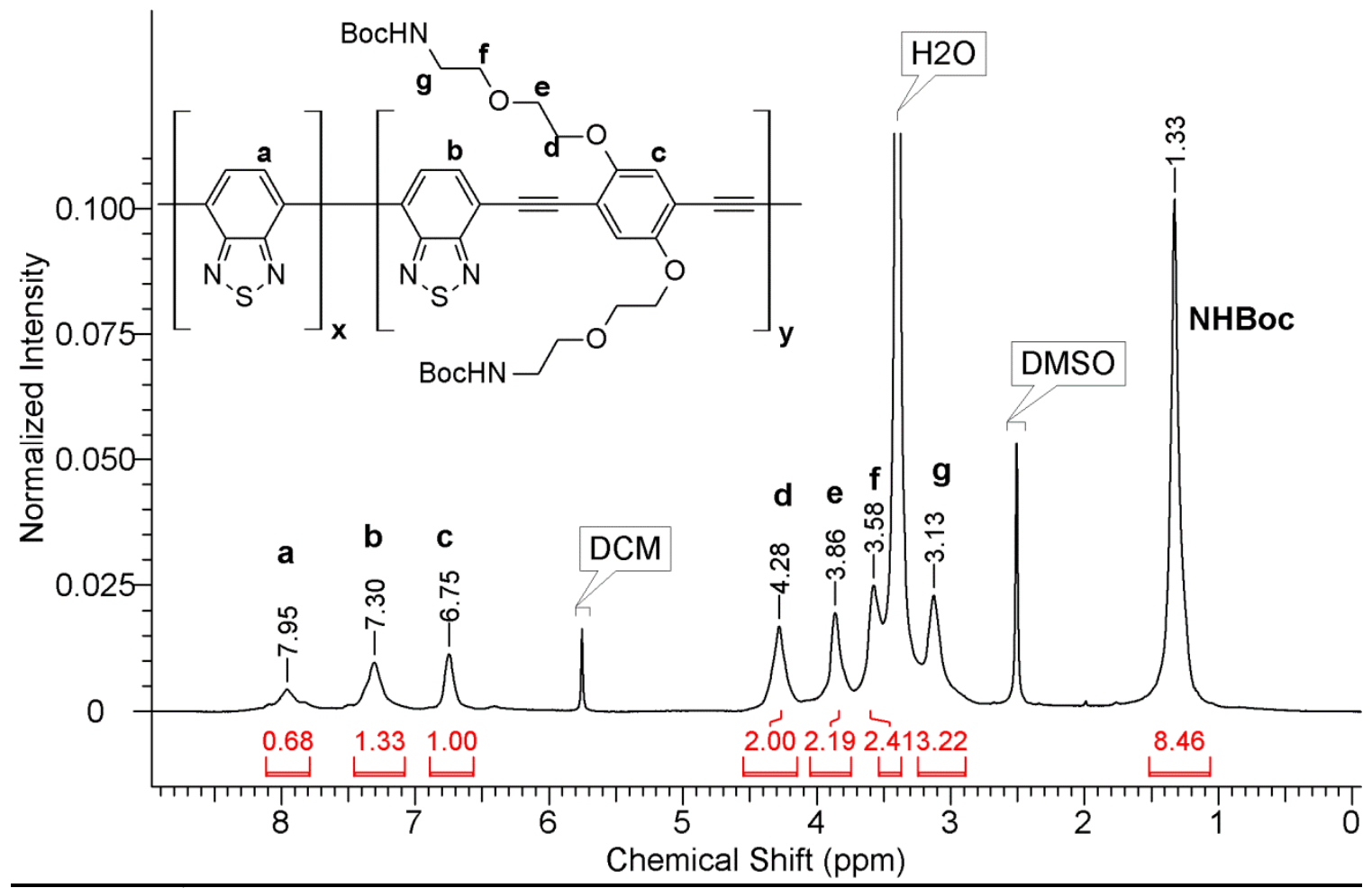

Figure 5.11. ${ }^{1} \mathrm{H}-\mathrm{NMR}$ for polymer P7 in $\mathrm{DMSO}-\mathrm{d}_{6}$

P8: GPC: $M_{\mathrm{w}}=14.7 \mathrm{kDa} ; \mathrm{M}_{\mathrm{n}}=7.75 \mathrm{kDa} ; \mathrm{PDI}=1.90 . \mathrm{UV} \lambda_{\max }=427 \mathrm{~nm}$; fluo $\lambda_{\max }(400$ $\mathrm{nm}$ ex $)=471 \mathrm{~nm} ; \mathrm{QY}=41 \%$ in DMF. ${ }^{1} \mathrm{H}-\mathrm{NMR}(400 \mathrm{MHz}): \delta=7.95(\mathrm{t}, 2.3 \mathrm{H}, \mathrm{HBt}-\mathrm{H})$, 7.30 (br, 1H, Bt-H), 6.74 (br, 1H, Ph-H), 4.28 (br, 2H CH $3.12\left(\mathrm{br}, 2 \mathrm{H}, \mathrm{OCH}_{2}\right), 1.33\left(\mathrm{~s}, 8 \mathrm{H}, \mathrm{OC}\left(\mathrm{CH}_{3}\right)_{3}\right)$. FT-IR (Neat): v = 3372 (br), $2982(\mathrm{w})$, 2935 (m), 2875 (s), 1710 (vs; C=O), 1513 (vs), 1461 (w), 1425 (m), 1425 (m), 1393 (m), 1363 (s), 1276 (s), 1219 (s), 1172 (m), 1120 (m), 1060 (m), 1033 (m). 


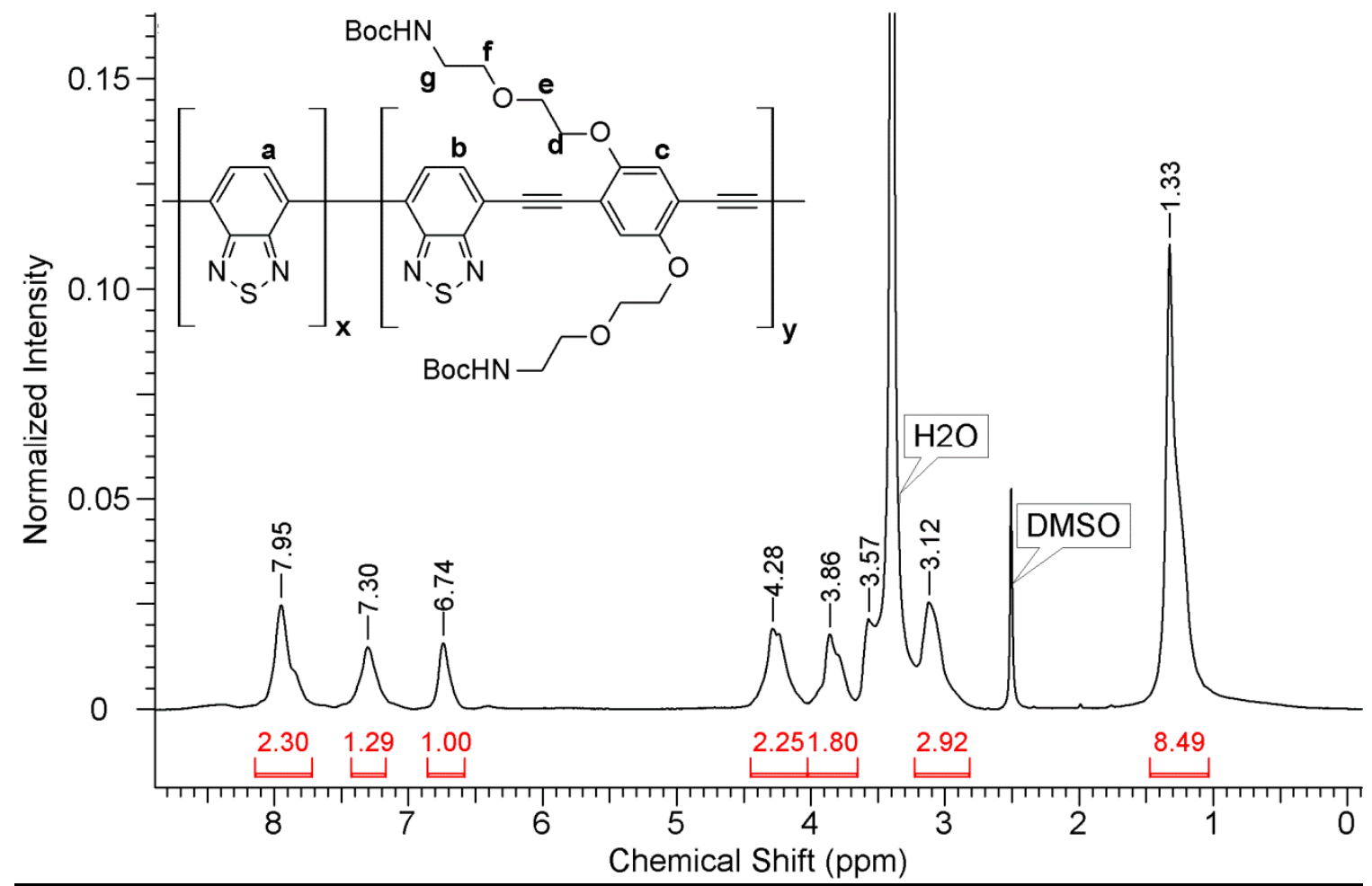

Figure 5.12. ${ }^{1} \mathrm{H}-\mathrm{NMR}$ for polymer P8 in $\mathrm{DMSO}-\mathrm{d}_{6}$

P9: GPC: $\mathrm{M}_{\mathrm{w}}=13.49 \mathrm{kDa} ; \mathrm{M}_{\mathrm{n}}=6.85 \mathrm{kDa} ; \mathrm{PDI}=1.97$. UV $\lambda_{\max }=427 \mathrm{~nm}$; fluo $\lambda_{\max }(400$ $\mathrm{nm}$ ex $)=471 \mathrm{~nm} ; \mathrm{QY}=41 \%$ in DMF. ${ }^{1} \mathrm{H}-\mathrm{NMR}(400 \mathrm{MHz}): \delta=7.95(\mathrm{t}, 2.3 \mathrm{H}, \mathrm{HBt}-\mathrm{H})$, 7.30 (br, 1H, Bt-H), 6.74 (br, 1H, Ph-H), 4.28 (br, 2H CH $3.12\left(\mathrm{br}, 2 \mathrm{H}, \mathrm{OCH}_{2}\right), 1.33\left(\mathrm{~s}, 8 \mathrm{H}, \mathrm{OC}\left(\mathrm{CH}_{3}\right)_{3}\right)$. FT-IR (Neat): v = 3372 (br), $2982(\mathrm{w})$, 2935 (m), 2875 (s), 1710 (vs; C=O), 1513 (vs), 1461 (w), 1425 (m), 1425 (m), 1393 (m), 1363 (s), 1276 (s), 1219 (s), 1172 (m), 1120 (m), 1060 (m), 1033 (m). 


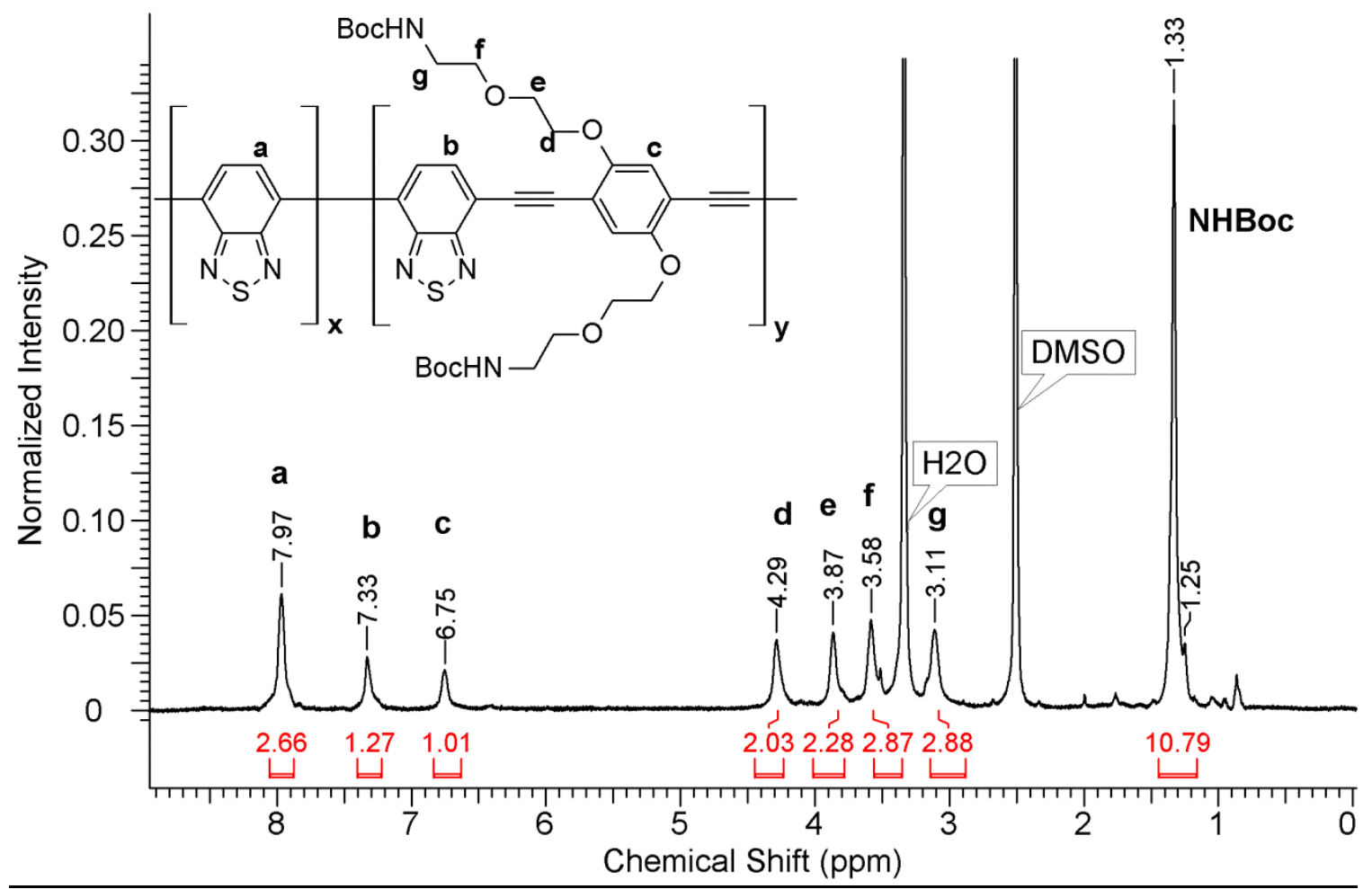

Figure 5.13. ${ }^{1} \mathrm{H}-\mathrm{NMR}$ for polymer P9 in $\mathrm{DMSO}^{-\mathrm{d}_{6}}$

P10: GPC: $M_{\mathrm{w}}=24.43 \mathrm{kDa} ; \mathrm{M}_{\mathrm{n}}=16.4 \mathrm{kDa} ; \mathrm{PDI}=1.49 . \mathrm{UV} \lambda_{\max }=427 \mathrm{~nm}$; fluo $\lambda_{\max }(400$ $\mathrm{nm}$ ex $)=471 \mathrm{~nm} ; \mathrm{QY}=41 \%$ in DMF. ${ }^{1} \mathrm{H}-\mathrm{NMR}(400 \mathrm{MHz}): \delta=7.96(\mathrm{t}, 0.3 \mathrm{H}, \mathrm{HBt}-\mathrm{H})$, 7.31 (br, 0.7H, Bt-H), 6.74 (br, 1H, Ph-H), 4.26 (br, 2H CH $\mathrm{CH}_{2} \mathrm{OPh}$ ), 3.84 (br, 2H, $\mathrm{OCH}_{2}$ ), 3.48 (br, 2H, $\left.\mathrm{CH}_{2} \mathrm{O}\right), 3.07$ (br, $\left.2 \mathrm{H}, \mathrm{OCH}_{2}\right), 1.33\left(\mathrm{~s}, 8 \mathrm{H}, \mathrm{OC}\left(\mathrm{CH}_{3}\right)_{3}\right)$. FT-IR (Neat): $v=$ 3372 (br), 2982 (w), 2935 (m), 2875 (s), 1710 (vs; C=O), 1513 (vs), 1461 (w), 1425 (m), 1425 (m), 1393 (m), 1363 (s), 1276 (s), 1219 (s), 1172 (m), 1120 (m), 1060 (m), 1033 (m). 


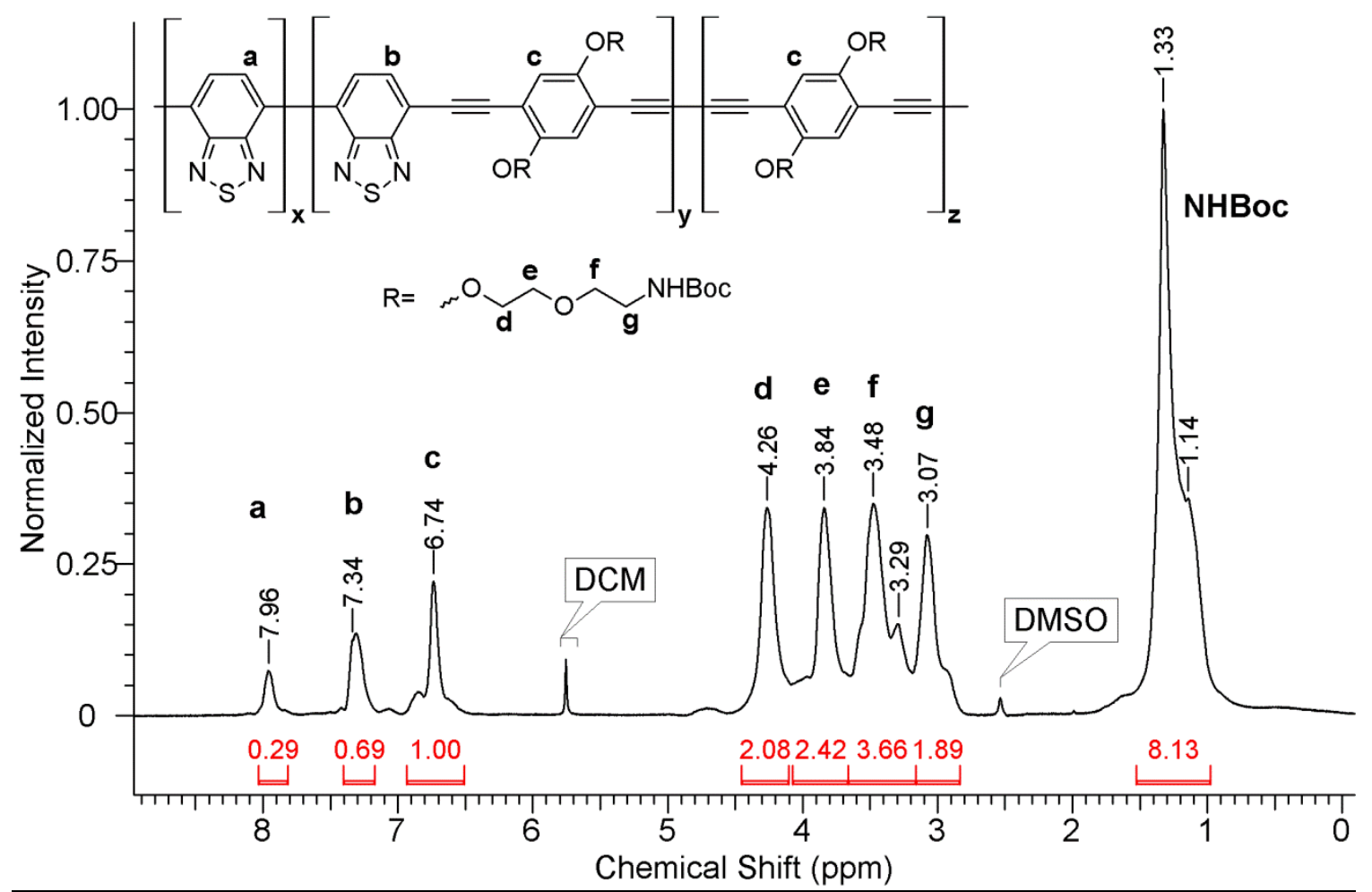

Figure 5.14. ${ }^{1} \mathrm{H}-\mathrm{NMR}$ for polymer $\mathrm{P} 10$ in DMSO- $\mathrm{d}_{6}$

P11: GPC: $\mathrm{M}_{\mathrm{w}}=24.43 \mathrm{kDa} ; \mathrm{M}_{\mathrm{n}}=16.4 \mathrm{kDa} ; \mathrm{PDI}=1.49 . \mathrm{UV} \lambda_{\max }=427 \mathrm{~nm}$; fluo $\lambda_{\max }(400$ $\mathrm{nm}$ ex $)=471 \mathrm{~nm}$; QY $=41 \%$ in DMF. ${ }^{1} \mathrm{H}-\mathrm{NMR}(400 \mathrm{MHz}): \delta=7.30$ (br, 0.3H, Bt-H), 6.74 (br, 1H, Ph-H), 4.27 (br, 2H CH $\left.\mathrm{H}_{2} \mathrm{OPh}\right), 3.83$ (br, 2H, $\mathrm{OCH}_{2}$ ), 3.56 (br, $2 \mathrm{H}, \mathrm{CH}_{2} \mathrm{O}$ ), 3.09 (br, 2H, $\left.\mathrm{OCH}_{2}\right), 1.33$ (s, 9H, OC( $\left.\left(\mathrm{CH}_{3}\right)_{3}\right)$. FT-IR (Neat): $v=3372(\mathrm{br}), 2982(\mathrm{w})$, 2935 (m), 2875 (s), 1710 (vs; C=O), 1513 (vs), 1461 (w), 1425 (m), 1425 (m), 1393 (m), 1363 (s), 1276 (s), 1219 (s), $1172(\mathrm{~m}), 1120(\mathrm{~m}), 1060$ (m), 1033 (m). 


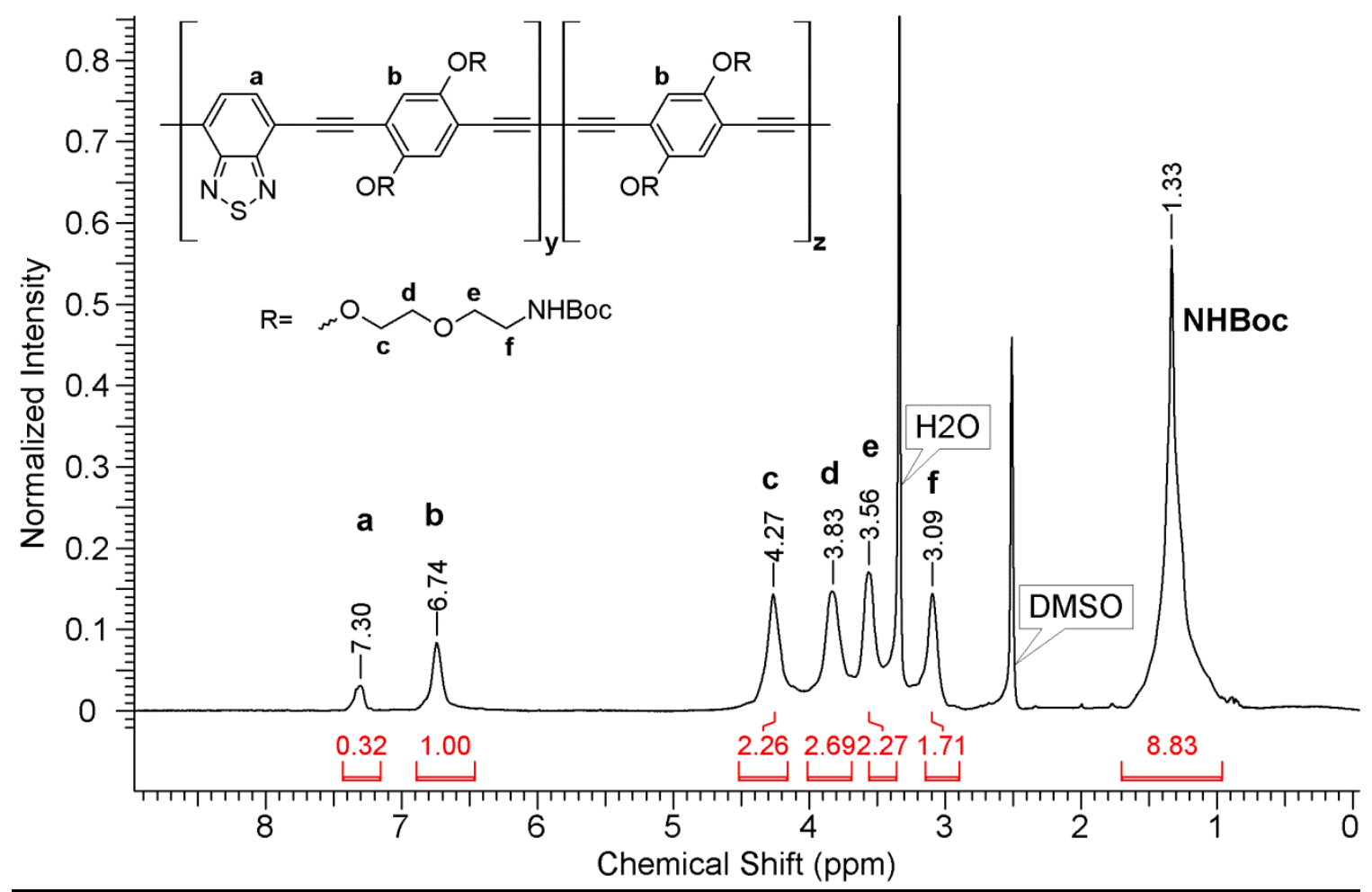

Figure 5.15. ${ }^{1} \mathrm{H}-\mathrm{NMR}$ for polymer $\mathbf{P 1 1}$ in DMSO-d ${ }_{6}$

Polymer Characterization. Confirmed using ${ }^{1} \mathrm{H}-\mathrm{NMR}$ data by looking at characteristic aromatic peak for homo-coupled benzothiadizole (7.97ppm), phenylene ethynylenecoupled benzothiaidzole (7.31), and phenylene (6.74) protons. IR samples were prepared by lyophilization to prepare neat sample. IR scans from 4000 to $700 \mathrm{~cm}^{-1}$ are presented below, depicting absence of boc-carbonate group and confirming deprotection.

\subsection{References}

1 C. G. Veinot and T. J. Marks, Acc. Chem. Res., 2005, 38, 632

2 A. C. Grimsdale, K. L. Chan, R. E. Martin, P. G. Jokisz and A. B. Holmes, Chem. Rev., 2009, 109, 897.

3 Kim, J. Jackiw, E. Robinson, K. S. Schanze, J. R. Reynolds, J. Baur, M. F. Rubner and D. Boils, Macromolecules, 1998, 31, 964. 
4 J. W. Baur, S. Kim, P. B. Balanda, J. R. Reynolds an M. F. Rubner, Adv. Mater., $1998,10,1452$.

5 J. M. Hodgkiss, G. Tu, S. Albert-Seifried, W. T. S. Huck and R. H. Friend, J. Am. Chem. Soc., 2009, 131, 8913.

6 F. Huang, H. B. Wu, D. L. Wang, W. Yang and Y. Cao, Chem.Mater., 2004, 16, 708.

7 H. B. Wu, F. Huang, Y. Q. Mo, W. Yang, D. L. Wang, J. B. Pengand Y. Cao, Adv. Mater., 2004, 16, 1826.

8 B. Liu, W.-L. Yu, Y.-H. Lai and W. Huang, Macromolecules, 2002, 35, 4975.

9 Q. L. Fan, S. Lu, Y. H. Lai, X. Y. Hou and W. Huang, Macromolecules, 2003, 36, 6976.

10 H.-H. Lu, C.-Y. Liu, T.-H. Jen, J.-L. Liao, H.-E. Tseng,C.-W. Huang, M.-C. Hung and S.-A. Chen, Macromolecules, 2005, 38, 10829.

11 E. Aharon, A. Albo, M. Kalina and G. L. Frey, Adv. Funct. Mater., 2006, 16, 980.

12 D. Braun and A. J. Heeger, Appl. Phys. Lett., 1991, 58, 1982.

13 Y. Cao, G. Yu, I. D. Parker and A. J. Heeger, J. Appl. Phys.,2000, 88, 3618.

14 H. B. Wu, F. Huang, J. B. Peng and Y. Cao, Synth. Met., 2005, 153, 197.

15 S. Maisonneuvea, Q. Fangb, J. Xie. Tetrahedron 2008, 64(37), 8716-8720

16 S.M. Brombosz, A. L. Appleton, A. J. Zappas, U. H. F. Bunz. Chem. Commun., 2010,46, 1419-1421 
VITA

\section{ELADIO MENDEZ}

Born, Santiago, Chile

2003-2009

B.A., Chemistry, Biochemistry Concentration

B.A., Political Science

Florida International University

Miami, Florida

2006-2009

Temporary Instructor

Miami-Dade Public Schools

Miami, Florida

2009-2015

Ph.D., Chemistry

Florida International University

Miami, Florida

\section{PUBLICATIONS AND PRESENTATIONS}

Mendez E; Manian RK; Myoung Y; Twomey M; Moon JH. Mitochondria-specific Conjugated Polymer Nanoparticles. Angewandte Chemie. Submitted.

Vokata T; Twomey M; Mendez, E; Moon, J. H. Synthesis of biodegradable conjugated polymers with controlled backbone flexibility. Journal of Polymer Science Part A:

Polymer Chemistry. In press.

Mendez, E (2014) Aggregation and photoluminescent tuning of conjugated polymer nanoparticles for biological applications. Scholarly Forum. Florida International University. Miami, FL.

Mendez, E (2014) One-pot control of homo-coupled benzothiadiazole segments onto conjugated polymer nanoparticles. MARC U*STAR \& MBRS RISE Biomedical MiniSymposium. Florida International University. Miami, FL.

Mendez E; Moon JH. Side chain and backbone structure-dependent subcellular localization and toxicity of conjugated polymer nanoparticles. Chemical Communications 2013, 49(54), 6048-6050. 
Twomey M; Na Y; Roche Z; Mendez E; Panday N; He J; Moon JH. Fabrication of CoreShell Nanoparticles via Controlled Aggregation of Semiflexible Conjugated Polymer and Hyaluronic Acid. Macromolecules 2013, 46(15), 6374-6378.

Kusano M; Mendez E; Furton KG. Comparison of the volatile organic compounds from different biological specimens for profiling potential. Journal of Forensic Sciences 2013, 58(1), 29-39.

Kreller DI; McGunigale SL; Mendez EA; Wolfe LG. Approach to Investigation of Dissolved Organic Matter Adsorptive Fractionation and Competitive Displacement on Minerals. Colloids and Surfaces A 2013, 422, 24-32.

Mendez, E (2013) Side-chain dependent subcellular localization and toxicity of conjugated polymer nanoparticles. Biomolecular Sciences Institute. Florida International University. Miami, FL

Mendez, E (2013) Side-chain dependent subcellular localization and toxicity of conjugated polymer nanoparticles.. MARC U*STAR \& MBRS RISE Biomedical MiniSymposium. Florida International University. Miami, FL.

Kreller DI; Young SP; Mendez EA; McGunigale SL. Chromatogram Handler: A Unique Computer Program That Efficiently Processes Data Generated in Liquid Chromatographic Investigations of Organic Ligand Adsorption on Mineral Surfaces. Computers \& Geosciences 2012, 46, 129-137.

Mendez, E (2012) Conjugated Polymer Nanoparticles for biological labeling. MARC U*STAR \& MBRS RISE Biomedical Mini-Symposium. Florida International University. Miami, FL

Moon JH; Mendez E; Kim Y; Kaur A. Conjugated polymer nanoparticles for small interfering RNA delivery. Chemical Communications 2011, 47(29), 8370-8372.

Ko YJ; Mendez E; Moon JH. Controlled Aggregation in Conjugated Polymer Nanoparticles via Organic Acid Treatments. Macromolecules 2011, 44(13), 5527-5530.

Kusano M; Mendez E; Furton KG. Development of headspace SPME method for analysis of volatile organic compounds present in human biological specimens. Analytical and Bioanalytical Chemistry 2011, 400(7), 1817-1826.

Mendez, E (2011) Controlled aggregation of conjugated polymer nanoparticles using organic acid treatments. Scholarly Forum. Florida International University. Miami, FL. 